\title{
Diagnostic and therapeutical aspects of lymphedema
}

Citation for published version (APA):

Damstra, R. J. (2009). Diagnostic and therapeutical aspects of lymphedema. [Doctoral Thesis, Maastricht University]. Stichting Lymfologie Centrum Nederland (SLCN). https://doi.org/10.26481/dis.20090626rd

Document status and date:

Published: 01/01/2009

DOI:

10.26481/dis.20090626rd

Document Version:

Publisher's PDF, also known as Version of record

\section{Please check the document version of this publication:}

- A submitted manuscript is the version of the article upon submission and before peer-review. There can be important differences between the submitted version and the official published version of record.

People interested in the research are advised to contact the author for the final version of the publication, or visit the DOI to the publisher's website.

- The final author version and the galley proof are versions of the publication after peer review.

- The final published version features the final layout of the paper including the volume, issue and page numbers.

Link to publication

\footnotetext{
General rights rights.

- You may freely distribute the URL identifying the publication in the public portal. please follow below link for the End User Agreement:

www.umlib.nl/taverne-license

Take down policy

If you believe that this document breaches copyright please contact us at:

repository@maastrichtuniversity.nl

providing details and we will investigate your claim.
}

Copyright and moral rights for the publications made accessible in the public portal are retained by the authors and/or other copyright owners and it is a condition of accessing publications that users recognise and abide by the legal requirements associated with these

- Users may download and print one copy of any publication from the public portal for the purpose of private study or research.

- You may not further distribute the material or use it for any profit-making activity or commercial gain

If the publication is distributed under the terms of Article $25 \mathrm{fa}$ of the Dutch Copyright Act, indicated by the "Taverne" license above, 
Diagnostic and therapeutical aspects of lymphedema 
Financial support for publication and distribution of this thesis by the SLCN was obtained from a grant by: Golden donation from Lomann \& Rauscher, Medi, Varitex, Varodem, and by Bauerfeind, BSN, 3M, Doove, Juzo, Smith \& Nephew, Thuasne

Painting on the cover: "Blue excentrique" (1992). Kor Onclin (1918-1998)

ISBN/EAN: 978-90-805399-2-1

(c) 2009, R.J. Damstra

No parts of this thesis may be reproduced or transmitted in any forms by means, electronic or mechanical, including photocopying, recording or any information storage and retrieval system, without permission in writing from the publisher

Publisher: Stichting Lymfologie Centrum Nederland (SLCN). Postbus 696, 9200 AR, Drachten, NL

Lay-out: P. van der Sijde, Groningen, NL

Printed by drukkerij van Denderen, Groningen, NL

Graphic design: Gravis ontwerpers, Groningen, NL 


\section{Diagnostic and therapeutical aspects of lymphedema}

\section{PROEFSCHRIFT}

ter verkrijging van de graad van doctor aan de Universiteit Maastricht, op gezag van de Rector Magnificus

Prof. mr. G.P.M.F. Mols

volgens besluit van het college van Decanen,

in het openbaar te verdedigen op

vrijdag 26 juni 2009 om 14.00 uur

door

Robert Jacobus Damstra geboren op 15 juli 1959 te Hengelo (ov) 
Promotiecommissie:

Promotor:

Prof. dr. P.M. Steijlen

Copromotoren:

Dr. M.A.M. van Steensel

Dr. J.C.J.M. Veraart

Beoordelingscommissie: Prof.dr. F.C.S. Ramaekers (voorzitter)

Prof. dr. A. Griffioen

Prof.dr. H.A.M. Neumann (Erasmus universiteit, Rotterdam)

Prof.dr. med. E. Rabe (University of Bonn, Germany)

dr. G.W.H. Schurink 
A pessimist sees the difficulty in every opportunity; an optimist sees the opportunity in every difficulty.

Sir Winston L.S. Churchill (1874 - 1965)

Voor Jorine, Anne Marijn, Josephine en Hugo 



\section{CONTENT}

List of abbreviations

Chapter 1 general introduction and aim of the thesis

- Anatomy, physiology, pathophysiology and immunological aspects

- Developmental and Genetic aspects of lymphatics

- Epidemiology of lymphedema

- Diagnosis of swelling and lymphedema

- Therapeutic aspects of lymphedema

- Aim of the thesis

- References

Chapter 2 Validation of the inverse water volumetry method: a new gold standard for arm volume measurements

Chapter 3 Novel missense mutations in the FOXC2 gene lead to increased transcriptional activity and causes lymphedema

Chapter 4 Erysipelas as a sign of subclinical primary lymphedema: A prospective quantitative scintigraphic study of 40 patients with unilateral erysipelas of the leg

Chapter 5 Cancer related secondary lymphedema due to cutaneous lymphangitis carcinomatosa: clinical presentations and review of literature

Chapter 6 Controlled, comparative study of relation between volume changes and interface pressure under short-stretch bandages in leg lymphedema patients

Chapter 7 Compression therapy in breast cancer related lymphedema. A randomized controlled, comparative study of relation between volume and interface pressure changes

Chapter 8 Lymphatic Venous Anastomosis (LVA) for treatment of secondary lymphedema. A prospective study of 11 LVA procedures in 10 patients with breast cancer related lymphedema and a critical review of the literature

Chapter 9 Reduction surgery by Circumferential Suction-Assisted Lipectomy (Brorson method) in end stage breast cancer related lymphedema: a prospective study

Chapter 10 Multidisciplinary guidelines for early diagnosis and management of lymphedema

Chapter 11 Diagnosis and therapy in children with lymphedema

Chapter 12 General discussion, summary and future research

Chapter 13 Algemene discussie, samenvatting en toekomstig onderzoek 


\section{List of abbreviations}

\begin{tabular}{|c|c|}
\hline ANG & Angiopoietins \\
\hline BCRL & Breast Cancer Related Lymphedema \\
\hline BMI & Body Mass Index \\
\hline CPT & Complex Physical therapy \\
\hline CSAL & Circumferential Suction Assisted Lipectomy \\
\hline CT & Compression Therapy \\
\hline ICC & Intra-class correlation coefficient \\
\hline IWV & Inverse Water Volumetry \\
\hline LE & Lymphedema \\
\hline LN & Lymph nodes \\
\hline LVA & Lymphatico Venous Anastomosis \\
\hline MLD & Manual lymph drainage \\
\hline PL & Primary lymphedema \\
\hline QoL & Quality of life \\
\hline RT & Radiotherapy \\
\hline SLD & Simple lymph drainage \\
\hline VEGF & Vascular Endothelial Growth Factor \\
\hline
\end{tabular}


General Introduction and Aim of the Thesis 


\section{INTRODUCTION}

The blood circulation and the lymphatic system are the two vascular systems of the body. Besides the well know major role of the lymphatics in tissue fluid regulation, they are also important in tumor metastasis and immune system function.

Lymphedema is defined as swelling of a body part due to the accumulation of interstitial tissue fluid. It is caused by insufficiency, either physical or functional of the lymphatic system and has a wide range of clinical manifestations and causes. Over the past few years, lymphedema has enjoyed an ever-increasing interest in the national and international health communities, primarily because of the morbidity it causes in many cancer survivors. More vocal patient groups have also played an important role in increasing awareness. These developments are fortunate, because lymphedema is not rare and can have devastating medical, psychological and social consequences for patients.

Despite the obvious need, most healthcare workers have relatively little knowledge of or experience in dealing with lymphedema. As a result, many patients are not adequately diagnosed and treated. Because many organ systems can be affected, several medical specialties can and should be involved in patient care. Multidisciplinary teams need a coordinator and it is the author's conviction that in cases of lymphedema a dermatologist should fill this position. Most lymphatic vessels in the extremities are situated between the muscular fascia and the epidermis and lymphedema often causes skin changes. Thus, a dermatologist will almost invariably be involved in diagnosis and treatment.

That said, lymphology, the study of the lymphatic system and its diseases, is in need of systematic research efforts to give it an evidence-based footing. This thesis addresses the first Dutch efforts in this direction. To provide a basis for understanding the work presented here, an overview will be given in the following paragraphs of the current state of the art in lymphology, covering anatomy, (patho) physiology, genetics, epidemiology, diagnostic approaches and therapeutic aspects.

\section{ANATOMY}

The lymphatic system consists of vessels and lymphatic organs ${ }^{1}$. Lymph vessels are a one- 
way system: there is no central pump, and the lymphatics start as minute, blind-ended, endothelial sacs in the intercellular space of all tissues, with the exception of avascular structures such as hair, nails, cartilage and the retina. The brain and spinal cord likewise do not have lymphatics.

The lymphatic system is divided into pre-lymphatic and lymphatic portions. The prelymphatic portion is defined as interstitial channels in the intercellular space without endothelial linings. The lymphatic portion is lined with endothelium and composed as follows, from small to large:

1. Initial lymphatics / lymph capillaries / lymph sacs. Endothelial lymphatic cells are connected to the surrounding elastic fibers in the extracellular matrix by fibrillar anchoring fibers ${ }^{2}$. These fibers can pull the endothelial cells of the lymphatics apart because the initial lymphatics are very thin and lack an endothelial membrane and pericytes ${ }^{3}$. The blind initial lymphatics are called lymph sacs. The endothelial cells of these lymph sacs, therefore, act as minute valves, called primary valves, and favor fluid drainage from the interstitium in a suction-pump action ${ }^{4}$, preventing inappropriate fluid transport from the initial lymphatics back into the interstitium. The primary valves are pulled opened, and their function is enhanced by movement of the surrounding tissues (this is the rationale behind manual lymphatic drainage therapy, see below). These capillaries do not have interluminal valves, and their main function is uptake of macromolecules and fluid from the interstitium.

2. Precollectors: The initial lymphatics converge into larger vessels with more overlapping endothelial cells. In these precollectors, intraluminal valves with two leaflets appear, the so-called secondary valves.

3. Collectors: Precollectors converge into collectors, larger vessels with diameters of 100$600 \mu \mathrm{m}$ containing three layers: endothelial cells, circular and longitudinal smooth muscular layers, and an outer collagen sheath. Collectors also contain valves. The segment between two valves is called a "lymphangion" and is a functional unit that can contract about 10-12 times per minute, regulated by autonomic nerves. Acting in concert, the lymphangia create a peristaltic movement that pumps lymph fluid towards the lymphatic vessels. 
4. Lymphatic vessels: More proximal collectors form lymphatic vessels transporting lymph to the lymph glands. The major lymphatic vessel is the thoracic duct, draining into the venous circulation at the junction of the left subclavian and internal jugular veins. A double thoracic duct is sometimes present.

The lymphatic (lymphoid) organs are divided into primary and secondary lymphatic organs. The red hematopoietic bone marrow and the thymus are the primary lymphatic organs in which the lymphocytes develop and differentiate from proliferating stem cells. The T-lymphocytes leave the bone marrow early and mature in the thymus, while the B-cells remain in the bone marrow for differentiation ${ }^{5}$.

The secondary lymphoid organs include the lymph glands, tonsils, Peyer's patches, spleen and the mucosa-associated lymphatic tissue (MALT), which is primarily located in the bronchial and digestive tracts. The MALT, present as diffuse lymphoid tissue along all mucosal surfaces, is the site of IgA transport across the mucosal epithelium ${ }^{6}$.

In the body, there are several chains of lymph glands. Superficial lymph glands are located in the popliteal and inguinal regions of the leg; the brachial, pectoral and axillary regions of the arm; and the head and neck region. The deep lymphatic system is located in parailiac, para-aortic and pre-aortic regions. The pre-aortic region drains all of the derivates of the alimentary canal. From the lymph glands, the lymph is transported upstream to the thoracic duct, which in turn empties into the left subclavian vein. The lymph glands in the gastrointestinal tract are situated close to the wall of the bowel, located both in the mesentery close to the branches of the arteries and also around the superior and inferior mesenteric artery.

The lymphatic vessels in the extremities are mainly located in the epifascial region. Deeper lymphatics are rare. The superficial, subcutaneous collectors roughly follow the course of the major cutaneous veins of the skin, forming wide bundles situated underneath the venous layer. Anastomotic branches between adjacent collectors enable the lymph to follow in several alternative routes so that blockage of a single collector does not affect drainage. Different body parts, however, have more or less separate drainage systems that are connected with just a few anastomoses. The borders between these areas are called "lymphatic watersheds" and are particularly susceptible to edema following damage to 
the lymphatics.

According to Clodius ${ }^{7}$, it is the collateral lymph circulation between these watersheds in the presence of a blockage that initiates lymphatic backflow toward the dermis. Stimulation of this flow is one of the main principles of MLD.

The deep lymphatics usually run alongside the arteries within the arterial fascia. The arterial pulsations, therefore, will influence the peristaltic function of the accompanying lymphatics. Perforators connect the epifascial and subfascial lymphatics to each other and direct the flow from deep to superficial, in contrast to venous perforators that guide flow in the opposite direction.

The lymphatic system lacks a central pump; therefore, lymphatic transport must be achieved by other means:

1. Intrinsic propulsion of the lymph collectors and lymph vessels ${ }^{8}$,

2. External propulsion by means of tissue movement,

3. Negative intra-thoracic / abdominal pressure, providing a suction pump action on the lymph fluid in thoracic duct.

The effects of these mechanisms are extremely variable: exercise can increase the lymph transport capacity more than $10-$ fold $^{9}$. Rhythmic contractions of the lymph vessels lead to an upstream deviated lymph flow as a result of intraluminal valves. The physiological and functional unit of a lymph vessel is called a lymphangion, i.e., the segment of the lymph vessel between two valves.

The distance between two valves is irregular and ranges from between three to ten times the diameter of the vessel. The intervals between valves are longer in the deep lymphatics than in the superficial ones. Specialized pacemaker cells initiate the contractions via an action potential that must be propagated efficiently along the vessels ${ }^{10}$. Dilatation of vessels and increased volume of lymph (preload) enhance the frequency and the distension of the lymphangions. Sympathetic activity and circulating vaso-active substances can enhance the force, frequency and distension of the functioning lymphangions ${ }^{11}$.

Lymphatic transport is externally enhanced by mechanical compression initiated by arterial pressure pulsations, arteriolar vasomotion, intestinal smooth muscle contractions and motility, skeletal muscle contraction, and skin tension. 
Any inborn or acquired disruption of the lymphatic system will lead to impairment of the lymph transport capacity, which is essential for homeostasis of the interstitium.

\section{Types of lymphatic impairment}

Based on (patho)physiological considerations, lymphatic impairment can be relative or absolute. There is either too much lymph production with a normally functioning lymphatic system, or there is a normal amount of lymph production with a diminished lymph transport capacity. These two opposites are called dynamic lymph insufficiency (high output failure) and static lymph insufficiency (low output failure), respectively. This distinction is essential in order to determine an optimal treatment program. Often, combinations of these two insufficiencies are present (see figure 1).

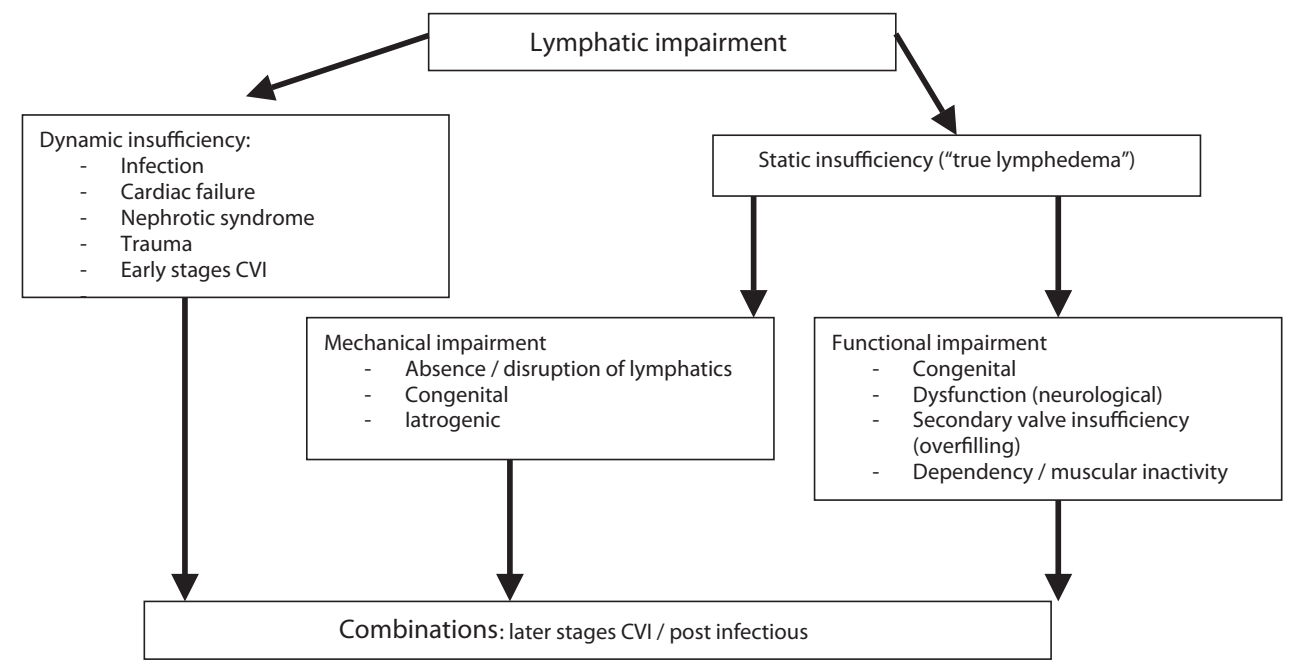

Figure 1: Various forms of lymphatic impairment

(Source: M. Földi and E. Földi. Földi's textbook of Lymphology, Mosby- Elsevier 2006, Munich, Germany)

\section{PATHOPHYSIOLOGY AND IMMUNOLOGIC ASPECTS OF THE LYMPHATIC SYSTEM}

What role does the lymphatic system play? The principal roles of the lymphatic system are (1) regulating the tissue pressure by preserving equilibrium between the amount of interstitial fluid, the capillary filtrate and plasma protein pressure, (2) immunological surveillance and facilitation of lymphocyte circulation and (3) absorption and transport of macromolecules, debris and chylomicrons (dietary fat in the intestine) ${ }^{12}$. 


\section{Interstitial fluid balance}

When the production and removal of interstitial fluid is not in balance, it will lead to edema by a complex mechanism. Factors influencing extracellular fluid production are venous pressure, osmotic pressure, interstitial pressure and permeability of the capillaries, which determines venous capillary filtration ${ }^{13}$. On the other hand, a network of initial lymphatic vessels removes fluid from the interstitium.

There is a large turnover of fluid in the microcirculation. The microcirculation of the skin may be defined as the blood circulation in arterioles (of diameter less than $300 \mu \mathrm{m}$ ), capillaries, and venules. The skin has a complex vascular system involved in providing nutrition for cutaneous cells and tissues and another that plays a central regulatory role in the homeostasis of core body temperature. The cutaneous microcirculation consists of $85 \%$ of the blood flow in the thermoregulatory bed and up to $15 \%$ of the blood flow in the nutritive capillary bed ${ }^{14,15}$.

About $90 \%$ of the total blood volume draining the microcirculation will return to the heart via the venous system, while about $10 \%$ will be removed by the lymphatic system ${ }^{16}$. The human circulation contains approximately 3 liters of plasma, and the thoracic duct produces about 1-3 liters of lymph per day (efferent lymph).

Recently, it was found that the afferent lymph flow (towards the lymph nodes) could be double the amount of fluid in the efferent system. This means that half of the water in lymph could be absorbed directly into the bloodstream as the lymph passes through the regional lymph nodes ${ }^{17,18}$. Considering these quantities, lymph transport through the lymph nodes must be important in the maintenance of interstitial and plasma volumes. Other factors can also influence the production of lymph (lymphatic load). Rapid swelling can be induced by Inflammation, which stimulates lymphatic preload with increased local microcirculatory filtration due to insufficient function of the endothelial barriers in the initial lymphatics and vascular capillaries. Reactive vasodilatation leads to further fluid leakage from the capillaries. Immunological reactions and swelling in the interstitium lead to additional failure of the primary lymphatic valves, which has two consequences. In the first place, fluid clearance from the tissue is less efficient due to insufficiency of the valve function, and second, the propulsion of fluid in the initial capillaries is impaired, both causing progression of edema. Naturally, leakage in the initial lymphatics allows inflammatory mediators to accumulate in the tissue, thereby enhancing interstitial and 
lymphatic inflammatory reactions ${ }^{19}$. Additionally, this cascade leads to vasodilatation and more swelling.

Hypoproteinaemia lowers the plasma osmotic pressure and therefore induces higher water volume in the interstitium, with a shift in the equilibrium to preserve interstitial osmotic pressure.

Enduring venous pressure can rise due to right ventricular cardiac failure (decompensatio cordis) or impairment of venous valves and venous hypertension (chronic venous insufficiency) leading to higher capillary pressure and increased microvascular filtration. Recurrent and persistent venous hypertension results in swelling. Diagnosing the origin of these types of swelling is important in order to begin effective treatment.

Edema is a clinical sign of too much fluid in the interstitium, independent of its pathophysiological nature. Recently two concepts regarding the physiological role of the lymphatics have emerged: the hydrostatic pressure theory and the oncotic pressure theory $^{20}$. The hydrostatic pressure theory relies on the transient development of hydrostatic pressure differences between the interstitial spaces and the lymphatic capillaries that pull lymph into the lumen. At odds with this theory is the observation that interstitial pressure is almost zero (1-4 mmHg), and in lymphatics it is just slightly positive. Movement of the primary valves and propulsion of collectors could perhaps generate intermittent lower pressure, which would initiate an influx of interstitial fluid.

The colloid osmotic pressure (oncotic) theory relies on the ability of lymphatics to concentrate protein in the lumen of the initial lymphatics.

\section{Immune surveillance}

Besides playing an important role in the maintenance of tissue fluid homeostasis, the lymphatic system also contributes to immune surveillance of the body. The major cell types in lymph are CD4 $\square$ memory $T$ cells and antigen-presenting dendritic cells (DCs) ${ }^{21}$. These cells have a remarkable capacity to traffic from peripheral tissues to the draining lymph nodes (LN), which is critical for the execution of their functions.

Traditionally, inflammatory mediators have been regarded to support DC migration to LNs because they induce the expression of molecules on DCs known to guide them to lymphatics. Recently, Angeli et al. ${ }^{22}$ showed that inflammatory signals present in a strong vaccine adjuvant, induced swelling in LNs accompanied by lymphangiogenesis 
in the draining LN and peripheral tissue. These increased lymphatics led to more robust migration of DCs for at least several days. The density of lymphatic vessels, however, can become over extended, and/or their function impaired, as observed during lymphedema and various chronic inflammatory reactions.

In situations where LNs are removed (e.g. after breast cancer surgery), the immune system is also disturbed. Mallon et al. ${ }^{23}$ studied 35 patients with BCRL and attempted to sensitize them with an obligate sensitizer, dinitrochlorobezene (DNCB), on either the healthy arm or the affected arm. Sensitization was significant delayed in the lymphodematous arm. After application of DNCB in a sensitized person, the response was significantly faster in the normal arm. They concluded that there were disturbances in efferent as well as afferent immune pathways in patients with breast cancer-related lymphedema. Considering the above data, it is possible that the correlation between swelling and erysipelas $(P<$ $0.0002)^{24}$ is due in part to an altered immune response to bacteria.

\section{Transport of macromolecules}

Plasma proteins and water are transported through the interstitial matrix at various speeds. The interstitial matrix consists of long chain glycosaminoglycans and other biopolymers with irregular spaces between them, and this varies according to the tissue. Within this matrix, a network of initial lymphatic capillaries is present. Depending on their size, small molecules such as fluorescein (379 Da) diffuse much more quickly into initial capillaries than large molecules such as albumin. Plasma can reach the initial lymphatics in two to three minutes in the rat mesentery ${ }^{25}$, whereas macromolecules take much longer. Powers et al. ${ }^{26}$ demonstrated that labeled intravascular albumin took 2-3 days to reach an equilibrium phase in the interstitium and lymph. This phenomenon is explained by the narrowness of the matrix clefts.

When the amount of fluid increases (e.g., in lymphedema), the matrix glycosaminoglycan concentration decreases. As a result, the interstitial colloid osmotic pressure (COP) drops, and the exclusion effect of macromolecules is reduced. Conversely, when the matrix glycosaminoglycan concentration rises, the COP is greater than the apparent concentration calculated as protein/total water volume. This leads to a greater degree of macromolecule exclusion $^{27}$. 
The uptake of macromolecules is an active process in initial lymphatics. The initial lymphatic network, with an endothelial layer lacking a basal membrane and pericytes, has an intercellular space of about $14 \mathrm{~nm}$ or more ${ }^{28}$ and serves a primary valve function. These junctions can be open and closed like roof tiles fixed with anchoring filaments in the interstitial matrix and collagen bundles. The pericytes function as flap valves, also called primary valves. When the intralumenal pressure rises, these valves will open. This precise mechanism of action is not completely resolved.

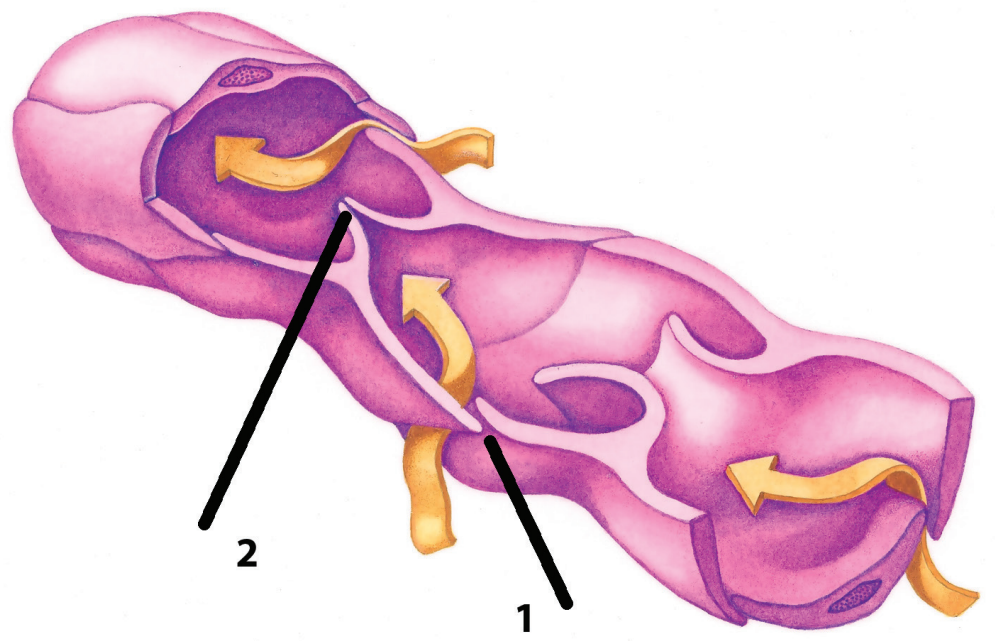

Figure 2: Initial lymphatics: 1: primary valves. 2: secondary valves (Source: DK.com images ${ }^{\circledR}$, permission obtained)

When the fluid content in the interstitial space increases, it is called edema. In order to maintain a balance between the filtration and absorption of water, factors such as venous pressure, plasma and interstitial osmotic pressure and lymphtransport capacity play key roles. When the swelling is caused by water with a less condensed matrix, the water can more easily be displaced. Clinically, discrete (transient) pitting edema is often the first sign of insufficient lymphatic transport capacity. At later stages, especially due to accumulation of interstitial macromolecules inflammatory changes are induced in the subcutaneous tissue, leading to induration and fibrosis.

The water in the interstitium cannot easily be displaced and this is referred to as low conductivity. Consequently the tissue does not "pit" as much after external pressure. A side effect of the accumulation of proteins is an increase in osmotic pressure, which 
leads to more edema ${ }^{29}$. Therefore, the classical sign of lymphedema as an irreversible, nonpitting edema is just the end stage of a continuum and "pitting" or "non pitting" edema is not evidence in itself for the existence of lymphedema.

The metabolic importance of lymphatics, especially in the gut, has long been under appreciated. The anatomical location of lymphatics throughout the gastro-intestinal tract places them in an opportune position to be an effective and essential metabolic organ in the uptake of lipids in specialized lymphatics of the gut called the lacteals. From here chylomicrons are transported to the thoracic duct and into the general blood circulation ${ }^{30}$.

\section{DEVELOPMENTAL AND GENETIC ASPECTS OF LYMPHATICS}

Research on lymphangiogenesis during embryology and in adults is an area of enormous progress. During embryogenesis, lymphatic development is closely related to the development of the blood vasculature. In adults, lymphangiogenesis plays a role in chronic inflammation and cancer metastasis.

\section{Embryonic development}

In the first weeks of development, endothelial cells of the cardinal vein develop into blood and lymph vessels. The embryonic development proceeds in three phases. Recently, molecular markers have been discovered for arterial, venous and lymphatic endothelial cells, which have enabled research into the field of differentiation at a cellular level ${ }^{31}$ in animal research. Many genes and their products are involved in this process. In general, endothelial cell specific growth factors and their receptors can be classified into the vascular endothelial growth factor (VEGF) and angiopoietin (Ang) families ${ }^{32}$. Among the various angiogenic factors, VEGF is probably active in vascularization and angiogenesis and works closely with other factors such as Ang, ephrins (Eph) ${ }^{33,34}$ and lymphatic vessel endothelial receptor-1 (LYVE-1) $)^{35}$.

\section{First phase}

This phase is restricted to early embryonic development and is called vasculogenesis, whereby endothelial precursor cells (embryonic stem (ES) cells) are primed and proliferate 
into tubular structures such as arterial and venous precursors. VEGF receptors, their ligands, and LYVE-1 are involved in the growth of embryonic stem cells (ES) into common progenitors (angioblasts) and then endothelial cells (EC), which differentiate further into either arterial or venous fates. These venous structures are lymphatic competent ${ }^{36}$. In early 2000, knockout studies suggested key roles for ephrin-B2 and its EphB4 receptor during this first stage of vascular development. An interaction between ephrinB2 on arteries and its EphB receptors on veins suggests a role in defining boundaries between the arterial and venous domains. ${ }^{37}$ The earliest event in lymphatic development is polarized expression of the hallmark gene Prox-1 (prospero homeobox 1) ) $^{38}$ in a subpopulation of endothelial cells in the cardinal vein (venous compartment). Through budding and sprouting, these cells give rise to the lymphatic system, and the vascular cells adopt a lymphatic vascular phenotype ${ }^{38}$. Further lymphatic differentiation occurs by budding off from venous structures in which lymph sacs arise under the influence of genes such as Prox-1, VEGFR-3 and LYVE-1. Once the lymph sacs are formed, the blood and lymphatic vascular systems continue to develop separately, although a few connections remain to allow the return of lymph into the blood circulation ${ }^{39}$.

In VEGF knockout mice that completely lack VEGF from the first stages of embryonic development, the complete vascular architecture is lacking ${ }^{40}$. Although VEGF inactivation is lethal during the first few post-natal weeks, in older animals it is much less traumatic. Thus, VEGF does not seem to have a continuous maintenance function in much of the adult vasculature. Prox-1 over-expression in human vascular endothelial cells suppresses blood vessel-specific genes and upregulates lymphatic endothelial-specific cell transcripts ${ }^{41}$.

\section{Second phase}

The next phase involves the angiogenesis of lymphatics, whereby the lymphatic network sprouts out, splits into branches and enlarges into a mature vascular pattern. Further separation from the venous system occurs during this phase. During angiogenesis, it seems that vessels first must be stabilized before the final steps of maturation can proceed. Genes involved in the process of lymphatic sprouting are Prox-1, SOX18, VEGFR3, LYVE-1 and podoplanin ${ }^{42}$. Recently, Francois et al. ${ }^{43}$ suggested that in studies with mice, Sox 18 acts at the nexus of differentiation of lymphatic endothelial progenitor cells from 
blood vascular precursors in the embryo. SOX18-null embryos show complete blockage of differentiation of lymphatics from the cardinal vein. In general, destabilization of genes involved in the growth of vessels leads to the regression of vascular structures ${ }^{44}$.

Third phase: Maturation of the lymphatic network

After the development of lymphatic competent cells, further differentiation and maturation occurs to create a mature lymphatic network with integration into the surrounding tissues, smooth muscle formation and valve development. Many specific lymphatic genes are involved in this process such as Prox-1, Podoplanin, VEGFR-3, LYVE-1, CCL21, FOXC2, Ang1,2 and neuroplin2 ${ }^{29,45}$.

Petrova et al identified FOXC2 as having a key role in regulation of the interaction between differentiation of lymphatic endothelial cells, formation of smooth muscle cell layers and in morphogenesis of lymphatic valves. FOXC2 and VEGFR-3 act through a common genetic pathway to establish distinct properties of the lymphatic vascular architecture ${ }^{46}$.

A schematic overview is shown in figure 3.

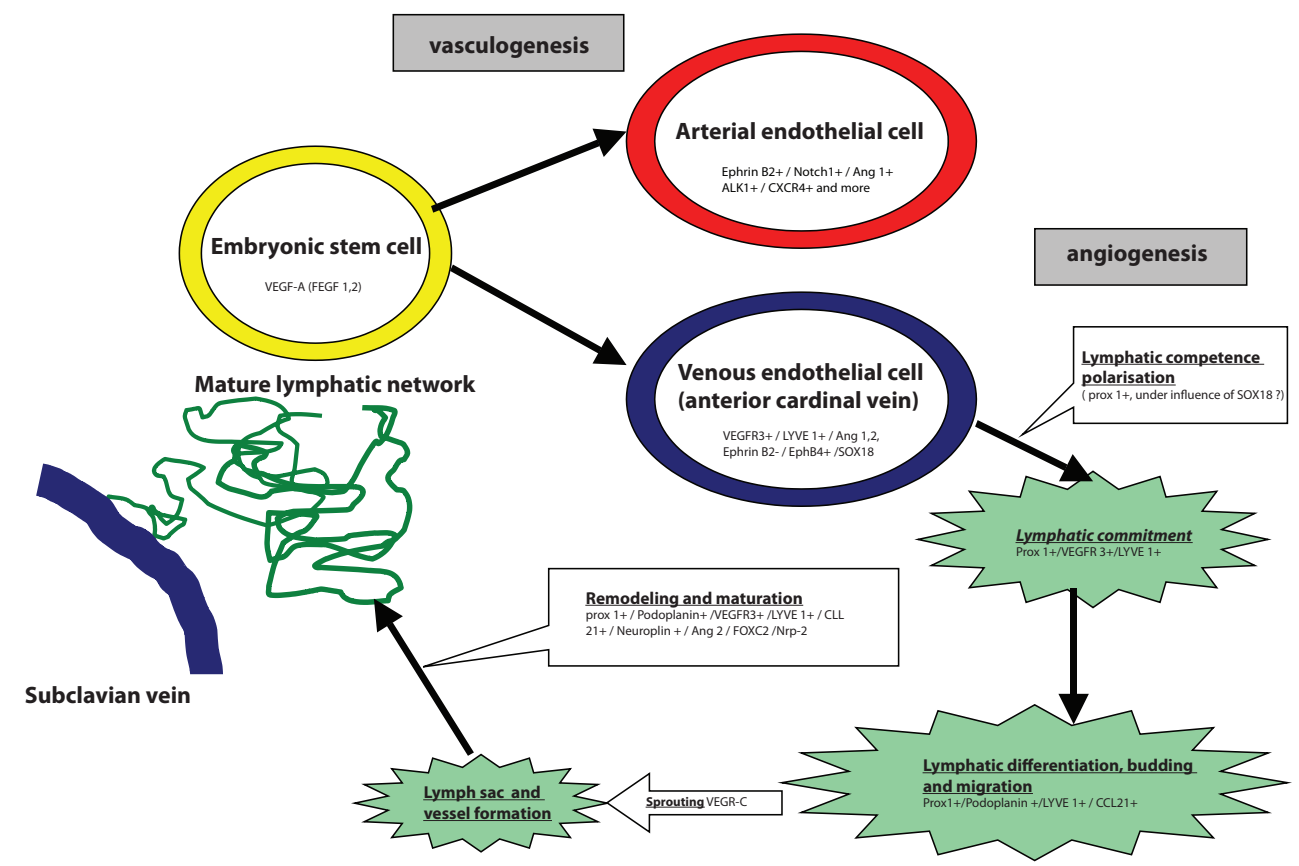

Figure 3: Summary of vasculogenesis and (lymph)angiogenesis with an indication of Growth factors and receptors involved. 


\section{Lymphangiogenesis in adults}

In adult organisms under special circumstances such as tissue repair, inflammation and tumor growth, lymphangiogenesis will occur. Currently, it is unknown if this lymphatic growth is due to the proliferation of local lymphatic cells or if there is an influx of new circulating endothelial progenitor cells to the site of lymphangiogenesis ${ }^{47}$. Studies have been performed to examine whether local (inflammatory) cells can produce lymphangiogenic factors or stimulate the formation of lymphatic endothelial cells (LECs). In tumor studies and during inflammation-associated lymphangiogenesis, macrophages have been suggested to trans-differentiate into $\mathrm{LECS}^{48,}{ }^{49}$.

VEGF-C and VEGF-D are the best characterized lymphangiogenic factors, in addition to recently indentified substances such as growth hormone $(\mathrm{GH})^{50}$ and adrenomedullin $(\mathrm{AM})^{51}$.

In the future these substances could perhaps be part of a therapeutic approach to stimulate or inhibit lymphangiogenesis (e.g., in lymphedema) or inhibit metastasis and tumor growth.

In some inflammatory diseases such as psoriasis ${ }^{52}$, ulcerative colitis ${ }^{53}$ and rheumatoid arthritis, lymphatic hyperplasia or increased lymphangiogenesis has been suggested in mice ${ }^{54}$. A crucial role for VEGF-A was shown with over expression studies, which led to the recruitment of macrophages, supplying VEGF-C and -D. Another role for VEGF-A is in the secretion of VEGF-C by immune cells such as dendritic cells, macrophages and neutrophils 5 .

In the last few years, a more extensive role has been discovered for lymphatics in cancer biology. Lymphatics function as a traffic route not just for immune competent cells but also for cancer cells. This lymphatic spread leads to metastasis in regional lymph nodes as first step in disseminated metastasis, which determines the prognosis and survival of the patient. Formerly, it was proposed that tumor cells invaded lymphatics, but currently, there are indications that tumor cells can actively induce lymphangiogenesis by secreting appropriate lymphatic growth factors such as VEGF-C 56 , VEGF-D ${ }^{57}$ and VEGF-A ${ }^{58}$, which promote tumor spread. Research has been focused on whether it is possible to predict the lymphangiogenic potency of various types of tumors and if there are ways to block this potency. A recent study provided a safe anti-lymphangiogenic strategy in mice by 
inhibition of the VEGF-C /-D pathway, which activate VEFGR-2 and VEGF-A ${ }^{59}$. Another study was performed and showed an anti-metastatic effect via blockade of VEGFR-2 with anti-VEGF-R2 and -R3 antibodies in lung metastases ${ }^{60}$. Recent studies have shown that expression of VEGF-C is a prognostic factor in esophageal cancer ${ }^{61}$, while LYVE-1 expression has been shown to be a predictor of metastatic spread in gastric cancer ${ }^{62}$.

\section{Primary lymphedema and genetics}

In most cases of primary lymphedema, especially those presenting from puberty, a developmental disorder leading to lymphatic impairment is likely if no other external cause for lymphatic impairment is present. Both autosomal dominant and recessive patterns of inheritance have been observed for primary lymphedema, and many single genes and syndromic forms have been described ${ }^{63}$ (see table 1). Despite advances made in the field of lymphatic development and research in knockout mice with lymphatic impairment, limited progress had been made in indentifying the genes that cause clinical lymphedema. Two genes (VEGFR3 and FOXC2) have been described, however, that are responsible for a very small number of cases of primary isolated lymphedema.

According to the Lymphedema Family Study, Ferrell identified 239 patients with clinical signs of lymphedema and a positive family history. Among these, 5\% (12/239) had mutations in the VEGFC/VEGFR3 (1) pathway; 7\% (17/239), in FOXC2 (2); and none (0/239), in SOX18 (3).

Ferrell et al. ${ }^{64}$ studied 25 other plausible candidate genes for lymphedema in families with a history of lymphedema. All families were first screened for mutations in FLT4, FOXC2 and SOX18, and when positive, they were excluded. The 70-100 remaining probands were screened for the 25 candidate genes by resequencing. Ferrell et al. only identified four genes with rare mutations that were consistent with causing lymphedema: FABP4, NRP2, SOX 17 and VCAM1. This study is still being discussed.

Among these four genes, FABP4 - also known as adipose tissue fatty acid binding protein (aP2) - is considered to be the most compelling candidate. FABP4 / aP2 is highly expressed in lymphatic tissue and is closely related to adipocyte tissue differentiation via induction. In FABP4/aP2 null mice, there is resistance to diet-induced insulin resistance and adipocyte hypertrophy, but no lymphedema ${ }^{65}$.

A study in adult Prox1+/- mice with obesity and lymphatic impairment with leakage 
of lymph from the mesenteric lymphatic vessels suggested a link between lymphatic dysfunction and adult-onset obesity in which lymph promoted lipid accumulation in adipocytes and adipogenic differentiation of pre-adipocytes to mature adipocytes in vitro. ${ }^{66}$ We speculate whether these findings give a clue to the rise of adipose tissue in long-lasting lymphedema in chapter 9.

The following forms of lymphedema have a well-known genetic basis:

1. M. Milroy: VEGFR3 (FLT4)

2. Lymphedema distichiasis syndrome: forkhead domain containing homeobox 2 (FOXC2)

3. Some types of syndromal lymphedema (see table 1)

\section{Milroy disease}

Milroy disease (hereditary lymphedema type I, OMIM 153100, autosomal dominant inheritance) is a persistent, painless swelling, typically of one (or both) lower limb(s), which is usually the first sign of lymphedema. Swelling is often present at birth or soon after. When the feet are swollen, discrete features in the foot such as swollen toes, upturned nails and non-pitting edema will be observed. Abnormal initial lymphatic capillaries that fail to uptake lymph are the cause Milroy disease. The isolate gene is located at $5 q 35.3$, and the gene mutated at this position is FLT4, which encodes VEGFR3 ${ }^{67}$.

In a study of 71 patients from 10 families with Milroy disease and VEGFR3 mutations, Brice et al. ${ }^{68}$ described an onset of lymphedema at birth in $97 \%$ of patients, distal edema (94\% total, $85 \%$ bilateral and $14 \%$ unilateral), hydrocele in males (37\%), prominent veins (23\%), cellulitis (20\%), and "ski jump" nails (14\%). Recently Connell et al. ${ }^{69}$ classified 52 patients with primary lymphedema into four classes: typical Milroy disease with positive family history (group I), typical Milroy disease without family history (group II), atypical Milroy disease (group III) and complex primary lymphedema (group IV). Typical Milroy disease is defined as bi / unilateral lower leg lymphedema present at birth, while atypical Milroy disease is defined as bi / unilateral lymphedema not present at birth but with an onset in < 6 years. Complex lymphedema is defined as other forms of primary lymphedema, involving other parts of the body as in syndromic lymphedema. This group found a high mutation prevalence in group I (75\%) and group II (68\%). Within group III and IV, the likelihood of 
detecting VEGFR3 mutations was very small ( $<5 \%)$. They concluded that VEGFR3 mutation analysis was only useful in phenotypic cases of Milroy disease with or without a positive family history. In all other cases, another diagnosis should be considered.

\section{Lymphedema-distichiasis}

In patients with lymphedema-distichiasis syndrome and a FOXC2 mutation, lymphedema usually develops in late childhood or early puberty, but onset can be delayed well into adulthood. A homeotic transformation of the meibomian glands into eyelid follicles results in distichiasis (a double row of eyelashes), which leads to keratitis. Other major complications that have been reported include cardiac defects, cleft palate, extradural cysts, photophobia and other ophthalmic complications ${ }^{70}$.

On the other hand, FOXC2 mutations can lead to isolated cases of lymphedema. Petrova et al. ${ }^{71}$ first reported that FOXC2 was essential for the morphogenesis of lymphatic valves in FOXC2-/- mice, which explains the typical clinical features. In a study from Mellor et al. ${ }^{72}$, all 18 patients with a FOXC2 mutation also showed venous valve failure and pathological reflux in the superficial venous system. Deep venous reflux was recorded in 14 of the 18 patients.

$\mathrm{Ng}$ et al. ${ }^{73}$ studied a total of 2060 complete female twin pairs aged 18-80 years to find a relationship of varicose veins and hemorrhoids with FOXC2 in a normal population without lymphedema. They found a linkage to a candidate marker for the FOXC2 gene suggesting that there is a functional variant(s) within, or in the vicinity of, the FOXC2 gene that predisposes individuals to varicose veins. The results demonstrated a heritable relationship between varicosities and hemorrhoids and suggested that FOXC2 had an important role in the development of varicose veins in the general population.

\section{Syndromic lymphedema}

The only syndromic lymphedema with a known genetic defect is Hypotrichosislymphedema-teleangiectasia (HLT) syndrome. It consists of autosomal dominant and recessive mutations in the SRY-box gene SOX-18, which cause the HLT syndrome of hypotrichosis of the scalp and eyebrows, localized lymphedema of the legs, and teleangiectasia of the palms and soles. The mutations can be autosomal recessive or autosomal dominant ${ }^{74}$. It has been suggested that SOX18 mutations present as isolated 
alopecia in young children, before the onset of lymphedema and as nonimmune hydrops fetalis of unknown etiology in others ${ }^{73}$.

In other forms of syndromic lymphedema, concomitant features will be present such as a dysmorphic phenotype, pediatric diseases or mental disorders. Signs of visceral lymphatic impairment due to lymphangiectasia can lead to chylothorax. Chylous reflux and/or protein-losing enteropathy should also be considered if there is a failure to thrive, diarrhea or dyspnea. (Table 1)

\section{Secondary lymphedema}

Secondary lymphedema is much more common than primary lymphedema and is caused by damage to the lymphatic transport capacity, e.g., by infection, trauma, surgery, radiotherapy or a combination of these. This classification is arbitrary because often a compensated primary lymphedema will become manifest after events such as trauma or infection and is then erroneously called secondary lymphedema (described extensively in chapter 4). Even in BCRL, there are suggestions that pre-existing factors in the lymphatic transport capacity determine whether one patient has a greater chance of developing lymphedema with breast cancer treatment than another ${ }^{79}$.

Many cases reports have been published regarding secondary lymphedema, e.g., after liver transplantation ${ }^{80}$, in morbidly obese patients (in up to $75 \%$ of patients with a body mass index $>75 \%)^{81}$, after heart catheterization, in joint-replacement, vascular reconstructive surgery $(4 \%)^{82}$ and dermatological diseases such as rosacea, acne and hydradenitis suppurativa ${ }^{83}$. Recently, a report was published of lymphedema after the administration of sirolumus in four kidney recipients ${ }^{84}$.

Dynamic lymphatic impairment with swelling occurs when interstitial fluid production is increased for a long period of time. Secondary lymphatics can be damaged, leading to "true" lymphatic impairment. This phenomenon is seen in chronic venous insufficiency (phlebolymphedema), longstanding lipedema (lipo-lymphedema), morbid obesity with fat collections around the belly or the knees ("lumpedema") and immobility due to neurological diseases (dependency edema / dynamic lymphedema).

Lymphedema can occur at all sites of the body such as the extremities, head, neck, trunk, 
Table 1. Summary primary lymphedema

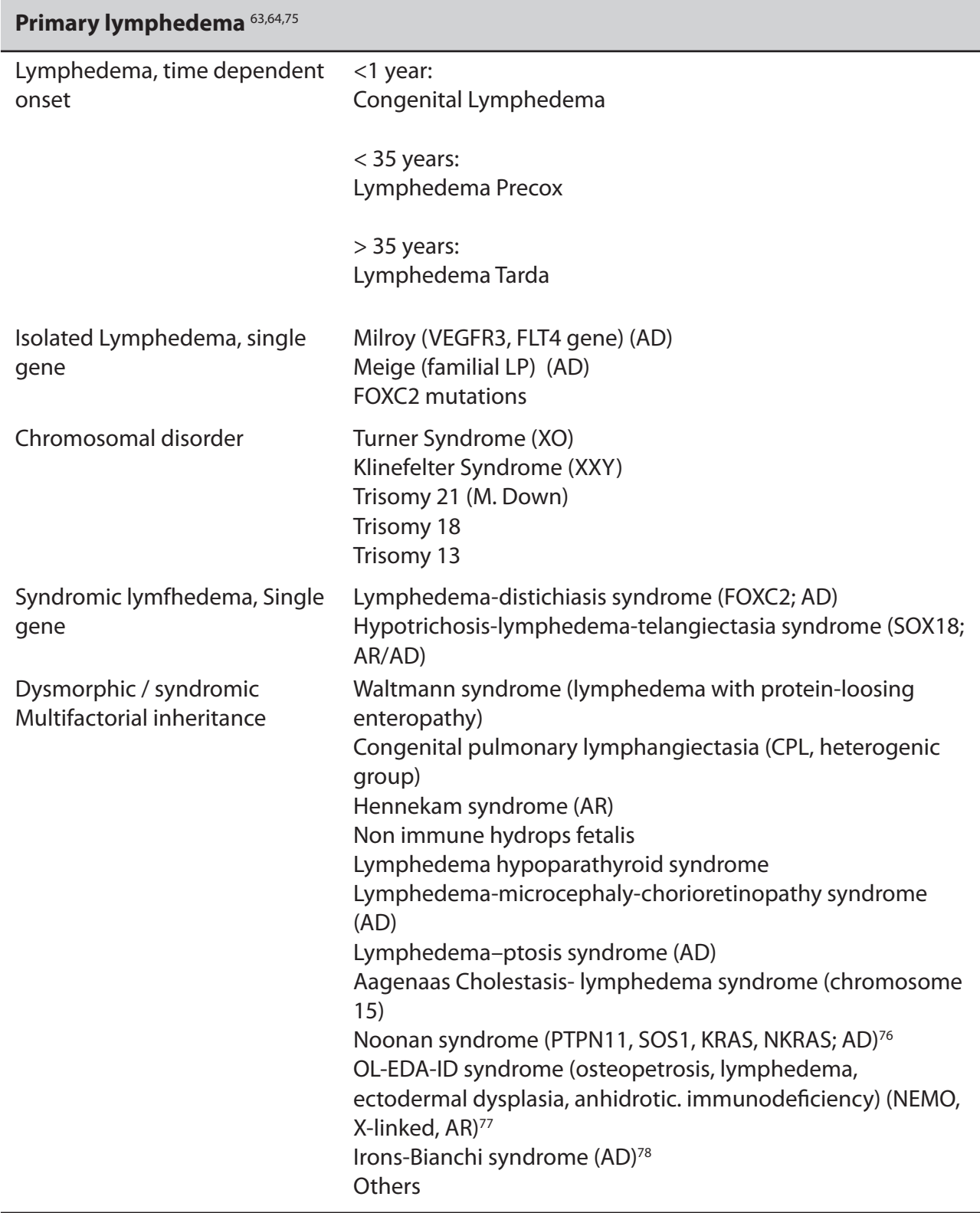

and external genitalia. It is well known that there can be leg lymphedema after abdominal surgery for bladder, prostate or cervical carcinoma in which an iliac lymphadenectomy is performed. Recently, Vanelli et al. ${ }^{85}$ focused on a special form of lymphedema without visible external swelling in patients undergoing abdominal surgery with removal of the 
pelvic lymph nodes. These patients often have many complications, including pelvic dysfunction such as pain, urinary and fecal limitations, and psychological problems. The pelvis is a functional unit in which the lymphatic vessels play an important role in the pathology of the pelvic floor and perineum and it is likely that this condition is caused by internal lymphedema with progressive pathological conditions with local inflammation, interstitial liquid retention with high protein concentration resulting in tissue hypertrophy and fibrosis. The study of "pelvic lymphedema" could be a key to change strategic therapy for pelvic disorders following pelvic surgery.

Forms of secondary lymphedema in Tropic regions: Lymphatic filariasis (filariasis elephantiasis)

In developing countries, especially in Africa and Asia, lymphatic filariasis (LF) is the most common reason for secondary lymphedema, with 120 million individuals infected and a further 1.3 billion at risk ${ }^{86}$. LF is a so-called neglected tropical disease caused by an infection with species of the nematode (round worm) family called Filariide: Wuchereria bancrofti, Brugia malayi, and Brugia timori. Major soil-transmitted helminth (STH) infections caused by Ascaris lumbricoides, Trichuris trichirura, Necator americanus and Ancylostoma duodenale can also cause $\mathrm{LF}^{87}$. These are all diseases of the poor in tropical countries. LF is vector-borne and is dependent on the presence of suitable mosquito vectors such as Culex quiquefasciatus. It causes extreme swelling of the lower limbs and male genitalia, leading to economic loss and social stigma ${ }^{88}$. Often, a chylous hydrocele is observed in LF. Only a small number of infected individuals will exhibit clinical signs of the development of large worms in the lymphatic system. History and clinical signs, the presence of eosinophilia, microfilaria in a nocturnal blood smear, and serological reactions to the presence of antigen make the diagnosis. Asymptomatic disease is an important reservoir of infection. Many global programs have been started to control this disease focusing on mass chemotherapy, school health activities and controlling morbidity. After complete elimination of the worm, patients can become antigen negative again. Since insecticide-treated bed nets are helpful in the prevention of malaria, Odermatt et al. ${ }^{89}$ showed further evidence that bed nets impregnated with insecticide were particularly important to prevent LF, especial during overnight stays in rural regions. 
Non-filariasis elephantiasis (podoconiosis)

In tropical, volcanic highland zones of Africa, Central America and northwest India, an endemic non-filarial form of elephantiasis is known as podoconiosis (non-infectious geochemical elephantiasis, non-filarial elephantiasis) ${ }^{90},{ }^{91}$. This specific disease has been known for more than 1,000 years and colloid sized mineral particles in clays such as aluminum, silicon, iron and magnesium play an important role. Patients walk bare foot, and these irritants will penetrate the sole where they are absorbed by macrophages and transported to the lymph nodes. Podoconiosis primarily begins in the feet, is bilateral and has no groin involvement. It is differentiated from leprotic lymphedema by the preservation of sensation in the toes and forefoot, the lack of tropical ulcers and the absence of thickened nerves or hand involvement. Podoconiosis is totally preventable by wearing footwear.

A classification of various types of secondary lymphedema according the type of lymphatic impairment is listed in Table 2.

Table 2. Classifications of secondary lymphedema

\begin{tabular}{|c|c|}
\hline Secondary lymphedema & \\
\hline Lymphatic obstruction & $\begin{array}{l}\text { Post infection (erysipelas, filariasis) } \\
\text { Podoconiosis (non-infectious geochemical elephantiasis) } \\
\text { latrogenic (radiation, surgery, trauma) } \\
\text { Malignant infiltration } \\
\text { Automutilation / strangulation } \\
\text { "Pelvic lymphedema" } \\
\text { Others }\end{array}$ \\
\hline $\begin{array}{l}\text { Lymphatic overload / } \\
\text { combinations }\end{array}$ & $\begin{array}{l}\text { Phlebo-lymphedema } \\
\text { Lipo-lymphedema } \\
\text { Dependency edema } \\
\text { "Lump-edema" in lipedema and morbid obesity }\end{array}$ \\
\hline
\end{tabular}

\section{EPIDEMIOLOGY OF LYMPHEDEMA}

When reviewing the literature, the terms "incidence" and "prevalence" are often used incorrectly. Incidence rates are described as the rate of new cases of a certain disease in a defined population within a specified period of time. Prevalence however, can be described as the number of people who have the disease within a defined population 
at any one time. Barker and Rose ${ }^{92}$ state that incidence rates have an advantage over prevalence rates because they are not influenced by the duration of the disease but that prevalence is a better tool to use when describing chronic diseases. A chronic disease is lasting and constant. lymphedema is such a condition, but it can develop at any time. Therefore, in post-oncology lymphedema the term incidence is often used to define the number of cases within a defined population during a longer period of time.

The epidemiology of lymphedema is not exactly known because it is not a regular registered disease. The number of patients worldwide is estimated at about 140-250 million ${ }^{93}$.

Table 3. Prevalence in primary lymphedema

\begin{tabular}{|c|c|c|c|}
\hline Author & Disorder & Prevalence & Remarks \\
\hline Smeltzer ${ }^{94}$. & $\begin{array}{l}\text { Primary lymphedema } \\
\text { in children }<20 \text { years }\end{array}$ & $1,15 / 100.000$ & 1955-1982 patients in Mayo clinic \\
\hline Greenlee $^{95}$ & M. Klinefelter & $1 / 500$ & High risk on lymphedema \\
\hline Dale ${ }^{96}$ & lymphedema at birth & $1 / 6000$ & $\begin{array}{l}312 \text { index patients }<36 \text { years Male/ } \\
\text { female }=1 / 3\end{array}$ \\
\hline Scharz ${ }^{97}$. & $\begin{array}{l}\text { Stemmer sign }+ \text { in } \\
\text { women }\end{array}$ & $8 / 100$ & 1000 adults \\
\hline \multirow[t]{3}{*}{ Pannier ${ }^{98}$} & & $<20$ years: & 62 patients \\
\hline & $\begin{array}{l}\text { Stemmer sign in } \\
\text { general population }\end{array}$ & $3,2 / 100$ & 294 patients \\
\hline & (Bonner Venenstudie) & $\begin{array}{l}\text { Patients with C0 } \\
\text { (CEAP): 5,8/100 }\end{array}$ & \\
\hline
\end{tabular}

Determining of the incidence or prevalence of various types of lymphedema is difficult. The variation in the type of study (e.g. retrospective, prospective, questionnaire, life visit), type of measurements and the outcome parameter is enormous. Therefore, proper numbers are not known. Table 3 lists a number of studies reporting the prevalence of primary lymphedema.

Numbers for the incidence of secondary lymphedema are more available. In westernized countries, secondary lymphedema cause by breast cancer treatment is most common and lymphedema is often mentioned as a complication. Limitations in this field include the variety of (combinations) of treatments and unfortunately there is no standardized 
Table 4. Incidence in secondary lymfhedema

\begin{tabular}{|c|c|c|c|c|}
\hline Author & Disorder & $\begin{array}{l}\text { No. } \\
\text { patients }\end{array}$ & $\begin{array}{l}\text { Incidence/ } \\
\text { prevalence }\end{array}$ & Remarks \\
\hline Pannier ${ }^{100}$ & $\begin{array}{l}\text { Stemmer sign } \\
\text { in general } \\
\text { population (Bonner } \\
\text { Venenstudie) }\end{array}$ & 3055 & $\begin{array}{l}\text { Prevalence: } \\
\text { All: } 17,2 \% \text { / } \\
\text { 14,6\% (F/M) } \\
\\
>60 \text { years: } \\
35,9 \%\end{array}$ & $\begin{array}{l}\text { Close relation to CVI } \\
\text { according to CEAP } \\
\text { classification. }\end{array}$ \\
\hline Moffatt ${ }^{100}$ & $\begin{array}{l}\text { All forms of "chronic" } \\
\text { swelling in general } \\
\text { population; } \\
\text { ascertainment } \\
\text { method through } \\
\text { healthcare workers. }\end{array}$ & 823 & $\begin{array}{l}\text { Prevalence: } \\
0,13 \%\end{array}$ & $\begin{array}{l}823 \text { patients } \\
\text { Limitation to study } \\
\text { with underestimate } \\
\text { of problem }\end{array}$ \\
\hline Kwan 101 & $\begin{array}{l}\text { Breast cancer } \\
\text { treatment }\end{array}$ & 744 & $\begin{array}{l}\text { Symptomatic } \\
\text { lymphedema: } \\
17,5 \% \\
\text { A-symptomatic } \\
\text { lymphedema: } \\
7 \% \\
\text { Axillary } \\
\text { dissection and } \\
\text { RTX: } 30 \%\end{array}$ & \\
\hline Paskett ${ }^{102}$. & $\begin{array}{l}\text { Breast cancer } \\
\text { survivors for } 3 \text { years } \\
\text { follow-up }\end{array}$ & 622 & $\begin{array}{l}\text { Prevalence: } \\
43 \% \text { (arm) } \\
34 \% \text { (hand) } \\
22 \% \text { (both) }\end{array}$ & $\begin{array}{l}\text { Relation OP and } \\
\text { obesity } \\
\text { Questionnaire }\end{array}$ \\
\hline Meeske $^{103}$ & $\begin{array}{l}\text { Riskfactor } \\
\text { lymphedema } \\
\text { in Breast cancer } \\
\text { treated patients }\end{array}$ & 494 & $\begin{array}{l}24 \% \\
\text { lymphedema }\end{array}$ & $\begin{array}{l}\text { Relation with } \\
\text { obesity and } \\
\text { hypertension }\end{array}$ \\
\hline Sener ${ }^{104}$ & Sentinel node in $B C$ & 303 & $3 \%$ & Prospective \\
\hline Wilke $^{105}$ & Sentinel node in $B C$ & 5327 & $6,9 \%$ & Prospective \\
\hline Lee $^{106}$ & $\begin{array}{l}\text { Meta-analysis } 32 \\
\text { articles between } \\
\text { 1966-2007 breast } \\
\text { cancer treatment }\end{array}$ & & $\begin{array}{l}\text { Prevalence; } \\
0-34 \%\end{array}$ & \\
\hline Beesley ${ }^{107}$ & $\begin{array}{l}\text { Gynecological } \\
\text { cancer with lymph } \\
\text { node dissection } 12 \\
\text { month follow-up }\end{array}$ & 802 & $\begin{array}{l}\text { Prevalence: } \\
\text { Cervix cancer: } \\
17 \% \\
\text { Vulvar cancer: } \\
36 \%\end{array}$ & $\begin{array}{l}\text { Retrospective mail } \\
\text { survey }\end{array}$ \\
\hline Gaarenstroom $^{108}$ & $\begin{array}{l}\text { Vulvar cancer with } \\
\text { groin dissection }\end{array}$ & 172 & $\begin{array}{l}\text { Lymphocyst: } \\
40 \% \\
\text { lymphedema: } \\
28 \%\end{array}$ & Follow-up study \\
\hline Catalona ${ }^{109}$ & Penis carcinoma & 6 & $50 \%$ & $\begin{array}{l}\text { Modified } \\
\text { lymphadenectomy } \\
\text { groin }\end{array}$ \\
\hline Rempelakos ${ }^{110}$ & Penis carcinoma & 360 & $45 \%$ & $\begin{array}{l}\text { Various types of } \\
\text { operation }\end{array}$ \\
\hline Lieskovsky $^{111}$ & Prostate carcinoma & 82 & $18 \%$ & \\
\hline
\end{tabular}


method of measure swelling. There are no assessment techniques for early diagnosis or generally accepted criteria to define lymphedema.

Studies regarding the incidence of lymphedema after gynecological cancer are very rare and in urological oncology lymphedema is not a topic of discussion yet. Gynecological and urological interventions in the pelvic region for cervical, prostate and bladder carcinoma or in the midline region in cases of penis and vulvar carcinoma, lack systematic attention for lymphedema. It is a very serious problem, however, with estimated incidences of 40 $60 \%$. Despite some very old studies, even in the latest guidelines for prostate carcinoma from the Dutch Institute for Health care improvement (CBO) from 2007, the complication of lymphedema is not mentioned at all ${ }^{99}$.

In table 4 some relevant studies on incidence are listed.

\section{DIAGNOSIS OF SWELLING AND LYMPHEDEMA}

In every patient with swelling of an extremity, the face or external genitalia, a diagnosis lymphedema should be considered. History and physical examination are the cornerstones in diagnosis. In early stage lymphedema, there is a reversible, pitting edema, which is sometimes difficult to diagnose. In more advanced stages with characteristic features of accumulation of macromolecules, fibrosis and interstitial inflammation, the diagnosis can easily be made by physical examination. In screening for lymphedema, clinical signs are of great importance. Stemmer's sign, first published in 1976 by Robert Stemmer ${ }^{112}$, is a very useful clinical sign for the diagnosis of lymphedema. It is defined as enlargement of the skin fold above the second toe due to fibrosis and hypertrophy: so-called cobble stone toes. This phenomenon in the second toe was originally described by Kaposi, but was redescribed by the French phlebotomist Stemmer and is, therefore, called a positive Stemmer sign when there is an inability to pinch up a fold of skin between the second and third toe on the dorsum of the foot. This sign is a very sensitive test for lymphedema with a high positive predictive value ${ }^{113}$. Földi ${ }^{114}$ and Stemmer ${ }^{115}$ stated that Stemmer's sign is never falsely positive for lymphedema of the legs. In early diagnosis of cancer treatment related lymphedema of the arm, genitals, face or even the leg, Stemmer's sign is not useful. 
Early diagnosis of lymphedema is essential to prevent more late stage, irreversible changes that could lead to high morbidity and preventable loss of quality of life. Therefore, prevention, awareness and education are mandatory in patients at risk to develop lymphedema or with early signs of lymphedema.

In what way can early swelling due to lymphatic impairment be diagnosed? The classic water displacement method ${ }^{116}$ in which a limb is slowly placed in a tank filled with water and the volume of the overflow is measured is not very practical, but it is generally accepted as the gold standard. In spite of the need for a more convenient measurement device, no consensus exists with respect to a commonly accepted and standardized method. Currently, there are many ways of describing the presence and severity of lymphedema and to monitor the response to treatment. These include photographing pre-operatively and postoperatively, a circumferential measurement, the patient's subjective description ${ }^{117}$, mathematical volume calculations related to circumferential measurements of the limb ${ }^{118}$, opto-electric volumetry ${ }^{119}$, and bioelectrical impedance ${ }^{120}$. Using circumference measurement at various levels on the arm, some authors ${ }^{121}{ }^{103}$ consider a difference between the arms of $2.5 \mathrm{~cm}$ measured at one point as lymphedema, while others use $2 \mathrm{~cm}$ of difference as the threshold ${ }^{123}$. Relative lymphedema measurement is a special technique for unilateral lymphedema according to Herpertz ${ }^{124}$. This method is a combination of a four-point circumference measurement of both limbs. A calculation is then made of the relative proportional swelling compared to the healthy side.

Most of the above measurement techniques have not been validated, except the Sitzia method ${ }^{125}$. Many studies with indirect volume measurement methods are not interchangeable with the water displacement method. Another major disadvantage is that all of these methods lack the ability to measure and include the volume of the hands and feet in the total volume. The validation study presented in this thesis regarding the inverse water displacement method introduces a new gold standard for arm swelling without the well-known restrictions ${ }^{126}$.

Given that many measuring methods are available, although most of them are not validated, the second question is what volume change is necessary for the diagnosis of lymphedema? Armer et al. ${ }^{127}$ compared four diagnostic criteria for lymphedema in 118 
BCRL patients: relative limb volume change of $10 \%(1)$, absolute volume changes of $200 \mathrm{~mL}$ (2), circumference measurement of $2 \mathrm{~cm}$ change (3), and subjective data including heaviness or pain (4). They found that a $10 \%$ volume change (1) was a more conservative definition of lymphedema compared to the others. In many guidelines a $10 \%$ volume change, either as a mutual comparison in unilateral lymphedema or for comparison of one limb with pre-operative values, is advised. A relative volume measurement eliminates differences in human physical stature and provides the opportunity for comparison of various scientific studies (meta-analysis).

In patients with swelling but without classical signs of lymphedema (as mentioned above) or in patients with erysipelas without a cause, additional diagnostics can be performed. Diagnostics methods can be divided into lymphological and non-lymphological examinations. The latter are focused on causes of lymphogenic obstruction in secondary lymphedema and visualizing the distribution of swelling in general.

\section{LYMPHOLOGICAL DIAGNOSTIC PROCEDURES}

Besides clinical signs, subjective parameters and volume changes to diagnose lymphedema, many methods have been described to visualize or quantify lymphedema. As stated before, anamnesis and clinical assessment are mostly sufficient to diagnose lymphedema. In cases of doubt or uncertainty based on lymphatic anatomy or function without clear signs of lymphedema, additional investigations are appropriate.

\section{Direct lymphography and Patent Blue test}

Direct lymphography was formerly performed by injecting oil containing X-ray contrast medium into a surgically dissected lymph collector in the region of the forefoot or the dorsum of the hand. Before microsurgical dissection, initial identification of the lymphatics was done with an intradermal injection of patent blue. This technique was mainly used to diagnose lymphatic diseases such as metastatic lymphoma in a lymph node in the era when there was no MRI or CT-scanning. The contrast medium was toxic to lymphatics, and one of the main complications was secondary lymphedema and micro-embolism in the pulmonary vessel system ${ }^{128}$. Direct lymphography is now obsolete ${ }^{129}$.

Sometimes the dye Patent blue V, methylene blue or chlorophyll was injected 
subcutaneously between the toes to visualize the lymphatics. This was often painful, with prolonged discoloration of the feet, and sometimes resulted in infection. Today it is still being used to 1) localize lymphatic fistulae when there is lymph leakage from a wound, (meanly located in the tibial region of the leg), and 2) in persistent seroma collectors after breast cancer surgery that do not respond to intermittent puncture and compression in cases of chylo-thorax.

In recent years this technique has become popular again for the visualization of lymphatics in the so-called sentinel node procedure. Prior to this procedure, a detector that is most often a dye or radioisotope colloid is used to localize the sentinel node ${ }^{130}$. This technique is widely used in breast cancer surgery, melanoma surgery and for lymph node mapping in gynecologic and urologic malignancies.

\section{Indirect lymphography}

In contrast with direct lymphography, indirect lymphography is performed with water soluble X-ray contrast media containing a high iodine concentration with an osmolarity equal to or less than the blood or interstitial fluid. The contrast medium is injected intracutaneously and can only be used to visualize the pre-capillary network to the collectors. Indirect lymphography can actually be considered as a radiographic "patent blue test."

A three-dimensional MR lymphography technique has recently been developed to visualize lymphatic vessels ${ }^{131}$. After injection of a gadolinium-based contrast agent in volunteers, lymph nodes can be seen on T1-weighted images within 30 minutes. This method is mainly used for research ${ }^{132}$.

\section{Fluorescence (micro) lymphography}

A new diagnostic imaging technique without the use of nuclear scanning or X-ray imaging is fluorescence lymphography. Several methods have been described. After injection of $0.5 \%$ Indocyanine green (containing iodides) subcutaneously at the dorsum of the foot, the dye can be visualized with an infrared light camera ${ }^{133}$. Bollinger and Amann-vesti ${ }^{134}$ injected FITC-dextran 150,000 subepidermally and visualized the initial lymphatics using an incident light fluorescence microscope. In particular, the distribution of the superficial lymph capillary network, signs of dermal backflow and dilatation of lymph collectors 
(lymphatic microaneurysms) can be visualized through the intact skin. This method is promising and could become an alternative lymphatic imaging technique for visualizing peripheral skin capillaries, although anaphylactic deaths have been reported due to Indocyanine ${ }^{135},{ }^{136}$.

\section{Qualitative and quantitative (isotope) lymphoscintigraphy}

Lymphoscintigraphy is a technique in which $99 \mathrm{~m}$ Tc-Nanocolloid is administered subcutaneously in the skin, and a high-resolution gamma camera allows assessment and visualization of the tracer distribution through the lymph vessels, the lymph nodes and up to the liver. For a functional evaluation, uptake values in the lymph nodes and clearance from the injection side can be calculated.

The qualitative lymphoscintigraphy criteria for lymphatic dysfunction include (1) delay (> 30 min), (2) asymmetric or absent visualization of regional lymph nodes, and (3) the presence of "dermal backflow." Additional findings include (4) asymmetric visualization of lymphatic channels (normally three to five vessels per calf and one to two vessels per thigh) and (5) collateral lymphatic channels. All of these parameters are correlated with a clinical diagnosis of lymphedema ${ }^{137,138}$.

Qualitative lymphoscintigraphy can also be used in other regions such as the face and the midline region to evaluated the direction of lymph flow. When retrograde lymph flow is suspected in gastro-intestinal lymphectasia, chylous reflux can be visualized in the contralateral leg after injection.

For further functional evaluation, uptake values in the lymph nodes and the clearance rate at the site of injection can be calculated. Quantitative lymphoscintigraphy is mainly used for the evaluation of lymphatic function in the leg or arm. In scintigraphy the use of a standardized protocol is essential. Qualitative and quantitative lymphoscintigraphy results are often in agreement, especially when clinical signs of lymphedema are more evident. Quantitative assessment can detect a reduction in lymphatic drainage capacity before clinical or qualitative lymphoscintigraphic signs appear. Quantitative analysis may thus increase the sensitivity and specificity of lymphoscintigraphy in the early diagnosis of lymphatic disorders ${ }^{139}$. The technique, therefore, is a useful tool in assessment of the (maximal) functional capacity of the lymphatic system and is especially useful in subclinical cases of lymphedema. 
In a protocol by the Dutch Society of Nuclear Medicine for lymphoscintographic studies of the legs, the uptake of radioisotope was measured in the groin lymph nodes at two hours in a standardized region of interest (ROI). This protocol used a standardized activity program: walking 20 times on a treadmill immediately after injection. After the first static and dynamic measurements at 30 minutes, the patient had to walk at a brisk pace for 60 minutes. After two hours, if the uptake value was calculated in the ROI to be less than 15\%, there was a clear shortage of lymphatic drainage. An uptake between 15-20\% was defined as borderline, and an uptake of more than $20 \%$ was normal ${ }^{140}$. Clearance from the foot was not taken in account because these values are less reliable and less sensitive for the diagnosis of lymphatic impairment ${ }^{141}$. Indicative values must be under $80 \%$.

Unilateral lymphoscintigraphy with $99 \mathrm{~m}$ Tc-Nanocolloid is used when one extremity is evaluated, and transport of the isotope to the liver is calculated. During the first 40 minutes following the injection, dynamic images are taken, including the entire arm, the axilla and the liver. Images are then made 60, 120, and 180 minutes after the injection. The images are interpreted in three ways: visual (qualitative), semi-quantitative using the Transport Index, and quantitative through calculation of the liver fraction after 60, 120, and 180 minutes.

In clinical practice, visual interpretation is the method most often used because it is easy to perform; however, small differences between pre- and postoperative studies may be difficult to recognize.

Kleinhans et al. have described a Transport Index ${ }^{142}$. In this index, five parameters describe the lymph flow: lymphatic transport kinetics $(K)$, distribution pattern (D), time lapse to appearance of lymph nodes ( $T$ in minutes, multiplied by 0.04 ), assessment of lymph nodes $(\mathrm{N})$, and assessment of lymph vessels (V).

Isotope lymphoscintigraphy is currently the most appropriate method to objectively investigate a clinical suspicion of lymphedema. In daily practice, quantitative lymphoscintigraphy is the method most often used and evaluates the lymphatic component in the clinical presentation of a swollen extremity without obvious pathogenesis. The examination is noninvasive and can be performed easily; however, it requires the expertise of a nuclear medicine sub-specialist, and only investigators who have good experience with lymphatic imaging should interpret the examinations ${ }^{143}$. 


\section{MRI and CT techniques}

In recent years, computed tomography $(\mathrm{CT})$ and magnetic resonance imaging (MRI) have been introduced to perform anatomical imaging. When only conventional imaging is available, enlargement of lymph nodes can be stated as a primary diagnostic criterion for lymphatic disease. This is particularly true in oncology patients with swelling, where nodal enlargement can be indicative of nodal metastases or lymphoma. Newer imaging methods such as positron emission tomography (PET), dynamic contrast-enhanced MRI (DCE-MRI) and color Doppler ultrasound (CDUS) can also provide a functional assessment of node status ${ }^{144}$. None of these techniques, however, is capable of detecting flow within the lymphatics, and therefore, we need the techniques mentioned above.

$\mathrm{CT} / \mathrm{MRI}$ techniques can be considered when swelling occurs in patients without a history of lymphedema and obstruction of lymphatics should be ruled out before starting lymphedema therapy regimes. Especially in older patients when lymphedema tarda is suggested, cardiac diseases, malignant infiltration in lymphatics or an external obstruction can be a common reason for swelling.

The diagnostic methods are summarized in table 5.

\section{THERAPEUTIC ASPECTS OF LYMPHEDEMA}

Treatment of lymphedema is very challenging. Therapeutic options in lymphedema include conservative and operative modalities and should be individualized with regard to the circumstances of the patient lymphedema. These circumstances include age, comorbidities, prognosis of (malignant) disease, psychosocial aspects, and physical potential. The goals for conservative treatment are to eliminate edema by reducing interstitial fluid production and to stimulate lymphatic propulsion by compression. In addition, lymph flow is stimulated by manual lymph drainage (MLD), sometimes with additional pressotherapy and by exercises to improve functional capacity. In order to minimize the risk of infection, maintenance of skin integrity and proper skin care are mandatory. The combination of these therapeutic modalities is called complex decongestive therapy (CDT). When the maximal therapeutic result is obtained, compression garments are then essential for longterm management ${ }^{145}$. 
Table 5. Summary of diagnostic tools

\begin{tabular}{|c|c|c|c|c|}
\hline Method & Type of method & $\begin{array}{l}\text { Visualization } \\
\text { of lymphatics }\end{array}$ & $\begin{array}{l}\text { Quantifying } \\
\text { function of } \\
\text { lymphatics }\end{array}$ & $\begin{array}{l}\text { Remarks of } \\
\text { method }\end{array}$ \\
\hline Direct lymphography & $\begin{array}{l}\text { Injection of } \\
\text { oil- containing } \\
\text { substance }\end{array}$ & $\begin{array}{l}\text { Yes. Especially } \\
\text { larger vessels } \\
\text { and nodes }\end{array}$ & Not possible & Obsolete \\
\hline Patent Blue test & $\begin{array}{l}\text { Injection of } \\
\text { dye locally and } \\
\text { clinically visible }\end{array}$ & $\begin{array}{l}\text { Yes. Small (pre) } \\
\text { collectors and } \\
\text { larger vessels } \\
\text { and nodes }\end{array}$ & Not possible & $\begin{array}{l}\text { For } \\
\text { lymphfistula } \\
\text { or sentinel } \\
\text { node biopsy. } \\
\text { No comparison } \\
\text { both sides }\end{array}$ \\
\hline $\begin{array}{l}\text { Indirect } \\
\text { lymphography }\end{array}$ & $\begin{array}{l}\text { Injection of dye } \\
\text { (bi) laterally and } \\
\text { visible with X-ray }\end{array}$ & $\begin{array}{l}\text { Yes. Small } \\
\text { (prae) } \\
\text { collectors and } \\
\text { larger vessels } \\
\text { and nodes }\end{array}$ & Not possible & $\begin{array}{l}\text { Sometimes in } \\
\text { research. Local } \\
\text { mapping }\end{array}$ \\
\hline $\begin{array}{l}\text { Fluorescence (micro) } \\
\text { lymphography }\end{array}$ & $\begin{array}{l}\text { Injection of } \\
\text { dye locally and } \\
\text { visible with } \\
\text { special light }\end{array}$ & $\begin{array}{l}\text { Yes. Especially } \\
\text { capillaries }\end{array}$ & Not possible & $\begin{array}{l}\text { Sometimes in } \\
\text { research. Local } \\
\text { mapping }\end{array}$ \\
\hline $\begin{array}{l}\text { Qualitative } \\
\text { lymphoscintigraphy }\end{array}$ & $\begin{array}{l}\text { Injection isotope } \\
\text { (bi) laterally } \\
\text { and visible with } \\
\text { gamma camera }\end{array}$ & $\begin{array}{l}\text { Yes. Small (pre) } \\
\text { collectors and } \\
\text { larger vessels, } \\
\text { nodes and liver }\end{array}$ & Not possible & $\begin{array}{l}\text { Daily practice. } \\
\text { Less effective. } \\
\text { Compare both } \\
\text { sides possible }\end{array}$ \\
\hline $\begin{array}{l}\text { Quantitative } \\
\text { lymphoscintigraphy }\end{array}$ & $\begin{array}{l}\text { Injection isotope } \\
\text { bilaterally and } \\
\text { visible with } \\
\text { gamma camera }\end{array}$ & $\begin{array}{l}\text { Yes. Small (pre) } \\
\text { collectors and } \\
\text { larger vessels, } \\
\text { nodes and liver }\end{array}$ & $\begin{array}{l}\text { Yes. Uptake } \\
\text { values and } \\
\text { clearance } \\
\text { rates in } \mathrm{ROI}\end{array}$ & $\begin{array}{l}\text { Preferable in } \\
\text { daily practice. } \\
\text { Compare both } \\
\text { sides and to } \\
\text { reference } \\
\text { values essential }\end{array}$ \\
\hline $\begin{array}{l}\text { Unilateral } \\
\text { lymphoscintigraphy }\end{array}$ & $\begin{array}{l}\text { Injection isotope } \\
\text { laterally and } \\
\text { visible with } \\
\text { gamma camera }\end{array}$ & $\begin{array}{l}\text { Yes. Small (pre) } \\
\text { collectors and } \\
\text { larger vessels, } \\
\text { nodes and liver }\end{array}$ & $\begin{array}{l}\text { Calculate } \\
\text { liver } \\
\text { clearance }\end{array}$ & $\begin{array}{l}\text { In research or } \\
\text { to visualize } \\
\text { chylous reflux }\end{array}$ \\
\hline CT technique & High radiation & $\begin{array}{l}\text { Anatomical } \\
\text { structures; } \\
\text { (extra) } \\
\text { lymphatic }\end{array}$ & Not possible & $\begin{array}{l}\text { In daily practice } \\
\text { in patients with } \\
\text { swelling and } \\
\text { suspicion of } \\
\text { tumor }\end{array}$ \\
\hline MRI technique & $\begin{array}{l}\text { No radiation; } \\
\text { magnetic field }\end{array}$ & $\begin{array}{l}\text { Anatomical } \\
\text { structures; } \\
\text { (extra) } \\
\text { lymphatic }\end{array}$ & Not possible & $\begin{array}{l}\text { In daily practice } \\
\text { in patients with } \\
\text { swelling and } \\
\text { suspicion of } \\
\text { tumor }\end{array}$ \\
\hline
\end{tabular}




\section{Manual lymph drainage (MLD)}

Manual lymphatic drainage was developed in the 1930s by Emil Vodder as a special massage technique to facilitate the lymphatic system and to increase lymph transport. This is accomplished through manual mechanical compression and traction, stimulating the smooth muscle surrounding the lymph vessels, which increases the pumping rate and, therefore, increases the propulsion of stagnant lymphatic fluid. As a result, lymph flow improves without increasing capillary filtration ${ }^{146}$.

MLD can be performed by four techniques: stationary circles, rotary, pump and scope techniques ${ }^{147}, 148$, each of them used for special locations of the body. All of these techniques have special frequencies of compression, and the relaxation phase may be gentle or more pronounced and may have a fixed rank. For example, the rank order for lymphedema of the arm is cervical paraspinal lymph vessels and lymph nodes, superficial and deep lymphatic structures of the abdomen, contralateral axillary lymph nodes, axilloaxillary anastomoses of lymph vessels, ipsilateral inguinal lymph nodes, axilloinguinal anastomoses of lymph vessels, intercostal lymph vessels, parasternal lymph nodes, and ipsilateral breast tissue $^{149}$.

In a recent study, Olszewski ${ }^{150}$ looked at the lympho-dynamic effects of compression therapy on the lymphatic system and showed that an increase in the tissue pressure led to a stretch of the anchoring filaments attached to the initial lymphatics, which caused an opening of the initial lymph capillaries. That study also found enhancement of the spontaneous contractions of the lymph-collectors that normally occurs under the influence of rhythmic pressure changes as a result of muscle movement and compression.

In 1988 Pecking et al. ${ }^{151}$ performed a study on the effect of prophylactic MLD compared to no treatment in breast cancer patients. They found a minute difference in the incidence of lymphedema of $30 \%$ versus $45 \%$, which was not significant. From the perspective of cost effectiveness, prophylactic treatment with MLD should not be considered.

To promote patients'self management and active participation in BCRL treatment, Williams et al. ${ }^{152}$ described a simplified method of MLD called simple lymphatic drainage (SLD). In that study, 31 patients were randomized into two groups: patients who received MLD 
followed by SLD or in the reverse order. SLD was used as a comparative intervention, since it was not thought possible to provide placebo or 'sham' MLD. The first treatment was given for 3 weeks daily, followed by a 6-week no treatment period, and then the opposite treatment was given daily for 3 weeks. After treatment, the patients wore an elastic garment. Volume measurements were conducted with the calculated cylinder method from Kuhncke ${ }^{153}$, which excludes the volume of the hand. SLD was used a comparative intervention and did not show a significant effect on the outcome measures, although there was a trend toward reduction in limb volume. MLD and compression provided a statistically significant reduction in limb volume and improvement in several quality of life parameters and symptoms associated with lymphedema. Thus, SLD is probably effective in the maintenance phase but is less suitable for the initial treatment of lymphedema.

Only a few studies have been performed to study the additional effects of MLD over compression therapy in lymphedema. Two controlled studies showed that compression therapy with or without additional MLD was equally effective for BCRL. Andersen et al ${ }^{154}$ performed a randomized controlled study in BCRL comparing MLD and compression ( $n$ $=20)$ to a control group that was only treated with compression therapy $(n=20)$. After 2 weeks, the control group actually had a greater percentage reduction in absolute edema (60\%) compared to the MLD group (48\%). Both groups experienced an equal reduction in the symptoms of heaviness and tightness, but the control group also had a reduction in reported discomfort. The reduction in absolute edema (66\%) was maintained at 12months of follow up (pooled data). Johansson et al ${ }^{155}$ studied the effect of short stretch bandages with or without MLD in 38 female patients. Both groups showed significant improvement in volume reduction (-11\% after 3 weeks) and fewer complaints.

A comparison of studies on MLD and compression therapy alone by Korpon et al. ${ }^{156}$ found no difference in volume change.

In a systematic review, Klingman et al. ${ }^{157}$ studied ten randomized controlled trials of treatment from BCRL. In all of these studies, the authors could not go further than stating that there was "some suggestion" that compression and MLD"may improve" lymphedema. The effectiveness of the use of life-long compression garments was more obvious. In daily practice, MLD is being used in several therapeutic schemes, especially when it is combined with various forms of compression therapy such as short-stretch multilayer 
bandaging applied after each MLD session ${ }^{158}$.

Although MLD has been used widely for many decades and is assumed by many to be a panacea in the treatment of lymphedema, there is currently no indisputable evidence that has been published about its effectiveness or its mode of action in improving lymphatic drainage.

\section{Compression therapy and hosiery}

The primary goal of lymphedema treatment is to eliminate edema and prevent it from recurring. Compression therapy is an effective way of reducing edema and has been extensively studied in chronic venous insufficiency ${ }^{159}$. Compression therapy can be subdivided into the initial phase of treatment (phase of edema reduction), which consists of bandaging, and the maintenance phase when hosiery is worn.

The impressive effects of compression on reducing lymphedematous limbs are explained by the following mechanisms ${ }^{160}, 161,162$

- Reduction of capillary filtration

- Shift of fluid into non-compressed parts of the body

- Increased lymphatic reabsorption

- Stimulation of lymphatic transport

- Improvement of the venous pump leading to reduction of venous filtration to the interstitium (reduction lymphatic preload)

- Breakdown of fibrotic tissue

The pressure of compression is different on the legs compared to the arms. It is important to note that the hydrostatic pressure that must be overcome by external compression is much higher in the legs than in the arms. In a standing position, the venous pressure in the distal leg is equal to the weight of the blood column between the heart and the measuring point, which is about $80-100 \mathrm{mmHg}$. The high intravenous pressure in the upright body position always increases the lymphatic load by promoting increased fluid extravasation. High external pressure is necessary in order to counteract this extravasation. The venous pressure in the arm is much lower than that in the leg due to the lower weight of the blood column between heart and the hand. Thus, less external compression will be needed 
to reduce extravasation from the venules into the tissue and to promote reabsorption of tissue fluid. The arm volume reduction from bandaging is probably due not only to a pressure-dependent shift in Starling's equilibrium but also to stimulation of lymphatic drainage.

Besides veno-dynamic issues, lympho-dynamic issues should also be considered. In healthy arms, the distance from the arm to the thoracic duct is short, and the intra-lymphatic pressure varies with the intra-thoracic pressure. Lymphatic drainage is stimulated with relatively low or even negative intra-lymphatic pressure. In BCRL, lymphatic drainage is deficient because of damage to the major lymph collectors and lymph nodes by surgery and/or radiation, leading to lymphatic congestion ${ }^{163}$.

In general two main effects of compression on the lymphatics have to be considered. The first of these is an increase in the tissue pressure, leading stretching of the anchoring filaments attached to the initial lymphatics, which causes the opening of initial lymph capillaries. Another is enhancement of the spontaneous contractions of the lymphcollectors that normally occurs under the influence of rhythmic pressure changes ${ }^{164}$. Inelastic compression material exerts relatively low resting pressure and high massaging pressure peaks during movement and may promote autonomous lymphatic contractions. The pressure required to achieve optimal edema reduction obviously depends on the underlying pathology in different body regions and is, therefore, difficult to assess. In order to practice more evidence-based medicine, the International Compression Club (ICC) proposed guidelines to measure the pressure in lower leg compression therapy ${ }^{165}$ to optimize the therapeutic effect of compression. This guideline was recently introduced to study compression devices and methods ${ }^{114}$.

When maximum edema reduction is achieved, a tailor-made compression garment is applied to maintain the optimal effect. Medical elastic compression stockings (MECS) are effective in the treatment of chronic venous insufficiency and are particularly effective under dynamic conditions. They work, among other ways, by improving venous hemodynamics and reducing edema. This can be ascribed to their physical characteristics, the most important of which are elasticity and stiffness ${ }^{166}$. In lymphedema these characteristics are equally important. To achieve optimal effectiveness, garments should be tailor-made and 
always flat knitted.

In 1999, Williams and Williams ${ }^{167}$ measured the pressure on the arm with various garments in nine patients during the maintenance phase. The pressure measured ranged from 7 to $64 \mathrm{mmHg}$ depending on the type of garment. They concluded that the selection of compression garments as part of lymphedema treatment is a complex endeavor, and "offthe-shelf" hosiery is not suitable. They found no relationship between the manufacturerindicated compression class and the actual pressure in patients.

Currently, no studies have been published that measure the interface pressure under inelastic bandages in BCRL.

In general, hosiery is measured when the maintenance phase is reached. In this phase there is no further volume reduction despite proper lymphedema treatment. The terms hosiery, garments and sleeves are often used interchangeably and include gloves, gauntlets, Bermudas and compression devices for toes. In case of lymphedema, garments should always be tailor made and flat-knitted with a high static stiffness and should be measured routinely during long term follow-up ${ }^{168}$. A full review of garments is outside the scope of this thesis.

\section{Intermittent pneumatic compression (pressotherapy)}

Intermittent pneumatic compression (IPC) uses an air pump to periodically inflate and deflate bladders incorporated into sleeves, which envelop legs or arms. There are a number of ways to apply intermittent pneumatic compression, using single (older types) or multiple chambers or bladders (modern techniques), or by using different types of pumps and compression cycles, e.g. variation of inflation and deflation times. IPC has been used to prevent the development of deep vein thromboses (blood clots) during long periods of rest, e.g. during surgery. It has also been used to treat limb swelling such as lymphedema and venous leg ulcers ${ }^{169}$. According the Cochrane group, it can be concluded that IPC may increase healing compared with no compression in the treatment of (venous) leg ulcers. It is not clear, however, whether IPC increases healing if combined with bandages or whether it can be used without any compression bandages at all. In lymphedema, IPC has been used for decades. Megens et al. ${ }^{170}$ reviewed the literature on physical therapy treatment of BCRL. Most studies were inappropriately designed and often 
lacked proper comparisons. They concluded that pressotherapy should be performed with multi chamber devices in combination with other therapeutic options such as MLD and compression. Monotherapy with IPC was discouraged.

In theory, the basis for IPC is interstitial fluid displacement. With pressure alone, fluid uptake in lymphatics is not stimulated because the pressure leads to the collapse of collectors. This is especially true when there is an obstructive lymphatic impairment. In these cases, IPC will lead to proximal stasis of fluid and fibrosis formation. In obstructive leg lymphedema, swelling of the genitals is often observed when IPC is applied. Therefore, IPC should not be performed as monotherapy (CBO guideline ${ }^{224,225}$ ). In dynamic lymph insufficiency such as that seen in chronic venous insufficiency, IPC is very effective.

\section{Physical exercise}

In lymphedema, both physiological and physical stimulation of lymphatics are essential. Therapeutic options include improving function of the joints and muscle systems in order to stimulate lymphatic drainage and specific exercise and breathing techniques. Too often patients are advised to rest, leading to aggravation of lymphedema and weight gain. Therefore, every program for lymphedema should contain an exercise program to improve and stimulate lymphatic drainage. This program should be designed for the physical capability and needs of each individual patient ${ }^{171}$. The goal of an exercise program is improvement of physical condition and improvement of mobility without too much muscle hypertrophy or strength gain ${ }^{172}$. Box et al. ${ }^{173}$ showed that exercise strategies were able to reduce the development of secondary lymphedema and alter its progression compared to the control group.

In BCRL, Didem et al. ${ }^{174}$ showed that shoulder mobility could be increased and edema could be decreased by the use of complex physiotherapy programs. Although most studies focus on BCRL patients, a positive effect can be expected for other forms of secondary lymphedema and non-cancer related lymphedema as well.

\section{Skin care, awareness and self-management}

Since lymphedema leads to impaired immunological responses, erysipelas is more common on sides with lymphatic impairment, and patients should be advised about 
skin care and skin hygiene. Prevention of small injuries (e.g. from gardening) should be attempted. Using anti bacterial soap and cream is mandatory. For leg lymphedema, extra attention should be paid to skin care of the sole and prevention of small cuts and yeast infection, and walking bare foot should be avoided.

Breast cancer patients in general, but those with an axillary lymph dissection and patients receiving an inguinal / abdominal dissection in particular, have a legitimate concern for developing lymphedema in the arm, leg or midline. Healthcare providers should keep in mind that lymphedema involves more than just a swollen limb and that the associated symptoms such as psychological distress, fatigue, and altered arm / leg sensations should also be assessed and treated when needed. Until true prevention strategies are developed or a cure is found, early identification of swelling and prompt referral for treatment remain the best hope for achieving optimal patient outcomes. In this process, the patients themselves play an important role $\mathrm{e}^{175}$.

Two stages can be distinguished in prevention: primary prevention in those who do not have lymphedema yet but are at risk, and secondary prevention in those who are already experiencing lymphedema or have only found a small swelling. In this second group selfassessment and self-treatment are very important.

Many articles have been published about patient independence, encompassing the concepts of the expert patient and self-management in which the nurse-patient relationship is based on partnership ${ }^{176}$. Bogan et al. ${ }^{177}$ described seven patients with non-cancer related lymphedema who were instructed during an inpatient treatment in self-exercise, self-management and advice about awareness. These results support the conclusions from Brouwer et al. with about 50 courses of self-management training in patients with BCRL and lymphedema of the legs ${ }^{178}$.

Well-designed, quality pretreatment lymphedema education in a manner that is tolerable to patients and family members during the stressful period of initial diagnosis of breast cancer must be offered to breast cancer survivors in order to reduce dissatisfaction with educational information about lymphedema. It may also serve as the foundation from which coping decisions and strategies are generated should lymphedema develop 
later $^{179}$. This awareness education consists of knowledge (educational information) and practical skills such as breathing techniques, skin care and mobility exercises and even self-massage (SLD) in a gentle form to stimulate lymphatic flow. The psychological issues of lymphedema and cancer are discussed in self-management courses, but they are not the main topics, because the courses are about prevention and awareness. When possible, family members or friends are included in the training in order to reach areas that the patient cannot massage alone and to help encourage compliance with this part of the home program ${ }^{180}$.

\section{Complex Decongestive therapy (CDT)}

In daily practice, a combination of various non-operative techniques is used to treat lymphedema and is called CTD. These consist of MLD, compression therapy, exercise, and skincare self-management. There is a wide range of inter-individual performance of MLD techniques, exercise and compression bandaging systems, which makes scientific assessment of CDT difficult. Only a few randomized controlled studies are available concerning the effects of CDT.

Although modern conservative treatment of lymphedema is based on CDT, the exact contribution of each of these separate procedures to the overall effect is unclear.

Ramos et al. ${ }^{181}$ studied 69 women with BCRL and looked at the duration of lymphedema, differences in arm circumference, percent differences in arm volume, volume of edema, reduction of edema volumes, and duration of treatment. They discovered that the initial edema volume difference predicted the success of a non-operative lymphedema treatment regardless of whether the intervention was early or late. These data emphasize the necessity of early detection of lymphedema in patients at risk while the limb is still relative edema free, and of early treatment for lymphedema.

Controlled, comparative studies are currently not available for the effectiveness of each separate modality in the treatment of lymphedema.

Moseley et al. ${ }^{182}$ conducted an extensive review of the literature in 2006 for common nonoperative treatment modalities for lymphedema and concluded that despite the identified benefits, there was still a need for large scale, clinical trials in this area. A combination of MLD with compression therapy improved the results. In most studies reviewed by Moseley 
et al. there was a mix of lymphedema types, mainly BCRL, and specific outcome parameters were often not defined. Specific studies on primary lymphedema are not available. In 2007 Hamner ${ }^{183}$ retrospectively studied 135 patients with BCRL receiving CDT. After 8 weeks, the volume reduction was about $18 \%$. A surprisingly positive effect was found on pain: 76 patients experienced pain before treatment, and 56 were free of pain after treatment (76\% reduction). It was concluded that lymphedema continues to be a problem for patients with breast cancer. A program of lymphedema therapy can reduce the volume of edema and, in particular, reduce pain in this population. Badger et al. ${ }^{184}$ compared the effects of 18 days of short stretch bandaging followed by compression hosiery to those of compression hosiery alone for leg and arm lymphedema. They showed that initial compression therapy with subsequent use of hosiery was twice as effective as hosiery alone.

Some studies have been performed by measuring the undergarment pressure ${ }^{185},{ }^{186} . A$ major limitation of these studies is the discrepancy between the undergarment pressure claimed by the manufacturer and the actual interface pressure due to the large variety of types of garments and inter-individual variation in measuring garments.

\section{Diet, weight and overweight control}

Diet and weight in general are suggested to influence the development, recurrence and prognosis of breast cancer ${ }^{187},{ }^{188}$. Some epidemiologic studies have linked consumption of a diet that is low in fat ${ }^{189}$ and high in vegetables ${ }^{190}$ with improved prognosis following a diagnosis of breast cancer.

In a preliminary report from the WHEL study, Rock et al ${ }^{191}$ studied 1,010 women treated for BC and could not find an association between diet intervention (reduction of fat intake and high vegetable intake) and significant weight loss after one year of follow up. They suggest that modification of diet composition may be more likely to promote weight loss in women who are far from menopausal or chemotherapy-induced hormonal changes, either by age or time since diagnosis and initial treatment.

Focusing on lymphedema, obesity and being overweight are both risk factors for lymphedema in breast cancer patients. In 1991 Werner et al ${ }^{192}$ prospectively studied 282 patients with stage I or II breast cancer who received additional radiation therapy by measuring differences in treated and untreated arms, and they identified being 
overweight as a risk factor in the development of lymphedema.

Shaw et al. ${ }^{193}$ showed in 2007 that weight loss due to dietary advice and reduction of energy intake could significantly reduce BCRL.

Vignes $^{194}$ retrospectively studied 537 patients with BCRL and found that the duration of lymphedema and body mass index were the only two predictors for reduction of lymphedema volume after intensive decongestive physiotherapy. In the maintenance phase, compliance with the use elastic garments was essential to stabilize the edema volume. There were some major limitations in this study, however, concerning the treatment procedure, the number of patients lost to follow-up, and the definition of success. At 6 months, $51 \%$ of patients (217 patients) had an increase in volume of more than $10 \%$ instead of a decrease. After 12 months, $66 \%$ of the patients still received MLD 1-3 times a week. According to these results, the effect of treatment is minor, and patients have a very long dependence on a healthcare worker.

\section{Pharmaceutical options}

Studies have also been performed on pharmaceutical interventions. The group of medication used has shown some effectiveness in varicose veins and venous insufficiency. The substances tested are from the flavonoid group (e.g. Benzopyrone ${ }^{195},{ }^{196}$ ) and aescin (horse-chestnut seed extract) $^{197}$. One study in 1993 showed a slow effect of 5,6 benzo(alpha)-pyrone ${ }^{198}$. Other studies have been performed with diuretics, benzopyrones and other derivates, but no significant effect has been demonstrated for any of these with long-term use $199,200,201,202$. Selenium supplements, which act as free-radical scavengers, have been studied and have shown promising effects in combination with $\mathrm{CDT}^{203}$. In conclusion, from the 1990's until today, there has been no convincing evidence of the effectiveness of any pharmaceutical intervention in lymphedema.

\section{Miscellaneous therapeutic options}

In the literature, various other therapeutic options are mentioned for lymphedema such as low-level laser (LLLT) and Endermologie ${ }^{\circledast}\left(\right.$ LGP $\left.^{\oplus}\right)$ treatment.

The introduction of low-level lasers to the treatment of BCRL did not show significant improvement immediately after any of the treatments. Carrati et al. ${ }^{204}$ concluded that considerably more work needs to be done to better understand the mechanism of action 
and improve the efficacy of LLLT in a range of applications, but the results of that study demonstrated that laser treatment for lymphedema may have some clinical benefit.

LPG $^{\circledR}$ is an apparatus containing two motorized, cylindrical skin rollers, which are applied to the skin. By rolling over the skin, the skin is picked up and massaged inside the treatment head. It was considered in pilot studies to be useful in decreasing induration and functional discomfort and enhancing lymph transport. In 2007, Moseley et al. ${ }^{205}$ studied the effect of $\mathrm{LGP}^{\circledast}$. Two study groups were formed of patients with $\mathrm{BCRL}$ and treated during 16 sessions (4 days of treatment, 3 days of no treatment): 25 minutes of localized treatment with $\mathrm{LPG}^{\circledR}$ and 30 minutes intensive treatment including the thorax. After $\mathrm{LPG}^{\circledR}$ treatment, compression bandaging was added until the next treatment. Compression bandaging was not worn, however, during the 3 days of non-treatment. Both treatment protocols produced similar results. A serious limitation of the study, however, was that there was no control group with bandaging alone.

\section{Surgical treatment of lymphedema}

Surgical treatment of lymphedema has a long history, but typically has not enjoyed any (long-term) clinical success. The surgical approaches can be categorized as reconstructive and reduction surgery. Many reconstructive techniques have been described such as lympho-venous anastomosis (LVA) ${ }^{206}$, lympho-venous-lymphatic (LVL) transplant (especially in the presence of venous hypertension ${ }^{207}$ ), and forms of lymph vessel transplantation ${ }^{208}$. LVA has been the most frequently used type of operation.

So far, most studies on LVA have demonstrated both a lack of significant volume reduction and considerable heterogeneity in the study population.

Because of this uncertainty in the literature, we decided to evaluate the effectiveness of LVA in the treatment of one-sided breast cancer related lymphedema in a limited prospective study using objective, validated measurement methods with very strict inclusion criteria; we also reviewed the literature. The conclusion of the study showed that although the LVA has been performed and studied for more than 3 decades, it has still not had a breakthrough and will, in our opinion, never become a treatment of choice in daily practice (see chapter 7$)^{209}$.

Patients with end stage, pronounced, non-pitting lymphedema do not respond to 
conservative treatment. Previous surgical efforts utilizing either total excision with skin grafts on the muscle fascia ${ }^{210}$ or longitudinal excision of full thickness skin and subcutaneous tissue ${ }^{211}$ did not result in acceptable cosmetic or functional results. One of the reasons that microsurgical reconstruction such as lymphovenous shunts ${ }^{212}$ or lymph vessel transplants ${ }^{213},{ }^{214}$ cannot completely remove the excess arm volume in chronic nonpitting lymphedema is that it does not remove the hypertrophic subcutaneous adipose tissue. Currently, circumferential suction-assisted lipectomy (CSAL) followed by lifelong compression garments is the only proven safe surgical treatment with even more than $100 \%$ reduction of excess volume over a long period of time, with the treated arm being somewhat smaller than the non-affected $\mathrm{arm}^{215}$.

In this surgical procedure, which is only suitable for a selected group of patients with non-pitting lymphedema of the arm (or leg), all supra-fascial adipose tissue and fibrosis are removed by liposuction. Postoperative treatment with life-long compression therapy by garments worn day and night is obligatory. With this technique, a 100\% reduction of irreversible, therapy resistant lymphedema is possible. Currently, this therapy has been developed and studied intensively in BCRL by Brorson $216,217,218,219$ and confirmed by another research group (See chapter 9.)

For extensive midline elephantiasis, surgical excision procedures can be beneficial in combination with conservative treatment ${ }^{220,221}$. Afterwards, adequate procedures such as bandaging, compression, skin care and other supportive supplies are needed to maintain the results.

In cases of extensive papillomatosis, verrucosis and tissue surplus, specific shaving techniques can be used in combination with compression therapy and stockings covering the toes 222 .

Trauma or injury of a lymphedema extremity can aggravate swelling or provoke erysipelas. A new field of interest is lymphedema patients who need to undergo an operation for another abnormality or disease such as arthrosis, ingrown toe, broken arm, hydrocele, or skin cancer. To prevent deterioration of the lymphedema after operation, special attention from a lymphological point of view (preventive lymphedema therapy such as compression bandaging) and an antibiotic shield are effective (Damstra RJ, Voesten HGJ, unpublished data). 
To achieve an optimal result, all surgical treatments for lymphedema should only be performed and centralized to a dedicated and well-trained multidisciplinary team in a lymphedema clinic.

\section{Guidelines}

The international Society on lymphology has a long history of establishing internationally accepted guidelines, which were last revised in $1998^{223}$. In 2003 guidelines were formed from an amalgamation of many discussions and meetings ${ }^{224}$. Often this process is the subject of political, semantic and organizational discussions with little scientific basis and has not yet achieved international agreement.

Because of the variety of individual strategies in the diagnosis and treatment of lymphedema, many of which lack scientific backbone, a working group on lymphedema was established in the Netherlands by the Dutch Institute for Healthcare Improvement (CBO) in cooperation with 17 representatives from medical, paramedical and patient organizations. After an extensive literature review and integrating expert opinions, consensus-based guidelines were established in $2003^{225}$. These guidelines form the basis for the lymphological care in the Netherlands. (See chapter 10). The national lymphedema framework project ${ }^{226}$ in 2006 was an international cooperation of experts who developed practical guidelines for lymphedema and came to similar recommendations as the CBO guidelines of 2003.

\section{AIM OF THE THESIS}

The aims of the studies described in this thesis are as follows:

1. To develop techniques for objectively measuring lymphedema volume in the arms, in order to create a reproducible and validated method for diagnosing lymphedema and monitoring the results therapeutic intervention. (Chapter 2)

2. To show that there is a significant relationship between interface pressures in nonelastic bandaging lymphedema volume reduction in legs and show that pressure reduction is not only caused by fatigue of the material but also by other parameters; 
to study differences between leg and arm lymphedema; and to determine which compression pressure is needed. (Chapter 3, 7)

3. For primary lymphedema, more genetic disorders have been discovered in the last few years, suggesting lymphedema as a developmental-genetic disorder. We wonder if there are more genetic defects to be identified, especially regarding the FOXC2 gene. On the other hand, there is evidence that erysipelas related lymphedema is not just secondary lymphedema. In order to understand the pathophysiology of this disease we must ask: is erysipelas caused by pre-existing lymphatic and immunological impairment, or is it responsible for lymphatic deterioration? (Chapter 3,4)

4. To focus on the necessity of close dermatological research in patients with minute skin features and secondary lymphedema previously treated for cancer and to discuss the term "malignant lymphedema", which is actually inappropriate (Chapter 5)

5. In the surgical approach to lymphedema, reconstructive and reductive treatments are described. We want to find out whether lympho-venous anastomosis in breast cancer related lymphedema can work or not (chapter 8) and to test an innovative surgical reductive treatment for chronic, therapy-resistant lymphedema (chapter 9)

6. To establish evidence and expert guidelines for the diagnosis and treatment of lymphedema in general and in children as well (Chapters 10,11) 


\section{REFERENCES}

1 Földi M, Földi E. Földi's textbook of lymphology. $2^{\text {nd }}$ edition. Mosby/Elsevier Munich 2006 (ISBN 13: 978-0-7234-3446-7) pp 1-149

2 Gerli R, Ibba L, Fruschelli C. Utratructural cytochemistry of anchoring filaments of human lymphartic capillaries and their relation to elastic fibers. Lymphology. 1991;24:105-12

3 Takada M. the ultrastructure of lymphatic valves in rabbits and mice. Am J anat. 1971;132:20717

4 Casley-Smith JR. Are the initial lymphatics normally pulled open by anchoring filaments? J Cell Biol. 1980;13:120-9

5 Kuper, CF, De Heer, E, van Loveren, H, Vos JG. Immune System. In Handbook of Toxicologic Pathology (W. M. Hascheck-Hock, C. G. Rousseaux, and M. A. Wallig, eds.), 2002; Vol. 2, pp. 585644. Academic Press, New York

6 Cesta MF. Normal structure, function and histology of mucosal-associated lymphoid tissue. Toxicol Pathol. 2006;34(5):599-608

7 Clodius I. Lymphedema. In Plastic Surgery McCarthy (Ed), vol. 6 Philadelhia. WB Saunders Co, 1990

8 Olszewski WL, Engeset A. Intrinsic contractility of prenodal lymphvessels and lymph flow in human leg. Am J Physiol. 1980;239:777-83

9 Schmid-Schonbein GW. Microlymphatics and lymphflow. Physiological Reviews. 1990;70:9871028

10 Van Helden DF. Pacemaker potentials in lymphatic smooth muscle of the guinea-pig mesentery. J Physiol. 1993;471:465-79

11 McHale NG. Innervation of the lymphatic circulation. In Johnston MG ed. Experimetal biology of the lymphatic circulation. Elsevier Science. 1985:121-40

12 Levick JR. Circulation of fluid between plasma, interstitium and lymph. In Levick JR ed. An introduction to cardiovascular physiology. London: Arnold 2003

13 Aukland K, Reed RK. Interstitial-lymphatic mechanisms in the control of extracellular volume. Phys Reviews. 1993;73:1-78

14 Humbert P, Sainthillier J-M, Mac-Ary S, Petitjen A, Creidi P, Aubin F. Capillaroscopy and videocapillaroscopy assessment of skin microcirculation: dermatologic and cosmetic approaches. J Cosmetic Dermatol. 2005;4:153-62

15 Hern S, Mortimer PS. Visualization of dermal blood vessels capillaroscopy. Clin Exp Dermatol. 1999;24:473-8

16 Casley-Smith Judith R, Casley-Smith JR. Modern treatment for lymphedema, $5^{\text {th }}$ edition. Lymphedema Association of Australia inc. 1997

17 Zweifach SS, Kramer GC, Renkin EM. Plasma to lymph transport of trcer albumin in the popleteal node of unanaesthetized sheep. Microvasc Research. 1984;27:271 A

18 Adair TH, Guyton AC. Modification of lymph by lymphnodes III. Effect of increased lymph hydrostatic pressure. Am J Physiol. 1985;249:777-82

19 Lynch PM, Delano FA, Schmid-Schönbein GW. The primary valves in the initial lymphatics during inflammation. Lymph Res Biol. 2007;5(1):3-10 
20 Zawieja D. Lymphatic biology and the microcirculation: past, present and future. Microcirculation. 2005;12 (1):141-50

21 Allan RS, Waithman J, Bedoui S, Jones CM, Villadangos JA, Zhan Y, Lew AM, Shortman K, Heath WR, Carbone FR. Migratory dendritic cells transfer antigen to a lymph node-resident dendritic cell population for efficient CTL priming. Immunity. 2006; 25:153-62

22 Angeli V, Randolph G. Inflammation, lymphatic function, and dendritic cell migration. Lymphat Res Biol. 2006; 4 (4):217-28

23 Mallon E, Powell S, Mortimer PS, Ryan TJ. Evidence for altered cell-mediated immunity in postmastectomy lymphoedema. Br J Dermatol. 1997;137:928-33

$24 \mathrm{Cox} \mathrm{NH}$. Oedema as a risk factor for multiple episodes of cellulitis/erysipelas of the lower leg: a series with community follow-up. Br J Dermatol. 2006;155:947-50

25 Ohshima N, sato M. mass transfer kinitics from blood to lymph in the mesenteric microcirculation studied by flurescent intravital microscope method. Microvasc Research. 1987;34:250-5

26 Powers MR, Wallace JR, Bell DR. Initial equilibration of albumin in rabbit hindpaw skin and lymph. Am J Physiol. 1988;254:89-101

27 Browse N, Burnand K, Mortimer PS. Diseases of the lymphatics. Arnold, London UK 2003 (ISBN: 034076203 9) pp 52-3

28 Rhodin JAG, Sue SL. Conbined intrvital microscopy and electron microscopy of the blind beginnings of mesenteric lymphatic capillaries of the rat mesentery. Acta Physiologica Scand Supl. 1979;463:51-8

29 Olszewski WL. Pathophysiological aspects of lymphedema of human limbs: I. Lymph protein composition. Lymphat Res Biol. 2003;1(3):235-43

30 Tso P, Balint JA. Formation and transport of chylomicrons by enterocytes to the lymphatics. Am J Physiol. 1986;250:715-26

31 Yamashita JK. Differentiation of arterial, venous, and lymphatic endothelial cells from vascular progenitors. Trends Cardiovasc Med. 2007;17(2):59-63

32 Korpelainen El, Alitalo K. Signaling angiogenesis and lymphangiogenesis. Curr Opin Cell Biol. $1998 ; 10,159-64$

33 Ferrara N, Davis-Smyth T. The biology of vascular endothelial growth factor. Endocr Rev.1997;18:4-25

34 Ferrara N, Alitalo K. Clinical applications of angiogenic growth factors and their inhibitors. Nat Med. 1999;5(12):1359-64

35 Gale NW, Prevo R, Espinosa J, Ferguson DJ, Dominguez MG, et al. Normal lymphatic development and function in mice deficient for the lymphatic hyaluronan receptor LYVE-1. Mol Cell Biol. 2007;27:595-604

36 Folkman J, Kaipainen A. Genes tell lymphatics to sprout or not. Nat Immunol. 2004;5(1):11-22

37 Adams RH. Wilkinson GA, Weiss C, Diella F, Gale NW et al. Roles for ephrinB ligands and EphB receptors in cardiovascular development: demarcation of arterial/venous domains, vascular morphogenesis, and sprouting angiogenesis. Genes Dev. 1999;13(3),295-306

38 Wigle, JT, Harvey N, Detmar M, Lagutina I, Grosveld G et al. An essential role for Prox 1 in the induction of the lymphatic endothelial cell phenotype. EMBO J. 2002;21(7),1505-13

39 Cueni LN, Detmar M. The Lymphatic System in Health and Disease. Lymphat Res Biol. 2008;6 (3-4)-109-22 
40 Ferrara N, Carver-Moore K, Chen H, Dowd M, Lu L et al. Heterozygous embryonic lethality induced by targeted inactivation of the VEGF gene. Nature. 1996;380(4),439-42

41 Petrova TV, Mäkinen T, Mäkelä TP, Saarela J, Virtanen I, et al. Lymphatic endothelial reprogramming of vascular endothelial cells by the Prox-1 homeobox transcription factor. Embo J. 2002;21:4593-99

42 Schacht V, Ramirez Ml, Hong YK, Hirakawa S, Feng D, et al. T1alpha/podoplanin deficiency disrupts normal lymphatic vasculature formation and causes lymphedema. Embo J. 2003;22:3546-56

43 Francois M, Caprini A, Hosking B, Orsenigo F, Wilhelm D, et al. Sox18 induces development of the lymphatic vasculature in mice. Nature. 2008;456(7222):643-7

44 Yancopoulos GD, davis S, Gale NW, Rudge JS, wiegard SJ, Holash J. Vascular-specific growth factors and blood vessel formation. Nature. 2000;407(6801): 242-8

45 Cueni LN, Detmar M. New insights into the molecular control of the lymphatic vascular system and its role in disease. J Invest Dermatol. 2006;126 (10):2167-77

46 Petrova T, Karpanen T, Norrmen C, Mellor R, Tamakoshi T et al. Defective valves and abnormal mural cell recruitment underlie lymphatic vascular failure in lymphedema distichiasis. Nat Med. 2004;10 (9):974-81

47 Salven P, Mustjoki S, Alitalo R, Alitalo K, Rafii S. VEGFR-3 and CD133 identify a population of CD34 lymphatic/vascular endothelial precursor cells. Blood. 2003;101:168-72

48 He Y, Rajantie I, IImonen M, Makinen T, Karkkainen MJ, et al. Preexisting lymphatic endothelium but not endothelial progenitor cells are essential for tumor lymphangiogenesis and lymphatic metastasis. Cancer Res. 2004;64:3737-40

49 Maruyama K, li M, Cursiefen C, Jackson DG, Keino H, et al. Inflammation-induced lymphangiogenesis in the cornea arises from CD11b-positive macrophages. J Clin Invest. 2005;115:2363-72

50 Banziger-Tobler NE, Halin C, Kajiya K, Detmar M. Growth hormone promotes lymphangiogenesis. Am J Pathol. 2008;773:586-97.

51 Fritz-Six KL, Dunworth WP, Li M, Caron KM. Adrenomedullin signaling is necessary for murine lymphatic vascular development. J Clin Invest. 2008;118:40-50

52 Kunstfeld R, Hirakawa S, Hong YK, Schacht V, Lange-Asschenfeldt B, et al. Induction of cutaneous delayed-type hypersensitivity reactions in VEGF-A transgenic mice results in chronic skin inflammation associated with persistent lymphatic hyperplasia. Blood. 2004;104:1048-57

53 Kaiserling E, Krober S, Geleff S. Lymphatic vessels in the colonic mucosa in ulcerative colitis. Lymphology. 2003;36:52-61

54 Zhang Q, LuY, Proulx ST, Guo R, Yao Z, SchwarzEM, Boyce BF, Xing L.Increased lymphangiogenesis in joints of mice with inflammatory arthritis. Arthritis Res Ther. 2007;9:R118.

55 Baluk P, Tammela T, Ator E, Lyubynska N, Achen MG, et al. Pathogenesis of persistent lymphatic vessel hyperplasia in chronic airway inflammation. J Clin Invest. 2005;115: 247-57

56 Hirakawa S, Brown LF, Kodama S, Paavonen K, Alitalo K, Detmar M. VEGF-C-induced lymphangiogenesis in sentinel lymph nodes promotes tumor metastasis to distant sites. Blood. 2007;109:1010-17.

57 Stacker SA, Caesar C, Baldwin ME, Thornton GE, Williams RA, et al. VEGF-D promotes the metastatic spread of tumor cells via the lymphatics. Nat Med. 2001;7:186-91 
58 Hirakawa S, Kodama S, Kunstfeld R, Kajiya K, Brown LF, Detmar M. VEGF-A induces tumor and sentinel lymph node lymphangiogenesis and promotes lymphatic metastasis. J Exp Med. 2005;201:1089-99

59 Karpanen T, Wirzenius M, Makinen T, Veikkola T, Haisma HJ, Achen MG, et al. Lymphangiogenic growth factor responsiveness is modulated by postnatal lymphatic vessel maturation. Am J Pathol. 2006;169:708-18

60 Roberts N, Kloos B, Cassella M, Podgrabinska S, Persaud K, et al. Inhibition of VEGFR-3 activation with the antagonistic antibody more potently suppresses lymph node and distant metastases than inactivation of VEGFR-2. Cancer Res. 2006;66:2650-57

61 Okazawa T, Yoshida T, Shirai Y, Shiraishi R, Harada T et al. Expression of vascular growth factor C is a prognostic indicator of esophageal cancer. Hepatogastroentrology. 2008;55(86-87):15038

62 Morita H, ishikawa Y, Akishima-Fukasawa Y, Ito K, Akasaka Y et al. Histopathological predictor for regional lymph node metastasis in gastric cancer. Virchows Arch. 2009;454(2):143-51

63 On Line Mendelian Inheritance in Man (OMIM). http://ncbi.nlm.nih.gov/sites/ entrez?db=omim

64 Ferrell RE, Kimak MA, Lawrence EC, Finegold DN. Candidate gene analysis in primary lymphedema. Lymphat Res Biol. 2008;6(2):69-76

65 Kubota N, Terauchi Y, Miki H, Tamemato H, Yamaguchi T et al. PPAR gamma mediates high-fat diet-induced adipocyte hypertrophy and insulin resistance. Moll Cell. 1999;4:597-609

66 Harvey NL, Srinivasan RS, Dillard ME, Johnson NC, Witte MH, Boyd K, Sleeman M, Oliver G. Lymphatic vascular defects promoted by Prox1 haploinsufficiency cause adult onset obesity. Nat Genet. 2005;37:1072-81

67 Irrthum A, Karkkainen MJ, Devriendt K, Alitalo K, Vikkula M. Congenital hereditary lymphedema caused by a mutation that inactivates VEGFR3 tyrosine kinase. Am J Hum Genet. 2000; 67:295301

68 Brice G, Child AH, Evans A, Bell R, Mansour S, Burnand K, et al. Milroy disease and the VEGFR-3 mutation phenotype. J Med Genet. 2005;42 (2):98-102

69 Connell FC, Ostergaard P, Carver C, Brice G, Williams N, Mansour S, Mortimer PS, Jeffery S; Lymphoedema Consortium. Analysis of the coding regions of VEGFR3 and VEGFC in Milroy disease and other primary lymphoedemas. Hum Genet. 2009 Jan;124(6):625-31

70 Erickson RP, Dagenais SL, Caulder MS, Downs CA, Herman G, et al. Clinical heterogeneity in lymphoedema-distichiasis with FOXC2 truncating mutations. J Med Genet. 2001;38 (11):761-6

71 Petrova TV, Karpanen T, Norrmén C, Mellor R, Tamakoshi T et al. Defective valves and abnormal mural cell recruitment underlie lymphatic vascular failure in lymphedema distichiasis. Nat Med. 2004;10(9):974-81

72 Mellor RH, Brice G, Stanton AWB, French J, Smith A et al. Mutations in FOXC2 are strongly associated with primary valve failure in veins of the lower limb. Circulation. 2007;115(14):191220

$73 \mathrm{Ng} \mathrm{MY}$, Andrew T, Spector TD, Jeffery S: Lymphoedema Consortium. Linkage to the FOXC2 region of chromosome 16 for varicose veins in otherwise healthy, unselected sibling pairs. J Med Genet. 2005;42(3):235-9

74 Irrthum A, Devriendt K, Chitayat D, Matthijs G, Glade C, Steijlen PM et al. Mutations in the 
Transcription Factor Gene SOX18 Underlie Recessive and Dominant Forms of HypotrichosisLymphedema-Telangiectasia. Am J Hum Genet. 2003;72 (6):1470-8

75 Browse N, Burnand K, Mortimer PS. Diseases of the lymphatics. Arnold, London UK 2003 (ISBN: 034076203 9) Chap. 5:102-8

76 Van Der Burgt. Review: Noonan syndrome. Orphanet J Rare Dis. 2007;2:4-6

77 Dupuis-Girod S, Corradini N, Hadj-Rabia S, Fournet JC, Faivre L, Le Deist F et al. Osteopetrosis, lymphedema, anhidrotic ectodermal dysplasia, and immunodeficiency in a boy and incontinentia pigmenti in his mother. Pediatrics. 2002;109(6):e97

78 van Steensel MAM, van Geel M, Schrander-Stumpel C, Steijlen PM, Veraart JCJM. Lymphedema, Cardiac Septal Defects, and Characteristic Facies: Possible New Case of Irons-Bianchi Syndrome. Am J med Genet A. 2007;143A(20):2448-51

79 Stanton AWB, Modi S, Bennett Britton T, Purushotham AD, Peters AD, Levick JR, Mortimer PS. Lymphatic drainage in the muscle and subcutis of the arm after breast cancer treatment. Breast Cancer Res Treat 2008: Epub ahead: DOI 10.1007/s10549-008-0259-z

80 Saab S, Nguyen S, Collins J, Kunder G, Busuttil RW. Lymphedema tarda after liver transplantation: a case report and review of the literature. Experimental and clinical transplantation: official journal of the Middle East Society for Organ Transplantation. 2006;4(2):567-70

81 Fife CE, Carter MJ. Lymphedema in the morbidly obese patient: unique challenges in a unique population. Ostomy Wound Manage. 2008;54(1):44-56

82 de Maeseneer MG, Vandenbroeck CP, Lauwers PR, Hendriks JM, de Hert SG, van Schil PE. Early and late complications of silicone patch saphenoplasty at the saphenofemoral junction. J Vasc Surg. 2006;44(6):1285-90

83 Faye O, Petit F, Poli F, Petit T, Wechsler J et al. Lymphedema as a complication of hydradenitis suppurativa in three patients. Ann dermaol venereol. 2007;134(6-7):567-9

84 Al-Otaibi T, Ahamed N, Nampoory MR, Al-Kandari N, Hallm MA et al. Lymphedema: an unusual complication of sirolimus therapy. Transplant Proc. 2007;39(4):1207-10

85 Vannelli A, Battaglia L, Poiasina E, Leo E. Pelvic lymphedema:Truth or fiction? Med Hypotheses. 2009;72(3):267-70

86 World Health Organisation Global Programme to Eliminate Lymphatic Filariasis. Weekly Epidemiological Record. 2006;22:221-32

87 Padmasiri EA, Montresor A, Biswas G, de Silva NR. Controlling lymphatic filariasis and soiltransmitted helminthiasis together in South Asia: opportunities and challenges. Trans R Soc Trop Med Hyg. 2006;100(9):807-10

88 Perera M, Whitehead M, Molyneux D, Weerasooriya M, Gunatilleke G. Neglected patients with neglected disease? A qualitative study of lymphatic filariasis. PloS Negl Trop Dis. 2007;21;1(2):e128

89 Odermatt $\mathrm{P}$, Leang R, Bin B, Bunkea T, Socheat D. Prevention of lymphatic filariasis with insecticide-treated bednets in Cambodia. Ann Trop Med Parasitol. 2008;102(2):135-42

90 Davey G, Tekola F, Newport MJ. Podoconiosis: non-infectious geochemical elephantiasis. Trans R Soc Trop Med Hyg. 2007;101(12):1175-80

91 Wanji S, Tendongfor N, Esum M, Che JN, Mand S, Tanga MbiC et al. elephantiasis of non-filarial origin (podoconiosis) in the highlands of north-western Cameroon. Ann Trop med Parasitol. 2008;102(6):529-40 
92 Barker D.J.P. \& Rose G. (1990) Epidemiology in Medical Pract 4th ed. Churchill Livingstone, Edinburgh.

93 Földi M, Földi E, Kubik S (eds). Textbook of Lymphology. München, Urban and Fischer, 2003.

94 Smeltzer DM, Gunnar B, Schirger A. Primary lymphedema in children and adolescents: a followup study and review. Pediatrics. 1985:76(2):206-18

95 Greenlee R, Hoyme H, Witte M, Crowe P, Witte C. Developmental disorders of the lymphatic system. Lymphology. 1993;26(4):156-8

96 Dale RF. The inheritance of primary lymphoedema. J Med Genet. 1985;22(4)274-8

97 Scharz U. Die Hauftigkeit des primairen Lymphödems. Eine epidemiologische Studie an über 100 probanden. Med Lymphol. 1990;1:29-34

98 Pannier F, Hoffmann B, Stang A, Jöckel K-H, Rabe E. Prevalence of Stemmer's sign in the general population. Results from the Bonn Vein Study. Phlebology. 2007;36(6):289-92

99 Kwaliteitsinstituut voor de Gezondheidszorg CBO. Richtlijn prostaat carcinoom: diagnostiek en behandeling. Alphen aan den Rijn: Van Zuiden Communications; 2007.

100 Moffatt, CJ, Franks PJ, Doherty DC, Williams A F, Badger C, Jeffs E. et al. Lymphoedema: An underestimated health problem. Quarterly J Med. 2003;96:731-8

101 Kwan W, Jackson J, Weir LM, Dingee C, McGregor G, Olivotto IA. Chronic Arm Morbidity After Curative Breast Cancer Treatment: Prevalence and Impact on Quality of Life. J Clin Oncol. 2002;20(20):4242-8

102 Paskett ED, Naughton MJ, McCoy P, Douglas Case L, Abbott JM. The epidemiology of arm and hand swelling in pre-menopausal breast cancer survivors. Cancer Epidemiol Biomarkers Prev. 2007; 16(4):775-82

103 Meeske KA, Sullivan-Halley J, Smith AW, McTiernan A, Baumgartner KB et al. Risk factors for arm lymphedema following breast cancer diagnosis in Black women and White women. Breast Cancer Res Treat. 2009;113(2):383-91

104 Sener SF, Winchester DJ, Martz CH, Feldman JL, Cavanaugh JA et al. Lymphedema after sentinel lymphadenectomy for breast carcinoma. Cancer. 2001;92(4):748-52

105 Wilke LG, Mccall LM, Posther E, Whiworth PW et al. Surgical complications associated with sentinel lymph node biopsy: results from a prospective international cooperative group trial. Ann Surg Oncol. 2006;13(4): 491-500

106 Lee TS, Kilbreath SL, Refshauge KM, Herbert RD, Beith JM. Prognosis of the upper limb following surgery and radiation for breast cancer. Breast Cancer Res Treat. 2008;110(1):19-37

107 Beesley V, Janda M, Eakin E, Obermair A, Battistutta D. Lymphedema after gynecological cancer treatment : prevalence, correlates, and supportive care needs. Cancer. 2007;109(12): 2607-14

108 Gaarenstroom KN, Kenter GG, Trimbos JB, Agous I, Amant F et al. Postoperative complications after vulvectomy and inguinofemoral lymphadenectomy using separate groin incisions. Int J Gynecol Cancer. 2003;13(4):522-7

109 Catalona W. Modified inguinal lymphadenectomy for carcinoma of the penis with preservation of saphenous veins: technique and preliminary results. J Urol. 1988;140:306-10

110 Rempelakos A, Bastas $\mathrm{E}$, Lymperakis $\mathrm{CH}$, Thanos A. Carcinoma of the penis: experience from 360 cases. J BUON. 2004;9(1):51-5

111 Lieskovsky G, Skinner DG, weisenburger T. Pelic lymphadenectomy in the management of carcinoma of the prostate. J Urol. 1980;124(5):635-8 
112 Stemmer R. Ein klinisches Zeichen zur Früh- und Differentialdiagnose des Lymphödems. VASA.1976;5:261-2

113 Stemmer R. Stemmer's sign: possibilities and limits of clinical diagnosis of lymphedema. Wien Med Wochenschr. 1999;149:(2-4):85-6

114 Földi E. Über das Stemmer'sche Zeichen. Vasomed. 1997;9:187-9

115 Stemmer R. Das Stemmer'sche Zeichen - Möglichkeiten und Grenzen der klinischen Diagnose des Lymphödems. Wien Med Wochenschr. 1999;149: 85-6

116 Kettle JH, Ruindle FF, Oddie TH. Measurement of upper limb volumes: a clinical method. Aust N Z J Surg. 1958;27:263-70

117 Mortimer PS, Bates DO, Brassington HD, Stanton AWB et al. The prevalence of arm oedema following treatment for breast cancer. Q J Med. 1996;89:377-80

118 Sitzia J.Volume measurement in lymphedema treatment examination of formulae. Eur J Cancer Care. 1995;4:11-6

119 Stanton AW, Northfield JW, Holroyd B, Mortimer PS, Levick JR. Validation of an optoelectric limb volumeter (Perometer). Lymphology. 1997;30(2):77-97

120 Cornish BH, Bunce IH, Ward LC, Jones LC, Thomas BJ. Bioelectrical impedance for monitoring the efficacy of lymphedema treatment programmes. Breast Cancer Res Treat. 1996; 38:169-76

121 Ryttov N, Holm V, Qvist N, Blichert-Toft M. Influence of adjuvant irradiation on the development of late arm mastectomy for carcinoma of the breast. Acta Oncologica. 1988;27:667-70

122 Farncombe M, Daniels G, Cross L. Lymphedema: the seemingly forgotten complication. J Pain Sympt Manage. 1994;9:269-76

123 Lin PP, Allison DC, Wainstock J, Miller KD, Dooley WC et al. Impact of axillary lymph node dissection on the therapy of breastcancer patients. J Clin Oncol. 1993;11:1136-44

124 Herpertz U. Messung und Dokumentation von Odemen. Lymphologie. 1994;18:24-30

125 Meijer RS, Rietman JS, Geertzen JH, Bosmans JC, Dijkstra PU.Validity and intra- and interobserver reliability of an indirect volume measurements in patients with upper extremity lymphedema. Lymphology. 2004;37(3):127-33

126 Damstra RJ, Glazenburg E, Hol W. The validation of the inverse water volumetry: New gold standard for arm volume measurement. Breast Cancer Res Treat. 2006;99(3):267-73

127 Armer JM, Jane M, Stewart BR. A comparison of four diagnostic criteria for lymphedema in a post-breast cancer population. Lymphat Res Biol. 2005;3(4):208-17

128 O'Brien BM, Das SK, Franklin JD, Morrison WA. Effect of lymphangiography on lymphedema. Plast Reconstr surg. 1981;68(6):922-6

129 Rosenberg SA. Lymphography: A great advance abondoned. J Clin Oncol. 2008;10;26(35):56623

130 Suami H, Pan WR, Mann GB, Taylor GI. The lymphatic anatomy of the breast and its implications for sentinel node biopsy: a human cadaver study. Ann Surg Oncol. 2008;15(3):863-71

131 Harika L, Weissleder R, Poss K, Zimmer C, Papisov MI, Brady TJ. MR lymphography with a lymphotropic T1-type MR contrast agent: Gd-DTPA-PGM. Magn Reson Med. 1995;33:88-92

132 Clement O, Luciani A. Imaging the lymphatic system: possibilities and clinical application. Eur Radiol. 2004;14:1498-1507

133 Unno N, Nishiyama M, Suzuki M, Yamamoto N, Inuzuka K et al. Quantitative lymph imaging for 
assessment of lymph function using indocyanine green fluorescence lymphography. Eur J Vasc Endovasc surg. 2008;36:230-6

134 Bollinger A, Amann-Vesti BR. Fluorescence microlymphography: diagnostic potential in lymphedema and the basis for the measurement of lymphatic pressure and flow velocity. Lymphology. 2007;40(2):52-62

135 Olsen TW, Lim Jl, Capone AJr, Myles RA, Gilman JP. Anaphylactic shock following indocyanine green angiography. Arch Ophthalmol. 1996;114(1):97

136 Hope-Ross M, Yannuzzi LA, Gragoudas ES, guyer DR, Slakter JS, Sorenson JA at al. Adverse reactions due to indocyanine green. Ophthalmology. 1994;101(3):529-33

137 Yuan Z, Chen L, Zhu J, Lu H, Zhu R. The role of radionuclide lymphoscintigraphy in extremity lymphoedema. Ann Nucl med. 2006; 20(5):341-4

138 Scarsbrook AF, Ganeshan A, Bradley KM. Pearls and pitfalls of radionuclide imaging of the lymphatic system: part 2: evaluation of extremity lymphoedema. Br J Radiol. 2007;80(951):21926

139 Weissleder $\mathrm{H}$, Weissleder R. Lymphoedema: evaluation of qualitative and quantitative lymphoscintigraphy in 238 patients. Radiology. 1988;167:729-35

140 Dutch Society of Nuclear Medicine. Recommendations in Nuclear Medicine 2007:88-97. ISBN 978-90-78876-01-04

141 Mostbeck A, Partsch H. Isotope lymphography: possibilities and limits in evaluation of lymph transport. Wien Med Wochenschr. 1999; 149:87-91

142 Kleinhans E, Baumeister, RGH, Hahn, D, Siuda, S, Bull U, Moser E. Evaluation of transport kinetics in lymphoscintigraphy: follow-up study in patients with transplanted lymphatic vessels. Eur J Nucl Med. 1985;10:349-52

143 Partsch H. Practical aspects of indirect lymphography and lymphoscintigraphy. Lymphat Res Biol. 2003;1(1):71-3; discussion 73-4

144 Barrett T, Choyke PL, Kobayashi H. Imaging of the lymphatic system: New horizons. Contrast Media Mol Imaging. 2006;1(6):230-45

145 Lymphedema Framework. Best practice for the management of lymphedema. International consensus. London: MEP Ltd 2006. ISBN 0-9547669-4-6

146 Wittlinger H, Wittlinger G. Introduction to Dr Vodder's Manual Lymph Drainage, Vol. 1: Basic Course, 4th edn. Haug Publishers, Heidelberg 1992

147 Földi MR, Stroszenreuther RH. Grundlagen der Manuellen Lymfdrainage, second edition Urban and Fisher Verlag, Munchen, Germany, 1994

148 Földi M, Földi E. Földi's textbook of lympology. 2nd ed Munich, Germany: Urban \& Fisher, 2006:526-46.

149 Mondry TE, Johnstone PAS. Manual lymphatic drainage for lymphedema limited to the breast. J Surg Oncol. 2002;81(2):101-4

150 Olszewski WL. Contractility patterns of human leg lymphatics in various stages of obstructive lymphedema. Ann N Y Acad Sci. 2008;1131:110-8

151 Pecking A, Lasry S, Boudinet A. Post surgical physiotherapeutic treatment: interest in secondary upper limb lymphedemas prevention. Lymphology. 1988;11:562-4

152 Williams AF, Vadgama A, franks PJ, Mortimer PS. A randomized controlled crossover study of manual lymphatic drainage therapy in women with breast cancer-related lymphoedema. 
European J Cancer Care. 2002;11 (4):254-61

153 Kuhnke E. Volumbestimmung aus unfangmessungen. Folia Angiology. 1976;24: 228-32

154 Andersen L, Hojris I, Erlandsen M, Andersen J. Treatment of breast-cancer-related lymphedema with or without manual lymphatic drainage: a randomized study. Acta Oncologica. 2000;39 (3):399-405

155 Johansson K, Albertsson M, Ingvar C, Ekdahl C. Effects of compression bandaging with or without manual lymph drainage treatment in patients with postoperative arm lymphedema. Lymphology. 1999;32(3):103-10 Comment in: Lymphology. 2000;33:69-70

156 Korpon MI, Vacuriu G, Schneider B. Effects of compression therapy in patients after breast cancer surgery. Annual congresses of the American college of Phlebology. San Diego, Carlifornia 2003: online www.phlebology.org (annual Meeting Abstracts)

157 Kligman L, Wong RKC, Johnston M, Laetsch NS. The treatment of lymphedema related to breast cancer: a systematic review and evidence summary. J Support Care Cancer. 2004;12(6): 42131

158 Yamamoto R, Yamanoto T. Effectiveness of the treatment-phase of two-phase complex decongestive physiotherapy for the treatment of extremity lymphedema. Int J Clin Oncol. 2007;12 (6):463-8

159 Rabe E, Partsch H, Jünger M, Abel M, Achhammer I, Becker F, et al. Guidelines for Clinical Studies with Compression Devices in Patients with Venous Disorders of the Lower Limb. Eur J Vasc Endovasc Surg. 2008;35(4):494-500

160 Badger C, Preston N, Seers K, Mortimer PS. Physical therapies for reducing and controlling lymphoedema of the limbs. Cochrane Database Syst Rev. 2004; 4: CD003141

161 McNeely ML, Magee DJ, Lees AW. The addition of manual lymphdrainage to compression therapy for breast cancer related lymphoedema: a randomized controlled trial. Breast Cancer Res Treat. 2004; 86(2): 95-106

162 EWMA focus document: Lymphoedema: bandaging in practice. Lymphoedema Framework (UK) London: MEP Ltd, 2005

163 Modi S, Stanton AWB, Svensson WE, Peters A, Mortimer PS, Levick JR. Human lymphatic pumping measured in healthy and lymphoedematous arms by lymphatic congestion lymphoscintigraphy. J Physiol. 2007;583 (Pt 1):271-85

164 Olszewski WL. Contractility patterns of human leg lymphatics in various stages of obstructive lymphedema. Ann N Y Acad Sci. 2008;1131:110-8

165 Partsch H, Clark M, Bassez S, Benigni J-P, Becker F, Blazek V, Caprini J, Cornu-Thenard A et al. Measurement of lower leg compression in vivo: recommendations for the performance of measurements of interface pressure and stiffness: consensus statement. Derm Surg. 2006;32(2): 224-32

166 Van Der Wegen-Franken K, Tank B, Neumann M. Correlation Between the Static and Dynamic Stiffness Indices of Medical Elastic Compression Stockings. Dermatol Surg. 2008;34(11):147785

167 Williams AF, Williams AE. "Putting the pressure on": a study of compression sleeves used in breast cancer related lymphoedema. J Tissue Viability.1999;9(3):89-94

168 Lymphoedema Framework. Template for Practice: compression hosiery in lymphoedema. London: MEP Ltd, 2006. 
169 Nelson EA, Mani R, Vowden K. Intermittent pneumatic compression for treating venous leg ulcers. Cochcrane database Syst Rev. 2008;16(2):CD001899. Review

170 Megens A, Harris SR. Physical therapist management of lymphedema following treatment for breast cancer: a critical review of its effectiveness. Phys Ther. 1998;78(12)1302-11

171 Lane KN, Dolan LB, Worsley D, McKenzie D. Upper extremity lymphatic function at rest and during exercise in breast cancer survivors with and without lymphedema compared with healthy controls. J Appl Physiol. 2007;103(3):917-25

172 Kirshbaum M. Promoting physical exercise in breast cancer care. Nurs Stand. 2005;19(41):41-8

173 Box RC, Reul-Hirche MR, Bullock-Saxton JE, Furnival CM. Physiotherapy after breast cancer surgery: results of a randomised controlled study to minimise lymphoedema. Breast Cancer Res Treat. 2002;75(1):51-64

174 Didem K, Ufuk YS, Serdar S, Zümre A. The comparison of two different physiotherapy methods in treatment of lymphedema after breast surgery. Breast Cancer Res Treat. 2005;93(1): 49-54

175 Ridner SH. Breast cancer treatment-related lymphedema A continuing problem. J Support Oncol. 2006:4(8); 389-90

176 Hughes SA. Promoting self-management and patient independence. Nurs Stand. 2004;19(10):47-51

177 Bogan LK, powell JM, Dudgeon BJ. Experiences of Living With Non-Cancer-Related Lymphedema: Implications for Clinical Practice. Qualitative Health Research. 2007;17(2): 21324

178 Brouwer E, Damstra RJ. Selfmanagement courses for patients with lymphedema. Results after 50 courses during 5 years in the Netherlands. Presentation ISL world congress Shanghai 2007

179 Ridner SH. Pretreatment lymphedema education and identified educational resources in breast cancer patients. Patient Educ Couns. 2006;61(1):72-9

180 Cohen SR, Payne DK, Tunkel RS. Lymphedema: strategies for management. Cancer. 2001;92(4 Suppl): 980-7

181 Ramos SM, O'Donnell LS,Knight G. Edema volume, not timing, is the key to success in lymphedema treatment. Am J Surg. 1999;178(4):311-5

182 Moseley AL, Carrati CJ, Piller NB. A systematic review of common conservative therapies for arm lymphoedema secondary to breast cancer treatment. Ann Oncol. 2007;18(4): 639-46

183 Hamner JB, Fleming MD. Lymphedema therapy reduces the volume of edema and pain in patients with breast cancer. Ann Surg Oncol. 2007;14(6):1904-8

184 Badger CM, Peacock JL, Mortimer PS. A randomized, controlled, parallel-group clinical trial comparing multilayer bandaging followed by hosiery versus hosiery alone in the treatment of patients with lymphedema of the limb. Cancer. 2000;15;88(12):2832-7

185 Johansson K, Lie E, Ekdahl C, Lindfeldt J. A randomized study comparing manual lymph drainage with sequential pneumatic compression for treatment of postoperative arm lymphedema. Lymphology. 1998; 31: 56-64

186 Swedborg I. Effects of treatment with an elastic sleeve and intermittent pneumatic compression in post-mastectomy patients with lymphoedema of the arm. Scand J Rehab Med. 1984;16:3541

187 Zhang S, Folsom AR, Sellers TA, Kushi LH, Potter JD. Better breast cancer survival for postmenopausal women who are less overweight and eat less fat: the lowa Women's Health 
Study. Cancer. 1995;76(2):275-83

188 Pierce JP, Natarajan L, Caan BJ, Parker BA, Greenberg ER et al. Influence of a diet very high in vegetables, fruit, and fiber and low in fat on prognosis following treatment for breast cancer: the Women's Healthy Eating and Living (WHEL) randomized trial. JAMA. 2007;298 (3);289-98

189 Saxe GA, Rock CL, Wicha MS, Schottenfeld D. Diet and risk for breast cancer recurrence and survival. Breast Cancer Res Treat. 1999;53:241-53

190 Jain M, Miller AB, To T. Premorbid diet and the prognosis of women with breast cancer. J Natl Cancer Inst. 1994;86:1390-7

191 Rock CL, Thomson C, Caan BJ, Flatt SW, Newman V, Ritenbaugh C et al. Reduction in fat intake is not associated with weight loss in most women after breast cancer diagnosis: evidence from a randomized controlled trial. Cancer. 2001;91(1): 25-34

192 Werner RS, McCormick B, Petrek J, Cox J, Cirrincione C et al. Arm edema in conservatively managed breast cancer: obesity is a major predictive factor. Radiology. 1991;180(1):177-84

193 Shaw C, Mortimer PS, Judd PA. A randomized controlled trial of weight reduction as a treatment for breast cancer-related lymphedema. Cancer. 2007;110 (8):1868-74

194 Vignes S, Porcher R, Champagne A, Dupuy A. Predictive factors of response to intensive decongestive physiotherapy in upper limb lymphedema after breast cancer treatment: a cohort study. Breast Cancer Res Treat. 2006;98(1):1-6

195 Piller NB, Morgan RG, Twycross RG. A double-blind clinical trial of hydroxyethylrutosides in obstructive arm lymphedema. Phlebology. 1993;Suppl. 1:22-8

196 Piller NB, Morgan RG, Casley-Smith JR. A double-blind, cross-over trial of O-(beta-hydroxyethyl)rutosides (Benzopyrones) in the treament of lymphoedema of the arms and legs. Br J Plast Surg. 1988;41:20-7

197 Diehm C, Trampisch HJ, Lange S, Schmidt C. Comparison of leg compression stockings and oral horse-chestnut seed extract therapy in patients with chronic venous insufficiency. Lancet. 1996;347:292-4

198 Casley-Smith JR, Morgan RG, Piller NB. Treatment of lymphedema of the arms and legs with 5,6 benzo(alpha)-pyrone. N Engl J Med. 1993;329(16):1158-63

199 Loprinzi CL, Kugler JW, Sloan JA, Rooke TW, Quella SK, Novotny P, et al. Lack of effect of coumarin in women with lymphedema after treatment for breast cancer. N Engl J Med. 1999;340:346-50

200 Mortimer PS, Badger C, Clarke I, Pallett J. A double blind randomized, parallel-group, placebocontrolled trial of $\mathrm{O}$-(beta-hydroxyethyl)-rutosides in chronic arm edema resulting from breast cancer treatment. Phlebology. 1995;10:51-5

201 Casley-Smith JR. There are many benzopyrones for lymphedema. Lymphology. 1997;30:38-9

202 Burgois A, Alcaide A, Alcoba C. Comparative study of the clinical efficacy of two different coumarin dosages in the management of arm lymphedema after treatment for breast cancer. Lymphology. 1999;32:3-10

203 Burns F, Micke O, Bremer M. Current status of selenium and other treatments for secondary lymphedema. J Support Oncol. 2003;1(2):121-30

204 Carrati CJ, Anderson SN, Gannon BJ, Piller NB. Treatment of postmastectomy lymphedema with low-level laser therapy: a double blind, placebo-controlled trial. Cancer. 2003;98(6):1114-22

205 Moseley AL, Esplin M, Piller NB, Douglass J. Endermologie ${ }^{\circledast}$ with and without compression therapy: a new tretment option for secondary arm lymphedema. Lymphology. 2007;40:129- 
37

206 O'Brien BM, Sykes PJ, Threlfall GN, Browning FS. Microlymphaticovenous anastomoses for obstructive lymphedema. Plas Reconstr Surg. 1977;60(2):197-211

207 Campisi C, Boccardo F, Zilli A, Maccio A. the use of vein grafts in the treatment of peripheral lymphedemas: long term results. Microsusrgery. 2001;21(4):143-7

208 Baumeister RGH, Frick A. Die autogen gefasstransplantation zur microchirurgischen Rekonstruktion des Lymphgefassysteems. Phlebology. 1996;25:83-8

209 Damstra RJ, Voesten HG, van Schelven WD, van der Lei B. Lymphatic venous anastomosis (LVA) for treatment of secondary arm lymphedema. A prospective study of 11 LVA procedures in 10 patients with breast cancer related lymphedema and a critical review of the literature. Breast Cancer Res Treat. 2009;113(2):199-206

210 Charles H. Elephantiasis of the leg. In: Latham A, English TC, Eds. A system of treatment. Vol 3. London: Churchill, 1912: 516

211 Thompson N. Surgical treatment of chronic lymphoedema of the lower limb. With preliminary report of new operation. BMJ 1962;2:1566-73

212 Campisi C, Davini D, Bellini C, Taddei G, Villa G, Fulcheri E, et al. Lymphatic microsurgery for the treatment of lymphedema. Microsurgery. 2006;26(1): 65-9

213 Baumeister RG, Siuda S. Treatment of lymphedemas by microsurgical lymphatic grafting: what is proved? Plast Reconstr Surg 1990;85(1): 64-74; discussion 75-6.

214 Baumeister RG, Frick A. The microsurgical lymph vessel transplantation. Handchir Mikrochir Plast Chir. 2003; 35(4): 202-9

215 Brorson $\mathrm{H}$, Svensson $\mathrm{H}$. Liposuction combined with controlled compression therapy reduces arm lymphedema more effectively than controlled compression therapy alone. Plast Reconstr Surg. 1998;102:1058-67

216 Brorson $\mathrm{H}$. Liposuction gives complete reduction of chronic large arm lymphedema after breast cancer. Acta Oncol. 2000;39(3):407-20

217 Brorson H. Liposuction in arm lymphedema treatment. J Scan Surg. 2003;92(4):287-95

218 Brorson $\mathrm{H}$, Svensson $\mathrm{H}$. Liposuction combined with controlled compressiontherapy reduces arm lymphedema more effectively than controlled compressiontherapy. Plast Reconstr Surg. 1998;102:1058-67

219 Brorson H. Svensson H. Complete reduction of lymphoedema of the arm by liposuction after breast cancer. Scand J Plast Reconstr Surg Hand Surg. 1997;31(2):137-43

220 Halperin TJ, slavin SA, Olumi AF, Borud LJ. Surgical management of scrotal lymphedema using local flaps. Ann Plast Surg. 2007;59(1):67-72

221 Modolin M, Mitre Al, da Silva JC, Cintra W, Quagliano AP, Arap S, Ferreira MC. Surgical treatment of lymphedema of the penis and scrotum. Clinics. 2006;61(4):289-94

222 Iwao F, Sato-Matsumura KC, Sawamura D, Shimizu H. Elephantiasis nostras verrucosa successfully treated by surgical debridement. Derm Surg. 2004;30(6):9339-41

223 Witte $\mathrm{MH}$, Witte $\mathrm{CL}$, Bernas $\mathrm{M}$. Consensus document revisited: suggested modifications (summarized from discussions at the $16^{\text {th }} \mathrm{ICL}$, madras, Spain, September 1997 and the Interim ISL Executive Committee Meeting. Lymphology. 1998;31(3):138-40

224 Consensus document of the International Society of lymphology. The diagnosis and treatment of peripheral lymphedema. Lymphology. 2003;36:84-91 
225 Damstra RJ, Kaandorp CJE. CBO richtlijn Lymfoedeem. Ned tijdschr Geneesk. 2003;147(14): 648-52

226 Morgan P, Doherty D, Moffatt C, Franks P. the National Lymphoedema Framework Project. Nurs Times. 2005;101(24):48 


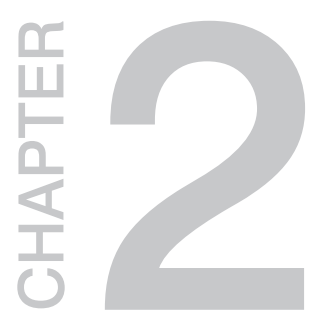

\section{Validation of the Inverse Water Volumetry Method: A New Golden Standard for Arm Volume Measurements}

R. J. Damstra, MD

E.J. Glazenburg, $\mathrm{MSC}^{1}$

W.C.J. Hop, PhD'

'Medical Department GlaxoSmithKline, Zeist, The Netherlands

2Department of Epidemiology and Biostatistics, Erasmus Medical Centre, Rotterdam,

The Netherlands 


\section{ABSTRACT}

Background: No consensus exists with respect to a commonly accepted and standardized method for measuring arm volumes in patients with lymphedema. Knowing the exact volume in (potential) lymphedemic arms and comparing this volume with healthy arms is important to detect the first signs of lymphedema and to study the effects of treatment.

Methods: A new apparatus, based upon the principle of measuring shortness of water, was developed to measure arm volumes. This measuring-method, inverse water volumetry, was prospectively validated in patients, suffering from lymphedema after complete or partial mastectomy for primary breast cancer. Healthy and lymphedemic arm were measured 3 times: twice by nurse $A$ ( $A 1$ and $A 2$ ) and once by nurse $B$ (B). Subsequently, these differences in volumes were compared with differences in volumes obtained by the Herpertz method, which is based upon circumferential measurement.

Results: In every patient at every occasion volume of the lymphedemic arm was bigger than the corresponding volume of the control arm. Mean volumes of healthy arms were 3958(A1), 3966(A2) and 3961(B) $\mathrm{ml}$ respectively. Mean volumes of lymphedemic arms were 4721(A1), 4752(A2) and $4773(B) \mathrm{ml}$ respectively, volume $B$ being significantly different from volume $A 1$. Volume difference of edemic arms minus control arms was not significant between measurements ( $A 1$ vs $A 2$ and $A 1$ vs $B$, respectively), while this difference was significant (A1 vs B) using the Herpertz method.

Conclusion: Inverse water volumetry is an easy measuring device with a high inter-and intra-observer agreement. The small but significant volume increase of lymphedemic arms in time compared to the constant volumes of control arms is as well indicative for the accuracy of the method as for the volume of lymphedemic arms to increase when no therapeutic garment is carried. 


\section{INTRODUCTION}

Secondary lymphedema of an extremity can develop as a serious complication after cancer treatment and is more common than primary lymphedema. Upper extremity lymphedema due to the treatment of breast cancer can affect 8-50\% of all patients undergoing surgery, chemotherapy and/or radiotherapy. All of these treatments damage the lymphatic system. ${ }^{1,2,3,5,6}$. Lymphedema can develop up till 12 years after the initial anti cancer treatment and is considered to be a lifelong process.

Measurement of the arm volume in patients at risk is very important in terms of an early detection method to be able to start an early treatment program ${ }^{7}$. Another indication for an adequate, sensitive and quantifiable volume measurement is the evaluation of the results of specific lymphedema treatment and follow-up.

In spite of the necessity of a measurement device for arm swelling no consensus exists with respect to a commonly accepted and standardized method. At this moment there are many ways of describing the presence and severity of lymphedema and to monitor the response to treatment. These include for example patient's subjective description ${ }^{8}$, description of clinical signs and staging it to various categories ${ }^{9,10,11}$, mathematical volume calculation related to circumferential measurement of the limb 12,13,14,15 and bioelectrical impedance ${ }^{16,17}$. By circumference measurement at various levels on the arm some authors ${ }^{18,19,20}$ consider a difference between the arms of $2,5 \mathrm{~cm}$ measured at one point as lymphedema where others use $2 \mathrm{~cm}$ of difference as the threshold ${ }^{6,21}$. A special technique for unilateral lymphedema is relative lymphedema measurement according to Herpertz ${ }^{22}$. This method is a combination of a four point circumference measurement of both limbs. Afterwards a calculation is made of the relative proportional swelling compared to the healthy side.

Most of the above measurement techniques have not been validated, except the Sitzia method ${ }^{23}$. Many studies that indirect volume measurements methods are not interchangeable with a water displacement method. The golden standard for the measurement of limb swelling is the water displacement method 24,25,26,27.

The disadvantage of all methods, except for the golden standard, is that they do not take into account the swelling of hand respectively finger(s). Especially by the circumference and volume calculating methods there is a substantial risk for interobserver variability 
and a poor reproducibility because of the variation in using a tape measure. For clinical practice in an outpatient clinic during a long period of time any method should be easy to perform by the nursing staff.

The classic water displacement method ${ }^{28}$, in which a limb is slowly placed in a tank filled with water and the volume of the overflow measured, has also many disadvantages. The method is time consuming, needs many handlings with water and water tanks thereby enhancing the possibility of introducing errors and, last but not least, is difficult to be performed by a nurse because of its heavy weight. The aim of the present study was to assess the validity of a new method of arm volume measurement, combining convenience for patient's and staff, accuracy, and saving of time by comparing it to the Herpertz method.

\section{MATERIALS AND METHODS}

\section{Inverse Water Volumetry and Herpertz method}

The classic way of performing the water displacement method is to measure the overflow of water. Concerning the disadvances of this overflow, a method was developed for measuring the shortness of water. By using a weighting device, based on the metal bending principal, the entire measuring device is used as one entity. Prior to use, calibration to zero is performed by filling the water tank till the reference point where the water flows in the overflow tube. Afterwards the system is emptied and ready for use. Patient's arm is placed into the apparatus in a special way shown below (see Figure 1, Step 1) and the tank is filled up to the overflow tube with water of $38^{\circ} \mathrm{C}$ (see Figure 1, Step 2). When the whole system is in equilibrium, patient's arm is removed and the system is disconnected (see Figure 1, Step 3). Subsequently, the display of the weighting device shows the shortness of water compared with the initial situation. Because the "lack of water" is measured, the method is named Inverse Water Volumetry. After each patient the device is emptied and cleaned properly.

In order to get the best possible standardization for measuring volumes of the arm in a patient friendly way the apparatus has a special form (see Figure 1, photograph). The arm is placed with the olecranon on the bottom of the Perspex tank while the elbow makes an angle of $90^{\circ}$. Because the olecranon always remains visible in the lymphedema arm, the 
distance between the olecranon and the overflow tube $(\mathrm{H})$ will always be the same for each patient. This gives an individual standardization. To minimize the death space and therefore to increase the accuracy, the apparatus has a lying L-shape. The IWV-apparatus can be moved vertically to adapt it to the standing position of the patient. After every patient the water is totally refreshed. To get antiseptic circumstances, a chloorhexidine $0,5 \%$ solution can be added to the water during or after the measurement. A daily calibration is performed to check the apparatus.

The Herpertz method ${ }^{22}$ is a simple and often applied method to calculate the relative swelling by unilateral lymphedema related to four fixed measurement points at a limb. Before the device was used, it was the common method of quickly measuring lymphedema in our hospital. Both lymphedemic and control arm were marked by the investigator with white stickers at 4 corresponding locations, viz. the wrist, halfway between the wrist and the elbow, a little above the elbow and close to the shoulder. At these locations the circumference was measured by the study nurse. To be sure that each measurement took place at the same position, nurses were asked to measure the distance from the top of the middle finger to the respective markers at every occasion. Subsequently, relative difference in volume at each location was calculated by the investigator sing the formula:

Mean Difference (in\%) $=\left\{\frac{(\text { Circumference edemic arm })^{2}}{{\text { (Circumference control arm })^{2}}^{2}}\right\} \times 100$

Finally, all percentages at these 4 locations were added and divided by 4 . The result of these calculations is fairly indicative for the difference in volumes between the edemic and the control arm, expressed as percentage of the control arm.

\section{Patients}

All patients eligible for the study had a history of lymphedema and were characterized by the following clinical definitions:

- an ipsilateral axillary node dissection after complete or partial mastectomy for primary breast cancer

- no signs of local recurrence of metastasis. 
Healthy and lymphedema arm were measured 3 times: twice by nurse $A$ (measurements $A_{1}$ and $A_{2}$ ) and afterwards once by nurse $B$ (measurement $B$ ). No other nurses were involved in the study. All measurements started with the IWV-apparatus and were followed by the Herpertz method. To avoid that previous data could influence subsequent measurements, IWV-apparatus and Herpertz data of measurement $A_{1}$ were immediately collected by the investigator, the same procedure was followed after measurements $A_{2}$ and $B$ respectively. Volume measurements of both arms with the IWV-apparatus took about 5 minutes, for the

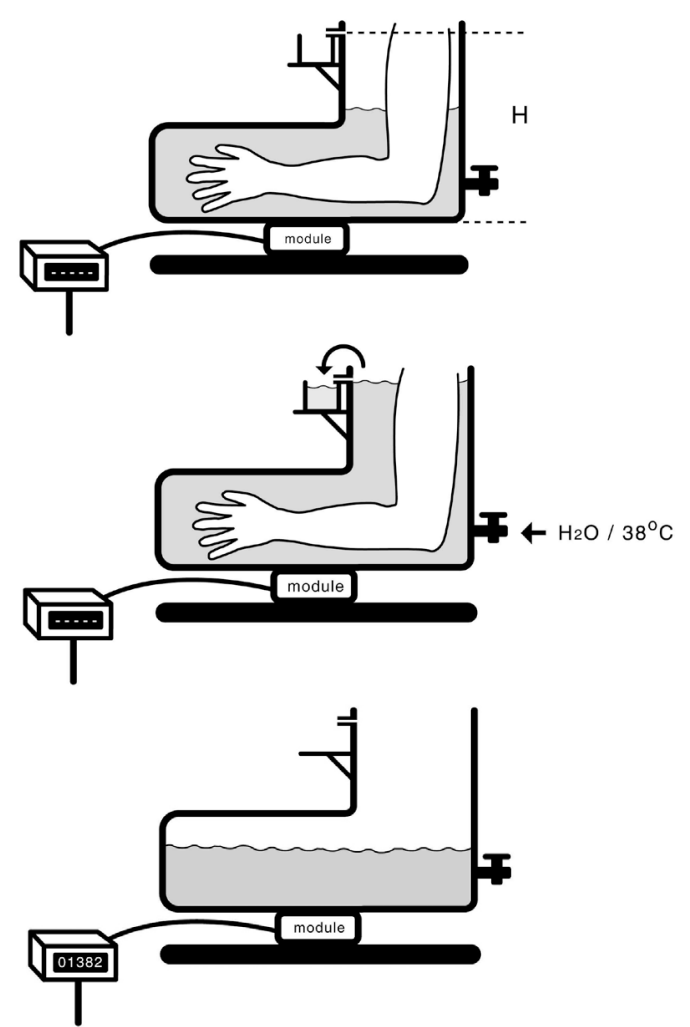

\section{Step 1.}

Place the arm in position with the olecranon in the right lower corner

\section{Step 2.}

Slowly fill the tank to the overflow tube and wait till the drops stop falling into the overflow box

Step 3.

Remove the arm, disconnect the system and read the display

Figure 1: Schematic outline of the process of measuring arm volumes (steps 1,2 and 3) and a photograph of one of the authors (RJD) demonstrating the Lymphometer 
Herpertz method the whole procedure lasted 8 minutes. The performance of the whole study took about 45 minutes per patient.

Prior to the investigation the study protocol was approved by the Medical Ethics Committee of the hospital. All patients provided their written informed consent.

\section{Statistics}

Intra- and interobserver variability studies are usually done with about 25 patients. Systematic differences between measurement occasions ( $A_{1}$ versus $A_{2}$ for intra-observer differences, and $A_{1}$ versus $B$ for inter-observer differences) for the different methods were evaluated using the paired t-test. Inter- and intra-observer agreement, and the agreement between both methods at the various occasions, was quantified using intraclass correlation coefficients (ICC). Standard deviations were compared using Pitman's test. $P=0.05$ (two-sided) was considered the limit of significance.

\section{RESULTS}

25 consecutive patients with an age range of $47-82$ years (mean \pm SD: $61.7 \pm 9.5$ ) were included into the study. Of these patients 10 underwent a complete, the remaining $15 \mathrm{a}$ partial mastectomy. History of lymphedema in these patients showed that the majority (18) had a history of less than 15 months, while the rest all suffered from lymphedema for more than 25 months with two patients even having a history of more than 5 years. Mean history of lymphedema was 18.1 months (SD: 22.0 ; range 1 - 72 months)

\section{Results inverse water volumetry}

A summary of all measured volumes in as well lymphedema arms as control arms, measured by the IWV-apparatus method, is shown in Table 1.

In every patient at every occasion, volume of the lymphedema arm was bigger than the corresponding volume of the control arm. As an example this is shown in Figure 2 for measurement occasion $A_{1}$, results of $A_{2}$ and $B$ confirm this finding (results not shown). The smallest difference between lymphedema arm and control arm was 1.7\% (volume lymphedema arm: $4087 \mathrm{ml}$, volume control arm $4018 \mathrm{ml}$ ), the biggest difference was 


\section{Table 1.}

\begin{tabular}{lccc}
\hline & Occasion $A_{1}$ & Occasion $A_{2}$ & Occasion B \\
\hline Lymphedema arm & & & \\
Mean volume (SD) & $4721(1025)$ & $4752(1010)$ & $4773(1025)$ \\
Range & $3160-6792$ & $3237-6900$ & $3328-6887$ \\
Control arm & $3958(784)$ & $3966(829)$ & $2736-6394$ \\
Mean volume (SD) & $2707-6239$ & $2789-6470$ & $3964)$ \\
Range & & & 2704 \\
\hline
\end{tabular}

Mean ( $\pm S D$ ) volumes and ranges of these volumes at measurement occasions $A_{1}, A_{2^{\prime}}$ and $B$.

All volumes and ranges are expressed in $\mathrm{ml}$.

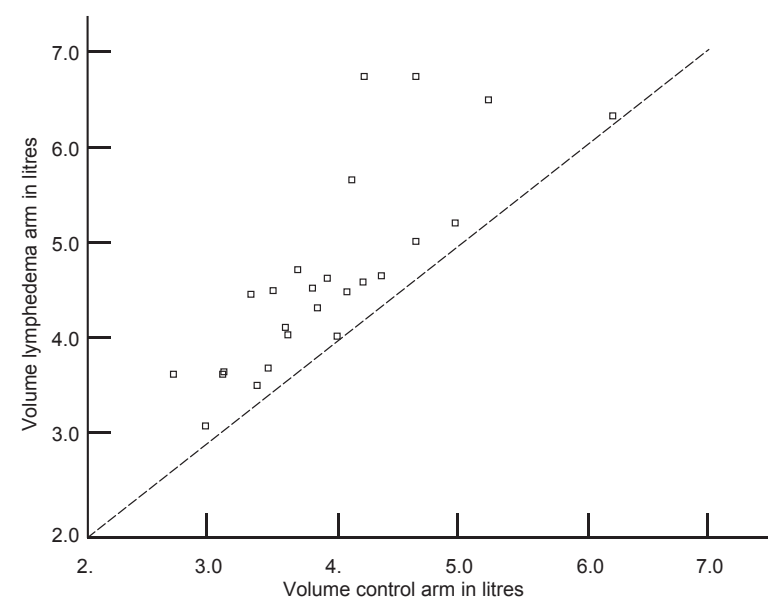

Figure 2: Results of Inverse Water Volumetry measurements at occasion $A_{1}$. Each square represents one patient. The dashed line represents the line of identity.

60.3\% (volume lymphedema arm $6789 \mathrm{ml}$, volume control arm $4234 \mathrm{ml}$ ), while all other differences in volumes at occasion $A_{1}$ were in between these values.

At occasion $A_{1}$ in all but one patient, the Herpertz method also resulted in lymphedema arms having a bigger volume than control arms. In this patient, control arm was $1.5 \%$ bigger than the lymphedema arm, while measurement with the IWV-apparatus showed a difference between these arms of 2.4\% (volume lymphedema arm $6391 \mathrm{ml}$, volume control arm $6239 \mathrm{ml}$ ). The biggest difference between volumes of both arms as measured by the Herpertz method was $81.8 \%$, in the same patient the IWV-apparatus also showed the biggest difference, $60.3 \%$ (volume lymphedema arm $6789 \mathrm{ml}$, volume control arm $4234 \mathrm{ml})$. 
At all measurement occasions $\left(A_{1}, A_{2}, B\right)$ there was an acceptable agreement between the Inverse Water Volumetry and the Herpertz method regarding the volume difference between the edematous arm and the control arm. The ICC's were, respectively, 0.91, 0.89 and 0.89. In single instances, however, the differences between both methods can be quite large. Figure 3 shows results of both techniques at occasion $A_{1}$. Out of the 25 patients assessed, there were 2 patients in whom the Herpertz outcome differed more than 10\% from the IWV-apparatus result.

Intra-observer variability results as measured via the Inverse Water Volumetry are shown in Table 2.

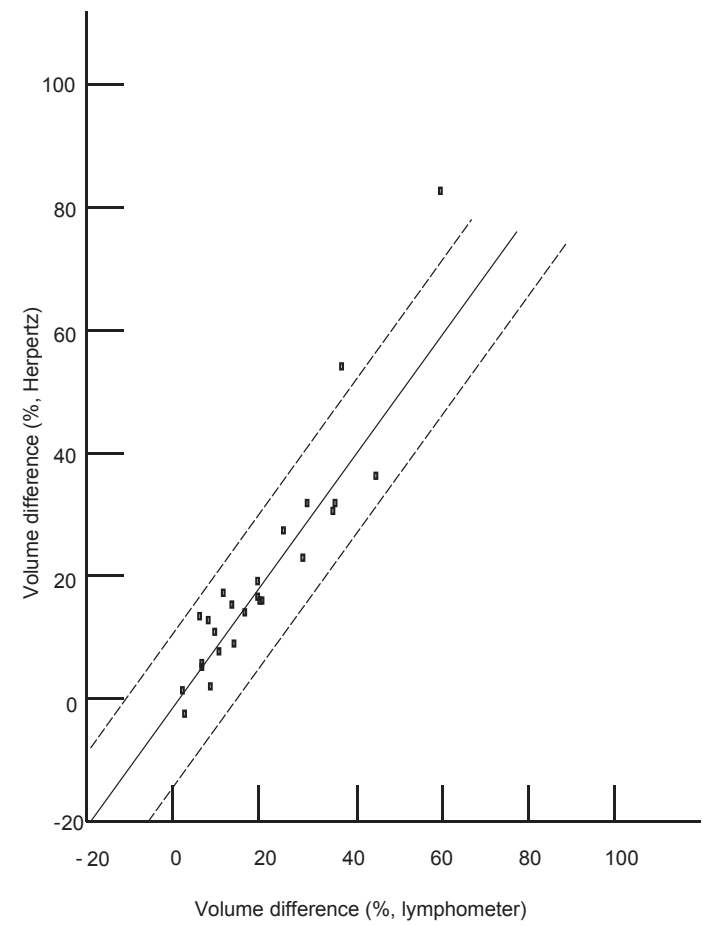

Figure 3: Comparison of the Herpertz Method and the Inverse Water Volumetry regarding the volume difference between the edematous arm and the control arm. Results at occasion A1, the solid line represents the line of identity; dotted lines represent values in which the Herpertz Method differs 10\% from the Inverse Water Volumetry.

Table 2.

\begin{tabular}{cccc}
\hline $\begin{array}{c}\text { Intra-observer } \\
\left(\mathrm{A}_{1} \text { versus } \mathrm{A}_{2}\right)\end{array}$ & $\begin{array}{c}\text { Mean }(\Delta) \\
\left(\Delta=\mathrm{A}_{1} \text { minus } \mathrm{A}_{2}\right)\end{array}$ & $\mathrm{SD}(\Delta)$ & Intra-class correlation coefficient \\
\hline Volume edema arm $(\mathrm{ml})$ & $-31(\mathrm{p}=0.06)$ & 78 & 0.997 \\
Volume control arm $(\mathrm{ml})$ & $-8(\mathrm{p}=0.80)$ & 154 & 0.982 \\
Volume difference\# $(\%)$ & $-0.7(\mathrm{p}=0.44)$ & 4.4 & 0.953 \\
\hline
\end{tabular}

\#difference of edema arm minus control arm, expressed as a percentage 
No significant systemic differences were found between the two measurements (all $\mathrm{P}>0.05)$. Intra-observer volume difference SD $(\Delta)$, as measured using the Inverse Water Volumetry method (4.4\%), did not significantly differ from the corresponding value of $3.0 \%$ via the Herpertz method.

Inter-observer variability results ( $A_{1}$ versus $\left.B\right)$, as measured via the Inverse Water Volumetry are shown in Table 3.

Although there was a significant systemic difference between observations $A_{1}$ and $B$ for the edema arm $(p=0.006)$, overall the agreement between observers was good as shown by the high intra-class correlations.

The standard deviation of the differences SD $(\Delta)$ using Inverse Water Volumetry was $2.5 \%$, which value was significantly (Pitman's test, $\mathrm{p}<0.01$ ) smaller as compared to the corresponding value of $5.3 \%$ obtained via the Herpertz method.

Table 3.

\begin{tabular}{cccc}
\hline $\begin{array}{c}\text { Inter-observer } \\
\left(\mathrm{A}_{1} \text { versus } \mathrm{B}\right)\end{array}$ & $\begin{array}{c}\text { Mean }(\Delta) \\
\left(\Delta=\mathrm{A}_{1} \text { minus B) }\right.\end{array}$ & SD $(\Delta)$ & Intra- class correlation coefficient \\
\hline Volume edema arm $(\mathrm{ml})$ & $-53(\mathrm{p}=0.006)$ & 87 & 0.995 \\
Volume control arm $(\mathrm{ml})$ & $-3(\mathrm{p}=0.88)$ & 93 & 0.993 \\
Volume difference\# $(\%)$ & $-1.2(\mathrm{p}=0.019)$ & 2.5 & 0.982 \\
\hline
\end{tabular}

\#difference of edema arm minus control arm, expressed as a percentage

\section{DISCUSSION}

In this study it is shown that Inverse Water Volumetry by a IWV-apparatus is an accurate measuring device directly related to the golden standard. Looking at mean volumes of control arms there is hardly any difference between occasion $A_{1}, A_{2}$ and $B(3958 \mathrm{ml}, 3966 \mathrm{ml}$, and $3961 \mathrm{ml}$ resp.). Comparison of volume measurements of occasion $A_{1}$ versus occasion $B$ showed for instance that of 25 patients, 11 had a bigger volume when measured at $A_{1}, 12$ had a bigger volume when measured at $B$, while 2 had the same volume in both occasions. Differences at both occasions were very small, maximum difference between volumes of the control arm was less than 5\%, absolutely this means a difference of less than $200 \mathrm{ml}$ at a total volume of approximately $4000 \mathrm{ml}$. In the majority of measurements this difference was (far) less than $100 \mathrm{ml}$. This means that independent of time of measurement and 
person who is performing the measurement, reproducibility is very high.

However, it is very remarkable that mean volumes of edema arms show an increase from occasion $A_{1}$ via occasion $A_{2}$ to occasion $B\left(4721,4752\right.$ and $4773 \mathrm{ml}$, resp). $A_{1}$ vs $A_{2}$ does not reach statistical significance $(p=0.06)$, neither does $A_{2}$ vs $B(p=0.31)$ but the difference between $A_{1}$ and $B$ is statistically different $(p<0.05)$. Increase in volume from $A_{1}$ to $B$ was $1.2 \%$, at occasion B 20 patients had a higher volume of their edema arms than at occasion $A_{1}$. Volume differences between control arms and edema arms at occasions $A_{1}$ and $B$ were also statistically significant (see table 3). A possible explanation for this small, but significant increase of volume in the afflicted arm could be the time difference between measurement $A_{1}$ and measurement $B$ (in between 30 and 45 minutes). During this time period no therapeutic elastic garment was carried by the patients and it can be imagined that swelling can take place under the influence of isometric arm muscle contractions. This phenomenon, of course, doesn't happen in control (healthy) arms.

Reliability of this absolute volume measurement by the IWV-apparatus has a great advantage when compared to relative volume measurements as in the Herpetz method. The IWV-apparatus measures the whole arm, inclusive the hand, while other methods like circumference measurements but also the optoelectronic volumetry, lack this important part of the arm. An additional water displacement measurement of the hand is sometimes performed to get a better idea of the volume of the arm, reliability of the outcome of this method seems questionable.

Volume calculation formulas as well as using an optoelectronic device (Volometer ${ }^{\circledR}$ or Perometer $\left.{ }^{\circledR}\right)$ can involve methodological faults or different calculation methods ${ }^{29}$. Foot and hand measurements are not possible with this technique. A recent study by Armer ${ }^{30}$ compared different diagnostic criteria for the definition of lymphedema of which two of the criteria tested where measured by perometry limb volume change. Especially in arm lymphedema the contribution of hand-volume can be significant and therefore IWV can be beneficial in producing more accurate data in these patients.

Methods by which tailor tape is used increase the risk for inter and intra observer variation because of differences in individual strength when limbs are measured. Reliability of measured values will vary over periods of time, especially when more physicians and nurses are involved in measuring these relative volumes. 
All disadvantages of the old water displacement method are absent by the inverse water volumetry. The method can be performed quickly, is easy to perform by all patients, including older and less mobile patients and does not need previous training for the nursing staff or the therapists. The most important fact is that the olecranon is maximal fixed in the $90^{\circ}$ anckle.

A very important aspect of absolute measuring of arm volumes is its use in detection, treatment and follow-up of lymphedema. A surveillance programme at certain time intervals after cancer treatment will indicate when lymphedema starts to develop. Depending on local protocols it can be decided that therapy should be started when volume of the lymphedemic arm has increased with a certain percentage. Results of this therapy can be measured at every visit and depending on the volume of the lymphedemic arm, therapy can be prolonged or changed. Every time a patient comes to the clinic, volume can be measured and in the course of many years reliable data on the development of the volume of the lymphedema arm can be collected.

Another important aspect, often forgotten, of absolute volumetry is the possibility of measuring volumes of the healthy arm. Hardly anything is known about increase or decrease of volumes in the healthy arm. It can be imagined that under normal circumstances the volume of the healthy arm increases in time. Reason for this is that the majority of patients will use their healthy arm more than they did before, just to spare the lymphedema arm. Absolute volumetry will show if indeed the volume of the healthy arm really increases in time. One of the disadvantages of relative measurements is the fact that a bigger increase of the volume of the healthy arm, compared to a smaller increase of the volume of the lymphademic, could lead to the conclusion that a chosen therapy is effective, while in reality lymphedema is increasing. Again, absolute measurements of volumes have a great advantage over relative measurements. Megens et al. ${ }^{31}$ determined if circumference measurement can substitute for water displacement volumetry. They conclude that both methods were reliable and closely related, but they were not interchangeable. Waterdisplacement is the most precise method according to what is important in (early) detecting swelling and lymphedema: the total upper extremity volume. 


\section{CONCLUSIONS}

Lymphedema is a substantial problem leading to much physical and psycho-social morbidity by the patient ${ }^{32,33,34}$ and it is related to high costs due to treatment. Nevertheless, there are hardly any simple, effective and validated measuring devices for early diagnostics, for measuring effects of treatment what so ever and for follow-up. In literature many ideas and treatment options about lymphedema exist without any consensus with respect to its definition, measurement or treatment ${ }^{35}$. In practice, many physicians and therapists use subjective or insufficient measuring techniques.

The IWV-apparatus method as described in this article, is very suitable for general use by physicians, physiotherapists and manual lymphtherapist for detection of beginning lymphedema and for effect measurements during treatment and follow-up. It is patient friendly and has shown excellent results in measuring arm volumes with respect to intraand interobserver variability.

This newly developed and validated method for objective measuring of arm volumes could be of great help to all active in the field of treating patients with lymphedema. It could enhance insight in the phenomenon of lymphedema and, by early detection and treatment of lymphedema, patients surely will experience a greater quality of life. 


\section{REFERENCES}

1 Kissin MW, Querci della Rovere G, Easton D, Westbury G, Risk of lymphedema following treatment of breastcancer. Br J Surg. 1986;73:580-4

2 Schunemann $\mathrm{H}$, Willich $\mathrm{N}$ Lymphedema after breastcancer. A study of 5868 casus. Dtsch Med Wochenschr. 1997;122(17):536-41

3 Kiel KD, Rademacker AW, Early stage breastcancer: edema after wide excicion and breast radiation. Radiology. 1996;198:279-83

4 Liljegren G, Holmberg L. Arm mobility after sector resection and axillary dissection with and without postoperative radiotherapy in breastcancer stage I. Results from a randomised trial. Uppsala Orebro Breast Cancer Study Group. Eur J Cancer. 1997;33:193-9

5 Cornish HB, Bunce IH, Ward LC et al. Bio-electrical impedance for monitoring the efficacy of lymphedema treatment programmes. Breast Cancer Res treat. 1996;38:169-76

6 Schunemann $\mathrm{H}$, Willich $\mathrm{N}$. Lymphedema of the arm after primary treatment of breast cancer. Anticancer Res. 1998;18:2235-6

7 Ramos SM, O'Donell LS, Knight G. Edema volume, not timing, is the ley to success in lymphedema treatment. Am J Surg. 1999;178:311-5

8 Mortimer PS, Bates DO, Brassington HD, Stanton AWB et al. The prevalence of arm oedema following treatment for breast cancer. Q J Med 1996;89:377-80

9 Pezner RD, Patterson MP, Hill LR. Arm edema in patients treated conservatively for breast cancer: relationship to patient age and axillary node dissection technique. Int Radiat Oncol Biol Phys. 1986;12:2079-83

10 Dewar JA, Sarrazin D, Benhamou et al. Management of the axilla in concervatively treated breast cancer. 592 patients treated at Institut Gustave-Roussy. Int J Radiat Oncol Biol Phys. 1987; 13: 475-80

11 Larson $D$, Weinstein $M$, Goldberg I et al. Edema of the arm as a function of the extent of axillary surgery in patients with stage I-II carcinoma of the breast treated with primary radiotherapy Int J Radiation Oncology Biol Phys. 1986;12:1575-82

12 Sitzia J, volume measurement in lymphedema treatment: examination of formulae. Eur J of CancerCare. 1995;4:11-6

13 Kuhnke E. Volumbestimmung aus Umfangmessungen. Folia Angiologica 1976;24:228-32

14 Lennihan R, Mackereth M. Calculating volume changes in a swollen extremity from surface measurements. Am J Surg. 1973;126:649-52

15 Brown J. A clinically useful method for evaluating lymphedema. Clin J Oncol Nurs. 2004;8(1):358

16 Göltner E, Fishbach JU, Mönter B, Kraus A, Vorherr H. Objektivierung des Lymphödems nach Mastektomie. Deutsche Med Wochenschrift. 1985;110:949-52

17 Cornish BH, Bunce IH, Ward LC, Jones LC, Thomas BJ. Bioelectrical impedance for monitoring the efficacy of lymphedema treatment programmes. Breast Cancer Research and Treatment. 1996;38:169-76

18 Brismar B, Ljungdahl I. Postoperative lymphedema after treatment of breast cancer. Acta Chir Scand. 1982 (149):687-9

19 Farncombe M, Daniels G, Cross L. Lymphedema: the seemingly forgotten complication. J Pain Sympt Manage. 1994;9:269-76

20 Ryttov N, Holm V, Qvist N, Blichert-Toft M. Influence of adjuvant irradiation on the development of late arm mastectomy for carcinoma of the breast. Acta Oncologica. 1988;27:667-70 
21 Lin PP, Allison DC, Wainstock J, et al. Impact of axillary lymph node dissection on the therapy of breast cancer patients. J Clin Oncol. 1993;11:1136-44

22 Herpertz U. Messung und Dokumentation von Ödemen. Lymphologie. 1994;18:24-30

23 Meijer RS, Rietman JS, Geertzen JH, Bosmans JC, Dijkstra PU.Validity and intra-and interobserver reliability of an indirect volume measurements in patients with upper extremity lymphedema. Lymphology. 2004;37(3):127-33

24 Kaulesar DMKS, den Hoed PT, Johannes EJ, van Dolder R, Benda E. Direct and indirect methods for quantification of leg volume: comparison between water displacement volume try, the disk model and the frustum sign model, using correlation coefficient and the limits of agreement. J Biomed Eng. 1993;15:477-80

25 Stranden E. A comparison between suface mesaerements and water displacement volumetry for the quantification of leg edema. J Oslo City Hosp. 1981;31:153-5

26 Mortimer PS. Investigation and management of lymphedema. Vasc Med Rev. 1990;1:1-20

27 Segerstrom K, Bjerle P, Graffman S, Nystrom A. Factors that influence incidence of brachial edema after treatment of breast cancer. Scand J Plast Reconstr Hand Surg. 1992;26:223-7

28 Kettle JH, Ruindle FF, Oddie TH. Measurement of upper limb volumes: a clinical method. Aust N Z J Surg. $1958 ; 27: 263-70$

29 Veraart JCJM, Movig I, Asselman AH, Neumann HAM. The volometer and the perometer; a clinical comparison.Scripta Phlebologica. 1995;5:9-11

30 Armer JM, Stwewart BR A comparison of four diagnostic criteria for lymphedema in a PostBreast cancer polulation. Lymphat Res and biology. 2006;3(4):208-17

31 Megens AM, Harris SR, Kim-Sang C, McKinzie DC. Measurement of upper extremity volume in women after axillary dissection for breast cancer. Arch Phys Med Rehabil. 2001;82(12):1639-44

32 Maunsell E, Brisson J, Deschenes L. Arm problems and psychological distress after surgery of breast cancer. Can J Surg. 1993;36:315-20

33 Velanovich V, Szymanski W. Quality of life of breast cancer patients with lymphedema. Am J Surg. 1999;177:184-8

34 Ganz PA. The quality of life after breast cancer-solving the problem of lymphedema. New Eng J Med. 1999(5);340:383-7

35 Pain SJ, Purushotham AD. Lymphedema following surgery for breast cancer. Br J Surg. 2000;87(9):1128-41 


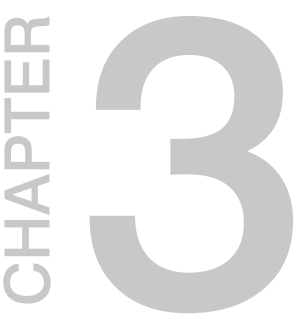

\title{
Novel Missense Mutations in the FOXC2 Gene Alter Transcriptional Activity
}

\author{
M.A.M. van Steensel MD, $P h D^{1}$ \\ R.J. Damstra MD \\ M. Heitink MD' \\ R.S. Bladergroen $M D, P h D^{1}$ \\ J.C.J.M. Veraart MD, $P h D^{1}$ \\ P.M. Steijlen MD, $P h D^{\prime}$ \\ M. van Geel MD, $P h D^{\prime}$
}

${ }^{1}$ Department of Dermatology, University Medical Center Maastricht, The Netherlands, GROW Research School for Oncology and Developmental Biology, University Maastricht 


\section{ABSTRACT}

Background: Mutations in the FOXC2 gene, which codes for a forkhead transcription factor, are associated with primary lymphedema that usually develops around puberty. Associated abnormalities include distichiasis and, very frequently, superficial and deep venous insufficiency. Most mutations reported so far either truncate the protein or are missense mutations in the forkhead domain that cause a loss-of-function. The haplo-insufficient state is associated with lymphatic hyperplasia in mice as well as in humans.

Methods and results: We analyzed the FOXC2 gene in 288 patients with primary lymphedema and found eleven pathogenic mutations, of which nine are novel. Of those, five were novel missense mutations, and four of those were located outside of the forkhead domain. To examine their pathogenic potential, we performed a transactivation assay using a luciferase reporter construct driven by FOXC1 response elements. We found that the mutations outside the forkhead domain cause a gain-of-function as measured by luciferase activity. Patient characteristics conform to previous reports with the exception of distichiasis, which was found in only two patients out of eleven.

Conclusion: FOXC2 mutations causing lymphedema-distichiasis syndrome result in haploinsufficiency and lead to lymphatic hyperplasia. Our results suggest that gain-of-function mutations may also cause lymphedema. One would expect that in this case, lymphatic hypoplasia would be the underlying abnormality. We have insufficient data to definitively confirm this assertion. It is possible that patients with activating mutations present with Meige disease. 


\section{INTRODUCTION}

Lymphedema is defined as a chronic swelling of tissues, mostly in the extremities, as a result of damage, dysfunction or defective development of the lymphatic vessels ${ }^{1}$. This common condition affects millions of people worldwide. Although many cases are genetically determined, only a few genes are presently known to be definitely associated with lymphedema ${ }^{2}$ Dominant mutations in the FOXC2 gene, which encodes the forkhead transcription factor FOXC2, cause a form of lymphedema that appears around puberty. Presumably depending upon genetic background, the lymphedema is accompanied by distichiasis (a double row of eyelashes) and varicose veins in a large percentage of patients ${ }^{3}$. Other abnormalities, such as cardiac defects and epidural cysts, have also been reported but are less common. Most mutations reported so far truncate the protein, likely causing disease by haploinsufficiency, as was concluded from findings in a mouse model $^{4}$. In FOXC2 +/- mice, there is a generalized hyperplasia of the lymphatic system. This observation was interpreted to suggest that reduced FOXC2 expression disrupts the normal equilibrium between lymph vascular growth promoting and inhibiting genes ${ }^{4}$. In line with this idea, previously reported missense mutations cause reduced transcriptional activity. Along those lines, it may be possible that increased FOXC2 activity could also cause lymphedema, although it would perhaps lead to lymphatic hypo- rather than hyperplasia. We now report eleven patients and families with mutations in the FOXC2 gene. Of these mutations, nine are novel, including five missense mutations. With a transactivation assay, we were able show that four of these missense mutations increase transcriptional activity.

\section{MATERIALS AND METHODS}

All patients gave their informed consent prior to venipuncture, in accordance with local guidelines.

\section{Patient selection}

The present study was performed as part of a larger survey of primary lymphedema genetics. For this, we screened 288 patients with primary non-congenital lymphedema 
for mutations in genes causing disorders with lymphedema as a primary symptom. These genes were FLT4, FOXC2 and SOX18. The laboratory was not aware of patient characteristics prior to the analysis. All patients had been personally examined and diagnosed by one of the authors (RD, MvS, MH, or JV).

\section{DNA isolation}

Chromosomal DNA was isolated from $10 \mathrm{ml}$ of peripheral EDTA blood on an AutoGenFlex STAR isolation robot in combination with the FlexGene DNA - AGF 3000 kit from Qiagen (Qiagen Benelux, Venlo, Netherlands).

\section{PCR}

Since the FOXC2 gene has $>60 \%$ GC content, all PCR reactions were performed using the GC-rich PCR kit from Roche (Roche, Lewis, UK) according to the manufacturer's recommendations. Primers were located in the $5^{\prime}$ and $3^{\prime}$-UTR of the gene (FOXC2F 5'-TGGCTCTCTCGCGCTCTCTC-3', FOXC2R 5'-CGTCTCTGCAGCCCCTTAATTG-3').

\section{Mutation analysis}

FOXC2 sequence analysis was performed on genomic DNA using the BigDye Terminator v3.1 Cycle Sequencing kit and an ABI 3100 capillary sequencer ( $A B I$, Foster City, CA, USA) according to the manufacturer's recommendations, using the PCR primers and five additional internal sequence primers (sequences are available upon request). Sequences were analyzed using the Phred/Phrap/Consed software package. All novel mutations were absent from 100 unrelated healthy Dutch controls.

\section{Cloning}

The pcDNA4C-HIS MAX-FOXC2 and FOXC1 luciferase reporter constructs were a kind gift from F. Berry ${ }^{5}$.

For cloning, FOXC2 was amplified from genomic DNA using primers containing an adapter that introduces BamHI and EcoRI sites. Wild type FOXC2 (WT) was cloned into vector pRLTK-luc. Incorporation of the mutations Y41F, R121C and S125L was achieved by using a Site Directed Mutagenesis kit (Stratagene, La Jolla, USA) according to the manufacturer's protocol. Mutations P402L, Q407H and Q444R were obtained by cloning the mutant gene 
into TOPO-XL (Invitrogen Ltd., Paisley, UK) from patient genomic DNA by PCR. Clones with the mutation were selected and digested with PfMI and BsrGI, which resulted in a 352 bp fragment containing the mutation. The wildtype FOXC2 PfIMI/ BsrGl fragment from the PCDNA4C-HIS MAX-FOXC2 construct was then replaced by the fragments with the mutations. All constructs were sequence verified in order to ensure that they did not contain additional mutations.

\section{Transfection}

HeLa-Ohio and CHO cells were used for transfection. Both cell lines were co-transfected with the FOXC1 luciferase reporter and wild type or mutated plasmids in a 1:6 ratio using the FuGENE-HD reagent (Roche), according to the manufacturer's recommendations. The $\operatorname{DNA}(\mu \mathrm{g}): \operatorname{FuGENE}(\mu \mathrm{l})$ ratio that was used was 2:4 in a 96-well format. Each transfection was set up in triplicate. Each experiment was repeated once and performed in HeLa and CHO cells.

\section{Luciferase assay}

To measure FOXC2 activity, all transfected cell lines were incubated for $48 \mathrm{~h}$ with $5 \%$ $\mathrm{CO} 2$ at $37^{\circ} \mathrm{C}$ prior to lysis of the culture and the addition of substrate from the ONE-GLO luminescence kit (Promega BNL, Leiden, Netherlands). Luminescence detection was accomplished with the Glomax luminometer (Promega).

\section{Localization assay}

An Xpress-tag fused to the FOXC2 N-terminus was incorporated in the plasmid construct. HeLa Ohio cells were cultured and transfected as described on $12 \mathrm{~mm}$ coverslips. After a 48 hour incubation, cultures were fixated and stained in a 1:500 solution of FITC-labeled anti-Xpress antibody in PBS-azide. Nuclei were stained with DAPI. Subcellular localization of the FOXC2 fusion protein was then evaluated with a Leica DM4000B fluorescence microscope. Overlay images were prepared using Adobe Photoshop software.

\section{Statistical analysis}

As described above, all activity experiments were set up in triplicate and then repeated. Data were entered into Numbers spreadsheet software (Apple Inc., San Francisco, CA, USA). 
For each clone, the average expression level in Fluorescence Units (FU) was calculated. These values were then corrected for endogenous expression, which was measured in separate cultures. Finally, these values were corrected for inter-plate variation. Data presented are FU mean values with the $95 \%$ confidence interval.

\section{RESULTS}

In 288 patient samples, we found eleven mutations in the FOXC2 gene. One was a nonsense, six were missense, and four were frameshift mutations (Table 1). Nine of these mutations have not been previously reported. We also found four mutations in FLT4, which codes for VEGFR3 (data not shown). Only two missense mutations, R121C and S125L, affect the forkhead domain. The four other missense mutations are located outside this domain. To study the consequences of these missense mutations, a transactivating luciferase assay was employed, which was previously developed by Saleem et al ${ }^{5}$. Mutation S125L had already been tested in this assay and served as a methodological control. Both mutations in the forkhead DNA binding domain decreased transcriptional activity, while the mutations located outside this domain all increased transcriptional activity in HeLa cells (Figure 1).

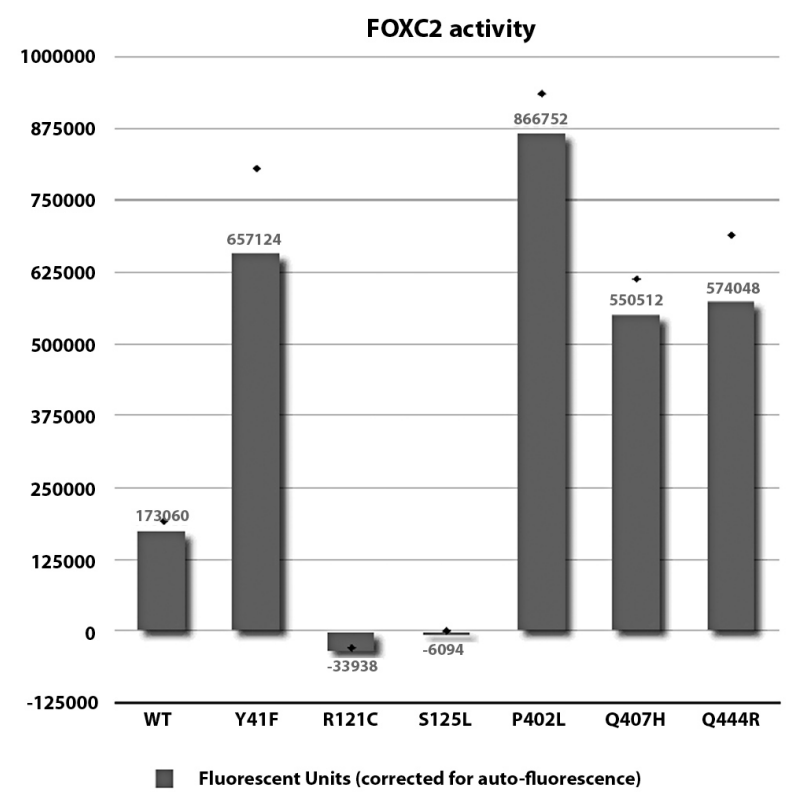

Figure 1. Transactivation assay results for the missense mutations. Bars indicate fluorescent units. The mutations outside of the forkhead domain all increase transcriptional activity. 
Table 1. FOXC2 mutations and associated phenotypes

\begin{tabular}{|c|c|c|c|c|}
\hline $\begin{array}{l}\text { Patient } \\
(\delta / q, \\
\text { current age) }\end{array}$ & $\begin{array}{l}\text { Family } \\
\text { history }\end{array}$ & $\begin{array}{l}\text { Nucleotide } \\
\text { change }\end{array}$ & Protein effect & Phenotype \\
\hline 1. $(9,45 \mathrm{y})$. & + & c. $122 \mathrm{~A}>\mathrm{T}$ & p.Tyr41Phe & Swollen feet at birth, varicose veins. \\
\hline 2. $\left(0^{\pi}, 22\right.$ y. $)$ & + & c.361C>T & p.Arg121Cys & $\begin{array}{l}\text { Swelling of feet and neck at birth, } \\
\text { lymphedema. Superficial and deep } \\
\text { venous insufficiency. }\end{array}$ \\
\hline 3. $(345 \mathrm{y})$. & + & c.374C $>\mathrm{T}$ & p.Ser125Leu & $\begin{array}{l}\text { Erysipelas from age } 10, \\
\text { lymphedema, varicose veins. } \\
\text { Superficial and deep venous } \\
\text { insufficiency. }\end{array}$ \\
\hline 4. $(+, 64 \mathrm{y})$. & + & c. $1205 C>T$ & p.Pro402Leu & $\begin{array}{l}\text { Lymphedema from age } 16 \text {, varicose } \\
\text { veins, insufficient deep venous } \\
\text { system with thrombosis right. } \\
\text { Scintigraphy: uptake R 0,5\%; L 1,7\%. } \\
\text { Clearance: } 94 / 92 \% \text {. }\end{array}$ \\
\hline 5. $(q, 52 \mathrm{y})$. & + & c. $1221 G>C$ & p.GLn407His & $\begin{array}{l}\text { Lymphedema left. Insufficient deep } \\
\text { venous system. Recurrent erysipelas. }\end{array}$ \\
\hline 6. $(+, 61$ y. $)$ & + & c. $1331 \mathrm{~A}>\mathrm{G}$ & p.Gln444Arg & $\begin{array}{l}\text { Lymphedema from age } 6 \text {, varicose } \\
\text { veins, aortic valve stenosis. }\end{array}$ \\
\hline 7. (?) & unknown & C.93C $>A$ & p.Tyr31Stop & Clinical data not available. \\
\hline 8. $(\hat{\jmath}, 24$ y. $)$ & unknown & c.559delC & p.Pro187ProfsX13 & $\begin{array}{l}\text { Valvular agenesis of deep venous } \\
\text { system. Insufficient greater } \\
\text { saphenous vein right side, } \\
\text { erysipelas. }\end{array}$ \\
\hline 9. $(\AA, 48 \mathrm{y})$. & + & c.794insA & p.Asn265LysfsX197 & $\begin{array}{l}\text { Lymphedema-distichiasis syndrome. } \\
\text { Agenesis of superficial and deep } \\
\text { venous valves. Recurrent erysipelas. }\end{array}$ \\
\hline 10. $(\widehat{\partial}, 45 \mathrm{y})$. & unknown & $\begin{array}{l}\text { c.876- } \\
\text { 877delCG }\end{array}$ & p.Arg293Argfs168X & $\begin{array}{l}\text { Swelling of ankles from } 10 \text { yrs of } \\
\text { age, venous insufficiency. Recurrent } \\
\text { erysipelas, superficial and deep } \\
\text { venous insufficiency. Scintigraphy: } \\
\text { dermal backflow L+R. }\end{array}$ \\
\hline 11. $(q, 37 y)$ & + & $\begin{array}{l}\text { c.902- } \\
\text { 920dup19 }\end{array}$ & p.Ala307Alafs166X & $\begin{array}{l}\text { Lymphedema-distichiasis, varicose } \\
\text { veins. Deep venous insufficiency. } \\
\text { Recurrent erysipelas. }\end{array}$ \\
\hline
\end{tabular}

Background fluorescence in the $\mathrm{CHO}$ cells was too strong to reliably measure differences in activity between mutant and wild type constructs. In addition, we analyzed if the subcellular localization of the mutated FOXC2 protein was affected. An antibody against an Xpress-tag fused to FOXC2 was used for detection. By screening multiple cells for each mutation, we found a nuclear distribution in all cases, which is equivalent to wild type FOXC2 (Figure 2). 


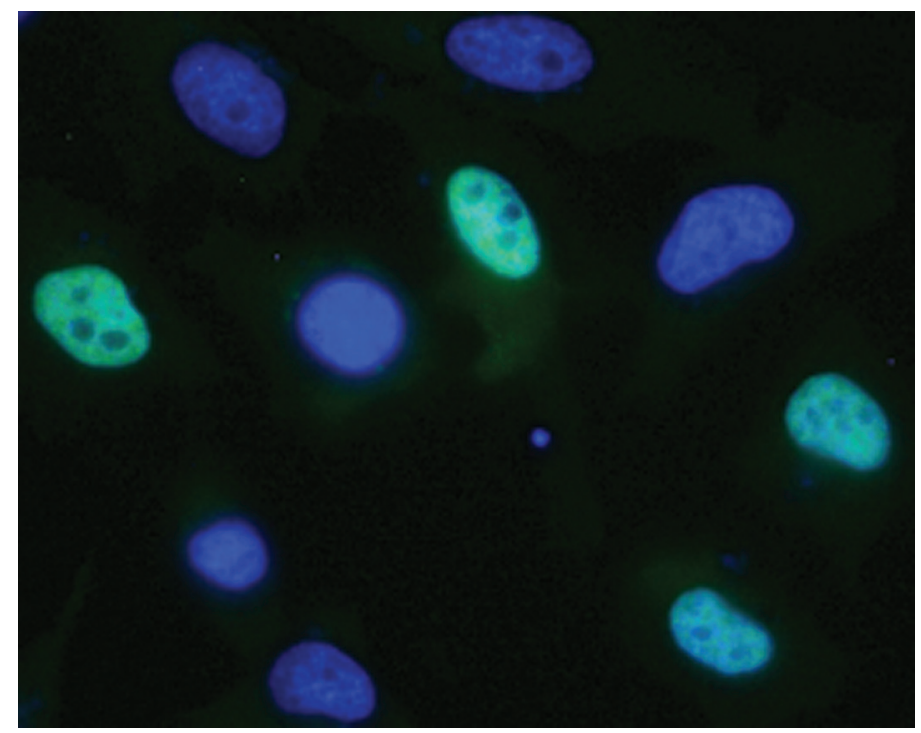

Figure 2. Nuclear localization of the mutant R121C. Nuclei are stained with DAPl; the fusion protein is pale green and localizes to the nucleus.

\section{DISCUSSION}

In a cohort of 288 patients with primary lymphedema, we found eleven mutations in the FOXC2 gene, five of which were novel missense mutations. The other five were all truncating mutations, and four of those were novel. Two patients with truncating mutations had clear distichiasis. It was not reported in the other patients, but it is a symptom that must be specifically looked for and may, therefore, have been missed, even considering that it is a highly penetrant symptom in lymphedema-distichiasis. Given that, our patients with mutations outside the forkhead domain may really not have distichiasis, as is discussed below. One missense mutation, S125L, had been reported previously ${ }^{6}$. From the limited number of patients that we have, a genotype-phenotype correlation does not readily emerge. It is of interest to note that their symptoms conform to what was previously reported for FOXC2 mutations. All of our patients have venous insufficiency that, in at least eight of them, also affects the deep system. A more extensive survey recently reported deep venous insufficiency in 14 out of 18 patients who were examined. As deep insufficiency can predispose an individual to thrombosis, it seems prudent to advise that all patients with confirmed FOXC2 mutations be examined using duplex ultrasound. 
Two of the mutations that we identified, R121C and S125L, affect the forkhead domain. To further examine how missense mutations outside of the forkhead domain cause disease, we focused on the novel missense mutations using $5125 \mathrm{~L}$ as an internal control. Earlier data have suggested that some mutations may cause protein mislocalization. However, we found no evidence to support such a mechanism for these mutations (Figure 2). In 2001, Saleem et al reported a luciferase assay to measure FOXC1 transactivational activity, and we used the same method, since it also works for FOXC2 ${ }^{5}$. Our results (Figure 1) suggest that R121C and S125L both decrease transcriptional activity, which is consistent with earlier findings for mutations $\mathrm{R} 121 \mathrm{H}$ and $\mathrm{S} 125 \mathrm{~L}{ }^{6}$. To our surprise, the four other mutations, which were located well outside of the forkhead domain, consistently increased transactivation. Because the mutations were associated with a clear phenotype and were not found in control samples, we consider this finding to be proof of pathogenicity. Interestingly, it contrasts with previous assertions to the effect that mutations in FOXC2 cause disease by haplo-insufficiency. However, a gain-of-function may well be just as deleterious, considering that FOXC2 is likely involved in determining the balance between promoting and inhibiting factors of lymph vessel growth ${ }^{4}$. Since FOXC2 +/- mice show lymphatic hyperplasia, our patients would be expected to have hypoplasia. This can be demonstrated in living patients with lymphangiography. Alternatively, lymphoscintigraphy may demonstrate increased lymph pathways ${ }^{7}$. A lymphoscintigraphy was performed in one of our patients, which revealed a lack of uptake of the radiopharmacon several hours after injection. This finding could be consistent with hypoplasia (Figure 3).

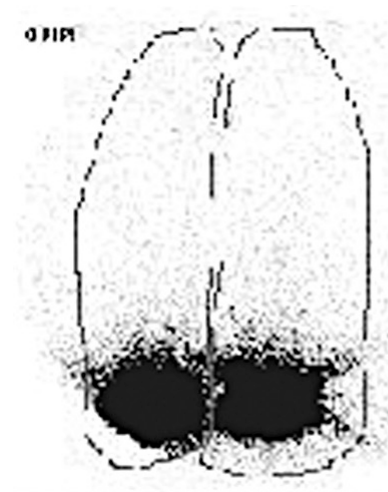

1 STRTIC

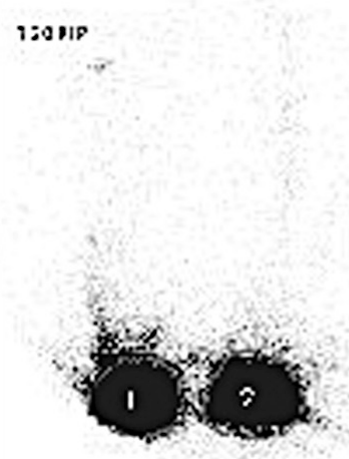

2 STATIC

Figure 3. Qualitative lymphoscintigraphy of patient 4 showing (left) the label in both feet directly after injection and (right) its retention there after two hours, indicating a lack of lymphatic transport. 
In contrast, the dermal backflow is typical for lymphedema-distichiasis syndrome ${ }^{7}$. A previous report clearly demonstrates, also by lymphangiography, increased lymph conducting pathways in several patients with a loss-of-function mutation ${ }^{7}$. It would be of considerable interest for future research to systematically perform lymphoscintigraphy or perhaps, if feasible, lymphangiography in patients with activating versus inactivating mutations in order to search for genotype-phenotype correlations. It is tempting to speculate that the activating mutations may represent a subset of Meige type lymphedema, where the lymphatic system is hypoplastic and dermal backflow is not seen, in contrast to lymphedema-distichiasis syndrome. Distichiasis was not seen in these patients and may have been absent, rather than overlooked. Meanwhile, it is not clear how mutations outside of the forkhead domain can cause increased transactivation. One might speculate that they cause the protein to interact more stably with DNA than its wild type counterpart.

\section{CONCLUSION}

Apart from five novel truncating mutations, we found five novel missense mutations in the FOXC2 gene in patients with primary lymphedema and demonstrated that four of those, which were located outside the forkhead domain, increase FOXC2 transcriptional activity in a luciferase assay. Hence, our results suggest that mutations in FOXC2 can also cause lymphedema by a dominant negative mechanism, which could possibly result in a decrease in lymph conducting pathways. Patients with such mutations may represent a subset of Meige type lymphedema. 


\section{REFERENCES}

1 Cheville AL, McGarvey CL, Petrek JA, et al. Lymphedema management. Semin Radiat Oncol. 2003;13(3):290-301

2 Karpanen T, Alitalo K. Molecular biology and pathology of lymphangiogenesis. Annu Rev Pathol. 2008;3:367-97

3 Vreeburg M, Heitink MV, Damstra RJ, et al. Lymphedema-distichiasis syndrome: a distinct type of primary lymphedema caused by mutations in the FOXC2 gene. Int J Dermatol. 2008;47 Suppl 1:52-5

4 Kriederman BM, Myloyde TL, Witte MH, et al. FOXC2 haploinsufficient mice are a model for human autosomal dominant lymphedema-distichiasis syndrome. Hum Mol Genet. 2003;12(10):1179-85

5 Saleem RA, Banerjee-Basu S, Berry FB, et al. Analyses of the effects that disease-causing missense mutations have on the structure and function of the winged-helix protein FOXC1. Am J Hum Genet. 2001;68(3):627-41

6 Berry FB, Tamimi Y, Carle MV, et al. The establishment of a predictive mutational model of the forkhead domain through the analyses of FOXC2 missense mutations identified in patients with hereditary lymphedema with distichiasis. Hum Mol Genet. 2005;14(18):2619-27

7 Brice G, Mansour S, Bell R, et al. Analysis of the phenotypic abnormalities in lymphoedemadistichiasis syndrome in 74 patients with FOXC2 mutations or linkage to 16q24. J Med Genet. 2002;39(7):478-83 


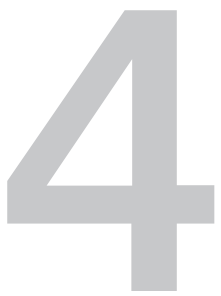

\title{
Erysipelas as a Sign of Subclinical Primary Lymphedema: A Prospective Quantitative Scintigraphic Study of $\mathbf{4 0}$ Patients with Unilateral Erysipelas of the Leg
}

\author{
R.J. Damstra, $M D$ \\ M.A.M. van Steensel, $M D P h D^{7}$ \\ J.H.B. Boomsma, $M D P h D^{2}$ \\ P. Nelemans, $M D P h D^{3}$ \\ J.C.J.M Veraart, $M D P h D^{1}$
}

'Department of Dermatology, University Medical Center Maastricht,

The Netherlands

2Department of Radiology and Nuclear Medicine, Nij Smellighe Hospital, Drachten,

The Netherlands

${ }^{3}$ Department of Epidemiology, Maastricht University, The Netherlands 


\section{ABSTRACT}

Background: Erysipelas is a common skin infection that is usually caused by ß-hemolytic streptococci group A. After having had erysipelas in an extremity, a significant percentage of patients develops persistent swelling or suffers from recurrent erysipelas. We hypothesize that in cases of erysipelas without a clear precipitating agent, subclinical pre-existing congenital or acquired disturbances in the function of the lymphatic system are present. The persistent swelling after erysipelas is then most likely caused by lymphedema.

Objectives: We designed a study to examine if erysipelas of unknown origin is associated with a preexistent insufficiency of the lymphatic system. If our hypothesis is correct, patients with erysipelas of unknown cause without previously evident lymphedema should have evidence of disturbed lymphatic transport in the unaffected extremity.

Methods: A prospective study, in which lymphoscintigraphy of both legs was performed in patients 4 months after_presenting with a episode of erysipelas only in one of both leg. No patient had any known risk factor for erysipelas, such as diabetes mellitus, chronic venous insufficiency or clinical signs of lymphedema.

Lymphoscintigraphy was performed in 40 patients by subcutaneous injection of Technetium$99 \mathrm{~m}$-labelled human serum albumin in the first web space of both feet. After 30 and 120 minutes, quantitative and qualitative scans were performed using a computerized gamma camera. During the lymphoscintigraphy, the patients performed a standardized exercise program. Lymph drainage was quantified as the percentage uptake of Tc-99m-labelled human serum albumin in the groin nodes at two hours after injection. Groin uptake of less than $15 \%$ is pathological; uptake between $15-20 \%$ is defined as borderline, and an uptake of more than $20 \%$ as normal.

Results: The mean \pm SD percentage uptake in the groin nodes in the affected limbs was $9.6 \% \pm$ $8.5 \%$ versus $12.1 \% \pm 8.9 \%$ in the nonaffected limbs. The mean paired difference in uptake between nonaffected versus affected side was $2.5 \%$ (95\% confidence interval $1.1 \%$ to $3.9 \%$ ). This indicates that lymphatic drainage in the nonaffected limb was only slightly better than in the affected limb despite the infectious event in the latter. Of 33 patients with objective impairment of lymph drainage in the affected limb, 26 patients (79\%) also had impaired lymph drainage in the nonaffected limb. Agreement in qualitative measurements between affected and nonaffected leg was less pronounced: 21 patients had abnormal qualitative results in the affected leg of which 9 had also impairment of the nonaffected leg (43\%).

Conclusions: Erysipelas is often presumed to be purely infectious in origin, with a high rate of recurrence and a risk of persistent swelling due to secondary lymphedema. In this study, we show that patients presenting with a first episode of erysipelas often have signs of pre-existing lymphatic impairment in the other clinically nonaffected leg. This means that subclinical lymphatic dysfunction of both legs may be an important predisposing factor. Therefore, we recommend that treatment of erysipelas should focus not only on the infection but also on the lymphological aspects and that longstanding treatment for lymphedema is essential in order to prevent recurrence of erysipelas and aggravation of the pre-existing lymphatic impairment. Our study may change the clinical and therapeutical approach to erysipelas as well as our understanding of its aetiology. 


\section{INTRODUCTION}

Erysipelas is a common superficial skin infection with lymphatic involvement and swelling that often persists after resolution of the infection. Streptococcus pyogenes or ß-hemolytic Streptococci of group A are the major causative agents, but Staphylococcus aureus can also be involved. In erysipelas, erythema and swelling are usually sharply demarcated from intact skin. It usually affects the legs, less frequently the face ${ }^{1}$ or arms.

The most common known local risk factors for erysipelas are venous insufficiency, previous or current local injury, fungal skin infections and lymphedema ${ }^{2,3,4}$. Systemic risk factors for erysipelas include diabetes mellitus, obesity, immunosuppression, upper respiratory tract infection and alcoholism ${ }^{5}$.

The clinical signs of lymphedema are pitting and/or non-pitting oedema and a positive Stemmer sign (thickening of the interdigital web space between the second and third toes). In long-standing edema, the skin shows papillomatous thickening. Fluid-filled "blebs" can develop and there is an increased risk of lymphangiosarcoma ${ }^{6}$. Lymphedema is caused by accumulation of protein-rich interstitial fluid due to a deficient capacity for lymphatic fluid transport ${ }^{7}$.

The lymphatic system is not only essential for the maintenance of the interstitial fluid balance, but also has an important immunological function. Therefore, impairment of the lymph system will also lead to a dysfunctioning immunological respons ${ }^{8}$. Lymphedema can be either primary or secondary. The former type is defined as genetically determined dysfunction, malformation or hypoplasia of the lymphatic circulation, and the latter as disruption of previously normal lymphatic circulation, for example due to infection or surgical procedures. De Godoy et al..$^{9}$ estimated that $77 \%$ of patients who have had 2 or more episodes of erysipelas has scintigraphic abnormalities correlating with lymphatic impairment.

We hypothesized that these patients will often have pre-existing primary subclinical lymphedema, which can also explain the high rate of recurrences. Our hypothesis predicts that patients with erysipelas will have a significantly higher incidence of lymphatic impairment in the nonaffected leg than the general population.

To test our idea, we set up the present study to look for an existing, bilateral lymphatic impairment in the legs without signs of lymphedema in patients with a first episode of 
unilateral erysipelas.

\section{MATERIALS AND METHODS}

\section{Study design and population}

The study was conducted at Nij Smellinghe hospital in Drachten, the Netherlands, from 1999 to 2006. The protocol performed is part of the routine practice for patients with erysipelas in our hospital. The study population consisted of 40 patients (28 men, 12 women) who were hospitalized because of one-sided erysipelas of the lower leg and who met the inclusion criterion. All patients were treated with intravenous antibiotics, wet wrap for the first days, compression therapy and compression hosiery for 4 months after discharge from the hospital. In addition, lymphoscintigraphy was performed.

\section{Inclusion and exclusion criteria}

The inclusion criterion for this study was a history of one to three episodes of unilateral erysipelas in one leg. The diagnosis of erysipelas was based on the presence of the following: acute onset of sharply demarcated erythema, swelling of and pain in one leg and fever $\left(>38.5^{\circ} \mathrm{C}\right)$.

Excluded were patients with known risk factors for erysipelas, such as clinically evident lymphedema, chronic venous insufficiency, pressure ulcers, diabetes mellitus, obesity $\left(\mathrm{BMl}>30 \mathrm{~kg} \mathrm{~m}^{-2}\right)$ or other skin diseases affecting the legs. Venous duplex ultrasonography was performed on all patients to exclude venous insufficiency.

\section{Data collection and lymphoscintigraphy}

The investigator completed a history and examined both legs. At 4 months after hospitalisation, a qualitative and quantitative lymphoscintigraphy was performed. We used Tc-99m-labelled human serum albumin microcolloid particles. The colloid size ( $95 \%$ of the particles have a diameter of $<80 \mathrm{~nm}$ ) is reproducible. The rapid clearance from the injection site makes the colloid suitable for quantitative studies, and injections are painless ${ }^{10,11,12}$. Uptake of radioisotope in the groin lymph nodes as measured by lymphoscintigraphy was used as indicator of the degree of lymphatic drainage. 


\section{Protocol}

In order to perform a reliable and reproducible quantitative lymphoscintigraphy, we used a standardized protocol: $40 \mathrm{MBq}$ per injection is administered subcutaneously in the web space between the first and second and the second and third digits of the foot. A second $40 \mathrm{MBq}$ dose is administrated in the contralateral foot. Images are recorded with a dualdetector gamma camera (SKY Light ${ }^{\circledR}$, Philips, Eindhoven, the Netherlands)

After injection, the first recording phase is static and the activity in the feet is monitored. Then the patient walks on a standardized treadmill (20 times; Buffalo mini Stepper ${ }^{\circledast}$; Quelle, Fürth, Germany) to give maximal stimulation of initial lymphatic transport. In the second dynamic phase, time-activity curves are performed during 30 minutes for both groins when the patient is placed in supine position between the dual-detector cameras. During the next static phase, the entire body area below the diaphragm is visualized. Then the patient is asked to walk at a brisk pace for 60 minutes without getting exhausted. The last recording phase is performed in the same way as the former.

Uptake percentages of the radioisotope in the groin lymph nodes and the clearance of the injection side on the feet are measured with the gamma camera. Qualitative and quantitative parameters are measured.

\section{Qualitative and quantitative assessment of the results}

Lymphoscintigraphy offers objective evidence to distinguish (late-stage) lymphatic pathology from non-lymphatic causes of peripheral oedema. Criteria for lymphatic dysfunction include delay (> $30 \mathrm{~min}$ ), asymmetric or absent visualization of regional lymph nodes, and the presence of "dermal backflow". Additional findings include asymmetric visualization of lymphatic channels (normally three to five vessels per calf and one to two vessels per thigh) and collateral lymphatic channels. All these parameters are correlated to a clinical diagnosed lymphedema ${ }^{13,14}$. We scored for six criteria as pathological signs of lymphatic impairment:

P1. Absence of radiotracer transport from the injecting side

P2. Delayed or absent flow after 30 minutes (proximal uptake vessels / groin within 30 $\min$ )

P3. Paucity or hypoplastic lymph vessels or absence of regional lymph nodes (normally three to five vessels per calf and one to two vessels per thigh) 
P4. Collateral vessels.

P5. Hyperplastic or ectatic lymph vessels

P6. Lymphatic leaks and dermal backflow

Interpretation of qualitative lymphoscintigraphy is highly subjective and it is difficult to quantify. Careful attention to technical performance and image evaluation is essential. It can help to distinguish between swelling of venous and lymphatic origin and may demonstrate an underlying lymphatic system abnormality ${ }^{14}$. We judged a qualitative lymphoscintigraphy pathological if one or more pathological signs were present (P1-P6).

Qualitative and quantitative lymphoscintigraphy results are usually in agreement. However, quantitative assessment can detect a reduction in lymphatic drainage capacity before clinical or qualitative lymphoscintigraphic signs appear. Quantitative analysis may thus increase the sensitivity and specificity of the lymphoscintigraphy in the early diagnosis of lymphatic disorders ${ }^{15}$.

In our protocol we measured uptake of radioisotope in the groin lymph nodes at $2 \mathrm{~h}$ in a standardized region of interest (ROI). When uptake in the ROI is less than $15 \%$, there is a clear shortage of lymphatic drainage. An uptake between $15-20 \%$ is defined as borderline, and an uptake of more than $20 \%$ as normal ${ }^{16}$. These data were confirmed by 20 scintigraphies in healthy control persons. These controls underwent the same lymphoscintigraphy protocol and where comparable for age and gender. Clearance of radioisotope from the foot was not taken in account in our study because these values are not reliable and less sensitive for the diagnosis of lymphatic impairment compared to uptake percentages of the lymph nodes $17,18,19$.

\section{Statistical analysis}

The limb in which the diagnosis of erysipelas was made will be referred to as the affected limb, and the limb without erysipelas will be referred to as the nonaffected limb. The mean percentage uptake of Tc-99m-labelled human serum albumin in the groin lymph nodes in the affected limb, was compared with the uptake in the unaffected limb and the mean paired difference was tested using the t-test for paired samples. The correlation between the uptakes in the groin nodes in both legs was evaluated using Spearman's correlation coefficient. In additional analyses, both the affected and nonaffected leg were assigned to 
categories according to percentage of uptake in the groin lymph nodes. In these analyses, impaired lymph drainage was defined as an uptake of $<15 \%$, whereas an uptake between $15 \%$ and $20 \%$ was considered to be borderline and an uptake of $>20 \%$ as normal. Using cross-tabulation we evaluated in which proportion of patients both the affected and nonaffected leg were impaired. All analyses were performed in SPSS (Chicago, IL, USA) and $p$-values $<0.05$ were considered statistically significant.

\section{RESULTS}

Forty patients (28 male and 12 female) were included in our study. Their mean age was 39.3 year (11 - 66). A complete lymphatic investigation was performed in all patients. Main clinical characteristics are presented in Table 1.

Table 1. Patient demographics and clinical characteristics

\begin{tabular}{ll}
\hline Mean age & 39.3 years (11-66) \\
\hline Gender & Male: 28 female: 12 \\
Affected side (left / right) & $21 / 19$ \\
One episode of erysipelas (\%) & $32 / 40(80 \%)$ \\
Two or three episodes (\%) & $8 / 40(20 \%)$ \\
Mean uptake groin after 2 hours: & $9.55 \%(\mathrm{sd}: 8.52)$ \\
Affected side & $12.07 \%(\mathrm{sd}: 8.89)$ \\
Non affected side & \\
\hline
\end{tabular}

The mean \pm SD percentage of uptake in the groin lymph nodes in the affected limbs was $9.6 \%( \pm 8.5)$ versus $12.1 \%( \pm 8.9)$ in the nonaffected limbs. The mean paired difference in uptake between nonaffected vs affected side was $2.5 \%$ (95\% confidence interval (CI) $1.1 \%$ to $3.9 \%)$. This indicates that lymphatic drainage in the nonaffected limb was only slightly better than in the affected limb, despite the infectious event in one of them.

There was a strong and significant correlation between percentage uptake in both legs as indicated by the Spearman's correlation coefficient, which was $r=0.81 \quad(p<0.001)$. The high and statistically significant Spearman's correlation coefficient implies that the hypothesis that there is no correlation between the two groups can be rejected. Also, in the nonaffected legs there are already signs of a disturbed lymphatic drainage which was probably pre-existing before the erysipelas. 
Figure 1 shows a graphical representation of the relation between the affected and the nonaffected limb. The percentage uptake of the injected radiopharmaceutical in the inguinal regions in the affected limb is plotted on the $X$-axis against the percentage uptake in the nonaffected limb on the Y-axis. The plot clearly shows that the uptake percentage in the nonaffected leg decreases when the uptake percentage of the affected limb decreases. Finally, lymph drainage in both limbs was assigned to one of three categories: impaired (uptake < 15\%), borderline (uptake 15-20\%) or normal (uptake >20\%).

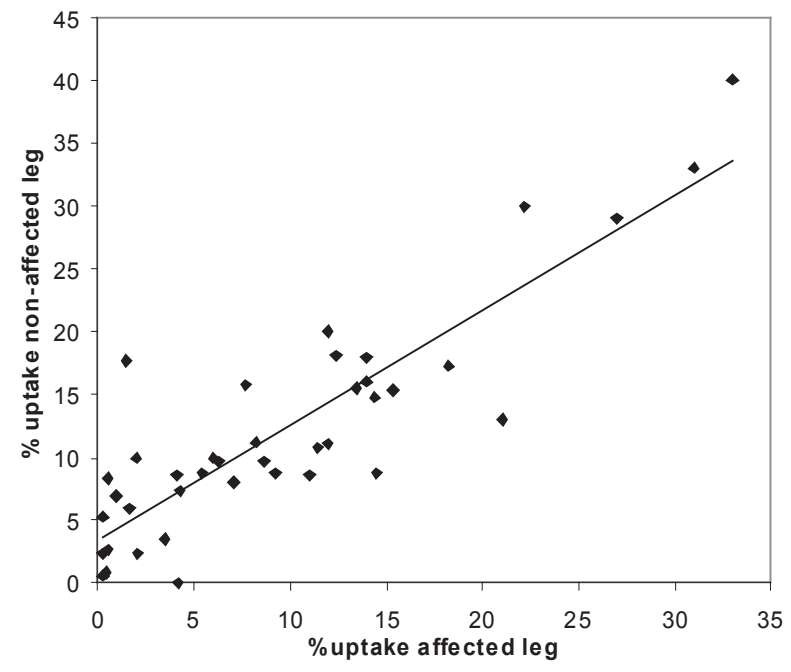

Figure 1: Relation between scintigraphic uptake in affected and nonaffected leg in patients with unilateralerysipelas $(n=40)$, showing a good correlation between both values $(r=0.81, p<0,001)$

The cross-table (table 2) shows that there is strong agreement between both limbs: lymph drainage in 33 of 40 (83\%) affected limbs was categorized as 'impaired' and in 26 of these 33 (79\%) patients the nonaffected limb also falls into this category. According to qualitative measurements, abnormal results indicative of lymph drainage

Table 2. Agreement between quantitative measurements in the affected and nonaffected limbs. Lymph drainage was categorized into one of three categories: impaired (uptake < 15\%), borderline (uptake 15-20\%) or normal (uptake $>20 \%$ ).

\begin{tabular}{lllll}
\hline & $\begin{array}{l}\text { Affected leg } \\
\text { uptake }<15 \%\end{array}$ & $\begin{array}{l}\text { Affected leg } \\
15 \%-20 \%\end{array}$ & $\begin{array}{l}\text { Affected leg } \\
>20 \%\end{array}$ & Total \\
\hline $\begin{array}{l}\text { Nonaffected leg } \\
<15 \%\end{array}$ & 26 & 0 & 1 & 27 \\
$\begin{array}{l}\text { Nonaffected leg } \\
15 \%-20 \%\end{array}$ & 7 & 2 & 0 & 9 \\
$\begin{array}{l}\text { Nonaffected leg } \\
>20 \%\end{array}$ & 0 & 0 & 4 & 4 \\
Total & 33 & 2 & 5 & 40 \\
\hline
\end{tabular}


Table 3. Agreement between qualitative measurements (normal vs pathological) in the affected and nonaffected limbs

\begin{tabular}{llll}
\hline & Affected leg Normal & $\begin{array}{l}\text { Affected leg } \\
\text { Pathological }\end{array}$ & Total \\
\hline Nonaffected leg normal & 16 & 12 & 28 \\
Nonaffected leg pathological & 3 & 9 & 12 \\
Total & 19 & 21 & 40 \\
\hline
\end{tabular}

impairment were observed in only 21 of 40 (53\%) affected legs. Of these 21 patients, just nine (43\%) showed qualitative pathology in the nonaffected leg. (Table 3). So the agreement in qualitative measurements between the affected and nonaffected leg was less pronounced than that in quantitative measurements.

\section{DISCUSSION}

For a long time, erysipelas has been considered as a purely infectious disease generally caused by Streptococci group $A$ and which should be treated with antibiotics. No attention was paid to underlying diseases of the lymphatics. In many studies, it was suggested that the presence of fungal infections is an important predisposing factor for the development of erysipelas $\mathrm{s}^{20,21,22,23,23}$. From a dermatological point of view, however, fungal infections and dermatosis of the feet are very common while erysipelas in these patients is not frequent at all. For example, in the Achilles project ${ }^{24}, 13486$ patients visiting a dermatologist were studied and $58 \%$ had foot diseases, independent of their presenting medical complaints. Thus, we hypothesized that there must be other predisposing factors. In 1987 Stöberl et al. ${ }^{25}$ studied retrospectively 16 patients with erysipelas of the legs. In 11 patients the infection was one-sided and by using indirect lymphography they showed in 6 patients signs of bilateral abnormalities. They wonder if initial lymphatic impairment could contribute to the cause of the erysipelas.

The recurrence rate of erysipelas is high, up to $30-54 \% \%^{26,27}$ after 2 years. Leclerc et al. ${ }^{28}$ presented 47 patients with recurrent erysipelas, 55,3\% of whom had persistent swelling and $29,8 \%$ local trauma / surgery preceding their erysipelas. He concluded that $76,6 \%$ had venous and / or pure lymphatic insufficiencies. Leclerc et al. concluded that antibiotic prophylaxis is indicated for recurrent erysipelas but did not address treatment of the lymphedema. In a recent study, $\operatorname{Cox}^{29}$ studied 171 patients with erysipelas and showed 
a $47 \%$ recurrence rate and $46 \%$ development of manifest oedema over a period of 3 years. They concluded that oedema is significantly correlated with erysipelas $(P<$ 0,0002). These results might also be interpreted to mean that several patients had preexisting lymphedema and developed permanent swelling due to clinical lymphedema. Björnsdóttir et al. ${ }^{3}$ mentioned two study groups (mean age of 66.5 years) in which $56 \%$ of the 100 patients with erysipelas had swelling, compared to a control group of 200 persons, of whom $66 \%$ had swelling as well (odds ratio 2,65, 95\% Cl 1.59-4.42). These figures support the idea that swelling in itself is not the issue, but that the swelling in erysipelas has a lymphatic origin. Vignes and Dupuy ${ }^{30}$, in 48 patients with breast cancerrelated lymphedema, demonstrated a recurrence rate of up to $26 \%$ after 1 year, despite the use of prophylactic antibiotics. Although there was a large variation in the severity of the edema, the amount of edema was no indicator for the risk of recurrence. Local immunological impairment can be a major factor in the risk of recurrent erysipelas. Mallon et al. ${ }^{31}$ showed disturbances in efferent as well as afferent immunological pathways in patients with breast cancer-related lymphedema. In none of the studies is the possibility discussed that locoregional sensitivity for erysipelas can be related to lymphological disturbances such as primary (subclinical) lymphedema.

However, a recent study by Brorson et al. showed that prolonged use of adequate elastic stockings leads to a dramatic reduction of the recurrence rate ${ }^{32}$. Our own findings support this observation by showing that pre-existing lymphedema is a significant risk factor for erysipelas. Logically then, prevention of post-erysipelas lymphedema by compression will reduce recurrence rates.

Quantitative lymphoscintigraphy is a non-invasive, effective and safe technique to determine the functional status of peripheral lymphatic vessels. It does not differentiate between primary and secondary lymphedema, but enables the physician to show functional deficits of the lymph transport capacity before the appearance of morphological clinical features, which will eventually occur such as non pitting edema, suprafacial fibrosis and epidermal changes. The literature provides little useful information about normal radioisotope uptake parameters by a sufficient lymph transport system.

The protocol in this study was designed according to recommendations published by the Duch Society of Nuclear Medicine ${ }^{16}$. We used a standardized lymphoscintigraphy protocol in which 20 healthy persons (20- 35 years; no erysipelas or any other exclusion 
criteria, symmetrical gender distribution) were investigated to confirm the cut-off point of maximal uptake in the groin at 2 hours mentioned in this guideline. All patients showed symmetrical uptake values between 20 and 25\% after two hours (M.J. de Haas, unpublished data). We realise that these figures have a variation according to the camera equipment and radioisotope used, the method used and some biometric figures. The percentages can therefore differ between hospitals according to the use of different protocols.

In our group 90\% (36/40) of patients with an episode of unilateral erysipelas also had demonstrable lymphatic disorders of the contralateral, nonaffected leg on quantitative lymphoscintigraphic examination when using a cut-off point of uptake $>20 \%$. When lowering the cut-off point to $15 \%, 68 \%$ (27/40) still had objective impairment of the lymphatic system in the nonaffected leg. This implies that a significant number of patients, even without previously manifest swelling of signs of lymphedema, have scintigraphic outcomes suggestive for a clinically compensated primary lymphedema, that predisposes to erysipelas.

The results of our qualitative measurements show that the agreement in qualitative measurement between the affected and nonaffected leg was less pronounced when compared with the agreement in quantitative measurements. Moreover, when performing qualitative lymphoscintigraphy, the affected leg was less often diagnosed as having deficient lymph drainage. An explanation for these findings may be that qualitative lymphoscintigraphy cannot detect minor defects in lymphatic transport and is more accurate when there are already clinical signs of lymphedema. On the other hand, abnormal scintigraphic features such as dermal backflow, anatomical changes or absence of lymph nodes would not be expected in patients without clinical signs of lymphedema.

Because erysipelas is an acute infection spread in the suprafascial compartment by lymph vessels, post-infectious lymphatic impairment can be expected. The results of this study strongly suggest that initial lymphatic impairment already exists before the erysipelas occurs. There, we recommend that, after the initial antibacterial treatment of erysipelas, all patients should follow a lymphological therapy protocol including compression, skincare and garments in order to prevent development of significant lymphedema and recurrence, which has been reported so frequently after erysipelas. 


\section{CONCLUSION}

The causative role of lymphatic dysfunction in erysipelas has long been neglected. We show that bilateral impaired lymphatic drainage is strongly correlated with an episode of unilateral erysipelas, and therefore is likely to constitute an important, independent risk factor that may be responsible for the high recurrences rates observed by erysipelas. In support of this notion, we demonstrate significant lymphatic impairment in the affected leg as well in the nonaffected, clinically normal leg in patients with one-sided erysipelas. Quantitative lymphoscintigraphy seems best suited to diagnose lymphatic impairment in these pre-clinical stages, in which a qualitative lymphoscintigraphy would not show any defects.

Consequently, treatment of erysipelas should address not only the infection itself but also the underlying lymphological impairment. We recommend that any therapeutic regimen include compression therapy and that patients be fitted with compression hosiery after completion of the initial therapy as is done in lymphedema treatment. When erysipelas recurs, or occurs without any obvious risk factor such as chronic venous insufficiency, diabetes, or pre-exsisting clinically evident edema, the diagnosis of primary lymphedema should be strongly considered and further investigated. 


\section{REFERENCES}

1 Mandell RG, Douglas Jr and Bennett JE. Principles and practice of infectious diseases (5th ed), Churchill Livingstone, New York 2000;1041-43

2 Jorup-Ronstrom C. Epidemiological, bacteriological and complicating features of erysipelas. Scand J Infect Dis. 1986; 18: 519-24

3 Björnsdóttir S, Gottfredsson M, Thórisdóttir AS, Gunnarsson GB, Rikardsdóttir H et al. , Risk factors for acute cellulitis of the lower limb: a prospective case-control study. Clin Infect Dis. 2005;41:1414-22

4 Vaillant L, Gironet N. Infectious complications of lymphedema. Rev med Interne. 2002Jun;23 (Suppl 3):S403-7

5 Crickx B, Chevron F, Sigal-Nahum M, Bilet S, Faucher F, Picard C, Lazareth I, Belaich S. Erysipelas: epidemiological, clinical and therapeutic data (111 cases). Ann DermatolVenereol. 1991;118:116.

6 Janse AJ, van Coevorden F, Peterse H, Keus RB, van Dongen JA. Lymphedema-induced lymphangiosarcoma Eur J Surg Oncol. 1995 Apr;21(2):155-8.

7 Földi M. Földi E, KubikS. Lehrbuch der Lymphologie. 6th edition. 2005. Elsevier GmbH München ISBN 3-437-45322-X

8 Angeli V, Randolph GJ. Inflammation, lymphatic function, and dendritic cell migration. Lymphat Res Biol. 2006;4(4):217-28

9 De Godoy, JMP, de Godoy MF, Valente A, Camacho EL, Paiva EV. Lymphoscintigraphic evaluation in patients after erysipelas. Lymphology. 2000(33):177-80

10 Nawaz K, Hamad MM, Sadek S, Awdeh M, Ekhof B, Abdel-Dayem HM. Dynamic lymph flow imaging in lymphedema: normal and abnormal pattern. Clin Nucl Med. 1986;11:653-58

11 Ogawa Y, Hayashi K. 99m-Tc-DTPA-HAS lymphoscintigraphy in lymphedema of the lower extremities: diagnostic significance of dynamic study and muscular exercise. Kaku lgaku. 1999;36:31-6

12 Szuba A, Shin WS, Strauss HW, Rockson S, The Third Circulation: Radionuclide Lymphoscintigrphy in the Evaluation of Lymphedema. J Nucl Med. 2003;44(1):43-57

13 Yuan Z, Chen L, Zhu J, Lu H, Zhu R. The role of radionuclide lymphoscintigraphy in extremity lymphedema. Ann Nucl med. 2006; 20(5):341-4

14 Scarsbrook AF, Ganeshan A, Bradley KM. Pearls and pitfalls of radionuclide imaging of the lymphatic system: part 2: evaluation of extremity lymphedema. Br J Radiol. 2007;80(951):21926

15 Weissleder H, Weissleder R. Lymphedema: evaluation of qualitative and quantitative lymphoscintigraphy in 238 patients. Radiology. 1988;167:729-35

16 Dutch Society of Nuclear Medicine. Recommendations in Nuclear Medicine 2007:88-97. ISBN 978-90-78876-01-04

17 Mostbeck A, Partsch H. Isotope lymphography: possibilities and limits in evaluation of lymphtransport. Wien Med Wochenschr. 1999;149:87-91

18 Rijke A, Croft BY, Johnson RA, Jongste AB de, Camps JA. Lymphoscintigraphy and lymphedema of the lower extremities. J Nucl Med. 1990;31:990-8

19 Partsch $\mathrm{H}$. Assessment of abnormal lymph drainage for the diagnosis of lymphedema by isotopic lymphangiography and by indirect lymphography. Clin dermatol. 1995;149:87-91

20 Dupuy A, Benchikhi H, Roujeau JC, Bernard P et al. Risk factors for erysipelas of the leg (cellulitis): case control study. BMJ. 1999;318(7198):1591-4 
21 Bonnetblanc JM, Bédane C. Erysipelas, Recognition and management. Am J Clin dermatol. 2003:4(3):157-63

22 Becq-Giraudon B. L'érysièle: préventio primaire et secondaire. Ann Dermatol Venereol. 2001;128:368-75

23 Lazzarini L, Conti E, Tositti G, de Lalla F. Erysipelas and cellulitis: clinical and microbiological spectrum in an Italian tertiary care hospital. J Infect. 2005;51:383-9

24 Roseeuw D. Achilles fool screening project: preliminary results of patients screened by dermatologists. J Eur acad Dermatol venereol. 1999;12 (suppl 1):S1-6

25 Stöberl C, Partsch H. Erysipel und Lymphödem-ei oder Henne?. Z Hautkr. 1987;62:60-4

26 Jorup-Rönstrom C, Britton S, Gavlevik A et al. The course, cost and complication of oral versus intravenous therapy of erysipelas. Infection. 1984;12:390-4

27 Pavlotsky F, Amrani S, Trau H. Recurrent erysipelas: riskfactors. J Dtsch Dermatol Ges. 2004;2:895

28 Leclerc S, teixeira A, Mahé E, Descamps V, Crickx B, Chosidow O. Recurrent erysipelas: 47 cases. Dermatology. 2007;214(1):52-7

29 Cox NH. Oedema as a risk factor for multiple episodes of cellulitis / erysipelas of the lower leg: a series with community follow-up. Br J Dermatol. 2006:155:947-50

30 Vignes S, Dupuy A. Recurrence of lymphedema-associated cellulitis (erysipelas) under prophylactic antibiotherapy: a retrospective cohort study. J Eur Acad Dermatol. 2006;20:81822

31 Mallon E, Powell S, Mortimer P, Ryan TJ. Evidence for altered cell-mediated immunity in postmastectomy lymphedema Br J Dermatol. 1997 Dec;137(6):928-33

32 Brorson $H$, Svensson H. Skin blood flow of the lymphedematous arm before and after liposuction.Lymphology. 1997; 30: 165-172 


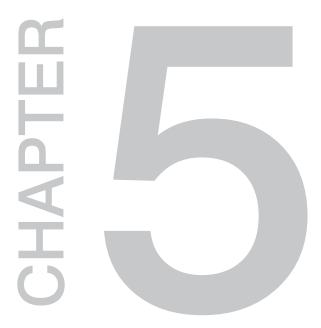

Cancer Related Secondary Lymphedema due to Cutaneous Lymphangitis Carcinomatosa: Clinical Presentations and Review of Literature

R.J. Damstra, MD

E. A. Jagtman'

P.M. Steijlen MD PhD²

${ }^{1}$ Medical student, Nij Smellinghe Hospital, Drachten, The Netherlands ${ }^{2}$ Department of Dermatology, University Medical Center Maastricht, The Netherlands 


\section{ABSTRACT}

Lymphedema is a clinical condition caused by impairment of the lymphatic system, which leads to swelling of subcutaneous soft tissues. As a result, accumulation of protein-rich interstitial fluid and lymphstasis often causes additional swelling, fibrosis and adipose tissue hypertrophy. Lymphedema is a complication frequently encountered in patients treated for cancer, especially after lymphadenoectomy and/or radiotherapy. Although lymphatic impairment is sometimes caused by obstructive solid metastasis, we present three remarkable cases of secondary lymphedema with minor dermatological features without detectable solid metastasis. Histopathological examination of the skin revealed diffuse lymphangitis carcinomatosa, which often leads to lymphedema and adjustment of the therapeutic approach. We reviewed literature on this rare presentation and advise close dermatological examination of minor skin abnormalities in patients with a history of cancer and lymphedema. 


\section{INTRODUCTION}

Lymphedema is a clinical condition marked by localized swelling of subcutaneous soft tissues due to a compromised lymphatic system. Accumulation of proteinrich interstitial fluids and lymph stasis leads to swelling, fibrosis and adipose tissue hypertrophy'. Lymphedema can be distinguished as primary or secondary with the latter form well known as a complication after lymphadenoectomy or radiation treatments. Progressive metastatic disease can cause obstruction of the lymphatic system by direct compression. A less common cause of lymphedema is malignant infiltration of cutaneous lymphatics, sometimes called "malignant lymphedema," which is often accompanied by dermatological abnormalities. In order to focus on malignant infiltration of the lymphatics leading to lymphedema, we will present three cases and discuss the current literature on the subject.

\section{Case report 1}

A 68-year-old woman presented with lymphedema of the breast and a history of breast cancer with axillary lymph node extirpation. Chest X-rays, bone scans and an echo of the abdomen displayed no signs of metastasis. The cancer had been treated with breastconserving surgery supplemented with additional radiotherapy and hormonal therapy. Physical examination showed swelling of the left breast with small, painless erythematous maculae above the sternum. No itching or induration was observed. (Figure 1a,b).

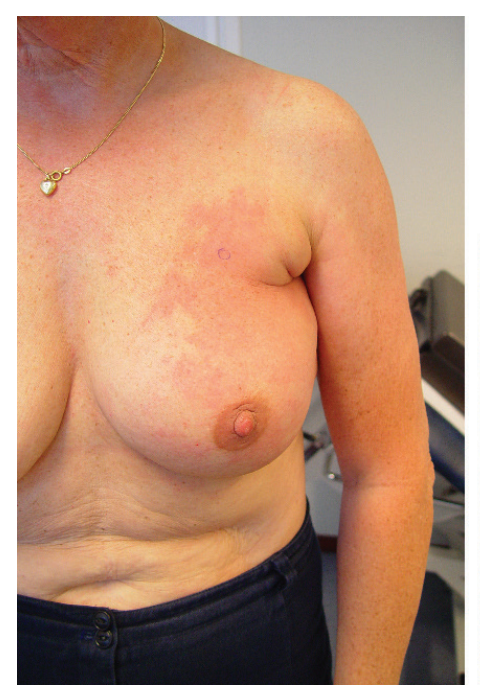

Figure 1a: Erythema and swelling of the breast and arm. The biopsy was taken from the spot marked with blue

b.: Detail 
Histopathological examination was performed on a biopsy at the erythematic site (Figure $1 c, d)$. The biopsy showed normal skin within the underlying dermal cluster of tumor cells located in thin-walled vessels, which appeared to be lymphatic in origin. The tumor cells had vesicular nuclei with a moderate amount of cytoplasm. In the centre of the clusters, necrosis was sometimes seen with occasional mitotic figures. This pattern fit with the clinical diagnosis of lymphangitis carcinomatosa caused by relapse of breast cancer.
c: Vascular permeation of metastatic breast
carcinoma in de skin (Hematoxylin-eosin stain;
original magnification $\times 25$ )

d: detail(x200)
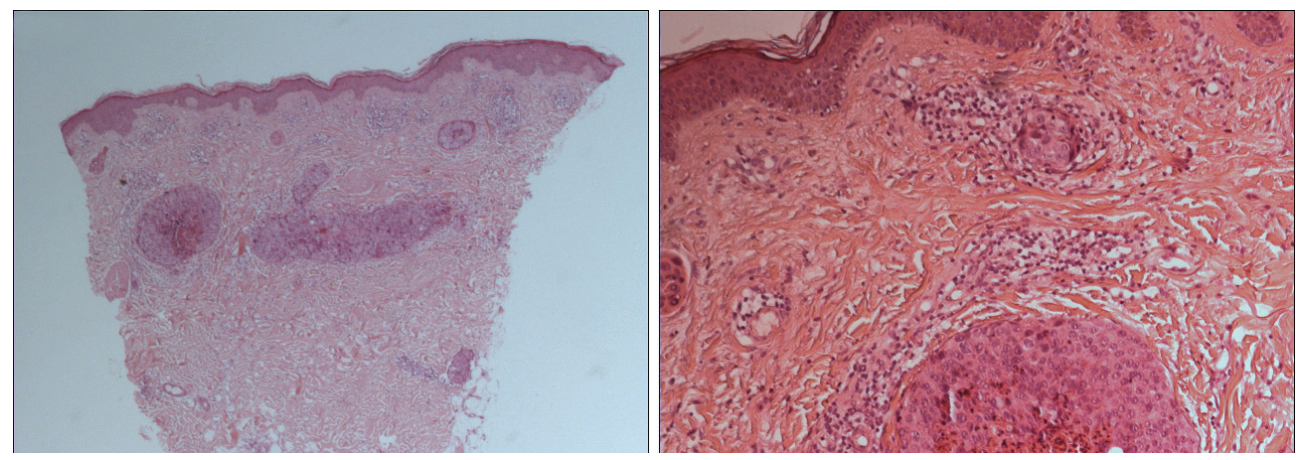

As metastatic breast cancer was diagnosed by dermal lymphatic localization alone, chemotherapy (docetaxel) was reinitiated. Unfortunately, the cancer disseminated to the supraclavicular lymph nodes and the mediastinum after four months. Administration of the capecitabine was started, but was interrupted due to toxicodermia. When pericarditis and pleuritis carcinomatosa developed, docetaxel was initiated again. However, disease progression continued. Concomitantly, lymphedema treatment focussed on skin care, compression therapy and manual lymph drainage. The patient opted out of further chemotherapy treatment, and pain medication was prescribed. The patient was discharged with terminal care and died two years after the initial diagnosis of lymphedema due to lymphangitis carcinomatosa.

\section{Case report 2}

A 73-year-old man was referred with progressive swelling of the right leg that later spread to the midline area. He had a history of squamous cell carcinoma of the upper right leg, which had been radically excised three years prior. 
A concomitant villous adenoma from the sigmoid was diagnosed and treated with sigmoid resection. Because of the small size, the lymphoma in the right groin was also extirpated in the same procedure. A biopsy of the lymphoma revealed squamous cell carcinoma metastasis. Further examination, including PET scans, MRI and CT scans, showed no other solid metastasis in the groin or abdomen. Due to the progressive swelling, a lymphadenectomy procedure was abandoned.

Swelling of the legs, scrotum and penis was observed upon physical examination. Large erythematous maculae were present on the upper right leg, around the pubis and on the left hip (Figure 2a,b). There were no palpable plaques or nodules detected.

Figure 2a: Erythema and lymphedema of the b: Detail scrotum, midline region and upper legs
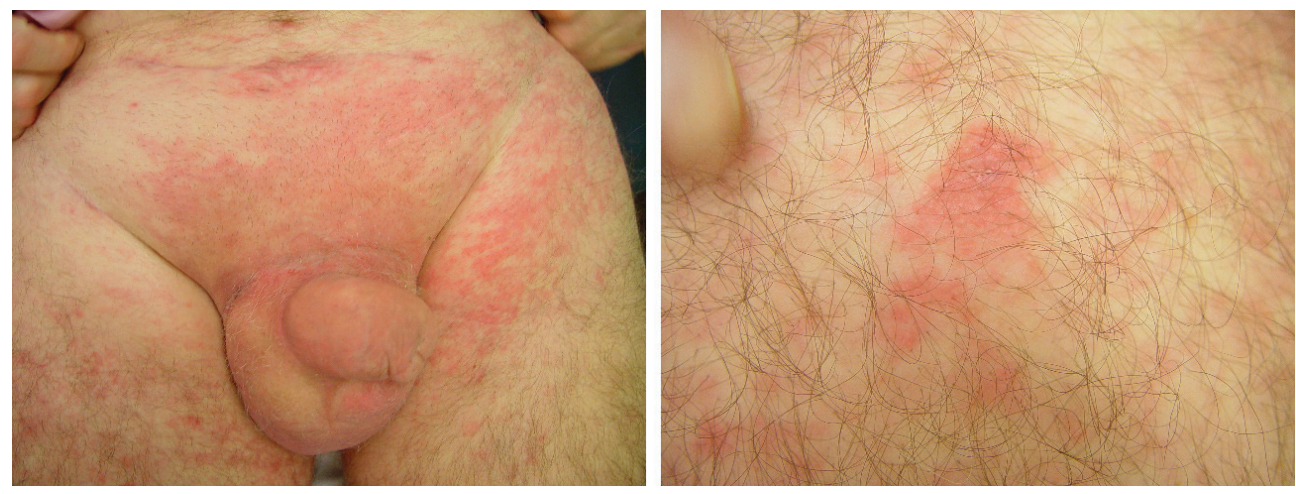

Histopathological examination of the erythematous lesion revealed the presence of tumor cells that had spread into the lymphatics with outgrowth into the surrounding dermis, consistent with metastatic squamous carcinoma (Fig. 2c,d). Revision of the biopsy from the skin, lymph node and the initial tumor showed the same cellular characteristics: Keratin (Ker) 5/6 was positive, but negative for Ker 7/20, Carcino-embryonal Antigen (CEA) and the nuclear tumor suppressor p53.

As metastasis was clearly seen, palliative chemotherapy with carboplatin and etoposide was started. The lymphedema was concomitantly treated in the clinic with compression therapy, manual lymph drainage, physical training and mobilization therapy. After three weeks, the lymphedema of the leg and midline region had decreased, and the patient was released from the hospital in a better condition with tailor made garments and improved quality of life. Chemotherapy was continued. 
c: Metastatic squamous carcinoma partly within lymphvessels (Hematoxylin-eosin stain; original magnification $\times 100$ )

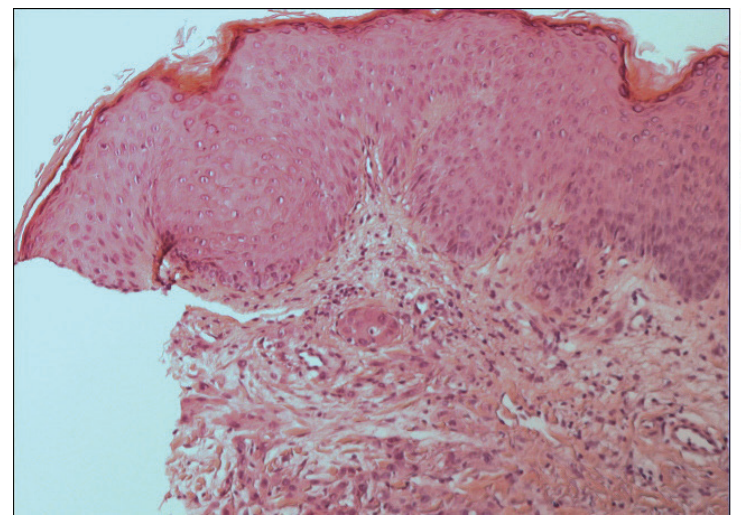

d: Detail of tumorcells (arrow) (x175).

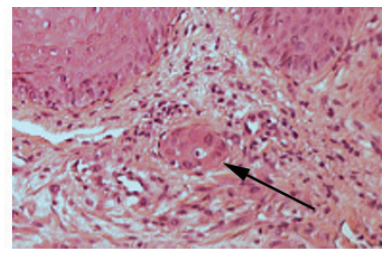

\section{Case report 3}

A 57-year-old woman was sent to our clinic for treatment. She had progressive lymphedema of the legs and a history of ovarian carcinoma with a small liver metastasis diagnosed one year earlier. Initial treatment consists of debulking, lymph node dissection and additional chemotherapy with paclitaxel and carboplatin. Complete clinical remission was achieved. However, the tumor marker CA-125 had been increasing over the following six months, and progressive lymphedema of the left leg had developed. Cytostatic doxorubicin treatment was initiated. Unfortunately, the lymphedema continued to progress, spreading to both legs as well as the midline region. Expression of CA-125 continued to increase up to $149 \mathrm{U} /$ ml. Despite extensive MRI and CT scans of the abdomen and thorax, no tumor localization could be detected. It was considered that the lymphedema was caused by lymphatic impairment after dissection of the Para aortic lymph nodes, since no tumor recurrence could be found. Chemotherapy and radiotherapy were not continued.

Physical examination revealed massive, firm, pitting edema of the legs, abdomen and inguinal area. Discrete but extended erythema was seen in these regions with some minute nodules (Figure 3a,b). The patient used a wheelchair as walking was difficult and painful. 
Figure 3a: Erythema and firm pitting edema

b: Nodule marked with a red circle
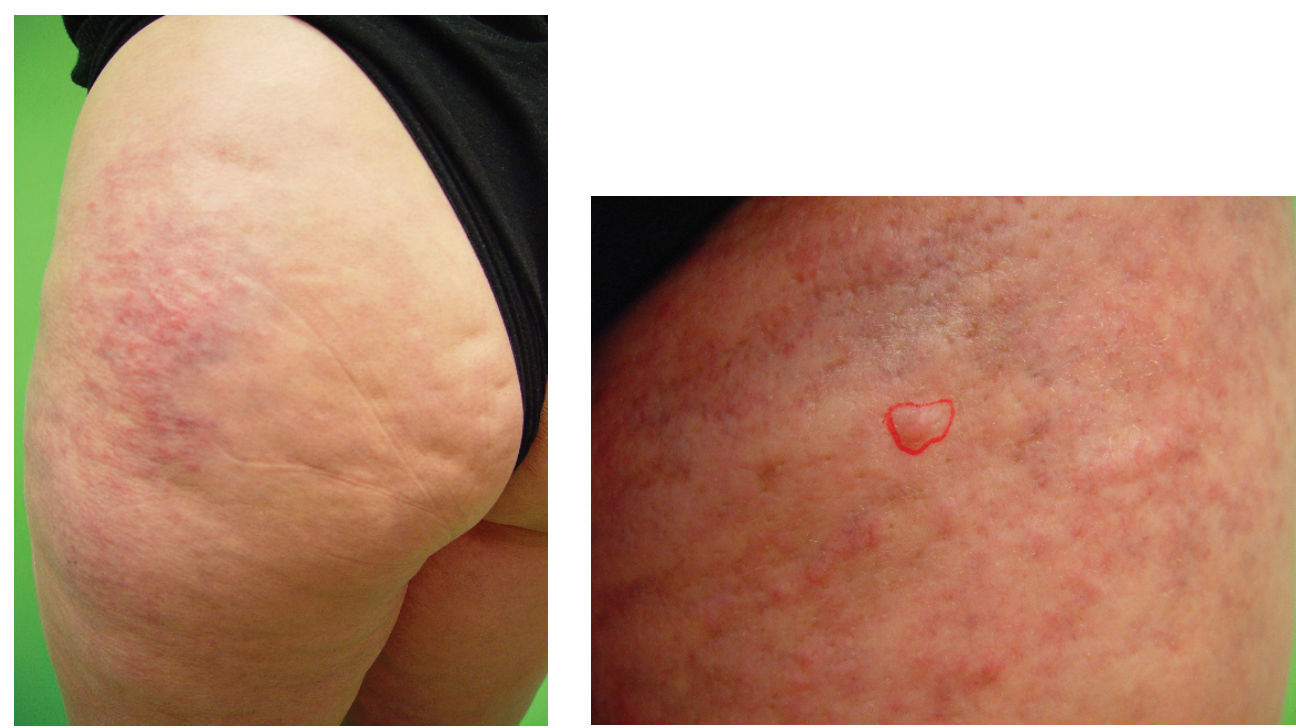

c: Skin ulceration due to massive tumor infiltration 3 months later

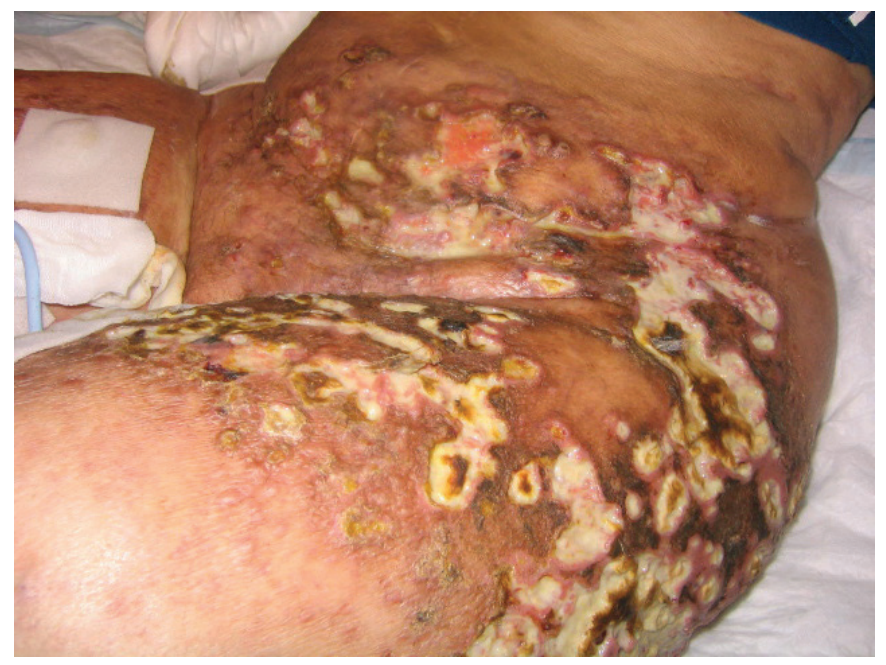

A skin biopsy showed massive proliferation of the carcinoma in the lymphatics and through the interstitial clefts of the dermis (Figure $3 \mathrm{f}, \mathrm{g}$ ). In addition to prominent nucleoli, large vesicular nuclei and abundant cytoplasm, the tumor cells grew in a pattern of atypical tubules in a partly papillary configuration. Morphologically, the tumor cells showed strong similarity to former ovarian carcinoma cells of the patient. These findings were consistent with metastatic serous papillary carcinoma of the ovary with extensive intra-lymphatic infiltration leading to lymphedema. 

d: Massive infiltration of the dermal lymphatics by metastatic ovarian papillary carcinoma
(Hematoxylin-eosin stain; original magnification x200)

e: Detail $(x 400)$
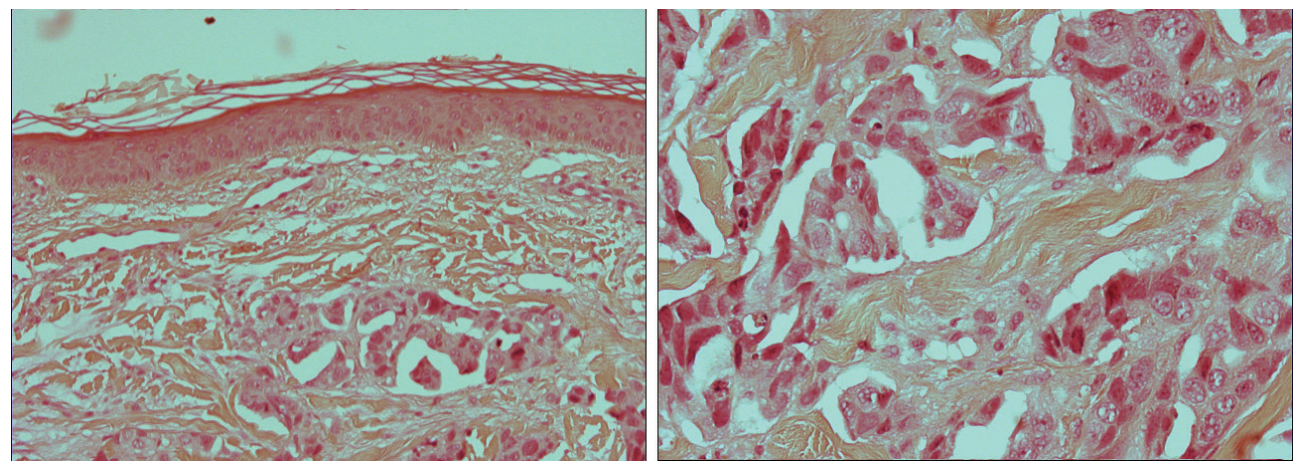

Due to the progressive and therapy-resistant nature of the disease, no additional cancer treatment was initiated. Palliative treatment of the lymphedema was focused on slight compression and oncological wound care at later stages. The patient died four months after the initial diagnosis of cutaneous lymphangitis carcinomatosa (Figure c).

\section{DISCUSSION AND REVIEW OF LITERATURE}

The correlation between lymphedema and cancer treatment is well known. The incidence of breast cancer-related lymphedema could rise up to $20-30 \%$ of all patients treated for breast cancer, depending on the therapeutical modalities applied ${ }^{2}$. After gynecological cancer treatment, the prevalence of lymphedema varies between $10-51 \%$ depending of the type of cancer ${ }^{3}$. In all these cases, the origin of the lymphatic impairment is not described, but is often due to lymphadenectomy with or without radiotherapy. Lymphedema is sometimes caused by obstructive malignant infiltration of the abdominal cavity and the deeper lymphatics or lymph nodes. Secondary lymphedema caused by infiltration of the superficial dermal lymphatics is rare and resembles dermatosis.

Various authors used various terms for malignant cell infiltration of the skin in the literature. We encountered terms such as lymphangitis carcinomatosa, erysipelas carcinomatosa and metastasis cutis. Metastatic skin lesions can clinically resemble erysipelas, which has led to the term erysipelas carcinomatosa, but there is no true infection in this case. True erysipelas is an acute, inflammatory disease of the corium that extends into the subcutis, 
and is caused by group A streptococci, Staphylococcus aureus, and Klebsiella pneumoniae. In America, erysipelas is an acute superficial form of cellulitis (deep skin infection) caused by group A streptococci involving dermal lymph vessels ${ }^{4}$. Metastasis cutis resembles more solid metastasis in the skin. Therefore, we prefer the term lymphangitis carcinomatosa when more disseminated lymphatic spread is present, as in the cases presented here.

The swelling is often incorrectly called malignant lymphedema, raising confusion as the lymphedema itself is not malignant but it is caused by malignant cell infiltration. Histologically, lymphangitis carcinomatosa exhibits extensive dermal and subcutaneous lymphatic invasion by cords of tumor cells ${ }^{5}$, as is demonstrated here. From an etiological point of view, cutaneous lymphangitis carcinomatosa is caused by lymphogenic spread, which is often clinically two-dimensional in the initial phase. In general, metastasis cutis is caused by lymphogenic, hematological spread or per continuum and describes the clinical sign of solid tumor formation, the end stage of lymphangitis carcinomatosa.

When the diagnosis of lymphedema is made in patients previously treated for malignancy, the physician must consider whether recurrence is the cause or lymphedema is a complication of the initial cancer treatment. In $25 \%$ of the patients previously treated for breast cancer and showing lymphedema, this is first sign of local tumor recurrence ${ }^{6}$. Secondary lymphedema due to malignant infiltration should be considered particularly when lymphedema develops quickly, is constantly present, dilated veins are visible and patients are complaining of intolerable, intense pain. This is probably caused by infiltration to the nervous system. The presence of cyanosis and/or dilated veins of the skin as well as necrosis or ulceration arouse suspicion and must be interpreted as potentially indicative of malignancy, sometimes leading to a lymphogenous ulcer ${ }^{2}$.

Secondary lymphedema due to a compromised lymphatic system is usually painless, develops gradually and worsens over time. It is intermittently related to physical exercise and often instigated by erysipelas or overburdening.

In general, cutaneous infiltration by cancer has been reported to occur in $0.7 \%-9 \%$ of all patients with malignant neoplasms $s^{8,9,10}$. A meta-analysis by Krathen et al. ${ }^{11}$ detected an overall incidence of $5.3 \%$. In a study by Marcoval et al. ${ }^{12}$ among cancer patients with skin infiltration, skin involvement was most commonly seen with breast cancer (44\%). Cutaneous infiltration accompanying melanoma was seen in $15.5 \%$ of patients, while skin 
involvement with other types of primary tumors, such as those described in this paper, were much more rare. Skin infiltration accompanying non-melanoma skin cancer and ovarian cancer was encountered in $2.1 \%$ and $1.8 \%$ of cases, respectively.

Cutaneous metastases often present as firm, discrete, reddish nodules. Inflammatory skin metastases occur infrequently compared to other histological patterns and have only been identified with certain tumors. Tumor cells clogging lymph vessels account for capillary congestion and the red and inflamed appearance of the skin. Metastasis cutis, recurring most frequently after breast cancer, exhibits as inflammatory, flat skin metastases in only $1 \%$ of $\operatorname{cases}^{13}$. Tumors associated with other inflammatory skin metastases are anal tumors ${ }^{14}$, lung or bronchial carcinoma ${ }^{15,16}$, melanoma ${ }^{17,18,19}$, gastric cancer ${ }^{20}$, pancreatic carcinoma, rectal carcinoma, ovarian/ cervical carcinoma and parotid gland tumors. However, the presence of lymphedema is often not mentioned in any of these cases. In contrast to true infections, inflammatory skin metastasis lack fever, chills and leucocytosis ${ }^{2}$. Metastasis should therefore be especially suspected in cases displaying signs of lymphedema. There are currently two reports in the literature on secondary lymphedema due to malignancy with itching and an erythematous papuleous reaction mimicking contact dermatitis ${ }^{22,23}$.

Studies have documented various intervals between cutaneous metastases and primary neoplasm's. Although a skin metastasis may be an initial symptom ${ }^{24,25,26}$, most metastatic skin lesions appear after the primary tumor has been diagnosed. When lung carcinoma spreads to the skin, it usually occurs before or concurrently with primary tumor diagnosis. Marcoval et al. ${ }^{10}$ found that cancer patients who did not show cutaneous infiltration at

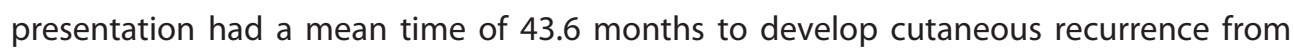
diagnosis of the primary tumor. Cutaneous recurrence after breast cancer tends to appear late (60.3 months), whereas lung carcinoma is the quickest to spread to the skin (15.75 months). Loco-regional post-mastectomy radiotherapy (PMRT) has been demonstrated to improve loco-regional control in patients with breast cancer. The impact of PMRT on survival is less clearly defined. Although the data pertaining to survival with PMRT are less consistent than those pertaining to loco-regional control with PMRT, three extensive trials and meta-analyses have demonstrated that PMRT improves disease-free and overall survival among women treated with systemic therapy ${ }^{27}$. 
Lymphedema is a chronic, incurable disease with variable causes, which needs a life long treatment. Thus after proper diagnosis, the therapeutic goal is to reach a stable state of maximal volume reduction without symptoms and an acceptable quality of life. Treatment of lymphedema consists of complex decongestive therapy (CDT) including a combination of manual lymph drainage, compression therapy with bandages and special stockings, physical training to improve mobility and dermatological skincare ${ }^{4}$.

Lymphedema caused by malignant infiltration is a chronic progressive disease with poor prognosis. Mean survival time is 3 months after diagnosis of cutaneous metastasis ${ }^{9}$. However, early diagnosis can lead to earlier anti-cancer treatments to improve survival. In combination with lymphedema treatment and psychological care, the patient's quality of life can improve and may even influence progression of the disease. Recognizing the cause of lymphedema is important, as suffering from lymphedema leads to morbidity, pain and immobility. Although the prognosis is unfavourable, additional palliative treatment combined with lymphologic treatment can reduce pain and edema by individual adjusted compression. Adequate psychosocial support and terminal care is crucial, particularly at the last stage of the disease.

\section{CONCLUSION}

When the diagnosis of lymphangitis carcinomatosa is initiated at an early stage, the patient's quality of life and disease prognosis can be positively influenced. Thus, early recognition of disease aetiology of local swelling in combination with (minor) dermatological features is essential. When confronted with lymphedema in patients previously treated for cancer, the physician should always consider if the origin of lymphedema is malignant recurrence, and close dermatological examination should be performed. Our case reports show that awareness of lymphedema is not enough, as lymphedema caused by malignant infiltration had not been considered. Therefore, we recommend consulting a dermatologist when discrete skin changes are seen in patients with a history of cancer and lymphedema. Additional dermatologic examination is invaluable for proper diagnosis of lymphedema origin and oncological treatment regime for lymphedema. 


\section{REFERENCES}

1 Warren AG, Brorson H, Borud LJ, Slavin SA. Lymphedema: a comprehensive review. Ann Plast Surg. 2007;59(4):464-72

2 Williams AF, Franks PJ, Moffatt CJ. Lymphoedema: estimating the size of the problem. Palliat Med. 2005;19(4):300-13

3 Beesley V, Janda M, Eakin E, Obermair A, Battistutta D. Lymphedema after gynecological cancer treatment: prevalence, correlates, and supportive care needs. Cancer. 2007;109 (12):2607-14, 2007

4 Földi M, Földi E, Kubik S. Földi's Textbook of lymphology - for physicians and lymphedema therapists. 2006: 2nd edn pp 245-259. Elsevier Urban \& Fisher, Munich

5 Lever W, Schaumberg-Lever G. Metastatic carcinoma and carcinoid. In: Histopathology of the Skin, 1990: $7^{\text {th }}$ edn, pp 651. JB Lippincott Company, Philadelphia

6 Soucek-Hadwiger B, Döller W. Das sekundäre maligne Lympödem. Wien Med Wochenschr. 2006;156/9-10:309-13

8 Lookingbill DP, Spangler N, Sexton FM. Skin involvement as the presenting sign of internal carcinoma. A retrospective study of 7316 cancer patients. J Am Acad Dermatol. 1990;22(1):1926

9 Lookingbill DP, Spangler N, Helm KF. Cutaneous metastases in patients with metastatic carcinoma: a retrospective study of 4020 patients. J Am Acad Dermatol. 1993;29 (1):228-36

10 Schwartz RA. Cutaneous metastatic disease. J Am Acad Dermatol. 1995;33(1):161-82

11 Krathen RA, Orengo IF, Rosen T. Cutaneous metastasis: A Meta-Analysis of Data. South Med J. 2003;96(2):164-67

12 Marcoval J, Moreno A, Peyrl J. Cutaneous infiltration by cancer. J Am Acad Dermatol. 2007;57(4):577-80

13 Krasnoff JB, Longley CK, Katz ME, Watsky KL. Inflammatory cutaneous metastases from cloagenic carcinoma of the anus. Dermatol Surg. 1995;21(8):725-7

14 Meadows KP, Egan CA.Vesicular carcinoma erysipelatodes. J Am Acad Dermatol. 1999;40(5):8057

15 Hazelrigg DE, Rudolph AH. Inflammatory metastatic carcinoma. Carcinoma erysipelatoides. Arch Dermatol. 1977;113(1):69-70

16 Homler HJ, Goetz CS, Weisenburger DD. Lymphangitic cutaneous metastases from lung cancer mimicking cellulitis. Carcinoma erysipeloides. West J Med. 1986;144(5):610-2

17 Böni R, Meuli C, Dummer R. Erysipelas melanomatosum. Br J Dermatol. 1997;137(5):833-4

18 Lindmaier A, Wolfgang J. Two cases of melanomatous erysipelas-differential diagnosis and terminology. Hautarzt. 1990;41(11):628-32

19 Ozkan S, Soyal MC, Fetil E, Bozkurt E, Tülay C, Günes AT. Erysipelas melanomatosum. J Eur Acad Dermatol Venereol. 1999;12(3):272-4

20 Hariri H, Abeler T, Melnik B, Vakilzadeh F. Erysipelas carcinomatosum in tubular adenocarcinoma of the stomach. Hautartzt. 2000;51(12):950-2

22 Palaia I, Angioli R, Cutillo G, Manci N, Panici PB. Skin relapse from cervical cancer. Gynecol Oncol. 2002;87(1):155-6 
23 Miyoshi I, Saito T, Bandobashi K, Kodama H, Ohtsuki Y, Taguchi H. Papuloerythematous rash due to intralymphatic cutaneous tissue metastasis of cancer. Intern Med. 2006;45(2):115-6

24 Keohane SG, McLaren KM, Doherty VR, Hunter JAA. Cutaneous lymphangitis carcinomatosa: a rare primary manifestation of malignancy. J R Soc Med. 1996;89(10):582-3

25 Emmerst S, Bertsch HP, Zutt M, Haenssle H, Hallermann C, Kretschmer L, Neumann C. Bizarrely patterned erythema and papules in a 39-year-old man. Lymphangiosis carcinomatosa as the chief symptom of disseminated metastatic breast carcinoma in a man. Hautartzt. 2002;53(7):495-8

26 Jang KA, Choi JH, Sung KJ, Moon KC, Koh JK. Cutaneous metastasis presenting as facial lymphedema. J Am Acad Dermatol. 1988;39(4):637-8

27 Truong PT, Olivotto IA, WhelanTJ, Levine M. Clinical practice guidelines for the care and treatment of breast cancer: Loco-regional post-mastectomy radiotherapy. CMAJ. 2004;170(8):1263-73 


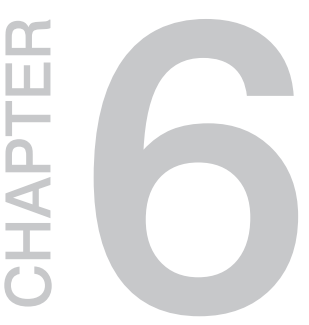

\section{Controlled, Comparative Study of Relation between Volume Changes and Interface Pressure under Short Stretch Bandages in Leg Lymphedema Patients}

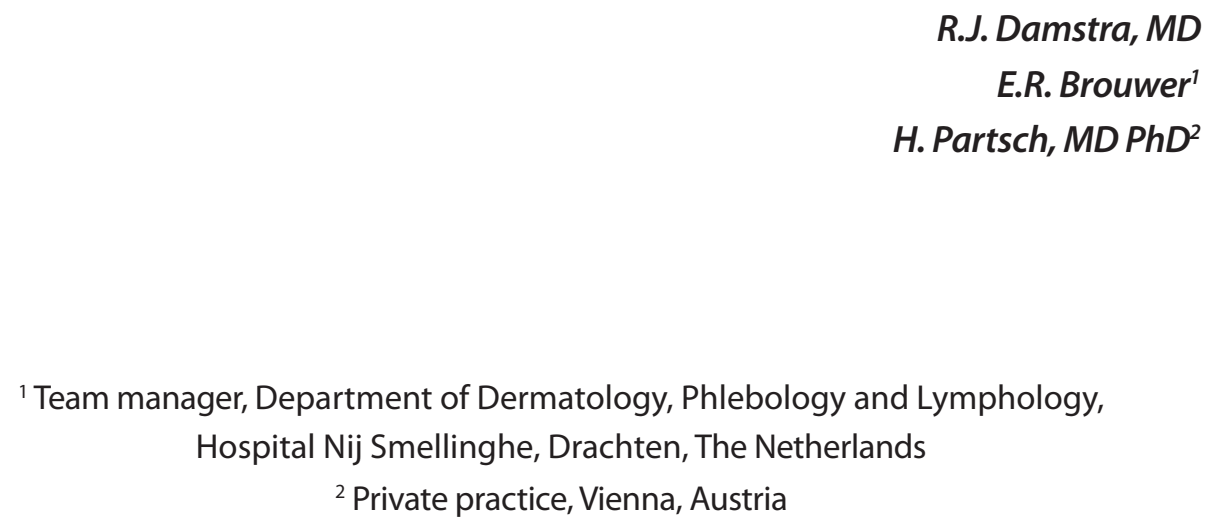

Dermatologic Surgery 2008; 34(6):773-8 


\section{ABSTRACT}

Background: Pressure loss under short-stretch bandages (SSBs) is a well-known phenomenon and is thought to be related to bandage relaxation and poor quality of application.

Aim: The aim was to demonstrate that therapeutically intended volume reduction of the compressed leg is the most important cause for the loss of bandage pressure.

Design: This was an experimental, controlled comparative study.

Methods: In 20 patients suffering from lymphedema of the lower extremities and in 9 healthy persons, lower leg volume was measured by water-displacement. After application of a pressure measurement device (Kikuhime ${ }^{\oplus}$ ) at the B1- region, SSBs were applied on one leg according to a standard protocol. Volume and pressure measurements were performed at 0, 2, 24 hours in supine as well as standing positions.

Results: A significant reduction of leg volume is already achieved 2 hours after bandage application, both in lymphedema patients and in normal controls. A further volume decrease of the lymphedematous legs is observed in the following 24 hours after application of a new bandage $(-290 \mathrm{~mL})$. The volume reduction is associated with a significant loss of bandage pressure from initial values over $60 \mathrm{mmHg}$ by $37 \%$ and $48 \%$ in controls and lymphedema patients, respectively.

Conclusions: Inelastic, multi-layer, multicomponent compression bandages lead to an immediate reduction of leg volume, both in lymphedematous and normal legs. This therapeutically intended volume reduction seems to be the main reason for the fast drop of the sub-bandage pressure. 


\section{PATIENTS}

\section{Study design and population}

The study was conducted at the Lymphedema Department in Nij Smellinghe hospital in Drachten, The Netherlands, from March to September 2006. A control group of 9 healthy volunteers was examined using the same measuring techniques.

The study population consisted of 20 patients (15 females, 5 males, age 20-78 years, mean age: 51,1years) who were hospitalized because of extensive lymphedema of the lower extremities. Three patients had bilateral lymphedema; therefore 23 legs were investigated. Clinical severity corresponded to a stage II lymphedema in all cases, 8 had reduced ankle mobility and walking ability. The control group consisted of 9 volunteers in whom bandages were applied on one healthy leg for two hours.

\section{Bandaging materials and techniques}

All patients and control group volunteers were treated with the same bandages by specially trained staff. Bandage kids (multilayer short stretch, Rosidal' Lymphset, Lohmann \& Rauscher, Rengsdorf, Germany) were used, consisting mainly of a foam layer and two short stretch cotton wool bandages, $5 \mathrm{~m}$ long $\times 10 \mathrm{~cm}$ wide. The bandages started at the base of the toes and covered the leg up to the capitulum fibulae in all cases.

The bandages were removed after 2 hours and new bandages were applied for the next 24 hours. On this first day all patients were encouraged to walk and treated exclusively with compression therapy of the whole leg. No other therapeutic interventions were performed.

\section{Measurement of sub-bandage pressure}

An air-filled pressure transducer was used to measure the sub-bandage pressure at the medial gaiter area (Kikuhime ${ }^{\circledR}$, TT Medi Trade, Soleddet 15, DK 4180 Soro) with the large probe (5 centimeter in diameter) see Figure1.

The accuracy of this method has already been described ${ }^{1}$. The pressure was measured at the $B 1$ region in supine and standing position after application of the bandage, after 30 minutes, 2 hours of moving and after 24 hours. B1 is the region at which the Achilles tendon changes into the calf muscles (about $10-15 \mathrm{~cm}$ proximal to the medial malleolus). 


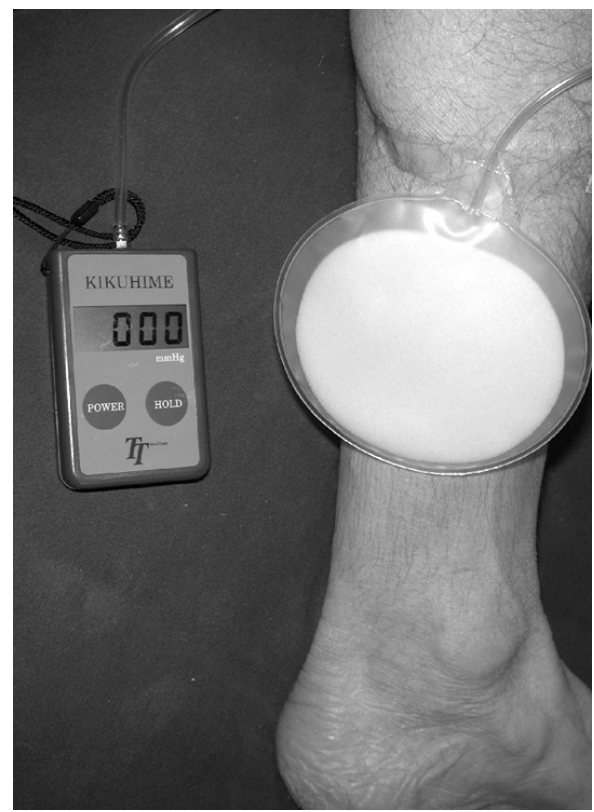

Figure 1: Kikuhime placed at the $B 1$ region

\section{Leg volumetry}

For the volumetry we used a water-displacement-device consisting of a plexi-glas container, which was filled up to $34 \mathrm{~cm}$ from the bottom with $30^{\circ} \mathrm{C}$ warm water (Vayssairat et al. ${ }^{2}$, see Figure 2). The lower leg is positioned slowly into the apparatus in the standing position. The displaced water is collected and its weight is measured on a precision scale. Water-displacement is the gold standard in leg volumetry and has a good reproducibility and very small interobserver variability ${ }^{2}$. The method measures precisely the total amount of leg volume including the volume of the foot and toe ${ }^{3},{ }_{1}^{4}$.

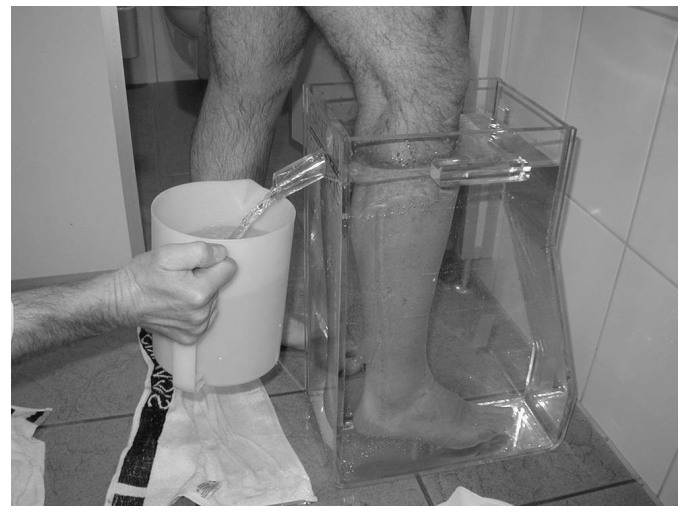

Figure 2: water displacement apparatus in use 
In the lymphedema group leg volumetry was done before bandage application, after removal of the first bandage ( 2 hours) and after removal of the second bandage ( 24 hours). In the healthy controls leg volumetry was performed before bandage application, 2 hours later after removal of the bandage and again after 2 hours with no bandages on the leg.

\section{Statistical analysis}

Median values with percentiles, minimal and maximal values are given. Repeated analysis of variance was used to compare the initial values of pressure and volume versus the several subsequent values. For comparison of matched pairs the Student t-test was applied. A comparison of pressure and volume loss was made using the nonparametric correlation Spearman coefficient (GraphPad, San Diego, CA).

\section{RESULTS}

\section{Sub-bandage pressure in lymphedema patients}

Figure 3 shows the subbandage pressure values measured on 20 lymphedema legs in the supine position. Immediately after bandage application the median values were 64 $\mathrm{mmHg}(46-113 \mathrm{mmHg})$. Already 30 minutes later the values are reduced by about onethird, and after 2 hours the median pressure was $32 \mathrm{mmHg}(20-64 \mathrm{mmHg})$.

Pressure at B1, supine

Lymphoedema, $\mathrm{n}=20$

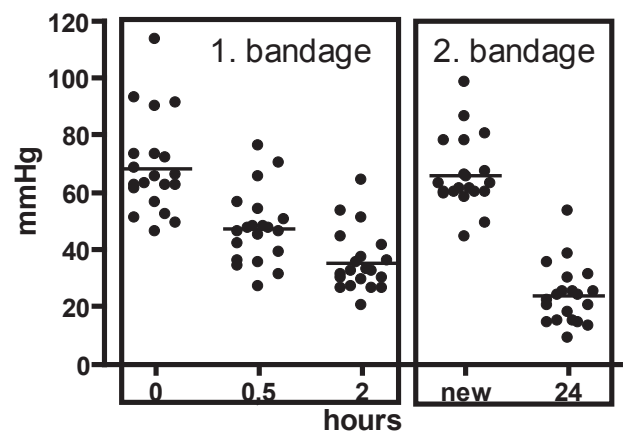

\begin{tabular}{l|ccccc} 
& 0 & 0,5 & 2 & new & 24 \\
\hline Minimum & 46.00 & 27.00 & 20.00 & 44.00 & 9.000 \\
25\% Percentile & 58.50 & 37.50 & 28.00 & 60.00 & 15.00 \\
Median & 64.00 & 46.50 & 32.00 & 62.00 & 23.00 \\
75\% Percentile & 73.00 & 52.00 & 39.00 & 72.50 & 27.50 \\
Maximum & 113.0 & 76.00 & 64.00 & 98.00 & 53.00
\end{tabular}

Figure 3: Left box: the sub-bandage pressure values show a significant pressure drop $(p<0.01)$ after 30 minutes and after 2 hours. Right box: Newly applied bandages exert pressures in a similar range compared to the initial bandages with a highly significant pressure fall after 24 hours $(p<0.001)$. (Only data from 20 patients are given in this figure since pressure measurement after application of the second bandage was missed in 3 patients.) 
A new bandage is applied that produces a similar median pressure of $64 \mathrm{mmHg}$ as the first bandage. Twenty-fours hours later, the pressure decreased to $23 \mathrm{mmHg}(9-53 \mathrm{mmHg})$, and the bandage had again to be renewed. This and the following treatment phase were outside the study.

\section{Control group}

The initial bandage pressure in the healthy control group was in the same range compared to the lymphedema patients (Figure 4, left). However, the pressure decrease in the first 2 hours was less pronounced $(37,5 \%$ vs. $48 \%$ in supine and $21 \%$ vs. $36 \%$ in the standing position) compared to the lymphedema group (Figure 4, right). Both in the control group and in lymphedema patients the sub-bandage pressure is higher and the pressure loss is less pronounced in the standing than in the supine position.
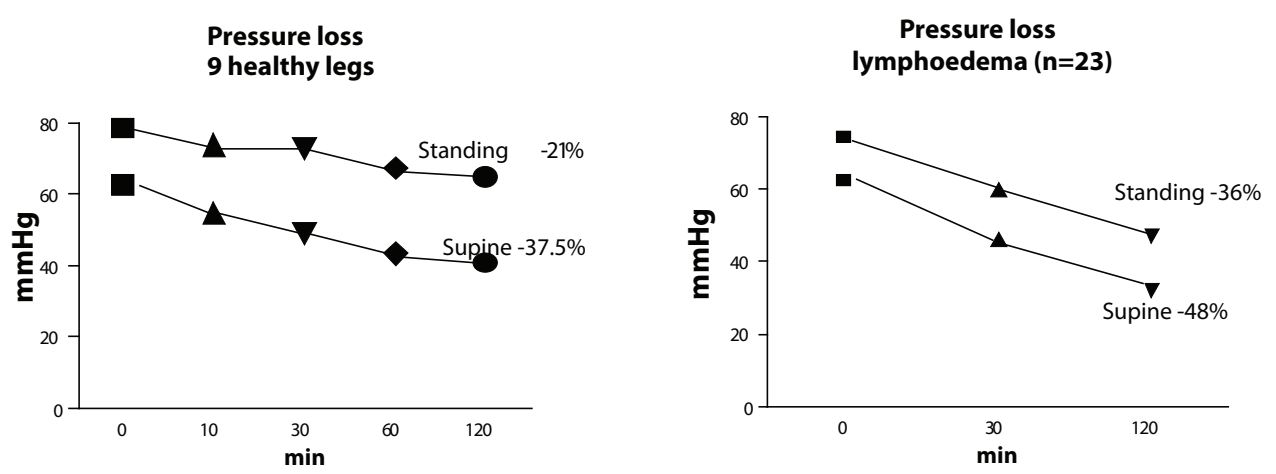

Figure 4: (Left) Average bandage pressure loss in healthy controls over time. In the supine position all values are significantly lower than the initial pressure $(p<0.01)$, in the standing position a significant reduction of pressure is found only after 60 and 120 minutes $(p<0.01)$. (Right) In patients with lymphedema, the pressure loss after 30 and 120 minutes is significant in the supine and standing position $(p<0.01)$.

\section{Leg-volume}

After 2 hours the reduction of the median leg volume was $60 \mathrm{~mL}$ in the healthy controls $(-2.6 \%)$ and $50 \mathrm{~mL}(-1.2 \%)$ in the lymphedema legs (Figure 5). 

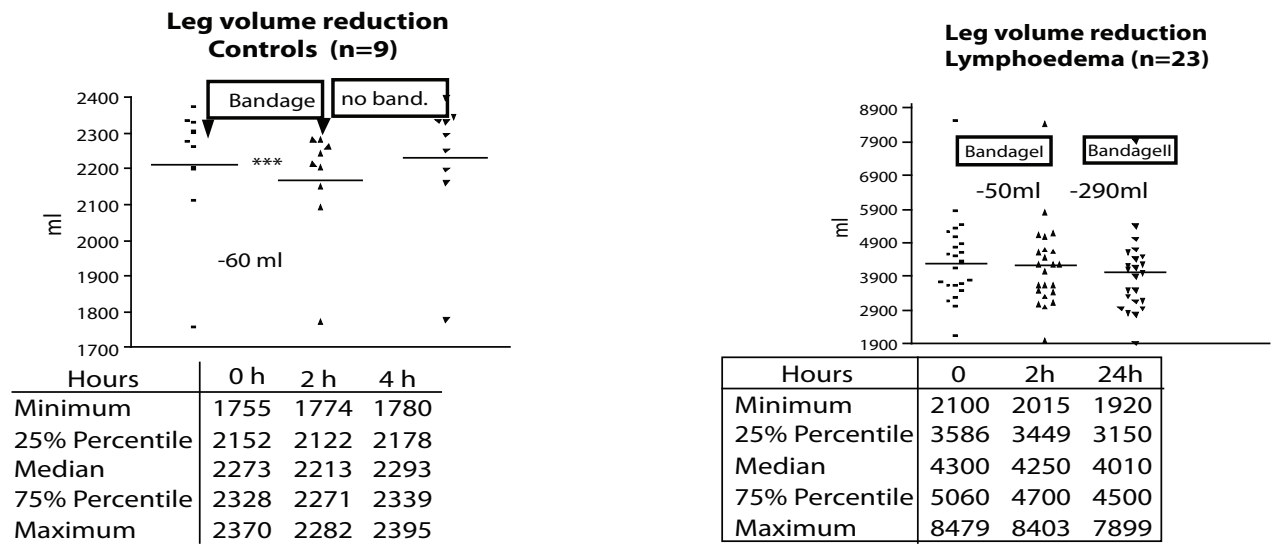

Figure 5: (Left) After 2 hours with a bandage, the leg volume is significantly reduced in the healthy controls ( $p<0.001)$. Two hours later (without bandage), the initial values are restored. (Right) In the lymphedema patients, there is a significant reduction of leg volume after 2 hours $(p<0.01)$ and after 24 hours $(p<0.01)$. The absolute amount of volume reduction after 2 hours is comparable in the healthy controls and in lymphedema patients.

\section{DISCUSSION}

Compression therapy is a very potent treatment modality in phlebology and lymphology as well. To compare results, it is necessary to use standardized bandaging methods and measuring equipment. Until recently there was no uniformity in standardized measurement of pressure between the skin and medical compression devices. In 2006, the International Compression Club (ICC) published recommendations for the performance of measurements of interface pressure and stiffness ${ }^{6}$. In this study we used these recommendations to study the effect of compression bandaging in lower leg lymphedema patients.

Although the treatment of lymphedema consists of several therapeutical options, we chose a study protocol focussing only on the short-term effect of short-stretch compression bandaging in relation to volume changes during 24 hours. The multicomponent bandaging system used had a high stiffness, which is defined as increase of compression pressure per centimetre increase of circumference measured at the B1 region ${ }^{4}$. Mosti and Mattaliano 7 showed that the most consistent parameter for determining static stiffness is the pressure difference between the standing and the lying position to measure the sub-bandage 
pressure. Their data reported with a comparable short-stretch multilayer bandage were compatible with the data we found (initial resting pressure between 40 and $70 \mathrm{mmHg}$ ). In chronic venous insufficiency (CVI) it had been shown that an increase of stiffness would lead to more effective reduction of volume ${ }^{8}$ and reflux ${ }^{9}$ when compression bandages with the same resting pressure are applied.

Little is known about the different effects of compression therapy in lymphedema using different pressures and various materials. However, multi-layer inelastic lymphedema bandaging with a resting pressure of more than $45 \mathrm{mmHg}$ is recommended as the standard intensive therapy for the initial management of lymphedema ${ }^{10}$.

The main disadvantage of short stretch bandages is their loss of interface pressure, which is much more pronounced than that of elastic material. As it is demonstrated by our experiments, this pressure loss is associated with a considerable reduction of the leg volume, taking place instantly not only in lymphedematous but in healthy legs as well. This volume reduction can only be explained by a reduction of the fluid content of the compressed parts of the lower extremities.

As it is demonstrated in Figure 6, taking into account all data from lymphedema legs after 2 hours ( $n=23)$ and healthy controls $(n=9)$, there is a rather poor correlation between the loss of sub-bandage pressure and the reduction of leg volume. This may be mainly due to the fact that the measurement of the pressure reflects only changes in a small area under the bandage while the volume reduction is covering the whole lower leg. As can be seen after 2 hours, compression showed a pressure decrease in each individual subject of at least $10 \mathrm{mmHg}$ while the leg volume was not diminished in 5 from 32 legs.

The decrease of subbandage pressure may therefore be explained in part also by some extension of the compression material.

One of the practical consequences of the pressure loss that starts immediately after the application of an inelastic bandage is the recommendation to apply such bandages with a very high tension producing a resting pressure on the distal leg of more than $60 \mathrm{mmHg}$. Two hours later the pressure will have decreased to about $40 \mathrm{mmHg}$ and will also be well tolerated in the supine. The pressure loss is less pronounced in the upright position exerting pressure peaks during walking that still produce an intermittent massage with every step ${ }^{6}$. 


\section{Correlation reduction of pressure vs}

reduction of leg volume after $2 \mathrm{~h}(\mathrm{n}=32)$

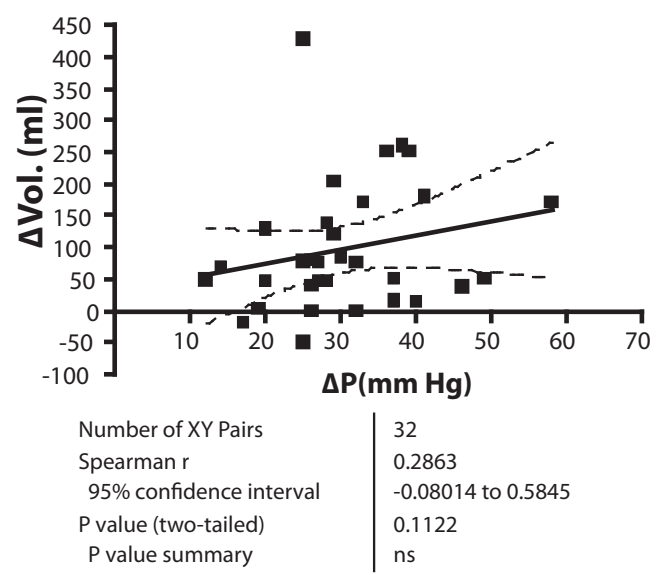

Figure 6: Correlation of pressure decrease after 2 hours and volume reduction in 23 lymphedema legs and 9 controls. The volume reduction is varying more $\left(-50\right.$ to $\left.425 \mathrm{~cm}^{3}\right)$ than the pressure decrease (at least $10 \mathrm{mmHg}$ ).

The measured volume reduction can be explained by an increased reabsorption of fluid from the tissue into the blood capillaries and by a shift into proximal, noncompressed parts of the upper leg. Redistribution to the upper part of the leg is plausible although abnormal congestion of fluid around the knee was not observed. Nevertheless, this option cannot be excluded by these results because we just focussed on the lower leg volume and the issue of redistribution was not the part of our study.

\section{CONCLUSION}

Compression bandaging is an essential part of the treatment of lymphedema. To achieve optimal volume reduction, high initial interface pressures are necessary to compensate pressure decrease, which is already significant after 2 hours. This pressure decrease is mainly caused by volume reduction and is also detectable in the control group. In the literature never before a study was performed that correlated the amount of pressure decrease under a stiff, inelastic bandage with the volume reduction of the leg. In-elastic, multi-layer, multicomponent compression bandages lead to an immediate reduction of leg volume in lymphedematous legs. This therapeutically intended volume reduction seems to be the main reason for the fast decrease of the subbandage pressure and explains the need for frequent bandage change in the beginning of lymphedema therapy. 


\section{REFERENCES}

1 Partsch $\mathrm{H}$. The static stiffness index: a simple method to assess the elastic property of compression materials in vivo. Dermatol Surg. 2005;31:625-30

2 Vayssairat M, Ziani E, Houot B. Efficacité versus placebo de la contention classe 1 dans I'insuffisiance veineuse chronique des membres inférieurs. J Mal Vasc. 2000;25:256-62

3 Kaulesar DMKS, den Hoed PT, Johannes EJ, et al. Direct and indirect methods for quantification of leg volume: comparison between water displacement volume try, the disk model and the frustum sign model, using correlation coefficient and the limits of agreement. J Biomed Eng. 1993; 15:477-80

4 Stranden E. A comparison between suface mesaerements and water displacement volumetry for the quantification of leg edema. J Oslo City Hosp. 1981;31:153-5

5 Mortimer PS. Investigation and management of lymphedema. Vasc Med Rev. 1990;1:1-20

6 Partsch H, Clark M, Bassez S, et al. Measurement of lower leg compression in vivo: Recommendations for the performance of measurements of interface pressure and stiffness. Dermatol Surg. 2006;32:224-33

7 Mosti GB, Mattaliano V. Simultaneous changes of leg circumference and interface pressure under different compression bandages. Eur J Vasc Endovasc Surg. 2007;33:476-82

8 Geest van AJ, Veraart JC, Nelemans P, Neumann HAM. The effect of medical elastic compression stockings with different slope values on edema. Measurements underneath three types of stockings. Dermatol Surg. 2000;26:244-7

9 Partsch H, Menzinger G, Mostbeck A. Inelastic leg compression is more effective to reduce deep venous refluxes than elastic bandages. Dermatol. Surg. 1999;25:695-700

10 Lymphedema Framework. Best practice for the management of lymphedema. International consensus. London: MEP Ltd 2006. ISBN 0-9547669-4-6 
Compression Therapy in Breast Cancer Related Lymphedema:

A Randomized Controlled, Comparative Study of Relation Between Volume and Interface Pressure Changes

\author{
R.J. Damstra, $M D$
}

H. Partsch, $M D P h D^{\prime}$

${ }^{1}$ Private practice, Vienna, Austria 


\section{ABSTRACT}

Objective: Short stretch bandages are very effective in the initial management of arm lymphedema. However, no studies to date have measured the pressure required to achieve specific amounts of volume reduction. The purpose of this study was to determine whether there is a difference between low and high-pressure bandaging in terms of therapeutically intended volume reduction of the compressed arm.

Methods: Experimental, randomized and comparative study with two study-groups consisting of high and low initial interface pressure bandages. Thirty-six hospitalized patients in Nij Smellinghe hospital suffering from moderate to severe unilateral breast cancer-related lymphedema not responsive to outpatient treatment were included. Bilateral arm volume was measured by inverse water volumetry before, after two hours and after 24 hours of bandaging. The amount of edema was calculated by subtracting the volume of the diseased arm from that of the contralateral side. Sub-bandage pressure was measured after bandage application and two hours later. Bandages were then re-applied and the pressure was measured again. Twenty-four hours later, the pressure measurement was repeated and bandages were removed for final volumetry. Patients were randomized into two groups: group A received low pressure bandages $(20-30 \mathrm{~mm} \mathrm{Hg}$ ) and group $B$ received high pressure bandages $(44-58 \mathrm{~mm} \mathrm{Hg})$. The main outcome measures were reduction of arm volume and edema volume in the affected arm in both study groups. Secondary outcome parameters were changes in sub-bandage pressure and patient comfort.

Results: Median arm volume reduction after 2 and 24 hours was $104.5 \mathrm{ml}(95 \% \mathrm{Cl} 51.2-184.2)(-2.5 \%)$ $(\mathrm{p}<.0001)$ and $217 \mathrm{ml}(95 \% \mathrm{Cl} 143.9-280.2)(-5.2 \%)(\mathrm{p}<.01)$ for group $\mathrm{A}$ and $56.5 \mathrm{ml}(95 \% \mathrm{Cl}-2.7-$ 123.1) (n.s.) and $167.5 \mathrm{ml}(95 \% \mathrm{Cl} 105.2-316.1)(-4.2 \%)(p<.01)$ for group $B$ respectively. There was no statistically significant difference between the volume changes in group A and group B. After 24 hours edema decreased by median percentage of $9.2 \%$ in group $A$ and $4.8 \%$ in group $B$ (n.s.). Bandages in group $A$ were better tolerated. The sub-bandage pressure drop in the first 2 hours was between 41 and $48 \%$ in both treatment groups at both measuring sites. After 24 hours the pressure drop was between $55 \%$ and $63 \%$. No proximal swelling above the bandage was observed.

Conclusions: Inelastic, multi-layer, multi-component compression bandages with lower pressure (20-30 $\mathrm{mm} \mathrm{Hg})$ are better tolerated and achieve the same amount of arm volume reduction as bandages applied with higher pressure $(44-58 \mathrm{~mm} \mathrm{Hg})$ in the first 24 hours.

Clinical Relevance: This study was conducted in the Lymphedema Department of Nij Smellinghe Hospital Drachten, The Netherlands, from June 2007 to September 2008. The Medical Ethics Committee of the hospital approved the study and all patients signed informed consent. 


\section{INTRODUCTION}

The major manifestation of lymphedema is chronic swelling, which causes discomfort, loss of function and morbidity due to lymphatic impairment. If left untreated, the condition will progress. After a proper investigation into the case of lymphedema and, in the case of lymphedema following cancer treatment, exclusion of recurrent malignancy, a conservative treatment program should be conducted. Breast cancer related lymphedema ( $B C R L)$ is one of the most frequent causes of lymphedema. The goals for treatment are to eliminate edema by reducing interstitial fluid production and to stimulate lymphatic propulsion by compression. In addition lymph flow is stimulated by manual lymph drainage (MLD) and by exercises that improve the functional capacity. To minimize the risk of infection, maintenance of skin integrity and proper skin care are mandatory. The combination of these therapeutic modalities is called complex decongestive therapy (CDT). When the maximal therapeutic result is obtained, compression garments are then essential for the long-term management ${ }^{1}$

In the treatment of lymphedema various compression materials can be used. Based on an in vitro assessment, it has been customary to differentiate between "elastic" ("long stretch") and "inelastic" ("no-stretch" or "short stretch") compression bandages². The elasticity is defined by the percentage of elongation of the material following application of a force of $10 \mathrm{~N} / \mathrm{cm}$ bandage width (Deutsches Institut für Normung (DIN) 61632: Standardization of production of Surgical dressings / Cotton crepe bandages). This elongation is between 0-10\% for "no-stretch" bandages, between 10-100\% for short stretch and > 100\% for long stretch.

By applying several layers over each other, the multilayer bandage system as a whole attains the characteristics of an inelastic system, even when the single components are elastic ${ }^{2}$.

Initial management of upper limb lymphedema with inelastic multi-layer bandaging (IMLB) is usually part of CDT. However, up to this point, the deciding parameter of the interface pressure, which is the dosage of compression therapy, has been measured only in patients with chronic venous insufficiency².

Only recently we reported the sub-bandage pressure measurements for leg lymphedema ${ }^{3}$. 
Studies to measure the pressure in arm lymphedema have rarely been performed before: thus, the compression pressure required to obtain the highest volume reduction per unit of time is unknown. In a pilot study we found interface pressure values between 30-40 $\mathrm{mmHg}$ exist after routine bandaging.

In this study, we aimed to compare the effect of low-versus high interface pressure for arm volume reduction in BCRL after 2 and 24 hours. Our working hypothesis was that high pressure would be more effective than low pressure in terms of volume reduction, since this has been demonstrated in leg lymphedema.

\section{METHOD}

\section{Study design and population}

This study was conducted in the Lymphedema Department of Nij Smellinghe Hospital in Drachten, from June 2007 to September 2008.

The study population consisted of 36 female patients with unilateral breast cancer-related lymphedema (BCRL) who were randomized by using sealed envelopes into two groups of 18 patients each. Group A received bandages with low interface pressure (20-30 mm $\mathrm{Hg}$ ) and group B received bandages exerting high interface pressure (44-58 $\mathrm{mm} \mathrm{Hg}$ ). All patients had lymphedema and were hospitalized because outpatient treatment was not successful in terms of removing pitting edema and improving the mobility and condition of the patient. The primary outcome parameters were the reduction of arm volume and reduction of edema volume in the affected arm. The difference in arm volume between the affected and the normal sides defined the amount of arm edema. The secondary outcome parameters evaluated were changes in sub-bandage pressure, patient comfort, side effects such as proximal swelling, and safety.

\section{Inclusion and Exclusion criteria}

All patients were female (more than 18 years of age) and had to be at least 12 months post-treatment for breast cancer without signs of recurrence. Only patients with moderate (volume difference 20-40\%) to severe edema (difference $>40 \%$ ) were included. Clinical severity was staged according to ISL guidelines ${ }^{4}$ to stage 2 lymphedema, with a real pitting component. Patients with allergies to any of the used materials, severe systemic diseases, 
acute superficial or deep vein thrombosis, or arterial occlusive disease or documented thrombophilia were excluded.

\section{Bandaging materials and techniques}

All patients were treated with the same bandages by specially trained staff. Certified multilayer short stretch compression bandages (Rosidal ${ }^{\circ}$ Lymphset, Arm, Lohmann \& Rauscher, Rengsdorf, Germany) were used, consisting of a foam layer and two short stretch cotton wool bandages. After applying pressure-measuring probes, the arm was carefully bandaged at either the high or low-pressure range. The bandages started at the base of the hand and covered the arm up to the shoulder. The hand and fingers were bandaged as well.

The bandages were removed after two hours in order to measure the short-term volume reduction and new bandages were applied for the next 24 hours within the same pressure range. All patients were encouraged to be active and no other therapeutic interventions were performed. Special attention was paid to the eventual signs of proximal swelling above the bandages at the shoulder. The first 18 patients were assessed for tolerability and comfort of the bandages using a visual analogue score (VAS).

\section{Measurement of sub-bandage pressure}

An air-filled pressure transducer (Kikuhime ${ }^{\circledR}$, TT Medi Trade, Sorø, Denmark) with the large probe (12 x 10.5 centimeter diameter) was used to measure sub-bandage pressure. The accuracy and variability of this method has been described previously ${ }^{5}$. Pressure was measured when the arm was extended to $160^{\circ}$ on a table at two locations: the dorsal side of the lower arm and the lateral side of the arm distal from the elbow (Figure 1). Pressure measurements were performed after bandage application, at 2 hours before and after bandage renewal, and at 24 hours. For pressure measurements, the strength of the bandage application was guided by pressure measurement during bandaging thereby avoiding higher pressures at the proximal measuring point compared to the distal. If the pressure was not in the required range, the arm was re-bandaged. Pressure group $A$ ranged from 21 to $30 \mathrm{mmHg}$ and group $B$ was bandaged within a range of 45 to $55 \mathrm{mmHg}$. Table 1 shows the initial mean pressure values measured at the distal and proximal arm. 


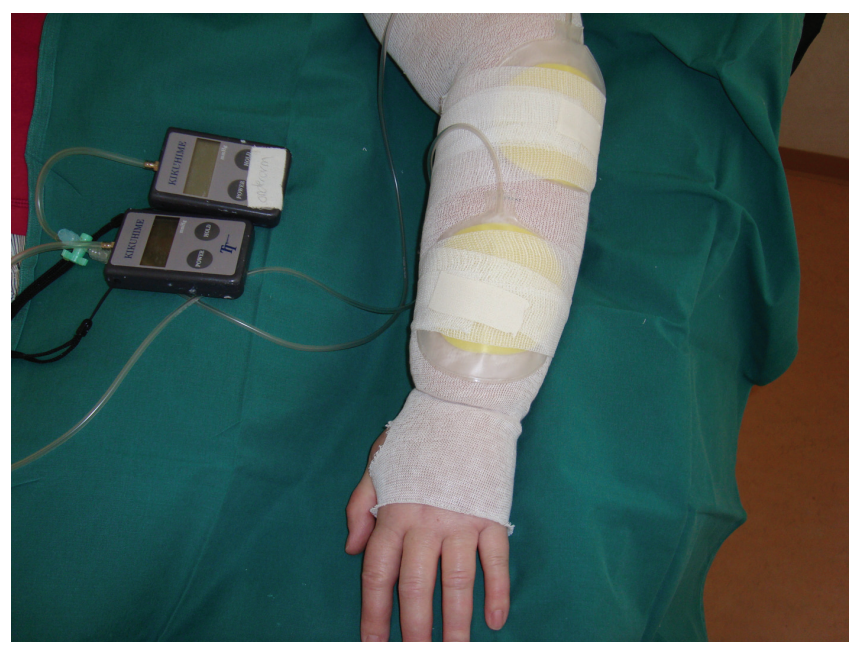

Figure 1

\begin{tabular}{llllll}
\hline & & $\mathrm{T}=0$ & $\mathrm{~T}=2$ hours & New bandage & $\mathrm{T}=24$ hours \\
\hline Group A & Distal & $27(26-39)$ & $16.5(14-19)$ & $28(25.529)$ & $10(7.5-12)$ \\
& Proximal & $26(25-27.5)$ & $15(13.5-17)$ & $27.5(24.5-29)$ & $10(8-12.5)$ \\
\multirow{2}{*}{ Group B } & Distal & $50.5(46-52.5)$ & $28.5(28.5-40)$ & $51(50-54)$ & $21.5(10-25.5)$ \\
& Proximal & $49(47-52.5)$ & $28.5(24-33)$ & $51(48 .-54)$ & $20(17-24)$ \\
\hline
\end{tabular}

Table 1. Sub-bandage pressures $(\mathrm{mm} \mathrm{Hg})(x+S D)$ measured at the distal and proximal sites in both treatment groups. Significant differences $(p<0.001)$ were observed between 0 and 2 hours, and between "new bandage" and 24 hours.

\section{Inverse water volumetry}

Inverse water volumetry (IWV) is a derivative of classic water displacement volumetry and measures a shortage of water instead of an overflow (Figure 2). This validated method measures the volume of the whole arm including the hand. IWV was performed on both arms at 0, 2 and 24 hours after application of compression bandages. The contralateral arm was used as the control. Edema in the lymphedematous arm was assessed by subtracting the volume of the healthy contra lateral arm from the volume of the diseased arm. During the volumetry, the staff was unaware of patients' treatment group.

\section{Statistical analysis}

The medians and interquartile ranges are given. Repeated analysis of variance (ANOVA) and Tukey's multiple comparisons were used to compare the initial values of pressure and 


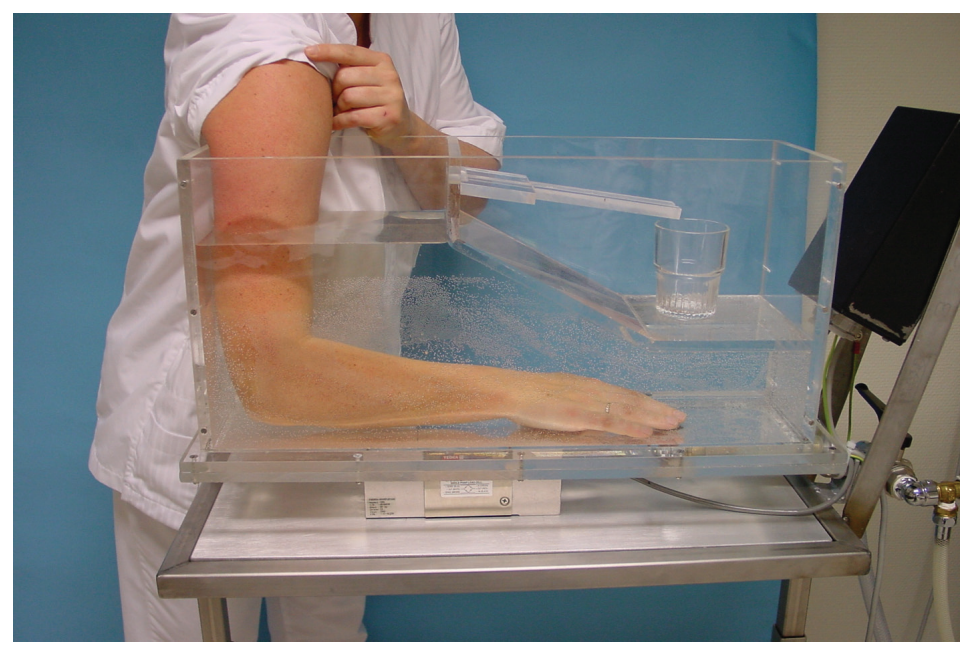

Figure 2

volume versus the several subsequent values.

Comparisons between the two treatment groups were performed using the non-parametric Mann-Whitney-test. The variation coefficient was given as the percent proportion of the statistical deviation from the mean in repeated measurements. A comparison of pressure and volume loss was made using the non-parametric correlation Spearman coefficient (Graph Pad, San Diego, California). P < 0.05 was accepted as significant. The power of our study with a sample size of $n=18$ for both groups was $7.1 \%$ with a standard deviation $(s d)$ of $(s d=137)$ for a $10 \%$ volume reduction and $18.6 \%(s d=137)$ for a $25 \%$ volume reduction.

To achieve a power of $80 \%$ with $95 \%$ reliability, the sample size in the case of $10 \%$ volume reduction is $n=741$ and for $20 \%$ reduction is $n=119$. However, from a practical point of view and regarding our research aim, these numbers are not realistic. This factor may be a statistical limitation of our study.

\section{RESULTS}

The basic characteristics of the patients included in the study are summarized in Table 2 .

\section{Reduction of total arm volume}

When compared to the initial stage, the arm volume in group A showed a significant median difference of arm volume after 2 hours of 104,5 ml (95\% confidence interval $[\mathrm{Cl}]$, $51.2-184.2)(-2.5 \%)(p<0.001)$ and of $217 \mathrm{ml}(95 \% \mathrm{Cl}, 143.9-280,2)(-5.2 \%)(p<0.01)$ after 24 
Table 2. Basic characteristics of study groups. There was no significant difference of any single parameter between group $A$ and group $B$.

\begin{tabular}{|c|c|c|}
\hline & Group A $(n=18)$ LPB & Group B $(n=18)$ HBP \\
\hline Mean age in years (SD) & 60,5 (45-84 years) & 61,2 ( $50-73$ years) \\
\hline Side of the arm (left / right) & $9 / 9$ & $9 / 9$ \\
\hline $\begin{array}{l}\text { Time of lymphedema onset after } \\
\text { operation (months) }\end{array}$ & $11.3(3-50)$ & $11.4(3-30)$ \\
\hline $\begin{array}{l}\text { Partial mastectomy with axillary } \\
\text { clearance }(\%)\end{array}$ & $7 / 18(38.8)$ & $6 / 18(33.3)$ \\
\hline $\begin{array}{l}\text { Total mastectomy with axillary clearance } \\
\text { (\%) }\end{array}$ & $11 / 18(61.1)$ & $12 / 18(66.6)$ \\
\hline Received radiotherapy (\%) & 100 & 100 \\
\hline $\begin{array}{l}\text { Absolute volume healthy arm (min-max) } \\
(\mathrm{ml}), \mathrm{t}=0\end{array}$ & $2841(2246-4326)$ & $3040(2029-4546)$ \\
\hline $\begin{array}{l}\text { Absolute volume affected arm (min-max) } \\
(\mathrm{ml}), \mathrm{t}=0\end{array}$ & $4390(2986-6592)$ & $4393(2243-5822)$ \\
\hline $\begin{array}{l}\text { Volume difference between both arms } \\
\text { (\%) at } \mathrm{t}=0\end{array}$ & 154 & 144 \\
\hline
\end{tabular}

hours $(\mathrm{p}<0.001)$. In group $B$ the corresponding values were $56.5 \mathrm{ml}(95 \% \mathrm{Cl}-2.7-123.1)$ (n.s.) and $167.5 \mathrm{ml}(95 \% \mathrm{Cl}, 105.2-316.1)(-4.2 \%)(\mathrm{p}<0.01)$. (Figure 3). There was no significant difference in the total volume changes between the two groups after 2 and 24 hours. In both groups, four patients showed a slight volume increase that was more pronounced in group $B$, thus explaining the wide range of confidence intervals.

\section{Reduction of arm edema}

Arm edema was calculated by subtracting the volume of the normal arm from that of the lymphedema arm. Compared to the baseline group A showed a significant reduction of edema with median values from $1347 \mathrm{ml}$ (interquartile range [IQR], 953.5-2129) to 1366 $\mathrm{ml}(\mathrm{IQR}, 963.5-1941)$ after 2 hours $(\mathrm{p}<0,05)$ and to $1222 \mathrm{ml}(\mathrm{IQR}, 832-1846)$ after 24 hours $(p<0.001)$. The corresponding values in group B were $1167 \mathrm{ml}(\mathrm{IQR}, 821.5-1845)$ before treatment, $1194 \mathrm{ml}$ (IQR 755-1811) after 2 hours and $1111 \mathrm{ml}$ (IQR, 661-1552) after 24 hours (Figure 4). Only the edema reduction after 24 hours was significant $(p<0.001)$. 
ArmVolume /Low pressure $(n=18)$

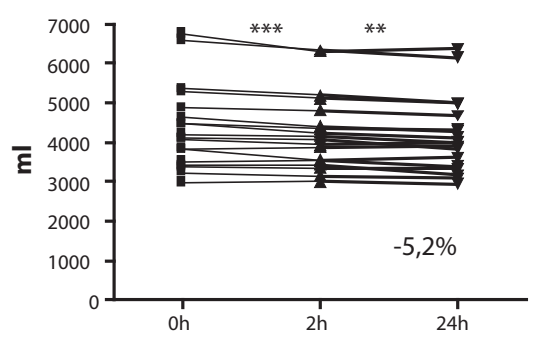

\begin{tabular}{l|ccc} 
& Oh & 2h & $24 \mathrm{~h}$ \\
\hline Minimum & 2986 & 3010 & 2950 \\
25\% Percentile & 3461 & 3484 & 3363 \\
Median & 4158 & 4130 & 4005 \\
$75 \%$ Percentile & 5086 & 4962 & 4832 \\
Maximum & 6748 & 6335 & 6373 \\
& & & \\
Mean & 4390 & 4272 & 4177 \\
Std. Deviation & 1067 & 969.8 & 968.8 \\
Std. Error & 251.4 & 228.6 & 228.3
\end{tabular}

Arm Volume /High pressure $(\mathbf{n}=18)$

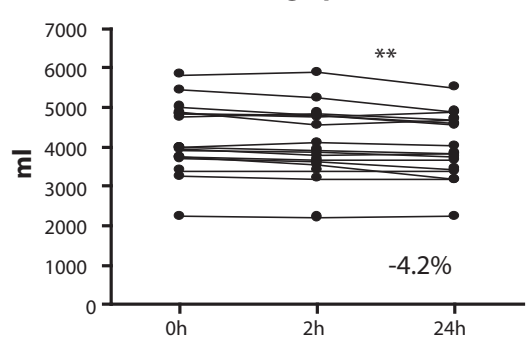

\begin{tabular}{l|ccc} 
& Oh & $2 \mathrm{~h}$ & $24 \mathrm{~h}$ \\
\hline Minimum & 2243 & 2210 & 2240 \\
25\% Percentile & 3721 & 3577 & 3414 \\
Median & 3984 & 4009 & 3921 \\
75\% Percentile & 4933 & 4834 & 4786 \\
Maximum & 7645 & 7796 & 7016 \\
& & & \\
Mean & 4394 & 4333 & 4183 \\
Std. Deviation & 1184 & 1218 & 1066 \\
Std. Error & 279.0 & 287.0 & 251.1
\end{tabular}

Figure 3: Volume reduction of lymphedematous arm. Group A (left) showed a significant volume decrease after 2 and 24 hours, group $B$ (right) only after 24 hours.

Differences compared to baseline: ${ }^{* * *} p<.001,{ }^{* *} p<.01$.
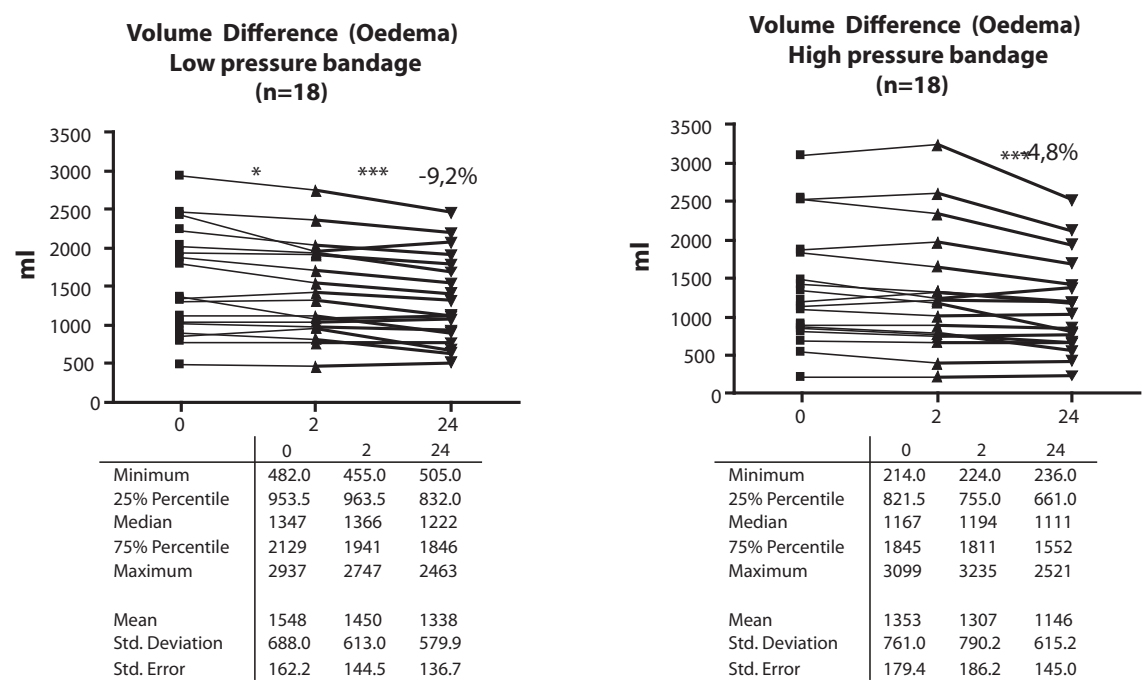

Figure 4: Edema reduction in the treated arm. Group A (left) shows a significant decrease after 2 and 24 hours, group B (right) only after 24 hours. Differences compared to baseline: ${ }^{* * *} p<.001,{ }^{*} p<.05$.

The median differences concerning total edema reduction after 24 hours were $230.5 \mathrm{ml}$ (95\% Cl, 135.5-283.9) in group A and $146 \mathrm{ml}(95 \% \mathrm{Cl}, 101.2-313.5)$ in group B (n.s.)

\section{Sub-bandage pressure in lymphedema patients}

Table 1 shows all sub-bandage pressure values measured in 36 lymphedema arms. Pressure 
values measured at the distal and proximal positions of the lower arm were similar, both for the initial bandages and for new bandages applied after 2 hours. The sub-bandage pressure drop in group $A$ at the distal measuring point was $48 \%$ for the first two hours and $63 \%$ after twenty-four hours respectively. The corresponding values in group B were $44 \%$ and $55 \%$.

There was no significant correlation between the changes in arm volume and sub-bandage pressure (Figure 5).

\section{Correlation Change of Pressure/Change of Volume} First 2 h, all bandages

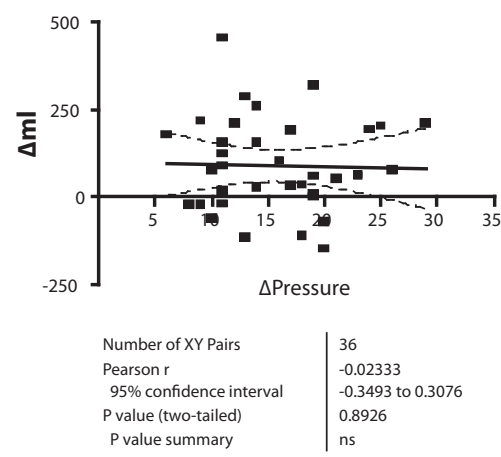

Correlation Change of Pressure/Change of Volume $2 \mathrm{~h}-24 \mathrm{~h}$, all bandages

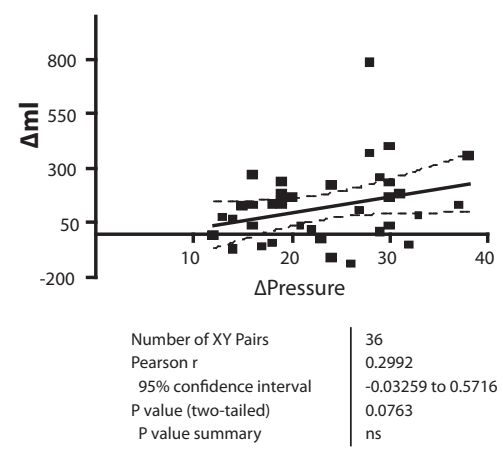

Figure 5: No correlation between change in arm volume and sub-bandage pressure in the first 2 hours, poor correlation between 2 and 24 hours.

\section{Quality of life and discomfort}

At the beginning and the end of the study (after 24 hours) the 18 participants ( 9 group A, 9 group B) filled out a questionnaire containing a visual analogue score (VAS). The group with the high-pressure bandage indicated more complaints of pain and discomfort, especially for the first two hours. The low-pressure bandage was better tolerated during the whole study. Close attention was paid to the proximal region of the shoulder above the bandage in order to monitor local swelling due to fluid movement by the bandage. This phenomenon was not observed, and no patient showed additional local pitting above the bandaged region.

\section{Discussion}

Modern conservative treatment of lymphedema is based on CDT consisting of compression, MLD, physical exercise and skin care. The exact contribution of each of 
these separate procedures to the overall effect is unclear. There is a wide range of interindividual performance of techniques, exercise methods and compression bandaging systems, which makes a scientific assessment of CDT difficult. Only a few randomized controlled studies are available concerning the effect of CDT.

In a recent systematic review, Moseley et al. ${ }^{6}$ found just four studies that investigated the effect of compression by bandaging or garment alone in BCRL. Two controlled studies showed that compression therapy with and without additional MLD was equally effective for $\mathrm{BCRL}^{7},$. . Badger et al. ${ }^{9}$ compared the effect of 18 days of short stretch bandaging followed by compression hosiery to that of compression hosiery alone in leg and arm lymphedema. They showed that initial compression therapy with subsequent use of hosiery was twice as effective as hosiery alone.

Some studies have been performed concerning measuring the under-garment pressure ${ }^{10},{ }^{11}$. A major limitation of these studies is the discrepancy between the under-garment pressure claimed by the manufacturer and the actual interface pressure due to the large variety of types of garments and inter-individual variation in measuring garments.

In 1999, Williams and Williams ${ }^{12}$ measured the pressure on the arm with various garments in 9 patients during the maintenance phase. The pressure measured ranged from 7 to $64 \mathrm{mmHg}$ depending on the types of garments. They concluded that the selection of compression garments as part of lymphedema treatment is a complex endeavor and that "off-the-shelf" hosiery is not suitable. They found no relationship between the manufacturer-indicated compression class and the actual pressure in patients.

Until now, no studies have been published that measure the interface pressure under inelastic bandages in BCRL.

In our protocol, we focused on compression by measuring the short-term effect of IMLB in relation to volume reduction depending on the interface pressure. IMLB is the preferred method and is usually applied by trained staff following existing guidelines ${ }^{13}$.

Water displacement devices are the gold standard for volumetry of the extremities ${ }^{14,15,16,17}$. The classic water displacement method measures the overflow of water. Due to many disadvantages of this overflow technique, inverse water volumetry (IWV) was developed for measuring the shortage of water. This volumetric method has been validated and shown to be reliable and highly reproducible with high intra-class correlation coefficients ${ }^{18}$. The pressure measuring divice Kikuhime ${ }^{\circledR}$ contains probes of two sizes; one with a size 
of $10 \times 12.5 \mathrm{~cm}$, the other one with a diameter of $3 \mathrm{~cm}$. We chose the large probe, mainly because some preclinical studies showed a lower degree of spontaneous pressure loss (only $8 \mathrm{mmHg}$ in 55 hours) ${ }^{19}$. The accuracy of pressure readings obtained immediately after application of the compression has been shown to be high, and the variation coefficient with repeated measurements was reported to be between 2.1 and $7.1 \%{ }^{20}$. By using the large probe the influence of the circumference differences at both sites is diminished, Due to the influence of the local radius at both measure points, a pressure gradient could be expected, according to Laplace's law. However, we measured the proximal and distal sub-bandage pressure within the range needed during bandaging. Therefore a pressure gradient was not present.

The outcome of our study is surprising because it disagrees with previous studies of edema reduction in the lower extremities. While it had been shown that compression reduces venous stasis-induced swelling in a dose-dependent manner in the legs ${ }^{21,22}$, the situation appears to be quite different in arm lymphedema where lower pressure is obviously at least as effective as high pressure. This is true not only for the first 2 hours after bandage application, but also after 24 hours.

The observed volume reduction can largely be explained by a decrease in swelling, as a shift of fluid to the upper part of the shoulder was not observed.

Regarding the different effects of compression pressure on the legs as compared to the arms, it is important to note that the hydrostatic pressure that must be overcome by external compression is much higher in legs than in arms. In standing position, the venous pressure in the distal leg equals the weight of the blood column between the heart and the measuring point, which is about $80-100 \mathrm{mmHg}$. The high intravenous pressure in the upright body position will always increase the lymphatic load by promoting increased fluid extravasation. High external pressure is necessary in order to counteract this extravasation. The venous pressure in the arm is much lower than that of the leg due to the lower weight of the blood column between heart and hand. Thus, less external compression will be needed to reduce extravasation from the venules into the tissue and to promote re-absorption of tissue fluid. Especially in the first two hours after starting compression, low-pressure bandages seem to be sufficient to remove large amounts of volume (Figure 5). The arm-volume reduction by bandaging is probably not only due to a 
pressure-dependent shift of Starling's equilibrium but also to a stimulation of lymphatic drainage.

Secondly, lympho-dynamics should also be considered besides the veno-dynamic aspect. In healthy arms, the distance from the arm to the thoracic duct is short and the intralymphatic pressure varies with the intra-thoracic pressure. The lymphatic drainage is stimulated with relatively low or even negative intra-lymphatic pressures. In $B C R L$, the lymphatic drainage is deficient because of the damage of major lymph collectors and lymph-nodes by surgery and/or radiation leading to lymphatic congestion ${ }^{23}$.

In general two main effects of compression on the lymphatics have to be considered. The first is that an increase of the tissue pressure leads to a stretch of the anchoring filaments attached to the initial lymphatics, which causes an opening of the initial lymph capillaries. Another is the enhancement of the spontaneous contractions of the lymph-collectors that normally occurs under the influence of rhythmic pressure changes ${ }^{24}$. Inelastic compression material exerting a relatively low resting pressure and high massaging pressure peaks during movement and may promote the autonomous lymphatic contractions ${ }^{24}$. The required pressure to achieve optimal edema reduction depends obviously on the underlying pathology in different body regions and is therefore difficult to assess.

Stanton et al. ${ }^{25}$ studied the patho-physiologic changes in 24 BCRL patients by scintigraphic research. They suggest that active contractile lymphatic collectors have to work against a central resistance caused by the axillary lymphatic impairment. This leads to pump failure, diffuse filling of the fine dermal network with a rerouting of fluid demonstrated scintigraphically by dermal backflow and clinically by swelling. Modi et al. ${ }^{23}$ performed lymphatic congestion lymphoscintigraphy in healthy and BCRL patients and demonstrated a lymphatic pump failure in BCRL. In healthy persons, a mean compression of $39 \mathrm{mmHg}$ (range 10-60 $\mathrm{mmHg}$ ) is required to allow lymph flow from the wrist to the axilla. This pressure range fits nicely into experiments, which showed that a bandage pressure of 40-70 $\mathrm{mm} \mathrm{Hg}$ prevents lymph-flow from the wrist to the axilla ${ }^{26}$. In BCRL, the lymphatic contractile force is reduced to $24 \mathrm{mmHg}$ (range $0-60 \mathrm{mmHg})^{24}$. These figures might explain the idea that high compression pressure could block the remaining lymphatics. 
In leg lymphedema, a resting pressure of around $45 \mathrm{mmHg}$ is recommended as the standard intensive therapy for initial management ${ }^{1}$. Pressure values higher than 60 $\mathrm{mmHg}$ are not beneficial concerning intra-lymphatic pressure and flow ${ }^{25}$. However, a considerable loss of sub-bandage pressure starting immediately after application of IMLB has to be taken in consideration. These bandages do not contain elastic fibres that would keep the pressure sustained due their raining force. Therefore the volume reduction of the extremity and partly with the fatigue of the material ${ }^{2,3}$ seem to be the main reasons for the pressure loss.

However, some patients in our present series showed no volume reduction but a clear drop in the interface pressure, explaining the poor correlation between the volume and pressure changes over time. In these cases, the local indentation of the pressure transducer into the skin and by softening of the compressed tissue, could explain the reduction of pressure but not the arm volume. In addition, the type and amount of padding under the bandage plays an obviously important role and should be considered in future studies ${ }^{27}$.

A practical argument favoring higher pressure comes into play when high-pressure bandages are left in place for several days, which may cause some initial discomfort. Due to the high amount of pressure loss, especially during the first hours after application, the sub-bandage pressure will soon come to a range comparable to the values achieved in our group A immediately after application. A bandage on the arm applied with high pressure would thus offer the advantage of staying in place for a longer time-period, but after the initial pressure loss, it would likely achieve a comparable effect to low pressure bandages changed every day.

The present data have distinct practical implications:

- In the initial treatment phase of arm lymphedema bandaging, the bandage is applied on a daily basis. Low-pressure (20-30 mm Hg) short stretch bandages are equally effective as bandages applied with much higher pressures $(50-60 \mathrm{~mm} \mathrm{Hg})$, but with less discomfort for the patient.

- If the bandages are to be left in place for several days, it may be advisable to use higher initial pressures, even when there is some initial discomfort, which will usually subside after some hours. Despite the high degree of pressure loss and initially reduced effectiveness, the longer time interval before the bandage has to be 
changed may be a practical advantage.

- Our data show an exponential arm volume decrease, with the largest amount of reduction in the first two hours. According to our experience and in accord with recent literature, the phase of dramatic volume reduction is terminated after two to three days ${ }^{28}$.

Future studies should investigate the stage at which time bandages can be replaced by compression stockings, while taking into account the practical problem of proper fit. A second area of interest would be to measure volume reduction in patients with lymphedema when using bandages applied with different strengths and padding in order to find the most effective pressure range.

\section{CONCLUSION}

Inelastic, multi-layer, multi-component compression bandages allow immediate reduction of volume in lymphedema arms. With daily bandage renewal, within the statistical limitations of our study, low sub-bandage pressures between $20-30 \mathrm{mmHg}$ are effective and better tolerated high-pressure bandages by the patient. The difference in effect of high sub-pressure and low sub-bandage pressure, if exists, is too small to make a preference for high-pressure bandages. The therapeutically intended volume reduction together with the type and amount of padding beneath the bandage is the main reason for the initial fast drop of sub-bandage pressure in high pressure bandaging, and explains the need for frequent bandage change at the beginning of lymphedema therapy. 


\section{REFERENCES}

1 Lymphedema Framework. Best practice for the management of lymphedema. International consensus. London: MEP Ltd 2006. ISBN 0-9547669-4-6

2 Partsch H, Clark M, Mosti G, Steinlechner E, Schuren J, Abel M et al. Classification of compression bandages: Practical aspects. Dermatol Surg. 2008;34(5):600-9

3 Damstra RJ, Brouwer ER, Partsch H. Controlled, comparative study of relation between volume changes and interface pressure under short stretch bandages in leg lymphedema patients. Dermatol Surg. 2008;34(6):773-8

4 Consensus document of the International Society of Lymphology (ISL). The diagnosis and treatment of peripheral lymphedema. Lymphology. 2003;36:84-91

5 Partsch $\mathrm{H}$. The static stiffness index: a simple method to assess the elastic property of compression materials in vivo. Dermatol Surg. 2005;31:625-30

6 Moseley AL, Carati, CJ, Piller, NB. A systematic review of common conservative therapies for arm lymphedema secondary to breast cancer treatment. Ann Oncol. 2007;18 (4):639-46

7 Andersen L, Hojris I, Erlandsen M, Andersen J. Treatment of breast-cancer-related lymphedema with or without manual lymphatic drainage--a randomized study. Acta Oncologica. (2000;39(3):399-405

8 Johansson $\mathrm{K}$, Albertsson M, Ingvar C, Ekdahl C. Effects of compression bandaging with or without manual lymph drainage treatment in patients with postoperative arm lymphedema. Lymphology 1999 Sep;32(3):103-10 Comment in: Lymphology. 2000;33:69-70

9 Badger CM, Peacock JL, Mortimer PS. A randomized, controlled, parallel-group clinical trial comparing multilayer bandaging followed by hosiery versus hosiery alone in the treatment of patients with lymphedema of the limb. Cancer. 2000 Jun 15;88(12):2832-7

10 Johansson $\mathrm{K}$, Lie $\mathrm{E}$, Ekdahl C, Lindfeldt J. A randomized study comparing manual lymph drainage with sequential pneumatic compression for treatment of postoperative arm lymphedema. Lymphology. 1998; 31: 56-64.

11 Swedborg l. Effects of treatment with an elastic sleeve and intermittent pneumatic compression in post-mastectomy patients with lymphedema of the arm. Scand J Rehab Med. 1984;16:3541

12 Williams AF, Williams AE. "Putting the pressure on": a study of compression sleeves used in breast cancer related lymphedema. J Tissue Viability. 1999;9(3):89-94

13 Partsch H, Clark M, Bassez S, Benigni JP, Becker F, Blazek V et al. Measurement of lower leg compression in vivo: Recommendations for the performance of measurements of interface pressure and stiffness. Dermatol Surg. 2006;32:224-33

14 Vayssairat M, Ziani E, Houot B. Efficacité versus placebo de la contention classe 1 dans I'insuffisiance veineuse chronique des membres inférieurs. J Mal Vasc. 2000;25:256-62

15 Kaulesar Sukul DMKS, Den Hoed PT, Johannes EJ, Van Dolder R, Benda E. Direct and indirect methods for quantification of leg volume: comparison between water displacement volume try, the disk model and the frustum sign model, using correlation coefficient and the limits of agreement. J Biomed Eng. 1993;15:477-80

16 Stranden E. A comparison between suface mesaerements and water displacement volumetry for the quantification of leg edema. J Oslo City Hosp. 1981;31:153-5

17 Mortimer PS. Investigation and management of lymphedema. Vasc Med Rev. 1990;1:1-20

18 Damstra RJ, Glazenburg E, Hol W. The validation of the inverse water volumetry: New gold standard for arm volume measurement. Breast Cancer Res Treat. 2006;Oct;99(3):267-73 
19 Rotsch C. Personal communication. Arbeitstreffen 19.08.2005, Lohmann \& Rauscher GmbH \& Co. KG, Rengsdorf

20 Partsch $\mathrm{H}$. The static stiffness index: a simple method to assess the elastic properties of compression materials in vivo. Dermatol Surg. 2005;31(6):625-30

21 Partsch H, Winiger J, Lun B. Compression stockings reduce occupational leg swelling. Dermatol Surg. 2004;30(5):737-43

22 Vanscheidt W, Ukat A, Partsch H. Dose-response of compression therapy for chronic venous edema: Higher pressures are associated with greater volume reduction. J Vasc Surg. In print

23 Modi S, Stanton AWB, Svensson WE, Peters A, Mortimer PS, Levick JR. Human lymphatic pumping measured in healthy and lymphedematous arms by lymphatic congestion lymphoscintigraphy. J Physiol. 2007;583 (Pt 1):271-85

24 Olszewski WL. Contractility patterns of human leg lymphatics in various stages of obstructive lymphedema. Ann N Y Acad Sci. 2008;1131:110-8

25 Stanton AWB, Svensson WE, Mellor RH, Peters AM, Levick JR, Mortimer PS. Differences in lymph drainage between swollen and non-swollen regions in arms with breast cancer-related lymphedema. Clin Sci. 2001;101(2):131-40

26 Howarth DM, Southee AE, Whyte IM. Lymphatic flow rates and first-aid in simulated peripheral snake or spider envenomation. Med J Aust. 1994;161: 695-700

27 Mosti G, Mattaliano V, Partsch H. Influence of different materials in multicomponent bandages on pressure and stiffness of the final bandage. Dermatol Surg. 2008;34(5):631-9

28 Yamamoto T, Todo Y, Kaneuchi M, Handa Y, Watanabe K, Yamamoto R. Study of edema reduction patterns during the treatment phase of complex decongestive physiotherapy for extremity lymphedema. Lymphology. 2008 Jun;41(2):80-6 


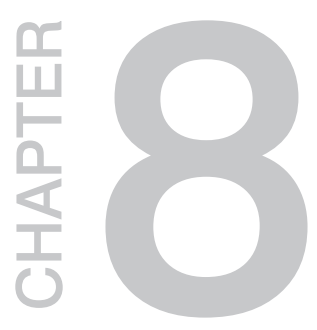

\title{
Lymphatic Venous Anastomosis (LVA) for Treatment of Secondary Arm Lymphedema: A Prospective Study of 11 LVA Procedures in 10 Patients with Breast Cancer Related Lymphedema and a Critical Review of the Literature.
}

\author{
R.J. Damstra, MD \\ H.G.J. Voesten $M D^{1}$ \\ W.D. van Schelven $M D^{2}$ \\ B. van der Lei $M D P h D^{3}$
}

${ }^{1}$ Department of Surgery, Nij Smellinghe Hospital, Drachten, The Netherlands

${ }^{2}$ Department of Nuclear Medicine, Medical Centre Leeuwarden, The Netherlands

${ }^{3}$ Department of Plastic Reconstructive, Aesthetic and Hand Surgery,

University Medical Centre Groningen, The Netherlands 


\section{ABSTRACT}

Objective: The incidence of breast cancer related lymphedema (BCRL) varies between 7-35\% depending on the combination of treatment modalities. Early detection of BCRL is crucial in order to start an effective non-operative treatment program. Because of the lack of prospective research on this topic, this study was undertaken to prospectively determine the effect of Lympho Venous Anastomosis (LVA) on BCRL and to review the current literature.

Study design and methods: Ten patients who were previously treated for breast cancer by surgery, radiotherapy, and chemotherapy, and were unresponsive to 12-weeks of non-operative treatment, underwent an LVA procedure (Degni-Cordeiro). Objective measurements were gathered for circumferential measurement, water displacement volumetry, and quality of life. Various types of lymphoscintigraphy were carried out pre-operatively and post-operatively at 3 and 12 months. Treatment was embedded in a multidisciplinary setting.

Results: Post-operative volume measurements initially showed a $4.8 \%$ reduction of lymphedema at 3 months and a $2 \%$ reduction after one year. Various scintigraphic parameters showed any improvement. Quality of life questionnaires reported minimal improvement.

Reviewing the literature, only retrospective studies were found; these reported varying results for LVA procedures. The selection of patients, classification of lymphedema, indications and types of LVA, and additional therapeutic options were heterogeneous, not comparable, and lacked a validated method of effect-assessment.

Conclusions: Our results showed a minimal reduction in volume of lymphedema following LVA; in the literature, there was no evidence of the success of LVA. Non-operative treatment and elastic stockings are still preferred by most patients with lymphedema, especially in early stages with few irreversible changes. 


\section{INTRODUCTION}

Lymphedema is a chronic disease caused by impairment of the lymphatic transport capacity, resulting in edema, excess of tissue proteins, and in latter stages, inflammation and irreversible changes such as fibrosis and excess of adipose tissue ${ }^{1}$. Lymph transport impairment and clinical signs of lymphedema can be acquired (secondary) or congenital (primary). Treatment of lymphedema is challenging. Therapeutic approaches consist of both non-operative and operative methods. The overwhelming majority of patients can effectively be treated by non-operative means such as complex decongestive therapy (CDT) in combination with manual lymphatic drainage, bandaging, physical exercises, skin care and elastic stockings. In the long lasting maintenance phase, therapeutic elastic stockings are mandatory. The goal of all non-operative treatment modalities is to reduce capillary filtration, improve drainage of interstitial fluid and macromolecules, and therefore reduce swelling, inflammation, recurrence of erysipelas, and improve quality of life $^{2}$. Operative treatment is only indicated in a few cases as a last resort.

Many reconstructive techniques have been described, such as lymphovenous anastomosis $(L V A)^{3}$, lympho-venous-lymphatic (LVL) transplant, (especially in the presence of venous hypertension ${ }^{4}$ ), and forms of lymph vessel transplantation ${ }^{5}$. LVA has been the most frequently used type of operation.

So far, most studies on LVA have both demonstrated a lack of significant volume reduction and considerable heterogeneity in the study populations. Therefore, we decided to evaluate the effectiveness of LVA in the treatment of one-sided breast cancer related lymphedema in a limited prospective study using objective, validated measurement methods with very strict inclusion criteria. These results will be discussed along with a review of the literature.

\section{PATIENTS, MATERIALS AND METHODS}

\section{Study design and population}

The study was conducted in the lymphedema Department of Nij Smellinghe Hospital in Drachten, The Netherlands, from 1999 to 2002. A systematic review of English and German language literature retrieved from MEDLINE, COCHRANE and Cinahl databases up to April 
2007 was performed. The articles were classified in levels of scientific evidence according the criteria for evidence-based medicine.

The study population consisted of 10 BCRL patients with severe lymphedema and persistent complaints, not responsive to maximal non-operative lymphedema treatment and who met the inclusion criteria for operative treatment. The patients were hospitalized in the lymphedema clinic to undergo a LVA according to our protocol.

\section{Inclusion and exclusion criteria}

In order to be included in this prospective study, patients with unilateral breast cancer related lymphedema had to meet the following criteria:

- No volume reduction after 3 months of complex decongestive treatment including manual lymph drainage, compression therapy, and physiotherapy, with persistent complaints such as heaviness, pain, shoulder function impairment, and recurrent attacks of erysipelas

- Persistent volume excess of more than $800 \mathrm{cc}$ measured by inverse water volumetry

- Proven scintigraphic signs of obstruction by absence of liver uptake and highly pathological transport index

- No recurrent malignancy

- Good patient compliance and willingness to wear therapeutic elastic stockings

- Operability

\section{Data collection and lymphoscintigraphy}

All patients underwent objective measurements with validated methods. The quality of life was measured preoperatively and 6 months postoperatively using the validated SF-36 quality of life assessment questionnaire ${ }^{6}$. Volume measurements were performed prior to LVA and at 3, 6, 12, and 24 months after LVA. Volumetry was performed with the inverse water volumetry method (gold standard) ${ }^{7}$. Furthermore, indirect circumferential measurements were taken according the Herpertz method ${ }^{8}$ for unilateral swelling, correlating the difference between the lymphedemic limb and the normal one.

The following clinical classification ${ }^{9}$ (Campisi) was used:

Stage 1a: no edema, in spite of the presence of lymphatic circulation anomalies (eg. due to mastectomy and axillary / inguinal lymphadenectomy; no difference 
in volume and consistency between limbs)

Stage 1b: same as stage $1 \mathrm{a}$ with mild edema, returning to normal after night rest

Stage 2: permanent edema, spontaneously regressing only with antideclivous position and night rest

Stage 3: permanent edema, not spontaneously regressing with antideclivous position, and ingravescent (erysipelas / cellulitis)

Stage 4: fibrolymphedema (initial lymphostatic verrucosis) with column limb

Stage 5: elephantiasis with severe limb deformation (including sclero-indurative pachydermitis and lymphostatic verrucosis)

\section{Scintigraphic protocol}

Unilateral lymphoscintigraphy was performed with focus on the liver uptake. On the anterior and posterior images, counts were determined in the liver and in the total field of view respectively. Subsequently, geometric means were calculated for the liver and the total field of view. The liver fraction was calculated. In cases of very early detection of liver uptake, the possibility exists for technical failure resulting from unintentional intravenous injection of radioactive tracer: the fast venous transport causes the tracer to show up in the liver very early. In the case of correct subcutaneous administration of the radioactive tracer, the liver can be visualized after some time through uptake via blood vessels. The radioactive tracer reaches the blood stream either via the thoracic duct or, in the case of a functioning lymphatic venous anastomosis, via this shunt. We defined any uptake at 120 and 180 minutes as sign of lymphatic drainage from the arm, which was preoperatively absent. Results were analyzed preoperatively and one year postoperatively.

In unilateral lymphoscintigraphy ${ }^{99 m}$, Tc-Nanocolloid was administered subcutaneously in the second interdigital space of the edematous arm. A dose of $80 \mathrm{MBq}$ and a volume of $0.1 \mathrm{ml}$ were used. Mobilization was standardized by asking the patient to make a fist repetitively during a fixed period of time. During the first 40 minutes following the injection, dynamic images were taken, including the entire arm, the axilla and the liver. Then images were made 60, 120, and 180 minutes after the injection.

The images were interpreted in three ways: visual (qualitative) interpretation, semiquantitative interpretation using the Transport Index, and quantitative interpretation 
through calculation of the liver fraction after 60,120 , and 180 minutes.

In clinical practice, visual interpretation is the method most often used, as it is easy to perform; however, small differences between pre and postoperative studies may be difficult to recognize.

Kleinhans et al. have described the Transport Index ${ }^{10}$. In this index, five parameters describe the lymph flow: lymphatic transport kinetics (K), distribution pattern (D), time lapse to appearance of lymph nodes ( $T$ in minutes, multiplied by 0.04 ), assessment of lymph nodes $(\mathrm{N})$, and assessment of lymph vessels (V). Each parameter can be given a score from 0 to 9, where 0 means that there are no abnormalities and 9 indicates that the condition for a given parameter could not be worse. The five scores are then added, resulting in the Transport Index, which can vary from 0 (normal) to 45 (most abnormal).

\section{Operating technique}

All LVA procedures were carried out under general anesthesia. A skin incision was made in the upper arm, about 7 to $10 \mathrm{~cm}$ above the elbow. No pneumatic tourniquet was used for exsanguination. Intradermal and subcutaneous injections of Methylene Blue were used 1 to $2 \mathrm{~cm}$ distal to the skin incision lines to outline the lymphatic system. All operative procedures were carried out by an experienced micro-vascular surgeon (BvdL) using an operating microscope. After skin incision, careful dissection was performed to identify small-sized veins ( 1 to $3 \mathrm{~mm}$ in diameter). After identifying a suitable vein, and collecting lymphatics (including some lymphatic vessels), lymphatic capillaries were dissected in the surrounding area. The diameters of these lymphatic vessels were $0.3 \mathrm{~mm}$ or less. With micro instruments, end-to-side anastomoses were made according to the DegniCordeiro procedure ${ }^{11}$, using 11-0 micro sutures; at least 3 to 4 anastomoses were made. Average completion time of the LVA procedure was about 60 minutes. Antibiotics were used perioperatively; the extremity was bandaged and elevated at night. Elastic stockings were continued permanently during the follow-up.

\section{RESULTS}

A total of 11 LVA procedures in 10 female patients were included in our study in the period from $1998-2002$. The mean age of the patients was 58.7 years ( $\Delta 46-68)$. All patients 
had stage 3 breast cancer related lymphedema according to Campisi, and were treated with mastectomy, axillary lymph node dissection, radiotherapy, and chemotherapy. lymphedema was present for a mean period of 5.3 years ( $\triangle$ 3-14 years) before LVA. None of the patients had responded sufficiently to our standardized conservative treatment program over 3 months. After removal of any pitting component, no further volume reduction could be achieved.

\section{Quality of life}

After 6 months, 5 of 10 patients had subjective relief of their complaints according to the SF-36 questionnaire.

\section{Volumetry (See also Table 1)}

After 3 months, there was a slight but insignificant reduction of volume. After one year this reduction diminished to almost zero (Table 1). The preoperative volume difference between both arms was $988 \mathrm{cc}$. After one year, the mean volume difference was $1075 \mathrm{cc}$ ( $\triangle 500-1856)$.

The Herpertz circumferential measurement demonstrated improvement of $4.8 \%$ after one year. The initial volume reduction with water displacement of $16 \%$ at three months was lost after one year, when no more than $2 \%$ volume difference was observed.

\section{Scintigraphy (see also Table 1)}

According to the Kleinhans transport index, there was no significant difference in transport before and one year after the operation: $43.0(\Delta 28-45)$ versus $42.2(\Delta 30-43)$.

Qualitative scintigraphic observation demonstrated an absence of lymph transport, dermal backflow and few signs of any organized transport, comparable with longstanding lymph-obstruction. In one patient, a lymph node in the elbow was visualized. After one year, a quantitative scintigraphical evaluation demonstrated no liver uptake after LVA, as compared with an initial lymphoscintigraphy.

\section{Long term follow-up}

Beyond the initial study design, at long term follow up in 2007 (mean follow-up 8 year), 2 patients had stable lymphedema using elastic stockings, 3 patients had died of metastasis, 
4 patients had complete volume reduction after circumferential suction-assisted lipectomy (Brörson method ${ }^{12}$ ) and 1 patient was lost to follow up. The main characteristics and results of 10 patients are presented in Table 1.

Table1. Summary of results

\begin{tabular}{ll}
\hline Mean age ( $\mathrm{n}=10)$ & 58.7 years $(\Delta 46-68)$ \\
Duration of lymphedema & 5.4 years $(\Delta 3-14)$ \\
\hline & \\
Clinical classification by Campisi & Stage 3: $\mathrm{n}=10$ \\
Inverse water volumetry: & \\
Total volume pre OP & 4253 cc $(\Delta$ 2817-6456) \\
Volume difference normal side pre OP & $988(\Delta 532-1400)$ \\
Volume difference normal side at 3 months & $841(\Delta 232-1256)$ \\
Volume difference normal side at 6 months & $994(\Delta 500-1789)$ \\
Volume difference normal side at 12 months & $1075(\Delta 500-1856)$ \\
Herpertz method at 0-12 months: (at four points) & \\
Mean Volume difference pre OP & $35.2 \%(\Delta 20-50 \%)$ \\
Mean volume difference 12 months & $33.5 \%(\Delta 18-49 \%)$ \\
Visual signs lymphoscintigraphy: & \\
Dermal back flow & 10 \\
Lymph vessels & 0 \\
Lymphnode in the elbow & 1 \\
Kleinhans Transport Index at 0-12 months: & \\
TI pre OP &
\end{tabular}

\section{DISCUSSION}

This prospective study clearly demonstrates that, although there was an initial period of relief of the subjective complaints in 5 of 10 patients, there were no significant improvements after LVA in our series of patients with chronic lymphedema; neither volume measurements nor scintigraphic measurements showed any effect. 
When reviewing the literature of the last decades (see Table 2), there is a striking lack of prospective and comparative studies concerning the effect of LVA on chronic lymphedema. All studies reviewed initially used non-operative treatment by CDT for a period ranging from 3 days up to 6 months. Although this might create a bias when selecting patients for LVA, the alternative is that many patients would have unnecessary operative treatment with perhaps detrimental effects. Most patients with early stages 1-3 of lymphedema can be treated successfully with $C D T^{13,14}$. Moreover, in many studies information is missing about the follow-up protocol and many do not report whether or not elastic stockings are mandatory after an LVA procedure.

In order to compare treatment options, an adequate classification is necessary. According to stages 1 to 3 , conservative treatment of lymphedema is sufficient in most patients ${ }^{13,14}$. In stage 3 lymphedema, the pitting component can often be treated successfully; however the fibrosis and access of adipose tissue will remain. Matsubara et al. ${ }^{29}$ studied LVA in 9 women with secondary lymphedema of the legs refractionary to non-operative management. He obtained the best results when operative procedures were combined with continued postoperative physiotherapy.

In a recent personal communication, Campisi ${ }^{15}$ suggested that from his point of view, LVA is most suitable in the early stages $1 \mathrm{~B}, \mathrm{II}$ and early III. No other postoperative therapeutic modalities such as elastic stockings, decongestive treatment or anti platelet clotting medication were mentioned . Campisi advised initial physical treatment for peripheral lymphedema. Additionally, in later stages (3,4 and 5), in the absence of scintigraphical visualization of lymphatics, it is standard procedure to reduce the lymphedema by nonoperative methods first, before considering microsurgery. According to Campisi, LVA is further contra-indicated for lymphatic-lymphnodal aplasia and stage 5 lymphedema.

For these stages Brorson ${ }^{12}$ described a promising method (circumferential suction-assisted lipectomy) that introduces reductive surgical therapy with good long-term results, demonstrating more than $100 \%$ volume reduction. Elastic stockings must be worn to maintain these excellent results. From this perspective, we used this method successfully in 4 of our 10 patients refractionary to LVA.

From a pathophysiological perspective, the goal for LVA is to reduce interstitial volume 


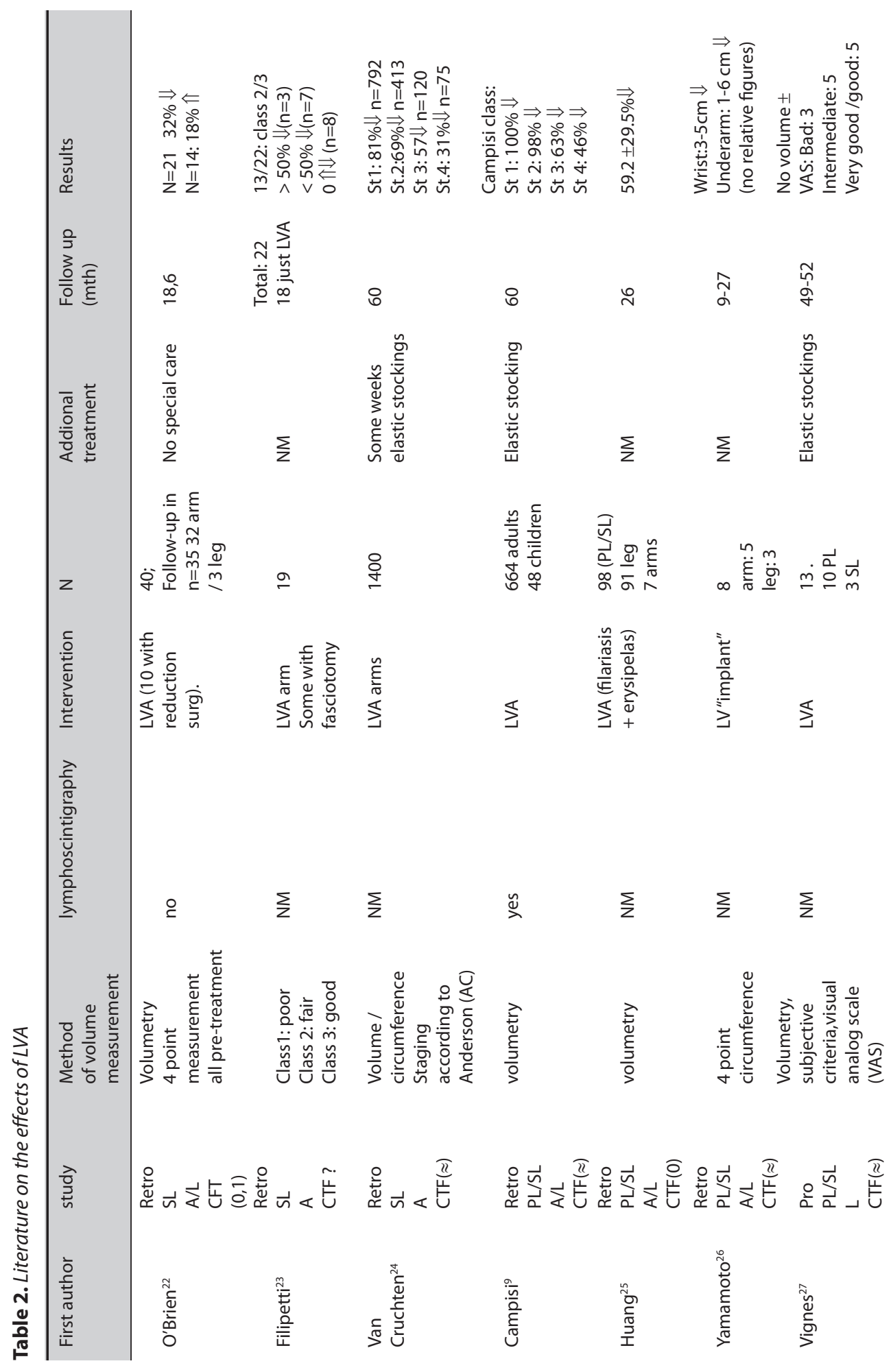




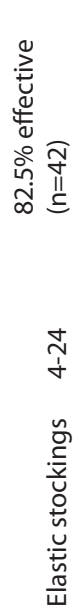

$\frac{8}{\frac{8}{1}}$

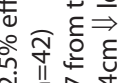

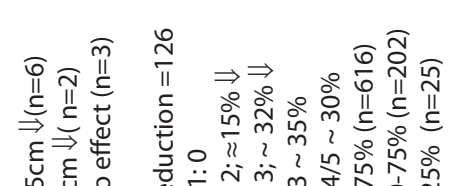

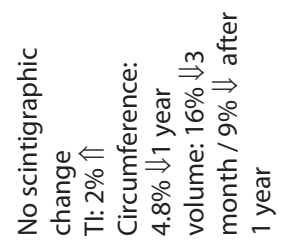

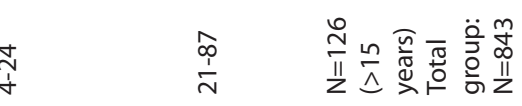

$\underset{\infty}{\stackrel{n}{\frac{0}{\pi}}}$

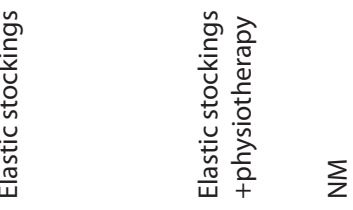

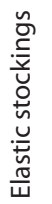

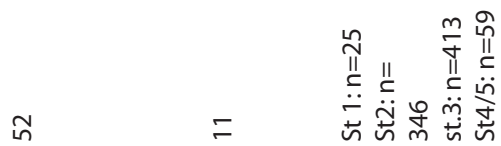

으

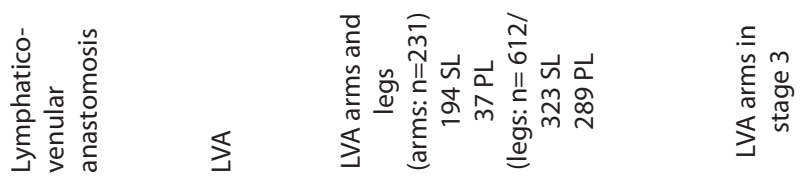

ㅇํㄷ

$\sum$

$\stackrel{๊}{2}$

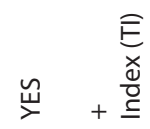

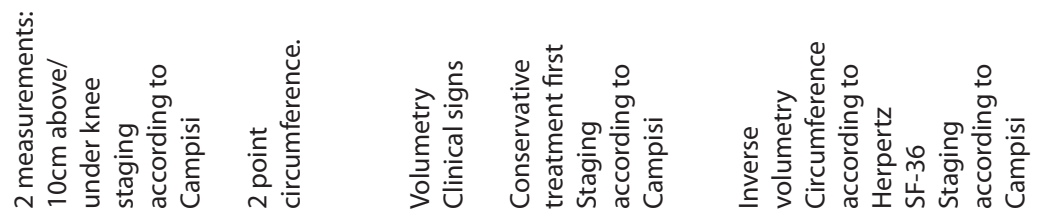

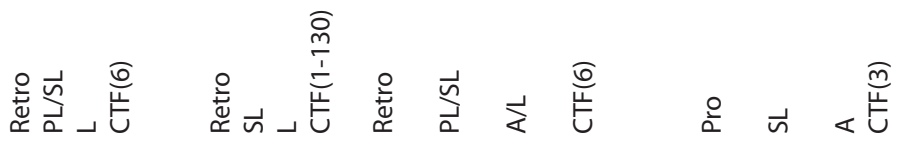

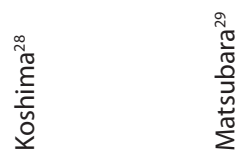

$\frac{\frac{0}{m}}{\frac{m}{0}}$

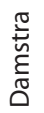


by improving lymphatic drainage. To exemplify the results of LVA, we chose objective outcome parameters for improvement of lymphtransport capacity, volume changes and quality of life. Kleinhans et al. demonstrated the usefulness of the Transport Index to evaluate the results of lymphatic grafting. ${ }^{16,17,18}$

In general, lymphoscintigraphy is performed bilaterally, offering objective evidence to distinguish (late stage) lymphatic pathology from non-lymphatic causes of extremity edema. Criteria for lymphatic dysfunction include delayed (> 30 minutes), asymmetric, or absent visualization of regional lymph nodes, and the presence of "dermal backflow". Additional findings include asymmetric visualization of lymphatic channels and collateral lymphatic channels. All of these parameters are correlated with a clinical diagnosis of lymphedema ${ }^{19} 20$. Liver fraction scanning ${ }^{21}$ is only of merit when the radionuclide is administered in the edematous extremity. Late uptake in the liver (after 3 hours) is an indication of lymphatic transport out of the injected arm. The theoretical advantage of using the liver fraction as an objective means to judge lymphovenous shunt efficacy is clear.

In the current study, we considered any uptake as a positive result. Therefore, we postulated, with an open and well functioning shunt, in due time the radionuclide would be transported from the arm via the shunt into the veins of the arm, followed by further transport to the reticulo-endothelial system, which is mainly located in the liver. A perceptible liver fraction on the postoperative images, when compared to the preoperative situation, thus should indicate an open, well functioning shunt. In this study we could not find any significant improvement in the objective parameters for volume change or liver uptake of ${ }^{99 \mathrm{~m} T c-N a n o c o l l o i d . ~ I n ~ t h e ~ l i t e r a t u r e, ~ c o n v i n c i n g, ~ v a l i d a t e d, ~ a n d ~}$ objective methods for visualization of the effects of a LVA are missing.

\section{CONCLUSION}

No effect could be measured using objective validated measurements methods. In this first prospective study on the LVA treatment of unilateral breast cancer related lymphedema, despite the limited number of patients, no effect could be measured using objective validated measurement methods. The effects of LVA in literature are also not proven; there is a lack of standardization of the patient population, and the measurement methods 
are not validated. Most studies are retrospective and often involve a mix of primary arm, secondary arm, and secondary leg lymphedema in the same study. On top of this, classification of lymphedema varies, and the indications and criteria for LVA are unclear. Therefore we conclude that, considering our results and the literature review, LVA is not effective for the treatment of unilateral breast cancer related lymphedema. Although the LVA has been performed and studied for more than 3 decades, this method still has not had a breakthrough and will never become a treatment of choice in daily practice.

Non-operative, decongestive treatment combined with the regular use of elastic stockings is the corner stone of treatment for most patients with lymphedema, especially in its early stages when it involves few irreversible changes; however, in later stages with more irreversible changes, LVA still does not effectively reduce volume. 


\section{REFERENCES}

1 Brorson H, Ohlin K, Olsson G, Nilsson M. Adipose tissue dominates chronic arm lymphedema following breast cancer: an analysis using volume rendered CT images. Lymphat Res Biol. 2006;4(4):199-210

2 Mortimer PS. Therapy approaches for lymphedoedema. Angiology. 1997;48(1):87-91

3 O'Brien BM, Sykes PJ, Threlfall GN, Browning FS. Microlymphaticovenous anastomoses for obstructive lymphedema. Plas Reconstr Surg. 1977;60(2):197-211

4 Campisi C, Boccardo F, Zilli A, Maccio A. The use of vein grafts in the treatment of peripheral lymphedemas: long term results. Microsusrgery. 2001;21(4):143-7

5 Baumeister RGH, Frick A. Die autogen gefasstransplantation zur microchirurgischen Rekonstruktion des Lymphgefassysteems. Phlebology. 1996;25:83-8

6 Aaronson NK, Muller M, Cohen PD, Essink-Bot ML, Fekkes M, Sanderman R, Sprangers MA, te Velde A, Verrips E. Translation, validation, and norming of the Dutch language version of the SF-36 Health Survey in community and chronic disease populations. J Clin Epidemiol. 1998 Nov;51(11):1055-68

7 Damstra RJ, Glazenburg E, Hol W. The validation of the inverse water volumetry: New gold standard for arm volume measurement. Breast Cancer Res Treat. 2006;Oct;99(3):267-73

8 Herpertz U. Messung und Dokumentation von Ödemen. Lymphologie. 1994;18:24-30

9 Campisi C, Boccardo F, Alitta P, Tachella M. Derivative lymphatic microsurgery: indications, techniques and results. Microsurgery. 1995;16(7):463-8

10 Kleinhans E, Baumeister RGH, Hahn D, Siuda S, Bull U, Moser E. Evaluation of transport kinetics in lymphoscintigraphy: follow-up study in patients with transplanted lymphatic vessels. Eur J Nucl Med.1985;10:349-352

11 Degni M. New techniques of lymphatic-venous anastomosis for the treatment of lymphedema. Lymphlology. 1981;14(2):61-3

12 Brorson H. Liposuction in arm lymphedema treatment. Scand J Surg. 2003;92(4):287-95

13 Földi E, Földi M, Clodius L. The lymphedema chaos: a lancet. Ann Plast Surg. 1989;22(5):148-51

14 Szuba A, Cooke JP, Youuf S, Rockson SG. Decongestive lymphatic therapy for patients with cancer related or primary lymphedema. Am J Med. 2000;109:296-300

15 Campisi C, Eretta C, Pertile D, Dan Rin D, Campisi C, et al. Microsurgery for treatment of peripheral lymphedema: long term outcome and future perspectives. Microsurgery. 2007;27(4);333-8

16 Baumeister RG, Siuda S. Treatment of lymphedemas by microsurgical lymphatic grafting: what is proved? Plast Reconstr Surg. 1990;85:64-76

17 Weiss M, Baumeister RGH., Hahn K. Post-therapeutic lymphedema: scintigraphy before and after autologous lymph vessel transplantation; 8 years of long-term follow-up. Clin Nucl Med. 2002;27:788-792

18 Vaqueiro M, Gloviczki P, Fisher J, Hollier LH, Schirger A, Wahner HW. Lymphoscintigraphy in lymphedema: an aid to microsurgery. J Nucl Med. 1986;27:1125-1130

19 Yuan Z, Chen L, Zhu J, Lu H, Zhu R. The role of radionuclide lymphoscintigraphy in extremity lymphedema. Ann Nucl Med. 2006;20(5):341-4

20 Scarsbrook AF, Ganeshan A, Bradley KM. Pearls and pitfalls of radionuclide imaging of the lymphatic system: part 2: evaluation of extremity lymphedema. Br J Radiol. 2007 Mar;80(951):219-26

21 Ketterings C, Zeddeman S. Use of the C-scan in evaluation of peripheral lymphedema. Lymphology. 1997;30:49-62 
22 O'Brien BC, Shafiroff BB. Microlymphaticovenous and resectional surgery in obstructive lymphedema. World J Surg. 1979;3(1):3-15

23 Filippetti M, Santoro E, Graziano F, Petric M, Rinaldi G. Modern approaches to postmastectomy brachial lymphedema. Microsurgery. 1994;15(8):604-6

24 Cruchten LH van, Neuborg L. Diagnose en behandeling van lymfoedeem. Ned Tijdschr Geneeskd. 1995:138:653-7

25 Huang GK. Ergebnisse microchirurgischer lymphvenöser Anastomosen bei Lymphödemen Bericht über 110 Fälle. Langenbecks Arch Chir. 1989;374:194-9

26 Yamamoto $Y$, Sugihara T. Microsurgical lymphaticovenous implantaton for the treatment of chronic lymphedema. Plast Reconstr Surg. 1998(1);101:157-9

27 Vignes S, Boursier V, Priollet P, Miserey G, Trévidic P. Quantitative evaluation and qualitative results of surgical lymphovenous anastomosis in lower limb lymphedema. J Mal Vasc. 2003;28(1):30-5

28 Koshima I, Nanba Y, Tstsuya T, Takahahi Y, Itoh S, Fujitsu M. Minimal invasive lymphaticovenular anastomosis under local anesthesia for leg lymphedema. Is it effective for stage III and IV? Ann Plast Surg. 2004;53:261-6

29 Matsubara S, Sakuda H, Nakaema M, Kuniyosh Y. Long term results of microscopic lymphatic vessel isolated vein anastomosis for secondary lymphedema of the lower extremities. Surg Today. 2006;36(10):859-64

30 Campisi C, Davini D, Bellini C, Taddei G, Villa G, et al. Lymphatic microsurgery for the treatment of lymphedema. Microsurgery. 2006;26(1):65-9 


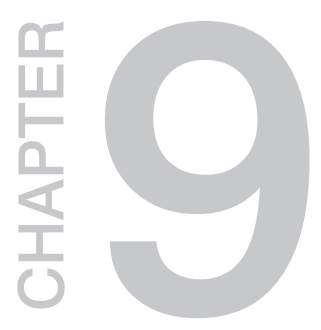

\section{Reduction Surgery by Circumferential Suction-Assisted Lipectomy (Brorson method) in End Stage Breast Cancer- Related Lymphedema: a Prospective Study}

R.J. Damstra MD

H.G.J.M. Voesten $M^{1}$

P. Klinkert MD,PhD ${ }^{2}$

H. Brorson MD, PhD

${ }^{1}$ Department of Vascular Surgery, Nij Smellinghe Hospital Drachten, The Netherlands

${ }^{2}$ Department of Vascular Surgery, Tjongerschans Hospital Heerenveen, The Netherlands

${ }^{3}$ Department of Clinical Sciences, Lund University Malmö,

Plastic and Reconstructive Surgery, Malmö University Hospital, Malmö, Sweden 


\section{ABSTRACT}

Background: The incidence of breast cancer-related lymphedema (BCRL) ranges between 1-49\%. Longstanding lymphedema leads to an increase in subcutaneous adipose tissue with various amounts of accumulated lymph. Although the majority of patients can be treated by non-operative means with satisfying results, end stage BCRL is often non-responsive, where the hypertrophy of adipose tissue limits the outcome.

Aim: Can the results of circumferential suction assisted lipectomy (CSAL) be reproduced?

Design: Prospective controlled study

Method: Thirty-seven women with unilateral BCRL were included. After conservative treatment for 2-4 days, patients were operated on. Limb compression with short stretch bandages was resumed postoperatively, followed by flat knitted compression garments.

Results: Mean preoperative excess volume was $1399 \mathrm{ml}$. Total aspirate volume was $2124 \mathrm{ml}$ with $93 \%$ aspirate adipose tissue content. After 12 months, an average reduction in excess volume of $118 \%$ was found. Percentage reduction in excess volume after 12 months was linearly related to the preoperative excess volume but showed no linear relationship with the operation serial number or duration of lymphedema.

Conclusion: CSAL with lifelong compression garments is an effective technique in end stage BCRL. The outcome confirms earlier published results and can safely be embedded in a specialized multidisciplinary lymphedema clinic. 


\section{INTRODUCTION}

Breast cancer is the most common malignant disease in women. A frequent complication is lymphedema, with an incidence of $1-49 \%$, depending on the combination of therapy, including mastectomy, sentinel node biopsy, standard axillary lymph node dissection and/or postoperative irradiation ${ }^{1}$. Although the sentinel procedure is associated with a lower risk of lymphedema, three prospective studies of 515, 5327 and 936 patients still reported a $5-7 \%$ risk of edema ${ }^{2,3,4}$. Presently there is no cure for lymphedema. With early diagnosis, the majority of patients can be treated by conservative treatment, such as complex decongestive therapy (CDT) consisting of manual lymph drainage, compression therapy, physical exercise, skin care and self-management aspects, followed by wearing flat knitted compression garments. ${ }^{5}$

Patients with end stage, pronounced, non-pitting lymphedema do not respond to conservative treatment because initial lymph stasis results in an accumulation of high protein fluid ${ }^{6}$ and inflammation, resulting in hypertrophy of adipose tissue and sometimes fibrosis. Previous surgical efforts utilizing both total excision and skin grafts on the muscle fascia $^{7}$ or longitudinal excision of the full thickness skin and subcutaneous tissue ${ }^{8}$ did not result in acceptable cosmetic and functional results. Microsurgical reconstruction, such as lymphovenous shunts and lympho-venous-lymphatic transplants ${ }^{9}$ or lymph vessel transplants ${ }^{10}$ does not result in complete removal of the excess arm volume in chronic non-pitting lymphedema because it does not remove the hypertrophic subcutaneous adipose tissue. In addition, a prospective study has shown that lympho-venous shunts do not increase lymph flow or result in significant loss of excess volume ${ }^{11 .}$

The rise of modern liposuction started in 1974 when Arpad and Giorgio Fischer developed a blunt hollow cannula connected to a suction device ${ }^{12}$ and the technique was further refined by several surgeons ${ }^{13}$ and later adapted by Brorson for the treatment of end stage lymphedema by performing Circumferential Suction Assisted Lipectomy (CSAL) ${ }^{14}$. It results in more than $100 \%$ reduction of excess volume over a long period of time, with the treated arm being somewhat smaller than the unaffected one.

CSAL results in significant improvement of Quality of Life and range of motion of shoulder 
and $\operatorname{arm}^{15}$. Although damage of lymphatic structures might occur, scintigraphic studies have not shown that CSAL for lymphedema further decreases the already impaired lymph transport capacity ${ }^{16}$.

The aims of the study were:

1. To reproduce and confirm the results of the novel liposuction technique according previous report.

2. To analyse the difference in percentages fat aspirated when a tourniquet is used (forearm and distal upper arm) and when a tumescent technique is used in the proximal upper arm.

3. To study the correlation between the total aspirate volume and the preoperative excess volume.

4. To determine if the extent of reduction depends on the preoperative excess volume, the duration of lymphedema or the operation serial number.

\section{METHODS}

\section{Patients}

A group of 37 patients with unilateral BRCL, who met the inclusion criteria, was enrolled and operated on between November 2004, and April 2007, at the Lymphedema Clinic of Nij Smellinghe Hospital, the Netherlands. The study describes an established treatment regimen as standard hospital procedures. All patients have signed an informed consent. The inclusion criteria were: no acceptable reduction of edema after three months of CDT without significant 'pitting', i.e. less that $5 \mathrm{~mm}$., at least an arm volume difference of $600 \mathrm{ml}$ (ratio: volume of affected arm/volume of unaffected arm > 15\%) compared to the unaffected arm, no active cancer or open wounds, no medical or family history of coagulation disorders or intake of drugs that affect coagulation, and physical condition sufficient to undergo surgery.

'Pitting' means that a depression is formed after pressure on the edematous tissue by the thumb, resulting in fluid being squeezed into the surroundings. To standardize the pitting test, one presses as hard as possible with the thumb on the region to be investigated for one minute, the amount of depression being estimated in millimeters. A swelling caused 
by hypertrophied adipose tissue, shows little or no pitting. In the preoperative briefing, full compliance was requested to wear garments 24 hours a day. A patient was not included if she was unwilling, or unprepared, to wear garments continuously after surgery.

Continuing postoperative compression therapy is not only essential to maintain maximum reduction results but is also of paramount importance to protect edematous arms against infection and subsequent erysipelas ${ }^{17}$.

\section{Inverse water volumetry}

In volumetry, water displacement devices are the gold standard and have been studied intensively for leg lymphedema $18,19,20,21$. The classic water displacement method measures the overflow of water. In order to overcome the disadvantages of this overflow technique, another method termed inverse water volumetry (IWV) was developed for measuring the decrease in water. This method has been validated for arm swelling and measures the volume of the arm including the hand. It is now regarded as the new gold standard ${ }^{22}$. The variation coefficient based on three volume measurements of each unaffected arm was between 1.4 and 3.7\%. This method has a high inter- and intra-observer reliability.

Volume measurements were performed at admission to the clinic 2-4 days prior to operation, preoperatively, and at $0.5,1,3,6$ and 12 months afterwards. Both arm volumes were recorded for each patient using the inverse water volumetry measurement method. Thus, both arms were measured at each visit, and the difference (volume of affected arm - volume of unaffected arm) in arm volumes was designated as the 'excess volume'. The decrease in excess volume was calculated as a percentage:

$\underline{\text { initial excess volume - present excess volume }}$ initial excess volume $\times 100$

In addition, the ratio of the affected to unaffected arm was also calculated. At all visits, a medical history was taken, focusing on functionality of the arm and shoulder.

\section{Preoperative treatment}

Patients underwent multidisciplinary, conservative treatment during 2-4 days preoperatively in order to minimize any pitting component. The treatment consisted of 
manual lymph drainage during forty-five minutes, short stretch compression bandaging and exercises to stimulate lymphatic drainage.

\section{Surgical procedure}

All patients were given general anesthesia. Cefazolin was given intravenously at induction of anesthesia and once during surgery after release of the tourniquet. Afterwards, no further antibiotics were given. The arm was rendered bloodless, and a tourniquet was applied on the upper arm, exerting a pressure of $100 \mathrm{~mm} \mathrm{Hg}$ above the systolic blood pressure. The first (distal) stage of the surgical procedure was performed using a 'dry' liposuction technique without local injection of epinephrine in the arm distal to the tourniquet ${ }^{23}$. Liposuction was performed with an electrically driven $2.0 \mathrm{~mm}$ reciprocating (4000 c/ min) suction cannula (MicroAire ${ }^{\circledR}$ ) PAL-600E, USA). Suction was provided by the hospital's central vacuum system operating at a pressure of $0.9 \mathrm{~atm}$. Various cannulas were used with diameters of 3,4 and $5 \mathrm{~mm}$ and lengths of 15 or $20 \mathrm{~cm}$. They were introduced through 10-12 small incisions ( $3 \mathrm{~mm}$ ) along the arm and occasionally on the back of the hand. When complete reduction of the lower arm and the distal part of the upper arm (below the tourniquet) was achieved, short stretch bandages were applied, and the tourniquet was released. The surgical procedure continued with the proximal part of the upper arm, including the area covered by the tourniquet, using a tumescent technique in order to minimize blood loss. The upper arm was injected with $1000 \mathrm{ml}$ normal saline $(154 \mathrm{mmol} / \mathrm{L}$, $0.9 \%)$ containing $1 \mathrm{ml}(1 \mathrm{mg} / \mathrm{ml})$ adrenalin. Finally, short stretch bandages were applied to the rest of the upper arm. After surgery, incisions were left open to drain into the short stretch bandages. The duration of the procedure and any need for blood transfusions were recorded.

\section{Fat measurements}

The aspirate was collected in $2000 \mathrm{ml}$ plastic containers graded to an accuracy of $10 \mathrm{ml}$. Supernatant fat and infranatant blood-tinged fluid solution was allowed to separate by overnight gravitational sedimentation before measuring their respective volumes.

\section{Postoperative course}

All patients were bandaged up to axilla and shoulder (including fingers) by specially 
trained staff with multilayer inelastic bandaging consisting of a foam layer and two short stretch cotton bandages. The first change of bandage was two days after surgery, when also measurements were taken to order custom-made flat knitted compression garments and gloves, two of each. As soon as the leakage from the small wounds had stopped, usually 4-6 days after surgery, bandaging was discontinued, and custom-made garments were worn, usually compression class 2. Manual lymph drainages were not performed anymore.

The patient was discharged from the hospital as soon as she was able to put on the flat knitted garment herself, normally 7 days postoperatively. Postoperatively temporary removal of garments was allowed when showering or swimming and on formal social occasions. Clean garments are put on every day, while the used ones are washed to be ready for use the next day. Washing the garment makes it shrink somewhat resulting in more compression and removing perspiration salts that can irritate the skin.

At the one-month visit, the limbs were measured for new custom-made compression garments. In the meantime, when compression became insufficient to the opinion of the patient, taking in slack of the garment with a sewing machine were carried out by the team or by the patient at home (controlled compression therapy) ${ }^{24}$. On a yearly basis, patients needed between four and six flat knitted garments. The dermatologist took measurements for all garments.

\section{Statistical analysis}

Measurements are presented as the mean, standard error of the mean (SEM), and range. The significance of differences was assessed using the Student's $t$ test for paired observations, and $p$-values $<0.05$ were accepted as significant. The postoperative reduction in excess volume was compared with the excess volume recorded before treatment. Regression analysis was performed to obtain the coefficient of correlation ( $r$ ) and the coefficient of regression ( $\beta$ ) with a 95\% confidence interval $(95 \% \mathrm{Cl})$.

The percentage reduction in the excess volume after 12 months was compared with the excess volume recorded preoperatively, the duration of lymphedema, and the operation serial number using multiple linear regression analysis. Linear regression was used to calculate the relationship between the volume of aspirate and preoperative excess 
volume. Regression analysis was performed to obtain the coefficient of correlation ( $r$ ) and the coefficient of regression $(\beta)$ with a $95 \%$ confidence interval $(95 \% \mathrm{Cl})$. The number of patients included in the study is based on attainability. According the $95 \%$ confidence interval related to the pre-operative excess of volume, this number is adequate to reach significant results.

\section{RESULTS}

The study population comprised 37 female patients with a mean age at cancer surgery of 48 (range $27-68$ ) years and age at time of CSAL 59 (range 31-80) years. The onset of lymphedema after cancer treatment was mean 3.4 (range 0-370 years and the duration of lymphedema till CSAL was 8.2 (range 1-24) years.

The patients' breast cancer was treated with mastectomy $(n=31)$, lumpectomy $(n=6)$, axillary dissection ( $n=37)$, postoperative radiotherapy $(n=31)$ and adjuvant chemotherapy $(n=24)$. Non-operative treatment with complex decongestive therapy and garments were initially performed in all 37 patients. In 33 patients pneumatic compression was used and 16 patients were previously unsuccessful treated with lymphatico-venous anastomoses.

Mean operating time was 122 minutes (range, 85-170 minutes). The mean excess volume at admission was $1540 \mathrm{ml}$ (range, 612-2987 ml) and the ratio of the swollen arm to the unaffected arm was 1.51 (range, 1.16-2.19). After 2-4 days of CDT it was $1399 \mathrm{ml}$ (range, 604-2721 ml (Figure 1), and the ratio was 1.47 (range, 1.16-2.17) (Figure 2). This corresponds to a mean preoperative reduction of $142 \mathrm{ml}$ (range, $-81-888 \mathrm{ml}$ ) or $8.1 \%$ (range, $-4,6-$ $35 \%, p<0.0001)$. The effect of the operation was obvious, and during the postoperative course, significant further reduction was seen in the excess volume $(p<0.0001)$. Two weeks postoperatively, the mean excess volume dropped to $119 \mathrm{ml}$ (range, -634 to 1042 $\mathrm{ml}$ ), and the ratio was 1.05 (range, 0.84-1.46). At 12 months postoperatively, the mean excess volume was $-149 \mathrm{ml}$ (range, -876 to $473 \mathrm{ml}$ ) with a ratio of 0.96 (range, $0.75-1.21$ ) corresponding to an average relative reduction of 118\% (range, $74-235 \%$ ). The reduction was $116 \%$ (range, $75-233 \%$ ) if compared to the excess volume at admission (Figure 1). There were no surgical complications, and no blood transfusions were necessary. 


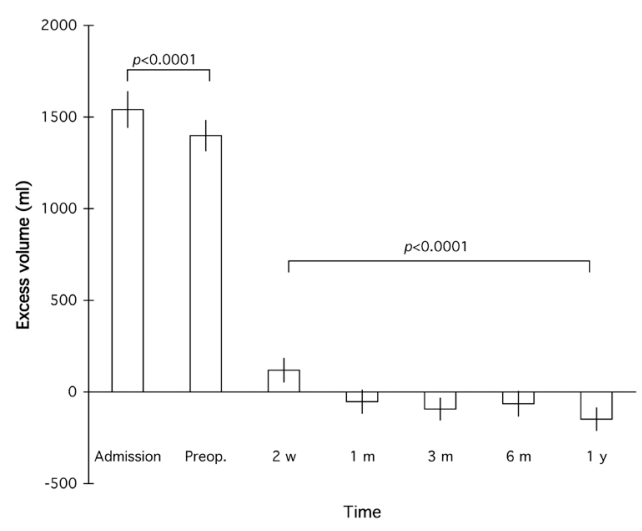

Figure 1. Mean (SEM) excess volume at admission, preoperatively, and after the operation. Note the pronounced effect of the operation and that complete reduction was achieved already after one month. Mean corresponding ratio at 12 months was 0.96 (range, 0.75-1.21).

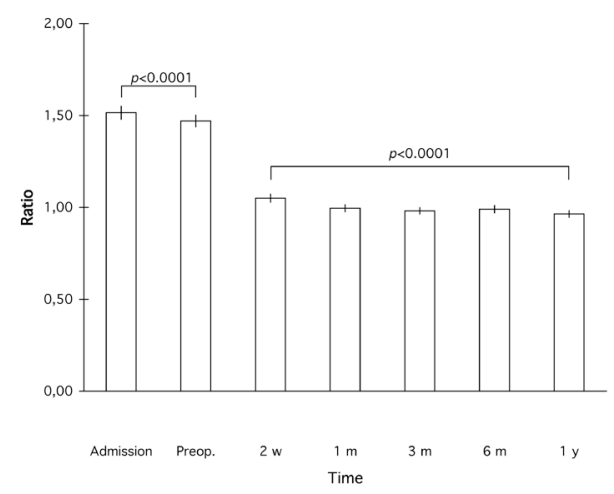

Figure 2. Mean (SEM) ratios (affected/unaffected arm) at admission, preoperatively and after the operation, corresponding to the outcome in Figure 1. Note the pronounced effect of surgery and the fact that complete reduction was already achieved after one month.

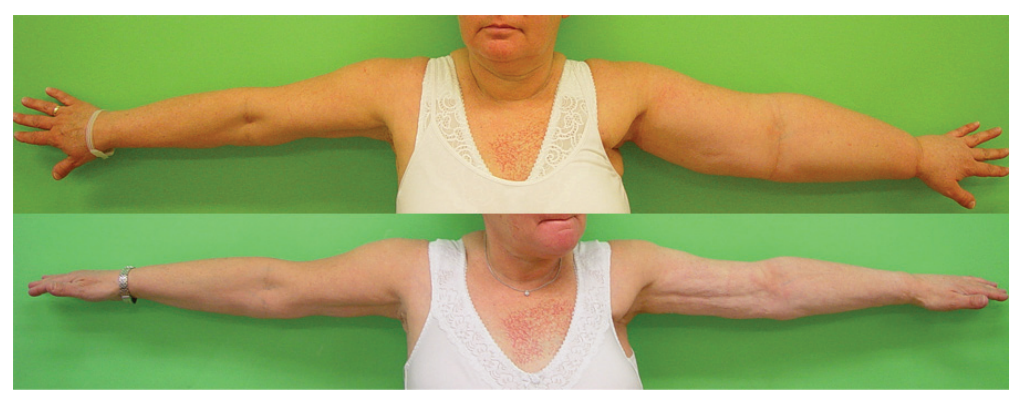

Figure 3a. A 54-year-old woman with lymphedema of the left arm for 9 years at admission. Excess volume at admission was $1794 \mathrm{ml}$ and preoperative excess volume of $1711 \mathrm{ml}(-83 \mathrm{ml})$. b) Clinical result one year after liposuction showing an excess volume of $-183 \mathrm{ml}$. 


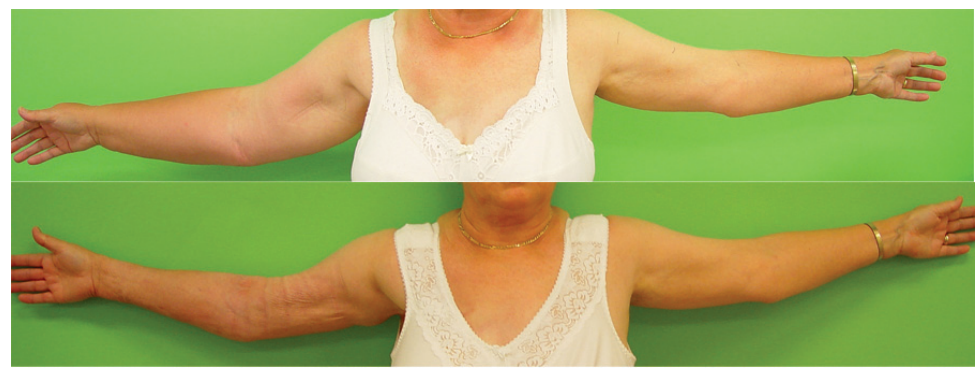

Figure 4a. A 66-year-old woman with lymphedema of the right arm for 6 years at admission. Excess volume at admission was $1441 \mathrm{ml}$ and $1102 \mathrm{ml}$ preoperatively $(-339 \mathrm{ml})$. b) Clinical result one year after liposuction with an excess volume of $-12 \mathrm{ml}$

The mean volume of aspirate removed when a tourniquet was used was $953 \mathrm{ml}$ (range 315-1700 ml), and the proportion of fat in the aspirate was 93\% (range 59-100\%). The mean volume aspirate removed when tumescence was used was $1172 \mathrm{ml}$ (range, 440$2470 \mathrm{ml}$ ), and fat comprised 64\% (range, 30-88\%) of the aspirate. Thus, the total mean aspirate volume was $2124 \mathrm{ml}$ (range, 945-4070 ml) (Figure 5).
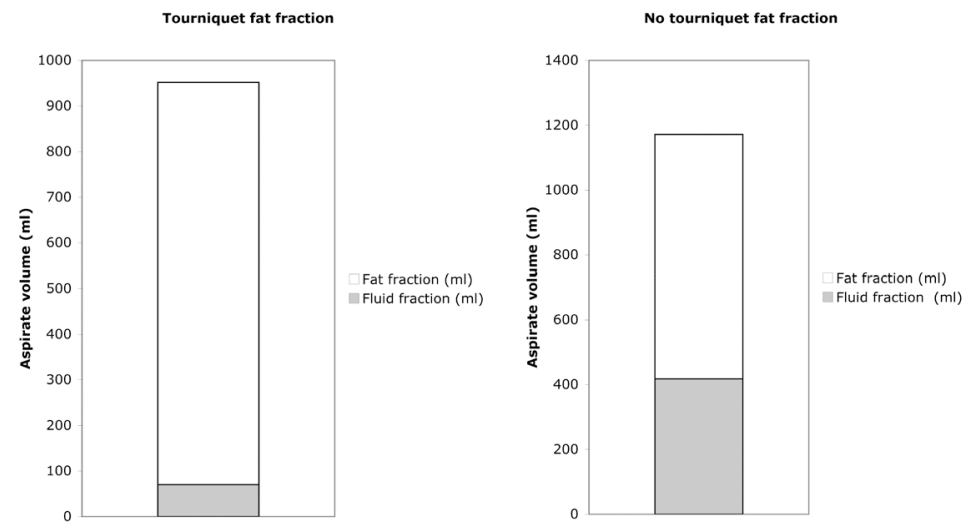

Figure 5a. Total aspirated volume using a tourniquet. The fat fraction comprised 93\% (range, 59-100\%) of the aspirate. b) without a tourniquet and using a tumescent technique in the upper arm, the fat fraction was 64\% (range 30-88\%).

The percentage reduction in excess volume after 12 months was linearly related to the preoperative excess volume $(\beta=-0.043(95 \% \mathrm{Cl}-0.065$ to -0.021$) ; r=-0.557, p=0.0004)$ (Figure 6), but showed no linear relationship with the operation serial number or duration of lymphedema. 


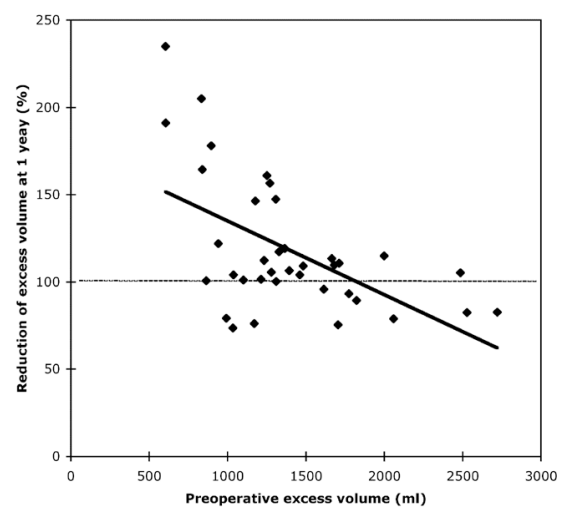

Figure 6. Correlation between the percentage reduction of excess volume after 12 months and preoperative excess volume

The correlation between the total aspirate volume and the preoperative excess volume is displayed in Figure 7 ( $\beta=0.333(95 \% \mathrm{Cl}-0.089-0.757) ; r=0.261, p<0.118)$.

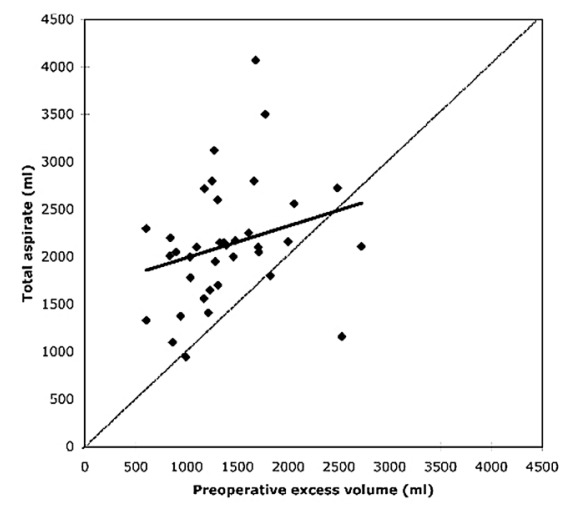

Figure 7. Regression between the total aspirate volume and the preoperative excess volume

\section{DISCUSSION}

In the early pitting stages of lymphedema, the majority of patients benefit from CDT in the initial phase and flat knitted compression garments during the maintenance phase. Compression with bandages and/or garments helps to decrease the amount of interstitial fluid formation, preventing back flow of lymph and enhancing the muscle pump by providing a barrier for it to work against ${ }^{24}$.

The effect of CDT on longstanding massive edema with excess adipose tissue is poor, 
since adipose tissue does not disappear by means of compression alone. In addition surgical intervention is reserved for patients with excess volume and heaviness causing severe strain in the shoulder and neck, functional impairment, and recurrent attacks of erysipelas, as well as problems with clothing.

Modern microsurgical techniques such as lympho-venous anastomosis orlympho-venouslymphatic transplants ${ }^{9}$ and lymph vessel transplantation ${ }^{10}$ seem to be a step forward, but the reported results are partly contradictory and not entirely successful. In particularly, lympho-venous anastomoses ${ }^{25}$ claim a decrease in lymphatic flow following the resolution of symptoms, which results in occlusion of the newly reconstructed conduits. $A$ recent study showed no convincing results of LVA, and a review of the literature not only demonstrated that studies were lacking significant volume reduction but also revealed the presence of considerable heterogeneity in the study population ${ }^{11}$. Although attractive in concept, none of these methods resulted in complete reduction, because excess tissue ('non-pitting' component) cannot be removed.

As for liposuction, an early report in 1989 by Sando and $\mathrm{Nahai}^{26}$, however, showed modest results. O'Brien et $\mathrm{al}^{27}$ reported slightly better results with a mean decrease in excess volume of $23 \%$. Brorson et $\mathrm{al}^{28}$ refined the technique (CSAL), combining it with continuous compression with garments, leading to complete reduction and long lasting results.

Using CSAL, we were able to achieve a result that parallels the outcomes of earlier published studies ${ }^{14,28}$. In light of this evidence, CSAL is a promising surgical technique that is capable of reaching predictable and reliable improvement in end stage cases of lymphedema.

Evaluating our present results in greater detail, more adipose tissue was removed in the fraction using a tourniquet (93\%) in comparison to a tumescent technique (65\%). This was because the aspirate using the tumescent technique also contained injected saline with adrenaline, in addition to some exsanguination.

No blood transfusions were needed with this combined technique, as compared to Brorson's first cases, where neither tourniquet nor tumescence was used, and thus transfusions were sometimes needed when the aspirate exceeded $2000 \mathrm{ml}$. The combination of a tourniquet and tumescence seemed to be a safe procedure in this study, where mean 
aspirate volumes were well over $2000 \mathrm{ml}$ and up to $4070 \mathrm{ml}$ in the maximum case. This parallels findings by Wojnikow et $\mathrm{al}^{23}$ showing that bleeding can be minimized with the use of a tourniquet and tumescence technique. Tumescence leads to the compression of vascular structures. Infiltration of large volumes of saline with adrenaline, not only leads to vasoconstriction, but also provides fluid mechanical distension of the targeted fatty tissue and stretching and dispersing of the fibrous wall ${ }^{29}$, thus amplifying the volume of the subcutaneous space and allowing for easier passage of the liposuction cannulas.

Similar to the study by Brorson and Svensson ${ }^{14}$, we also found that the percentage reduction in the volume of edema after one year was linearly related to the preoperative excess volume (Figure 6). In concordance with the cited study, we could not demonstrate a correlation between outcome and duration of the edema. In contrast, we did not find any correlation to the operation serial number with regard to excess volume reduction, probably because we were taught the technique, leading to a steeper learning curve. Complete reduction of volume difference was easier to achieve when the excess volume was less pronounced. Despite inter-subject variations in responsiveness, the results clearly showed that complete reduction of the excess volume was possible in patients whose excess volume was up to approximately 2000 ml (Figure 3, 4) Substantial reduction can be achieved in even more severe cases. In this series, for example, edema of $2721 \mathrm{ml}$ was reduced by $83 \%$ in one patient. In some cases, the results were less positive, possibly as a result of fibrosis, although multiple regression analysis did not indicate that duration of the edema was a significant factor. The total aspirate was larger than the preoperative excess volume in 33 patients and the aspirated fat volume exceeded the preoperative excess volume in 25 patients leading to a calculated overcorrection. In contrast to Brorson et $\mathrm{al}^{14}$ there was no correlation between the aspirate volume and the preoperative excess volume (Figure 7), most probably due to that tumescence was not used in this first series, thus leading to smaller total aspirate volumes

The goal is a slight overcorrection, thus allowing for some marginal increase of volume without compromising the results. Patients treated with CSAL are more satisfied and show a significant increase in quality of life compared to the pre-operative situation ${ }^{30}$. This benefit overwhelms a presumptive disadvantage of wearing garments. On the contrary, 
patients are already used to wearing their garments and have no problems wearing them. Essential is of course that all garments are made-to-measure and flat knitted.

When CSAL is performed in a lymphedema clinic, embedded in a conservative treatment program, even preoperative lymphedema without significant (less than $5 \mathrm{~mm}$ ) 'pitting', i.e. a non-pitting edema, could be reduced by $8.1 \%$, thus improving the preoperative condition (Figure 1).

\section{CONCLUSION}

Patients with lymphedema not responding to 3 months of complex decongestive treatment were accepted for CSAL. Preoperatively, a residual pitting component was removed by adding 2-4 days conservative treatment with short stretch bandaging leading to $8.1 \%$ volume reduction. Subsequently residual hypertrophied adipose tissue was removed by CSAL, resulting in complete reduction already after one month and this was maintained through constant use of compression garments postoperatively. In this series of patients, an average reduction in excess volume of $118 \%$ was achieved,

This prospective study with one-year follow-up in 37 patients demonstrates that CSAL, embedded in a multidisciplinary setting with opportunities for optimum of pre-operative conditions, is an effective and safe method for treating end stage non-pitting $B R C L$, confirming the results of earlier studies. 


\section{REFERENCES}

1 Petrek JA, Senie RT, Peters M, Rosen PP. Lymphedema in a cohort of breast carcinoma survivors 20 years after diagnosis. Cancer 2001;92:1368-77

2 Mansel RE, Fallowfield L, Kissin M, Goyal A, Newcombe RG, et al. Randomized multicenter trial of sentinel node biopsy versus standard axillary treatment in operable breast cancer: the ALMANAC Trial. J Natl Cancer Inst 2006; 98:599-609

3 Wilke LG, McCall LM, Posther KE, Whitworth PW, Reintgen DS et al. Surgical complications associated with sentinel lymph node biopsy: results from a prospective international cooperative group trial. Ann Surg Oncol 2006;13:491-500

4 Mclaughlin SA, Wright MJ, Morris KT, Giron GL, Sampson MR et al. Prevalence of lymphedema in women with breast cancer 5 years after sentinel lymph node biopsy or axillary dissection: objective measurements. J Clin Oncol 2008;26:5213-9

5 Mosely AL, Carati CJ, Piller NB. A systematic review of common conservative therapies for arm lymphedema secondary to breast cancer treatment. Annals of Oncology 2007;18:639-46

6 Brorson H, Ohlin K, Olsson G, Nilsson M. Adipose tissue dominates chronic arm lymphedema following breast cancer: an analysis using volume rendered $\mathrm{CT}$ images. Lymphatic Res and Biology 2006;4:199-210

7 Charles H. Elephantiasis of the leg. In: Latham A, English TC, Eds. A system of treatment. Vol 3. London: Churchill, 1912: 516

8 Thompson N. Surgical treatment of chronic lymphoedema of the lower limb. With preliminary report of new operation. BMJ 1962;2:1566-73

9 Campisi C, Davini D, Bellini C, Taddei G, Villa G, Fulcheri E, et al Lymphatic microsurgery for the treatment of lymphedema. Microsurgery 2006;26:65-9

10 Baumeister RG, Frick A. The microsurgical lymph vessel transplantation. Handchir Mikrochir Plast Chir 2003;35:202-9

11 Damstra RJ, Voesten HG, van Schelven WD, van der Lei B. Lymphatic venous anastomosis (LVA) for treatment of secondary arm lymphedema. A prospective study of 11 LVA procedures in 10 patients with breast cancer related lymphedema and a critical review of the literature. Breast Cancer Res Treat 2009;113:199-206

12 Fischer A, Fischer $\mathrm{G}$. First surgical treatment for molding body's cellulite with three $5 \mathrm{~mm}$ incisions. Bull Int Acad Cosmet Surg 1976;3:35

13 Flynn TC, Coleman WP 2nd, Field LM, Klein JA, Hanke CW. History of liposuction Dermatol Surg 2000;26:515-20

14 Brorson H, Svensson H. Complete reduction of lymphoedema of the arm by liposuction after breast cancer. Scand J Plast Reconstr Surg Hand Surg 1997;31:137-43

15 Brorson H, Ohlin K, Olsson G, Långström G, Wiklund I, Svensson H. Quality of life after liposuction and conservative treatment of arm lymphedema. Lymphology 2006; 39; 8-25

16 Brorson H, Svensson H, Norrgren K, Thorsson O. Liposuction reduces arm lymphedema without significantly altering the already impaired lymph transport. Lymphology 1998;31:156-72

17 Brorson H, Svensson H. Skin blood flow of the lymphedematous arm before and after liposuction. Lymphology 1997;30:165-72

18 Vayssairat M, Ziani E, Houot B. Efficacité versus placebo de la contention classe 1 dans 
I'insuffisiance veineuse chronique des membres inférieurs. J Mal Vasc 2000;25:256-62

19 Kaulesar Sukul DM, den Hoed PT, Johannes EJ, van Dolder R, Benda E. Direct and indirect methods for quantification of leg volume: comparison between water displacement volume try, the disk model and the frustum sign model, using correlation coefficient and the limits of agreement. J Biomed Eng 1993;15:477-80

20 Stranden E. A comparison between surface measurements and water displacement volumetry for the quantification of leg edema. J Oslo City Hosp 1981;31:153-5

21 Mortimer PS. Investigation and management of lymphedema. Vasc Med Rev 1990;1:1-20

22 Damstra RJ, Glazenburg E, Hol W. The validation of the inverse water volumetry: New gold standard for arm volume measurement. Breast Cancer Res Treat 2006;99:267-73

23 Wojnikow S, Malm J, Brorson H. Use of a tourniquet with and without adrenaline reduces blood loss during liposuction for lymphoedema of the arm. Scand J Plast Reconstr Surg Hand Surg 2007;41:243-49

24 Brennan MJ, Miller LT. Overview of treatment options and review of the current role and use of compression garments, intermittent pumps, and exercise in the management of lymphedema. Cancer 1998;1983 (suppl 12b): 2821-27

25 Vignes S, Boursier V, Priollet P, Miserey G, Trevidic P. Quantitative evaluation and qualitative results of surgical lymphovenous anastomosis in lower limb lymphedema. J Mal Vasc 2003; 28:30-5

26 Sando WC, Nahai F. Suction lipectomy in the management of limb lymphedema. Clin Plast Surg 1989; 16: 369-373

27 O'Brien BM, Khazanchi RK, Kumar PA, Dvir E, Pederson WC. Liposuction in the treatment of lymphedema; a preliminary report. Br J Plast Surg 1989;42:530-33

28 Brorson H. Liposuction in arm lymphedema treatment. Scand J Surg 2003;92:287-95

29 Samdal F, Amland P, Bugge J. Blood loss during liposuction using the tumescent technique. Aesth Plast Surg 1995;18:157-60

30 Brorson H, Ohlin K, Olsson G, Långström G, Wiklund I, Svensson H. Quality of life after liposuction and conservative treatment of arm lymphedema. Lymphology 2006; 39; 8-25 

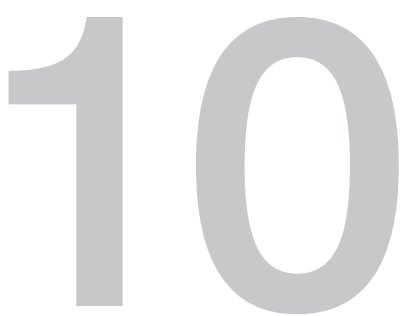

\title{
Multidisciplinary Guidelines for the Early Diagnosis and Management of Lymphedema
}

\author{
Robert J. Damstra, $M D^{1}$, \\ Carola .J.E. Kaandorp MD PhD² \\ 1. Chairman, working group on lymphedema, Dutch Institute for Healthcare \\ Improvement $\mathrm{CBO}$, Utrecht \\ 2. Advisor, Dutch working group on lymphedema, Dutch Institute for Healthcare \\ Improvement CBO, Utrecht
}




\section{ABSTRACT}

In 1999, the Dutch Institute for Healthcare Improvement (CBO) organized a taskforce on lymphedema to evaluate the current literature and to propose evidence- and expert-based recommendations suitable for national implementation of a guideline for the treatment of lymphedema. The articles were classified by using the criteria for evidence-based medicine according to levels of scientific evidence.

\section{Conclusions/recommendations of the guidelines}

Lymphedema is a symptom of congenital or acquired tissue fluid accumulation that arises as a consequence of impaired lymphatic drainage, for example, after breast cancer treatment. Early diagnosis of a swollen limb and adequate treatment are important in order to prevent irreversible changes. Patient history and characteristic clinical presentation are essential steps in the diagnostic process. Lymphoscintigraphy gives additional information to confirm impaired lymphatic flow or abnormal distribution of lymph fluid. Information and recommendations on precautions, preventive measurements and self-management instructions are important for all patients with (or at risk of) lymphedema. Treatment of lymphedema has to be adjusted to the individual patient and may consist of several therapeutic options, including manual lymphatic drainage (MLD). After volume reduction has been accomplished, a well-fitted compression garment is essential in the maintenance phase. Surgical procedures for lymphedema have limited use. Lymphedema is treated by many medical disciplines. Based on specific knowledge gained through diagnostic evaluation and treatment, a therapeutic program is designed. Being a chronic condition, lymphedema requires life-long treatment and follow-up. 


\section{INTRODUCTION}

Lymphedema is a common and disabling problem, caused by a dysfunction of the lymphatic system. For the patient it leads to loss of quality of life due to swelling, discomfort, fatigue and cosmetic deformity. To achieve a national, widely accepted guideline on lymphedema, which includes aspects such as uniformity in (early) diagnosis, treatment, volume measurement and follow-up, a multidisciplinary working group was formed by the Dutch Institute for Healthcare Improvement CBO with representatives from medical scientific societies, paramedical, nursing and patients organisations.

\section{Objectives}

The objectives of the guidelines were to provide recommendations in diagnostics, early recognition, multidisciplinary treatment and follow up of lymphedema to physicians, paramedics, nurses, healthcare workers and patients to facilitate best practice in the management of lymphedema.

\section{Evidence}

A systematic review of English and German literature retrieved from Medline, Cochrane and CINAHL databases up to April 2001 was carried out. Some recent, relevant articles were added to update some aspects of the guidelines. The articles were classified according to the criteria for evidence-based medicine.

\section{Validation}

An initial draft of the guidelines was developed by the working group and discussed during a national congress on 5th April 2002 organized by the CBO. The results of these discussions were incorporated into a revised draft, which was approved by all representatives in the working group on lymphedema.

The complete guideline ${ }^{1}$, and a summary have been published in Dutch ${ }^{2}$. The working group considers this guideline suitable for all types of lymphedema, although most literature concerns cancer related lymphedema. The following is a summary of the key points covered by the guidelines, together with supporting evidence and rationale where appropriate. 


\section{Pathophysiology of lymphedema}

Lymph consists of tissue fluid and accumulated proteins collected from the interstitial space by a network of capillary lymph vessels, collectors and large lymph vessels which ultimately drain into the venous system by way of the thoracic duct. Lymphedema is the result of a disturbance of a dynamic equilibrium in the interstitium in which the lymph transport capacity is insufficient in relation to the amount of lymph that is being produced. This discrepancy can be the result of a subnormal transport capacity or an excess of lymph production. Discrete (transient) pitting edema is often the first sign of a insufficient lymphatic transport capacity. In a later stage, especially due to accumulation of interstitial macromolecules inflammatory changes are induced in the subcutaneous tissue, leading to induration and fibrosis. A side effect of the accumulation of proteins is an increase of osmotic pressure, which leads to more edema ${ }^{3}$. Therefore, the classical sign of lymphedema as an irreversible, non-pitting edema is just the end stage of a continuum and the sign of "pitting" or "non pitting" edema is not evidence in itself for the existence of lymphedema.

\section{Primary and secondary lymphedema}

The supposed aetiology of the lymph flow abnormality has led to a classification that categorizes lymphedema as either primary or secondary. Primary lymphedema refers to a developmental or functional disorder in the lymphatics and can present early or later on in life. In some cases a genetically base is determined and lymphedema can also occur as part of a syndrome. Secondary lymphedema is more common and caused by trauma, surgery or infection; although this classification is arbitrary, because often a compensated primary lymphedema will become manifest after events as trauma or infection and is then erroneously called a secondary lymphedema. Scharz showed that in a group of 1000 women, up to $8 \%$ had clinical signs of lymphedema of the lower extremities ${ }^{4}$.

\section{Phlebolymphedema}

Phlebolymphedema is considered as a sub-form of lymphedema. Initially, lymph transport capacity is normal, but is overloaded by accumulation of interstitial fluid as a result of venous hypertension (dynamic insufficiency). As a secondary effect the lymphatic system will become defect and an accumulation of macromolecules will then contribute to a 
further tissue edema.

\section{Incidence}

The incidence of lymphedema as reported in many studies, mostly concerns breast cancer related lymphedema. Extended searches of literature show an incidence varying from 1343\%. A study in 2001 among 303 patients with breast cancer who underwent a sentinel node biopsy showed that $3 \%$ of them developed lymphedema 5 . Recent studies even show an increased incidence of lymphedema up to 6-9\% after performing a sentinel node biopsy procedure in breast cancer treatment ${ }^{6,7}$.

A study in 2003 by Moffatt et al. ${ }^{8}$ showed that lymphedema is an underestimated problem. Unfortunately there is no standardisation of measurement method and assessment techniques, nor are there any generally accepted criteria to define lymphedema. Also there is a large variation in cancer therapy protocols.

The prevalence of lymphedema after gynaecological and urological interventions in the pelvic region for cervix, vulvar, penis and bladder carcinoma varied between $20 \%$ and $60 \%$, especially when a lymphedenectomy is performed ${ }^{9}$.

\section{Diagnostics in lymphedema}

In every patient with swelling of an extremity, the face or the external genitals, the diagnosis lymphedema should be considered. History and physical examination are the cornerstone of the diagnosis. In early stage lymphedema there is just a reversible, pitting edema. Later on, the characteristic features of accumulation of macromolecules, fibrosis and interstitial inflammation will occur. Additional diagnostics can be performed by means of a dynamic lymph scintigraphy, which involves a subcutaneous injection of a solution of radio labelled nanocolloid, with subsequent external scintillation detection in the regions of interest by measuring the uptake.

This method is an assessment of the functional capacity of the lymphatic system. Lymph scintigraphy is indicated when previous investigations failed to establish the aetiology of the swelling. For a proper interpretation of a lymph scintigram we advise the use of standardized scintigraphy protocols to minimize inter-observer variability. 
Indications for additional scintigraphy:

- Inexplicable edema at a young age (<35 years);

- Edema and swelling of unknown cause and doubts concerning lymphedema;

- Edema during the follow-up of patients belonging to a high-risk group;

- Progressive development of edema with venous and/or neurological symptoms following oncological treatment of the regional lymph node station; it is important, in this regard, to distinguish lymphedema as a result of (recurrent) malignancy from benign edema;

- Unilateral persistent edema following an episode of erysipelas and adequate follow-up treatment with a therapeutic elastic stocking;

- Lymphedema not responding to an objective, optimal performed treatment program

- Discrepancy between a trauma and the (persistent) resulting swelling, for example following an insect bite, a sprained ankle or knee surgery;

- Discrepancy between the subjective symptoms of a patient and the degree of objectively measured swelling of the extremity.

\section{(Early) diagnostics and effect measurement}

In patients at risk, lymphedema assessment can be performed by taking the specific history, and measuring the volume or the circumference of the affected extremity.

The following aspects should be referred to during the specific history:

- The manner and time of development and the course;

- The effect of gravity on the edema;

- The effects of exercise, ambient temperature and pregnancy;

- The type and nature of the symptoms;

- The family history pertaining to the affections and symptoms that have been determined;

- The prior history and co morbidity;

- Limitations of function;

- Previous therapy. 
The following aspects should be evaluated during the specific physical examination:

- The presence of scars from previous surgery or radiotherapy;

- Signs of venous insufficiency;

- The nature of the swelling: 'pitting' versus 'non-pitting', unilateral versus bilateral, proximal versus distal;

- Any accompanying symptoms, such as redness, warmth, pain on palpation, hyperpigmentation, thickening of the skin with congestive papillomatosis, cutaneous fibrosis and hyperplasia

- Stemmer's test; when the result is positive, it is no longer possible to make a crease by pinching the skin on top of the foot at the level of the proximal phalanx of the second and third toes as a result of thickening of the skin (fibrosis);

- Abnormalities in the nails, such as abnormal or slower growth;

- Indications of recurrent tumour growth;

The results of a retrospective study support the necessity to start lymphedema treatment early with small volume changes to improve the outcome..$^{10}$ In this study, irreversible changes such as fibrosis were shown to be less pronounced with early treatment than with delayed intervention.

The $\mathrm{CBO}$ guideline supports a strategy to improve awareness on the development of early stage lymphedema in patients at risk such as breast cancer treated patients, patients after treatment for gynaecologic, urologic oncology and patient with primary lymphedema (see figure 1)

\section{Lymphedema assessment: Trend- en effect measurements}

Unfortunately, many methods are used for lymphedema assessment such as circumference measurement and water displacement volumetry. All members of the CBO working group agree on the necessity of having an objective, validated method, which can be applied in a clinical or outpatient setting ${ }^{11}$. In the literature ${ }^{10-15}$, absolute circumference measurement is often cited as a reliable technique. The multidisciplinary working group considers this method inadequate because the increase in circumference caused by edema must be related to the absolute circumference. A relative method, which correlates the enlargement to the total diameter is preferable. The CBO recommends the use of 


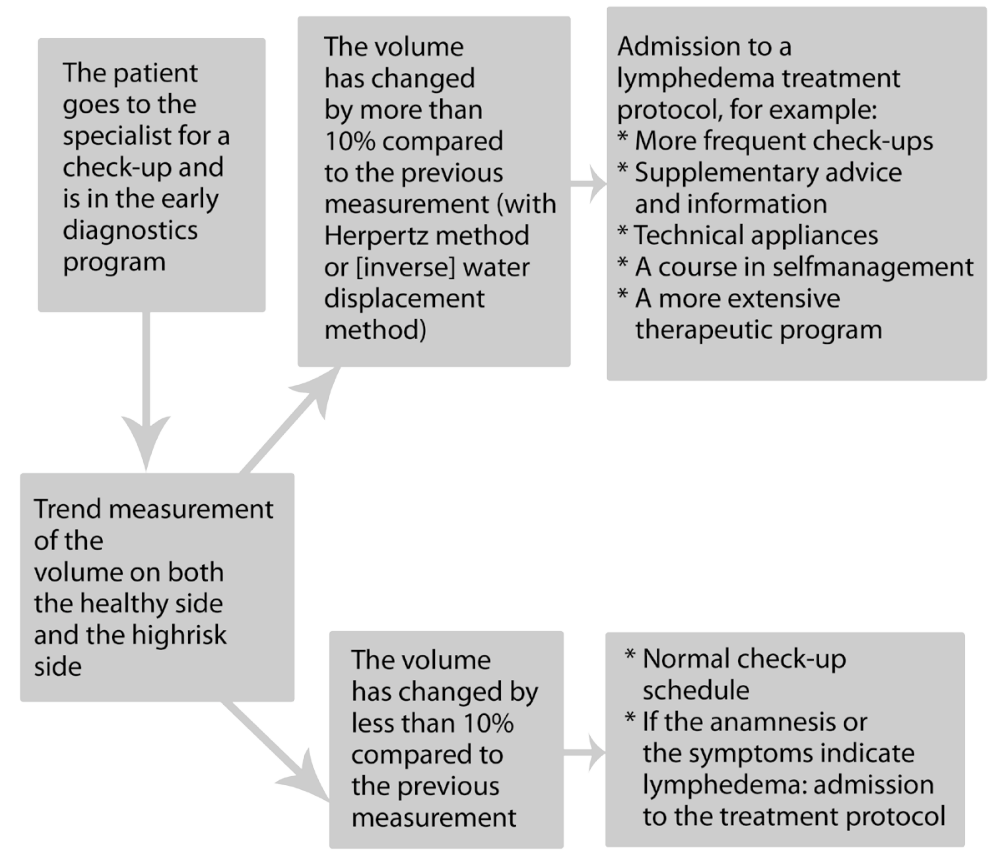

Figure 1: A scheme for early detection of lymphedema in the extremities in patients at risk.

the 4-point circumference measurement (Herpertz method ${ }^{12}$ ) with a calculated volume percentage. This method is suitable for unilateral (risk) of edema. Another assessment is the Kuhnke method ("4-cm-method ${ }^{13 ")}$. An optoelectrical device might be reliable but still is not validated. Neither of these methods is able to measure hand and foot volume ${ }^{14}$.

Currently the water displacement method is considered the gold standard ${ }^{15}$. It can be used to measure an entire extremity ${ }^{16}$ although it is time consuming and not suitable for daily practice.

In a new device has been developed to perform an inverse water volumetry method for arms, which has none of the disadvantages of classic volumetry ${ }^{17}$. In comparison to the classic water displacement method, it measures the deficit of water in the device, not the surplus, after placing the arm in position.

A relative volumetric change of $10 \%$ in arm volume compared to the initial volume is defined as lymphedema and needs further treatment. In other structures, smaller differences do not exclude lymphedema (eg. the chest wall, face or the fingers) ${ }^{18}$. Armer et al. ${ }^{19}$ compared four diagnostic criteria for lymphedema and also concluded that a relative volume change of $10 \%$ is useful and corresponds to a more conservative definition of 
lymphedema. This method can be performed with a validated measurement technique

\section{PREVENTION, TREATMENT AND GUIDANCE}

\section{Information and awareness.}

Lymphedema interferes strongly with the quality of life and psycho-social functioning of a patient ${ }^{20,21,22,23}$. Although no evidence-based advice is available, many precautions in preventing lymphedema are suggested and generally accepted ${ }^{24,25,26}$. Apart from health care professionals working in the field of lymphedema, there are some patientorganisations active in organising support groups, courses for self -management and information on awareness on lymphedema eg., the National Lymphedema Network (NLN) in the US and the Dutch Lymphedema Network (NLNet) in Holland and the Lymphedema Support Network (LSN) in the UK.

\section{Early diagnostics and follow-up}

In most patients, lymphedema will develop after a period of slight, preclinical swelling and is triggered by trauma, infection or over-exercise. Therefore the consensus guidelines advise programmes for early detection of swelling in patients at risk, eg. patients treated for breast cancer or gynaecological tumours. These include routine measurement of the affected extremity, careful history-taking and physical assessment, all of which are crucial for the early detection of a decompensating lymphatic system.

For these patients special attention will focus on the reduction of lymph production by controlling the exercise program, wearing a preventive compression stocking on the at risk limb, and improving lymph flow by a special training program and a self management course ${ }^{27}$. Also, patients are informed about special bra holders (these have broad straps which do not dig into the skin), prostheses, precautions that can be taken (eg. skincare) and other recommendations that might apply.

\section{Therapy of lymphedema}

Treatment should be individualized, as there are many treatment options for lymphedema that address different aspects of the disorder. Every lymphedema therapy is concluded with the prescription of a therapeutic elastic stocking, which should be worn for life. 


\section{Non-surgical treatment}

In general practice, health care professionals are often not aware of the available therapeutic options for lymphedema. After a proper investigation of the cause of the lymphedema and, in the case of lymphedema following cancer treatment, exclusion of recurrent malignancy, a conservative treatment program should be conducted.

The goals for treatment are to eliminate edema by stimulating lymph drainage with Manual Lymphatic Drainage (MLD) and reduce interstitial fluid production by compression. MLD is a specific therapeutic approach consisting of several forms of massage ${ }^{28}$. This treatment is combined with inelastic multilayer bandaging, which should be applied after each MLD session. When maximum edema reduction is judged to have been achieved, a tailormade compression garment should be applied to control the edema. Other therapeutic measures include improving the function of the joints and muscle system, by specific exercise and breathing techniques. Additionally, intermittent pneumatic compression (IPC) can be useful with low pressures ( $<40 \mathrm{mmHg}$ ) in combination with a MLD session in circumstances where there is no proximal swelling to shoulder or groin/genital region.

In phlebolymphedema, there is no indication for MLD because the lymph transport capacity is normal. The first goal of therapy is to reduce the fluid production that results from the increased intravenous pressure due to the chronic venous insufficiency. Therefore, compression by bandaging is essential.

Every successful lymphedema treatment protocol is concluded by the application of adequate compression hosiery. Specialists in the field must prescribe therapeutic elastic stockings. Flat-knit stockings with a high degree of stiffness (coefficient of elasticity) and little longitudinal stretch are preferred. For lymphedema of the legs a compression stocking (36-46.5 $\mathrm{mmHg}$, or sometimes $47 \mathrm{mmHg}$ or higher) is preferred, while for lymphedema of the arms the flat nitted stockings much be tailor made. Such stockings should be replaced three times a year and worn lifelong. ${ }^{29}$

There is currently no convincing evidence for the effectiveness of any pharmaceutical intervention in the treatment of lymphedema. Studies have been performed for diuretics, benzopyrones and some derivates, but no significant effect could be demonstrated in any of them ${ }^{30,31,32,33}$. 


\section{Surgical treatment of lymphedema}

Surgical treatment of lymphedema has a long history mostly without any (long-term) clinical success. The surgical approaches can be categorised in reconstructive and reduction surgery. Reconstructive surgery presumes to restore the lymphatic flow. However, particularly in primary lymphedema, there is mostly a functional insufficiency more than an anatomical one. The CBO group was of the opinion that there may be an exceptional indication for lympho-venous shunt in patients for whom conservative treatment is not successful and who have a total blockage as determined by qualitative lymphoscintigraphy. These patients should only be treated in a multidisciplinary team in a lymphedema clinic. For arm lymphedema, reduction surgery is successful by liposuction. This has been reported to achieve a long-term effect although patients must wear compressive arm stockings for life after the surgery ${ }^{34}$. For extensive elephantiasis, surgical excision procedures can be beneficial in combination with conservative treatment.

\section{Follow-up}

Every treatment of lymphedema must be followed by objective effect measurement. The $\mathrm{CBO}$ working group on lymphedema developed a protocol for systematic early detection of lymphedema in patients at risk, and for follow-up after treatment is started.

\section{Organisation of lymphological care}

Lymphedema is a chronic, debilitating disease that is frequently misdiagnosed, treated too late, or not treated at all ${ }^{35}$. The medical profession should increase its efforts to diagnose lymphedema earlier. Treatment protocols can be individually designed and applied by certified therapists. Most strategies for the management of lymphedema are based breast cancer related lymphedema and give no generally accepted therapeutical or logical guideline to cope the problem/ risk of lymphedema. For good management, a widely accepted guideline is needed that can form the basis for more uniform, effective and efficient lymphedema care for all patients with primary or secondary lymphedema. Lymphedema assessment should be incorporated into the routine follow-up for all these patients.

The CBO guidelines recommend that when a volume change of more than $10 \%$ compared 
to the (previous) pre-operative measurement (with Herpertz method or (inverse) water displacement method) is detected, a specific protocol is initiated including:

- Frequent check-ups

- Supplementary advice and information

- Technical appliances, such as bra holder, prostheses, (semi) orthopaedic shoes

- A course in self-management ${ }^{36,37}$

- Starting or intensifying a therapeutic lymphedema treatment programe

The routing for a diagnostic program and the special tasks for each of the professionals involved are shown in figure 2.

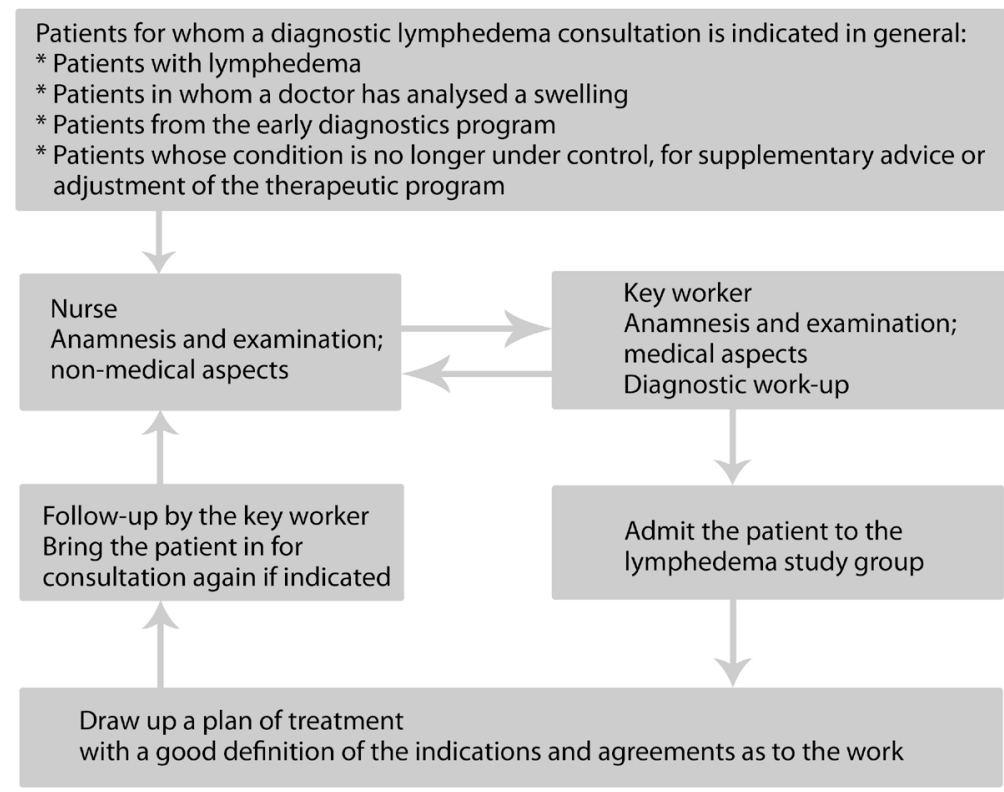

Figure 2: Recommended work-up for patients with (suspected) lymphedema and swelling.

\section{CONCLUSION}

Lymphedema is an increasing health problem. After surviving cancer with modern anti-cancer therapy it is dispiriting that a complication such as lymphedema is so badly recognized and therefore, left untreated. For patients with primary lymphedema the situation is even worse. The quality of life depends on the morbidity and resulting irreversible changes that are the consequence of lymphedema. It is essential that early and 
long-lasting treatment and follow-up are available for all patients. Intensive cooperation between all healthcare workers is necessary to improve awareness, and to bring about the optimum treatment and education of these patients. This first national guideline on lymphedema has been accepted by consensus in the Netherlands and offers strategies and management protocols which will be beneficial for all patients suffering from the various types of lymphedema. 


\section{REFERENCES}

1 Kwaliteitsinstituut voor de Gezondheidszorg CBO. Richtlijn Lymfoedeem. Alphen a/d Rijn: Van Zuiden Communications; 2002. (Dutch)

2 Damstra RJ, Kaandorp CJ. Richtlijn lymfoedeem. Ned Tijdschr Geneeskd. 2003;5;147(14):64852 (Dutch)

3 Olszewski WL. Pathophysiological aspects of lymphedema of human limbs: I. Lymph protein composition. Lymphat Res Biol. 2003;1(3):235-43

4 Scharz U. Die Haufigkeit des primairen Lymphödems. Eine epidimiologische Studie an über 100 Probanden. Med.Lymph. 1990;1:29-34

5 Sener SF, Winchester DJ, Martz CH, Feldman JL, Cavanaugh JA. Lymphedema after sentinel lymphadenectomy for breast carcinoma. Cancer. 2001;92:748-52

6 Mansel RE, Fallowfield L, Kissin M, et al. Randomized multicenter trial of sentinel node biopsy versus standard axillary treatment in operable breast cancer: the ALMANAC Trial. J Natl Cancer Inst 2006; 98(9):599-609. Erratum in: J Nat Cancer Inst. (2006) 98(12): 87

7 Wilke LG, McCall LM, Posther KE, et al. Surgical complications associated with sentinel lymph node biopsy: results from a prospective international cooperative group trial. Ann Surg Oncol. 2006;13(4): 491-500

8 Moffatt CJ, Franks PJ, Doherty DC, et al. Lymphedema: an underestimated health problem. QJM. 2003; 96(10): 731-8

9 Gaarenstroom KN, Kenter GG, Trimbos JB, Agous I, Amant F, Peters AA, Vergote I. Postoperative complications after vulvectomy and inguinofemoral lymphadenectomy using separate groin incisions. Int J Gynecol Cancer. 2003 Jul-Aug;13(4):522-7

10 Ramos SM, O'Donell LS, Knight G. Oedema volume, not timing, is the way to success in lymphedema treatment. Am J Surg. 1999;178:311-5

11 Stanton AWB, Badger C, Sitzia J. Non-invasive assessment of the lymphedematous limb. Lymphology. 2000;33:122-35

12 Herpertz U. Messung und Dokumentation von Ödemen. Lymphologie. 1994;18:24-30

13 Megens AG, Harris SR, Kim-Sing C, McKenzie DC. Measurement of upper extremity volume in women after axillary dissection for breast cancer. Arch Phys Med Rehabil. 2001;82:1639-43

14 Stanton AWB, Northfield B, Holroyd B, Mortimer PS, Levick JR. Validation of an optoelectronic limb volumeter (perometer®). Lymphology. 1997;30:77-97

15 Kettle JH, Ruindle FF, Oddie TH . Measurement of upper limb volumes: a clinical method. Aust N Z J Surg. 1958;27: 263-70

16 Stranden E. A comparison between surface measurements and water displacement volumetry for the quantification of leg oedema. J Oslo City Hosp. 1981;31:153-5

17 Damstra RJ, Glazenburg EJ, Hop WC. Validation of the inverse water volumetry method: a new gold standard for arm volume measurements. Breast Cancer Res Treat. 2006; 99(3):267-73

18 Stanton AWB, Levick JR, Mortimer PS. Current puzzles presented by postmastectomy edema breast cancer related lymphedema). Vasc Med. 1996;1:213-25

19 Armer JM, Stewart BR. A comparison of four diagnostic criteria for lymphedema in a post breast cancer population. Lymphat Res Biol. 2005;3(4): 208-17

20 Logan V, Barclay S, Caan W, McCabe J, Reid M. Knowledge of lymphedema among primary 
health care teams: a questionaire survey. Br Gen Pract. 1996;46:607-8

21 Woods M, Tobin M, Mortimer P. The psychosocial morbidity of breast cancer patients with lymfhedema. Cancer Nursing. 1995;18:467-71

22 Passik SD, McDonald MV. Psychological aspects of upper extremity lympfedema in women treated for breast carcinoma. Cancer. 1998;83:2817-20

23 Tobin MB, Lacey MD, Meyer L, Mortimer PS. The psychological morbidity of breast cancerrelated arm swelling. Cancer. 1993;72:3248-52

24 Coward DD. Lymphedema prevention and management knowledge in woman treated for breastcancer. Oncol Nurs Forum. 1999;26:1047-53

25 The 18 steps to prevention of lymphedema in the lower extremeties. New-York: National Lymphedema Network; 1998

26 Petrek JA, Pressman PI, Smith RA. Lymphedema: Current Issues in Research and Management. CA Cancer J Clin. 2000;50:292-307

27 Turner J, Hayes S, Reul-Hirche H. Improving the physical status and quality of life of women treated for breast cancer: A pilot study of a structured exercise intervention. J. Surg. Oncol. 2004;86:141-146

28 Földi MR, Stroszenreuther RH. Grundlagen der Manuellen Lymfdrainage, second edition Urban and Fisher Verlag, munchen, 1994

29 Swedborg l. Effects of treatment with an elastic sleeve and intermittent pneumatic Compression in post-mastectomy patients with lymphedema of the arm. Scand J Rehab Med. 1984;16:3541

30 Loprinzi CL, Kugler JW, Sloan JA, Rooke TW, Quella SK, Novotny P, et al. Lack of effect of coumarin in women with lymphedema after treatment for breast cancer. N Engl J Med. 1999;340:346-50

31 Mortimer PS, Badger C, Clarke I, Pallett J. A double blind randomized, parallel-group, placebocontrolled trial of O-(beta-hydroxyethyl)-rutosides in chronic arm edema resulting from breast cancer treatment. Phlebology. 1995;10:51-5

32 Casley-Smith JR. There are many benzopyrones for lymphedema. Lymphology 1997;30:38-9

33 Burgois A, Alcaide A, Alcoba C et al. Comparative study of the clinical efficacy of two different coumarin dosages in the management of arm lymphedema after treatment for breast cancer. Lymphology. 1999;32:3-10

34 Brorson $\mathrm{H}$, Svensson $\mathrm{H}$. Liposuction combined with controlled compressiontherapy reduces arm lymphedema more effectively than controlled compressiontherapy. Plast Reconstr Surg. 1998; 102:1058-67

35 Szuba A, Shin WS, Strauss HW, Rockson S. The third circulation: Radionuclide lymphscintigeaphy in the evaluation of lymphedema. J Nucl Med. 2003;44:43-57

36 Cohen SR, Payne DK, Tunkel RS. Lymphedema, strategies and management. Cancer. 2001;92:980-7

37 Armer JM, Heckathom PW. Post breast cancer lymphedema in aging women: self-management and implications for nursing. J Gerontol Nurs. 2005;31(5): 29-39 

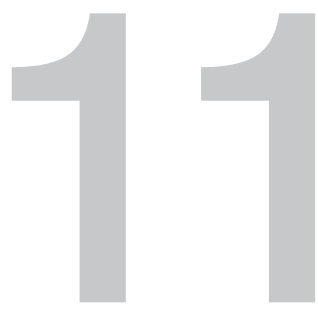

\title{
Diagnosis and Therapy in Children with Lymphedema
}

\author{
R.J.Damstra, $M D$ \\ P.S. Mortimer MD FRCP ${ }^{1}$ \\ 'Department of Cardiac and Vascular Sciences (Dermatology), St George's Hospital Medical \\ School, University of London, UK
}




\section{ABSTRACT}

Introduction: Lymphedema is a disorder characterized by persistent swelling caused by impaired lymphatic drainage because of various aetiologies, including lymphatic injury and congenital functional or anatomical defects.

Objective: Literature review and expert opinion about diagnosis and treatment of lymphedema in children.

Results: lymphedema is rare in children, with a prevalence of about 1.15/100,000 persons, 20 years old. The management of lymphedema in children differs considerably from adults in terms of origin, co-morbidity and therapeutic approach. The objective of this presentation is to discuss practical issues related to clinically relevant information on the diagnosis, etiology, work-up and treatment of lymphedema in children. In contrast to adults, who usually experience secondary lymphedema because of acquired lymphatic failure, most cases in children have a primary origin. The diagnosis can be made mainly on the basis of careful personal and family history, and physical examination. lymphedema in children can be part of a syndrome if there are other concomitant phenotypic abnormalities and if a genetic defect is recognizable. Treatment of lymphedema is mostly conservative utilizing decongestive lymphedema therapy including compression therapy, directed exercises, massage and skincare. In the neonate, initial observation alone may be sufficient, as delayed lymphatic development and maturation can result in spontaneous improvement. The role of parents is crucial in providing the necessary input.

Conclusion: We present a review emphasizing a practical approach to treating a child with lymphedema according to current publications and our own experience. 


\section{INTRODUCTION}

The main function of the lymphatic system is to drain protein-rich fluid, macromalocules and cells from the interstitium to lymphcollectors, then to larger collecting lymph vessels, to the lymph nodes and eventually into the venous circulation. lymphedema is defined as swelling of a part of the body due to impairment in lymph transport capacity based on the malfunction or malformation of the lymphatics. There is usually a pitting component present. In general, a pitting component is due to unbalance between capillary filtration and lymph drainage capacity. In many types of edema it is due to an increased capillary filtration and normal lymph drainage. In early form of lymphedema, especially when there not yet secondary changes due to protein accumulation, a pitting component is present due to lymphatic impairment. However, in long-lasting stages of lymphedema, more sustained finger pressure to the skin (of at least 20 seconds) is required to demonstrate an indentation due to the firmer and thicker nature of the skin and the subcutaneous compartment $^{1}$. In long-lasting lymphedema, interstitial accumulation of proteins ${ }^{2}$, inflammatory cells, adipose tissue hypertrophy and fibrosis make pitting less evident ${ }^{3}$. Erysipelas (cellulitis) is common, and if lymphedema remains untreated, recurrent bouts of infection are increasingly likely and may lead to greater morbidity. Early recognition and diagnosis, proper treatment management and long-lasting follow-ups are crucial for preventing progressive disease and complications.

\section{Purpose of review}

The purpose of this review is to provide clinically relevant information regarding the aetiology, diagnosis, work-up and treatment of lymphedema in children through a synthesis of the current literature and our own experience.

\section{Classification and description of types of lymphedema in children}

Lymphatic drainage impairment can be either congenitally determined (primary) or be a consequence of acquired lymphatic failure due to obstruction or damaged lymphatics (secondary). Primary lymphedema is considered to be due to an intrinsic or constitutional fault in lymph drainage that can become manifest at different ages of life depending on the underlying cause. 
While lymphedema results from disturbances or dysfunction in drainage routes at many levels (capillary, collector or main lymphatics levels), lymphatic malformations may or may not interfere with lymph drainage and can produce isolated swelling (due to the malformation), and not inevitable to impairment of lymphatic transport capacity. Congenital lymphatic developmental disorders can produce lymphedema, a lymphatic malformation (LM) or both. Congenital Vascular Malformations (CVM) may possess blood-, vascular- and lymphatic malformations. The Hamburg classification of CVM distinguishes two forms of LM: a truncular (LM-T) and an extratruncular (LM-ET) form ${ }^{4},{ }^{5}$. Both are the result of a developmental defect in lymphangiogenesis that can be based on a mono-or polygenetic origin. In early embryogenesis, lymphangiogenesis focuses on the formation of lymph sacs and on the migration of lymphatic endothelial cells in the tissues; in later phases of embryogenesis, the differentiation and separation of blood and lymphatic vessels takes place. In the later phase, the emphasis is on the maturation of the lymphatic architecture as valve formation and smooth muscles occur within the lymphatic vessel ${ }^{6}$. The embryological stage at which developmental arrest occurs determines the type of LM. Early dysadjustment in embryogenesis leads to LM-ET forms of LM, while later arrest exposes more LM-T forms.

In this classification, LM-T is known as primary lymphedema; the LM-ET include micro / macro cystic or cavenous lymphangioma, and are closely tied to other forms of CVM.

LM can be confused with vascular malformations known as hemolymphatic or mixed vascular malformations ${ }^{7}$. LM-T and LM-ET need a separate therapeutic approach. In this article, we will focus on primary lymphedema (LM-T).

\section{Primary lymphedema}

In children, nearly all lymphedemas are classified as primary. Lymphedema in children is rare, with an estimated prevalence of 1,15/100.000 persons less than 20 years old ${ }^{8}$. Genetic conditions associated with lymphedema are reported in frequencies varying from solitary case reports to estimates of approximating $1 / 500$ birth in case of Klinefelter syndrome 9 . A study by Dale in 312 index patients younger than 36 years with primary lymphedema reported a frequency at birth of $1 / 6000$ and a sex ratio of one male to three females ${ }^{10}$. lymphedema has a wide phenotypic variability, even within the hereditary forms. Usually one or two limbs are affected but other parts of the body can be involved, including 
visceral organs such as the heart, lungs and intestines. In a large study from Smeltzer et al. ${ }^{8}$ analyzing 291 children, only 42 (14\%) had a family history of lymphedema.

\section{Secondary lymphedema}

As determined by the total numbers of patients, infectious (secondary) lymphedema is most frequent in tropical regions of the world. Endemic lymphatic filiariasis is a major mosquito-borne tropical disease that threatens more than 1 billion people living in 83 countries. In endemic regions, the prevalence of antigenaemia in children aged 0-5 years is $18,9 \%$ [i]. In this review we will focus on non-filiarial lymphedema.

\section{Classification}

Classification can be based on several parameters such as age of onset, anatomical variations or patho-physiological phenomena. Primary lymphedema is traditionally classified according to the time of onset: congenital lymphedema, lymphedema praecox or lymphedema tarda. Congenital lymphedema is present at birth or soon there after. The recent discovery of disease causing mutations has helped to reclassify lymphedema according to the genotype. Other genetic forms of lymphedema in which the genetic fault is not known must rely on phenotypic classification. Lymphedema can either be the only clinical sign (Milroy disease) or can sometimes be a part of a phenotypical complex of defects, as in lymphedema-distichiasis syndrome. In chromosomal disorders, the defect is due to a deficiency of genes contained within a whole chromosome or a chromosome segment, as in Klinefelter syndrome or Turner syndrome. Lymphedema praecox presents between 1-35 years of age and is mostly sporadic. Familiar cases of lymphedema precox are called the Meige syndrome.

In some cases, primary lymphedema will manifest after 35 years of age. This is known as lymphedema tarda. This type of primary lymphedema is a developmental abnormality of the lymphatic system that only becomes clinically evident after 35 years of age and is often precipitated by trauma, an inflammatory event or a physical immobility ${ }^{12}$. Presumably, a pre-existing covert constitutional weakness in lymph drainage is exposed by an extrinsic event, like infection.

The frequencies of the various types of primary lymphedema vary ${ }^{13,14}$ : congenital 
lymphedema (onset <1 year after birth) occurs in 6-12\%, lymphedema precox (onset between 1-35 years) occurs in $77-94 \%$ and lymphedema tarda frequencies of $11 \%$ of primary lymphedema patients are reported.

An anatomical classification by using lymphoscintigraphy into aplasia, hypoplasia or hyperplasia does not lead to a change in attitude according to diagnosis and treatment and will burden a child unnecessary.

Patho-physological classification depending on origin of the lymphatic impairment can be useful in order to made a therapeutical plan. Lymphatic impairment can be classified in high and low out insufficiency (dynamic / static insufficiency) depending if there is an overload of the lymphatics (eg infection, cardial failure) or an impairment of the transport capacity of the lymphatic system (true lymphedema). sometimes combinations of both types can be observed.

Several types of primary lymphedema are categorized in Table 1.

Table 1. classification of lymphedema $a^{9,15,16}$

\begin{tabular}{ll}
\hline Lymphedema, time & $<1$ year: Congenital Lymphedema \\
dependent onset & $<35$ years: Lymphedema Precox \\
& $>35$ years: Lymphedema Tarda \\
& Secondary lymphedema \\
Lymphedema, single & Milroy (VEGFR3, FLT4 gene) (AD) \\
gene & Meige (familial LP) (AD) \\
Chromosomal disorder & Turner Syndrome (XO) \\
& Klinefelter Sydrome (XXY) \\
& Trisomy 21 (M. Down) \\
& Trisomy 18 \\
& Trisomy 13 \\
& Lymphedema-distichiasis syndrome (FOXC2; AD) \\
& Hypotrichosis-lymphedema-telangiectasia syndrome (SOX18; AR/ \\
Single gene defect, & AD) \\
syndromal & Waltmann syndrome (lymphedema with protein-loosing \\
& enteropathy) \\
Dysmorphic / syndromal & Congenital pulmonary lymphangiectasia (CPL, heterogenic group) \\
Multifactorial inheritance & Hennekam syndrome (AR) \\
& Non immune hydrops foetalis \\
& Lymphedema hypoparathyroidy syndrome \\
& Lymphedema-microcephaly-chorioretinopathy syndrome (AD) \\
& Lymphedema-ptosis sysndrome (AD) \\
& Cholestasis- lymphedema syndrome (chromosome 15) \\
& Noonan syndrome (AD) \\
& OL-EDA-ID syndrome ( osteopetrosis, lymphedema, ectodermal \\
dysplasia, anhidrotic. immunodeficiency) (X-linked, AR) & Others \\
Legend: AD = Autosomal Dominant AR=Autosomal Recessive \\
\hline
\end{tabular}




\section{Milroy disease}

Persistent, painless swelling, typically of one (or both) lower limb(s), is usually the first sign of lymphedema. Swelling is often present at birth or soon afterwards. Due to the accumulation of protein-rich interstitial fluid, thickening of the skin over the digits occurs. This phenomenon at the second toe was originally described by Kaposi, but was reinvented by the French phlebologist Stemmer and is therefore called a positive Stemmer sign when there is an inability to pinch up a fold of skin between the second and third toe on the dorsum of the foot. This sign is a sensitive test for lymphedema that does not give false positive findings ${ }^{17}$.

When the feet are swollen, discrete features in the foot such as swollen toes, upturned nails and non-pitting edema will be observed.

In a study of 71 patients from 10 families with Milroy disease and VEGFR3 mutations, Brice et al. ${ }^{18}$ described an onset of lymphedema at birth in $97 \%$ of the patients; distal edema (94\%), bilateral (85\%), unilateral (14\%), hydrocèle in males $(37 \%)$, prominent veins $(23 \%)$,

Figure 1: Typical signs of distal swelling: foot, toe and nail deformity in Milroy disease

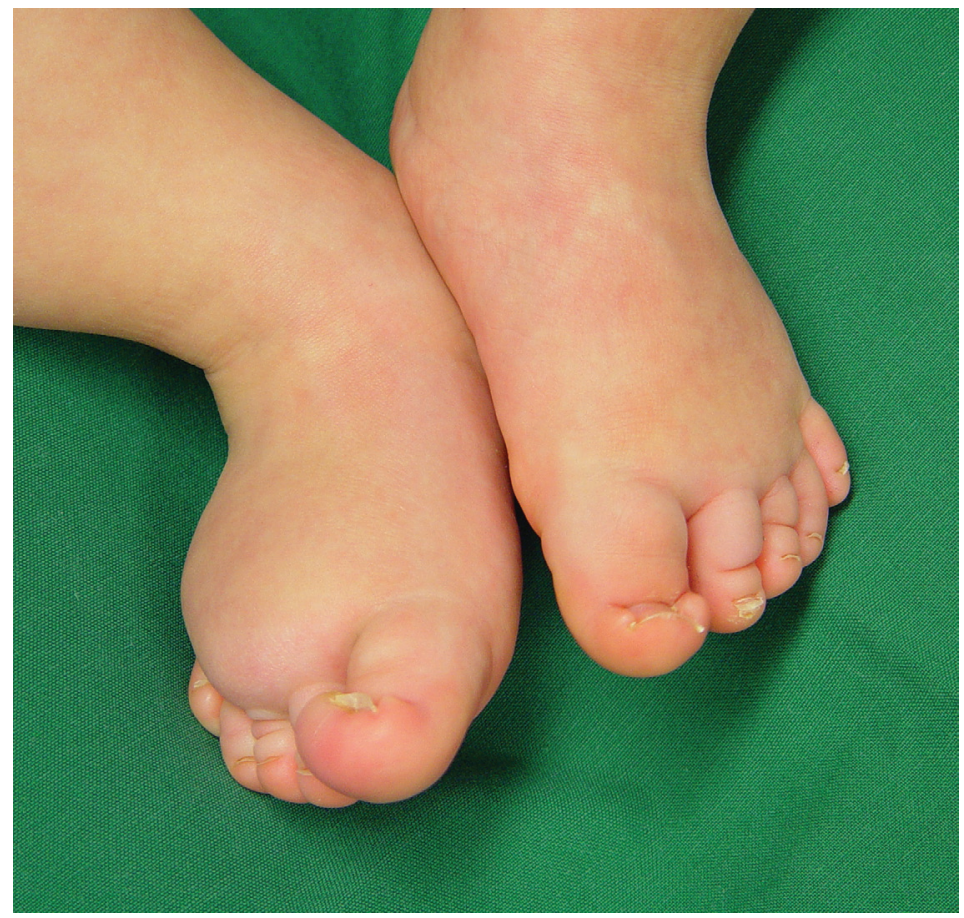


cellulitis (20\%) and ski jump nails (14\%) were other phenotypic features that Brice et al. described.

\section{Lymphedema-distichiasis}

In patients with lymphedema-distichiasis syndrome and a FOXC2 mutation, lymphedema usually develops in late childhood, but onset can be delayed well into adulthood. A failure of differentiation of eyelid follicles into the meibomian glands results in distichiasis (a double row of eyelashes) that leads to eyelash irritation of the cornea. Other major complications that have been reported are cardiac defects, cleft palate defects, extradural cysts, photophobia and other ophthalmic complications ${ }^{19}$. Petrova et al. ${ }^{20}$ first reported that FOXC2 is essential for the morphogenesis of lymphatic valves in FOCC2-/- mice, which explains the typical clinical features of this entity. In a study from Mellor et al. ${ }^{21}$, all 18 patients with a FOXC2 mutation showed also venous valve failure and pathological reflux in the superficial venous system. Deep venous reflux was recorded in 14 of the 18 patients.

\section{Syndromal lymphedema}

In syndromal lymphedema, other concomitant features will be present, such as a dysmorphic phenotype, paediatric defects or mental disorders. Signs of visceral lymphatic impairment due to lymphangiectasia can lead to chylothorax. Chylous reflux or proteinlosing enteropathy should be considered if there is a failure to thrive, diarrhea or dyspnea. Clinical signs, which should be closely examined, are listed in Table 2.

\section{Diagnosis}

Diagnosis of lymphedema, particularly in more advanced stages can easily be made by analyzing the typical history and clinical signs. In children, signs are often less pronounced and to determine the type of primary lymphedema, a full history and physical examination is obligatory. The history focuses on the antenatal and postnatal periods, as well as the family pedigree. The diagnostic process also includes the clinical investigation of relatives if hereditary lymphedema is suspected. Physical examination includes assessing the whole body and looking for the extent of edema, for cutaneous birthmarks, for overgrowth and for systemic involvement. 
Table 2. minor and major clinical signs of lymphedema

\begin{tabular}{|c|c|}
\hline Location & Clinical Signs \\
\hline Head and neck & $\begin{array}{l}\text { Mental condition / retardation/ neurodisability } \\
\text { Alopecia } \\
\begin{aligned} \text { Dysmorphic features face: } \\
-\quad \text { low ear position } \\
-\quad \text { hypertelorism / ptosis } \\
-\quad \text { facial swelling } \\
-\quad \text { distichiasis } \\
-\quad \text { prominent epicanthic folds } \\
-\quad \text { scalp deformity } \\
-\quad \text { neck webbing } \\
-\quad \text { teeth abnormality / cleft palate } \\
-\quad \text { lymph)angiomatosis }\end{aligned}\end{array}$ \\
\hline trunk & $\begin{array}{l}\text { vascular or ectodermal birthmarks in the skin } \\
\text { cardiac abnormalities / valve defects(particularly pulmonary) / septum } \\
\text { defects/ pericardial effusions } \\
\text { pulmonary abnormalities (pleural effusions, pulmonary } \\
\text { lymphangiectasia) }\end{array}$ \\
\hline Midline / genitals & $\begin{array}{l}\text { Genital (penis, scrotum or labia) swelling } \\
\text { lymphangiectasia, lymphcysts } \\
\text { urethral abnormalities } \\
\text { hydrocèle } \\
\text { lymphadenopathy }\end{array}$ \\
\hline Arms / hands & $\begin{array}{l}\text { Swelling fingers / dorsum hands } \\
\text { Skin disease / nails } \\
\text { Increased joint laxity } \\
\text { Digit abnormalities/ overgrowth } \\
\text { Infections (fungal, viral warts) } \\
\text { Nails (yellow) } \\
\text { "ski jump" nails } \\
\text { Positive Stemmer sign }\end{array}$ \\
\hline Legs / foot & $\begin{array}{l}\text { Swelling / region } \\
\qquad \begin{array}{l}-\quad \text { distal-proximal } \\
-\end{array} \\
\text { Pymmetrical / unilateral } \\
\text { Prominent veins } \\
\text { Thickened skin / papillomatosis / verrucosis } \\
\text { Tissue overgrowth }\end{array}$ \\
\hline Others & $\begin{array}{l}\text { Infections (erysipelas / viral warts/ fungus) } \\
\text { Non immunological hydrops foetalis } \\
\begin{aligned} \text { Visceral / abdominal abnormalities } \\
-\quad \text { dyspnea } \\
-\quad \text { diarrhea } \\
\text { - } \quad \text { swelling abdomen } \\
-\quad \text { failure to thrive }\end{aligned}\end{array}$ \\
\hline
\end{tabular}


In well-defined cases with suspicion of syndromal lymphedema, paediatric consultation can be helpful to examine for systemic involvement. Close follow-up is essential in order to see how the condition evolves, as swelling can resolve and new swelling can appear elsewhere. Volume measurement will not be very beneficial, because a child will grow in length, circumference of the limbs and weight. Therefore photographic documentation can be supportive in evaluating the patient.

Sometimes erysipelas (cellulitis) can be a first sign of pre-existing lymphatic impairment (Figure 2). Patients with erysipelas of unclear origin have a high risk of developing subsequent lymphedema with persisting swelling in up to $55 \%$ of $\operatorname{cases}^{22}$ and a high recurrence rate of erysipelas in up to $30-54 \%, 23,24$.

Recently, we showed that in patients with a first episode of unilateral erysipelas without signs of lymphedema, $79 \%$ had bilateral lymph transport impairment ${ }^{25}$. Therefore we consider more than one attack of erysipelas in children without predisposing factors a strong indication of lymph transport impairment.

Figure 2: A 10-month-old child with erysipelas of unknown cause, suggesting a lymphatic impairment

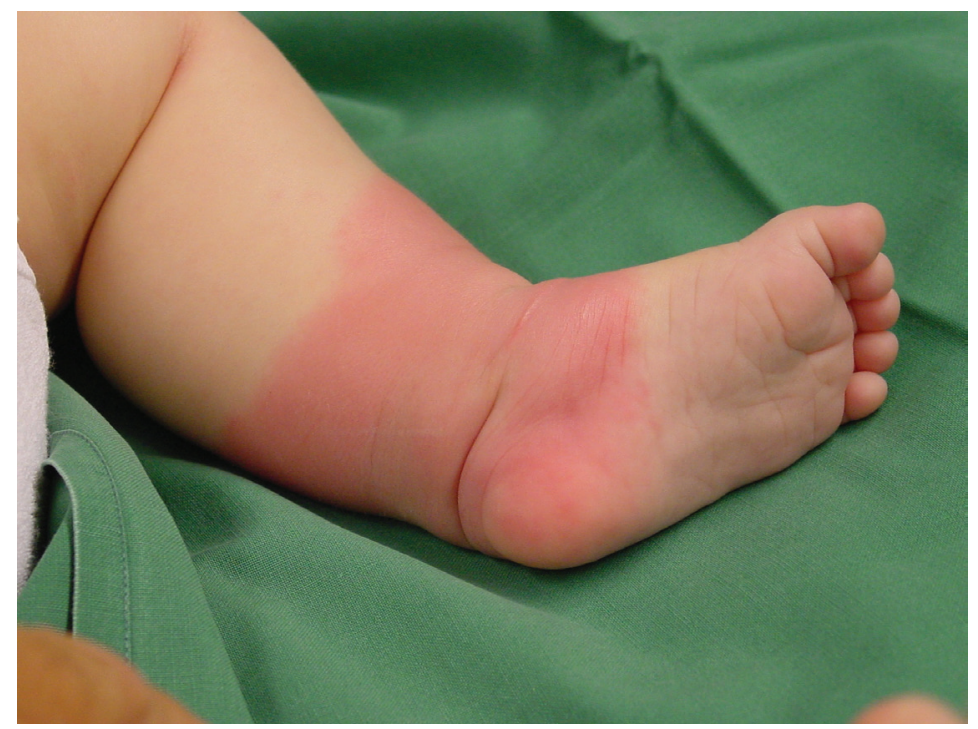

\section{Specialized diagnostic procedures}

Venous duplex scanning is easy to perform and allows for a thorough assessment of superficial and deep venous valves. In a study of 71 patients with Milroy disease ${ }^{26}$ and 18 patients with lymphedema-distichiasis syndrome ${ }^{21}$, superficial venous reflux was 
present in 16/71 and 18/18 respectively. Duplex scanning can also be useful to get an idea about the amount of interstitial fluid, visualized by clefts and splitting in the supra facia compartment. Performing routine imaging techniques, such as lymphoscintigraphy, magnetic resonance imaging (MRI) or computed tomography scanning is not helpful in making the diagnosis lymphedema ${ }^{4}$. In some rare cases, as with early non-pitting lymphedema or with some vascular stigmata like heamangioma and asymmetric leg length, it may be necessary to determine whether the swelling is due to lymphedema, tissue overgrowth or a vascular malformation using MRI. The extent and depth of tissue involvement may also be determined, see figure 3 .

The clinical usefulness of lymphoscintigraphy depends upon scrupulous technique and careful image evaluation ${ }^{27}$. For radionuclide evaluation, Tc-99m-labeled microcolloid particles are intradermally or subcutaously injected. Qualitative and quantitative assessments are made to visualize lymphatic clearance and measure uptake values at regions at interest. A standardized protocol is obligatory.

Qualitative lymphoscintigraphy can be helpful for understanding if swelling is (or is not) lymphatic in origin, and if so what the mechanism might be. Quantitative lymphoscintigraphy in children is difficult to interpret because of a lack of control parameters. No literature is available on this issue. Nevertheless, lower limb lymph drainage is usually symmetrical, and a substantial reduction in ilio-inguinal nodal uptake on one side would indicate lymphedema even in the absence of any qualitative differences. Routinely performing lymphoscintigraphy for the diagnosis lymphedema is absolutely not necessary if the clinical diagnosis is not in doubt, but it can be helpful in understanding mechanisms. For example, in Milroy disease there is no peripheral uptake of tracer (lower limb), indicating initial lymphatic failure. A fluorescence microlymphangiography study by Bollinger et al. ${ }^{28}$ showed that Milroy's disease is characterized by an absence of initial lymphatics. However, in lymphedema-distichiasis syndrome, tracer take-up is seen and transported up the legs collecting lymphatics. But, the tracer then refluxes back down the leg due to valve failure, showing the scintigraphic phenomena of dermal backflow.

For special indications, such as chylous reflux, lymphoscintigraphy can be useful (discussed subsequently) ${ }^{29}$. 
Figure 3: Clinical signs oflymphedema (left). Magnetic resonance imaging of transverse and longitudinal sections with pure supra-muscular fascia region thickening and trabecular densities, corresponding to fibrosis and an excess of adipose tissue.
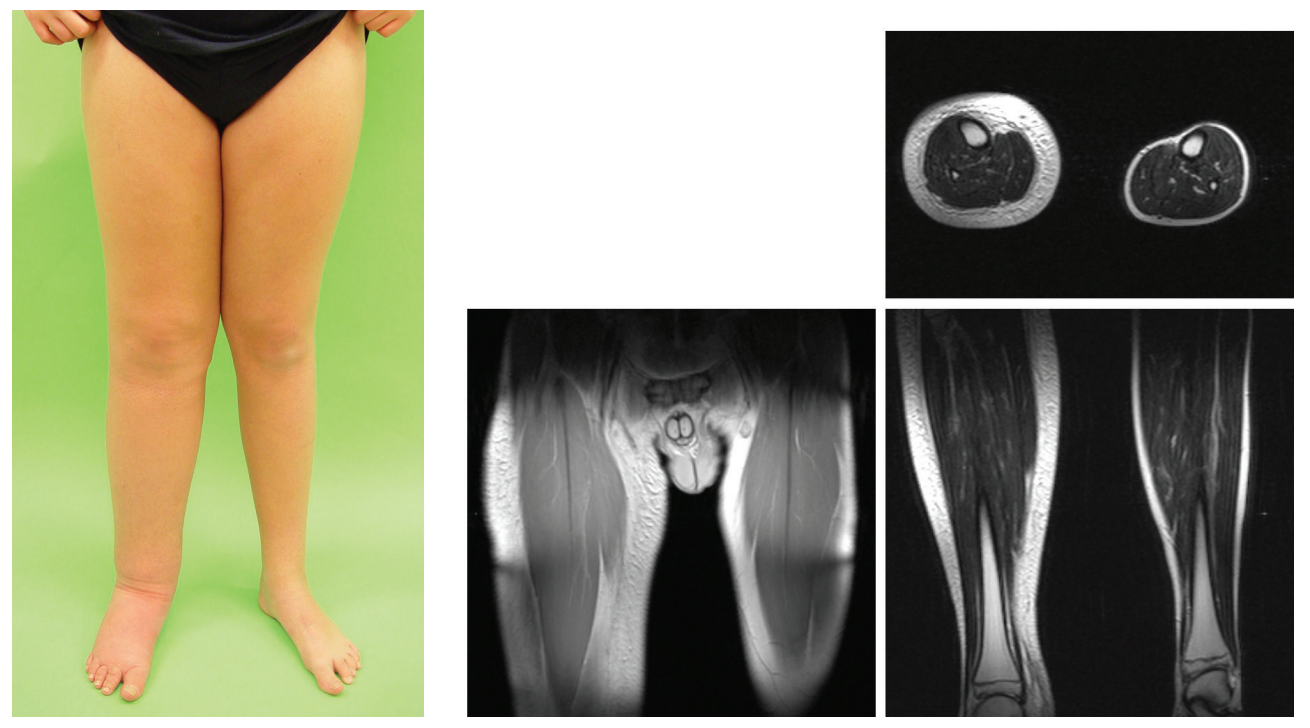

\section{Visceral forms of lymphedema: chylous effusion}

Visceral forms of lymphatic impairment can sometimes accompany lymphedema. If lymphostasis occurs in the cisterna chyli, the drainage from the entire intestine can be deficient. Primary chylous ascites is closely correlated to generalised lymphatic dysplasia. Chylous ascites is the accumulation of triglyceride-rich, milk-like peritoneal fluid due to the presence of intestinal lymph in the abdominal cavity ${ }^{30}$.

Chyle can also occur in the thorax (chylo-thorax), urine (Chyluria) or can leak into the gut (protein-losing enteropathy).

Incompetent lymphatics throughout the limbs, abdomen and chest permits reflux and produces reflux syndromes with chyle reflux into the genital region, or even in the leg and foot. Some assume that dilated lymphatics, which can sometimes be visualized in the abdomen and chest, are probably due to upsteam congenital hypo- or aplasia, but this is still being discussed.

Chylous lymphangiectasia on the skin can leak a white, milky substance from surface lymph blisters that represent grossly engorged superficial dermal lymphatics. Chylous reflux syndromes are very rare. Diagnosis and treatment of chylous reflux should be centralized in a centre with special experience in this field. 
Lymphoscintigraphy is useful to diagnose lymphatic impairment in the legs, but does not give sufficient information about dilated lymphatics. Lymphangiography is in general obsolete to diagnose lymphedema, but only is useful to visualize ectasia via injection in a

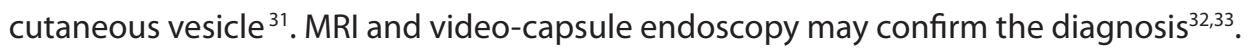

\section{Family history / genetic counseling}

Lymphedema in children is usually genetically based. A very meticulous recording of the family history is essential to discover inheritance. The genetics of lymphedema are highly variable and lymphedema is associated with a very wide range of penetration, relatives often may not know if they are affected. Therefore, careful examination of as many family members as possible is recommended. This is very important in order to perform genetic counseling to the parents to help them understand the inheritance of lymphedema. Although a genetic base is expected, most cases of primary lymphedema are sporadic (90\%), and have a negative family history. Consulting a clinical geneticist is advised. For

probands suspected of Milroy disease or lymphedema-distichiasis syndrome, testing of mutations in VEGFR3 and FOXC2 is now available.

\section{Treatment}

Although there are many treatment modalities for lymphedema, a cure is a not available. The cornerstones of lymphedema therapy are compression therapy, manual lymph drainage (MLD) and exercise ${ }^{34,35}$ to reduce pitting edema, enhance lymph transport and maintain mobility. In children, parents should be educated to help in the treatment. The combination of compression therapy, directed exercise, MLD and skincare is called decongestive lymphedema treatment or complex physical therapy.

As lymphedema is a chronic disease, life-long treatment is essential. Proper monitoring and follow-up of the patient will help prevent complications such as deterioration of lymphedema, irreversible skin changes or erysipelas.

Monitoring the effect of treatment in children differs from adults; volumetry is not suitable as a parameter because of natural growth in length and weight, but monitoring of height and weight and the child's physical and psychological development is very important. In general, surgical treatment of lymphedema in children is discouraged. Sometimes, there can be an indication for operation for visceral involvement or ingrown toenails. 


\section{Compression}

The aim of external compression is to reduce interstitial capillary fluid filtration, and therefore the lymphatic preload. On the other hand, compression when combined with exercise leads to increased lymphatic drainage by stimulation of initial lymphatic absorption and lymph propulsion. Compression therapy can be performed in many ways with various pressures: by bandaging with a variety of non-elastic bandages, by using flat knitted elastic stockings and by using pneumatic compression therapy $36,37,38$. Bandaging and hosiery can be combined with localized padding to raise local pressure on the tissues and to improve the shape and hardness of tissues. In children many therapies have technical limitations due to the size of the legs or arms, the cooperativeness of the child and circumstances such as incontinence of urine or stool. As the child grows, the possibilities for treatment options will increase. The child's therapist should try to involve the parents as much as possible.

\section{Manual lymphdrainage}

MLD is a special massage technique based on the principles described by Winiwarter, Vodder and Földi ${ }^{39}$. The goal of the massage is to increase lymphatic drainage by stimulating existing or collateral lymph drainage routes in order to redirect the lymph flow toward other, less affected regions. The particular massage technique of MLD is very gentle with stretch and soft pressures applied by a variety of rhythmic hand movements. Some easy massage techniques are suitable for self management and can be taught to and performed by the parents. No evidence-based figures are available on the way of performing MLD and on the recommended interface pressure of bandages or hosiery in children. They are mostly based on experience and expert opinion. We consider a discussion about this beyond the aim of this article.

\section{Physical exercise}

Physical exercise meets several goals: it will stimulate functional rehabilitation and improvement of mobility; it will improve muscular activity, which leads to internal compression of (lymph) vessels under bandages or hosiery. Intermittent pressure changes between muscles and external compression stimulates lymph drainage. Breathing patterns stimulate intrathoracic pressure changes, which lead to a stimulation of lymph 
flow through the thoracic duct. It is important especially in children to integrate these therapeutic options into daily life. Prohibiting physical activities should be discouraged and the child must be allowed to recreational activities as normally as possible.

\section{Skin care and self management}

One of the main complications in lymphedema is infection. Lymphatics play a crucial role in the local immunology. Mallon et $\mathrm{al}^{40}$. demonstrated an impaired immunological response in the efferent and the afferent pathways in patients with breast cancer-related lymphedema. Local antiseptic soap can be effective in reducing skin colonisation; thereby, reducing bacterial entry into the affected limb and proper antiseptic wound care can be beneficial. Tinea pedis, fungal infections and onychomycosis are less frequent as in adults varying with a prevalence in children of about 3-9\% ${ }^{41}$, Good foot-care with eventual use of antifungal agents is recommended. Dry skin should be avoided by using moisturisers. Obesity must be prevented because this can increase the risk of lymphedema ${ }^{42}$. Obese children must be advised to lose weight and must exercise.

To improve the awareness and independence of professional healthcare workers, patients and their parents should be educated to learn more about lymphedema and the lymphatic system. Self-management can be taught so that the family is in control of the treatment.

\section{Psychological aspects}

The psychological aspects of swelling are often neglected. Adolescents especially experience the feeling that they are different and cannot fulfil all the demands of this stage of life. Lymphedema can affect leisure opportunities ${ }^{8}$ as well as social and sexual relationships. Maintaining self-esteem is an important aspect of living and coping with lymphedema.

\section{Treatment of chylous disease}

Conservative treatment is based on a diet free of fats containing long chain fatty acids. These fats are replaced with low-fat medium-chain triglyceride (MCT diet) intake in order to reduce chyle production. Paracentesis to reduce the intra-abdominal pressure from ascites or thoracentesis to reduce pleural effusion may be necessary ${ }^{27}$. Sometimes total 
parenteral nutrition is necessary in combination with somatostatin analogues ${ }^{43}$ to reduce intestinal fluid production. This program will be combined with other non-operative treatment options for lymphedema such as manual lymph drainage and compression.

Browse et al. demonstrated in a series of 45 patients with chylous ascites a $34 \%$ success rate with conservative management ${ }^{44}$. Aalami ${ }^{28}$ reviewed world literature and reported from a total group of 156 patients a $43 \%$ success rate with conservative treatment.

Operative modalities include laparotomy with ligation of refluxing (mega)lymphatics / fistulae, resection of the affected part of the small bowel or peritoneo-venous shunt in order to create a new drainage route. In chylothorax, thoracocentesis and diet management should be performed. When chyle leak in children will continue with $100 \mathrm{ml}$ per year of age per day, surgical intervention such as thoracocentesis, thoracotomy, fistula closure or pleurodesis is indicated ${ }^{45}$.

\section{Microsurgical procedures}

Extensive experimental work has been performed on the microsurgical reconstruction of lymphatic impairment with bypass surgery, lympho venous anastomosis (LVA) or lymphvessel transplantion. Browse et al. ${ }^{46}$ comment that microsurgical techniques are challenging and require a dedicated microsurgeon. Long lasting follow up or controlled studies are not performed and many questions need answering. Although microsurgery studies in primary lymphedema are not available, Damstra et al. ${ }^{47}$ studied 10 patients with breast cancer related lymphedema and reviewed literature. They found a minimal reduction in volume of lymphedema following LVA; in the literature there was no convincing evidence of the success of LVA. Some publications suggest a better chance of success when microsurgical procedures are performed in the early stages of obstructive lymphedema ${ }^{48}$. Fortunately, at this early stage, conservative treatment is often very effective to treat and control lymphedema.

\section{Complications}

Lymphedema can lead to complications, especially when not treated properly. Deterioration of lymphedema can lead to immobility, progressive skin changes, recurrent infections as well as psychological impairment, social impairment and disability. The most common complication is erysipelas / cellulitis, which gives rise to high fever, vomiting, a 
painful redness of the skin and sometimes blister formation. The infection causes further lymphatic impairment, resulting in further increase of swelling and yet more infection leading to a dangerous vicious cycle.

In general, the recurrence rate of erysipelas is high, up to $30-54 \%{ }^{21,}, 49$ after 2 years. In breast cancer related lymphedema, Mozes et al..$^{50}$ reported a rate of inflection up to $41 \%$. Figures in primary lymphedema are controversial. In the original paper from Milroy ${ }^{51}$, no attacks of erysipelas are described in families with congenital lymphedema. Others reported rates of infection are up to $31 \%$ in primary lymphedema ${ }^{27}$. If recurrent bouts of infection occur, prophylactic antibiotics (penicillin) in preventing erysipelas appear to contribute to a reduction of infections when combined with foot-care ${ }^{52}$. In our experience, when lymphedema has been treated effectively, the chance of infection is diminished.

In very rare cases, long-lasting lymphedema can be complicated by the development of malignant tumours. Increased frequencies of tumors are reported in lymphedema patients, including Kaposi's sarcoma, malignant lymphoma, squamous and basal cell carcinoma and melanoma ${ }^{53}$. Stewart-Treves lymphangiosarcoma is the most aggressive tumour, presenting as multicentric red-brownish patches before tumour formation in the later stages. This neoplasm is very aggressive and patients have a 5-year survival rate varying from $5-29 \%{ }^{54}$. It has been documented in both primary ${ }^{55,56}$ and secondary lymphedema ${ }^{57}$.

\section{Flowchart for work up}

Lymphedema in children is rare, and it requires a specialized, multidisciplinary approach and an experienced physician. The aim of the diagnostic process is to categorize the lymphedema and to evaluate the pre-existence of syndromal or familial forms. To facilitate the diagnostic process, the treatment programme and the follow-up, we present a flowchart.

\section{CONCLUSION}

The diagnosis and management of lymphedema in children differs significantly from adults in terms of origin, co-morbidity and approach. Most lymphedema in children 
Table 3. Flowchart diagnostics, treatment and follow-up

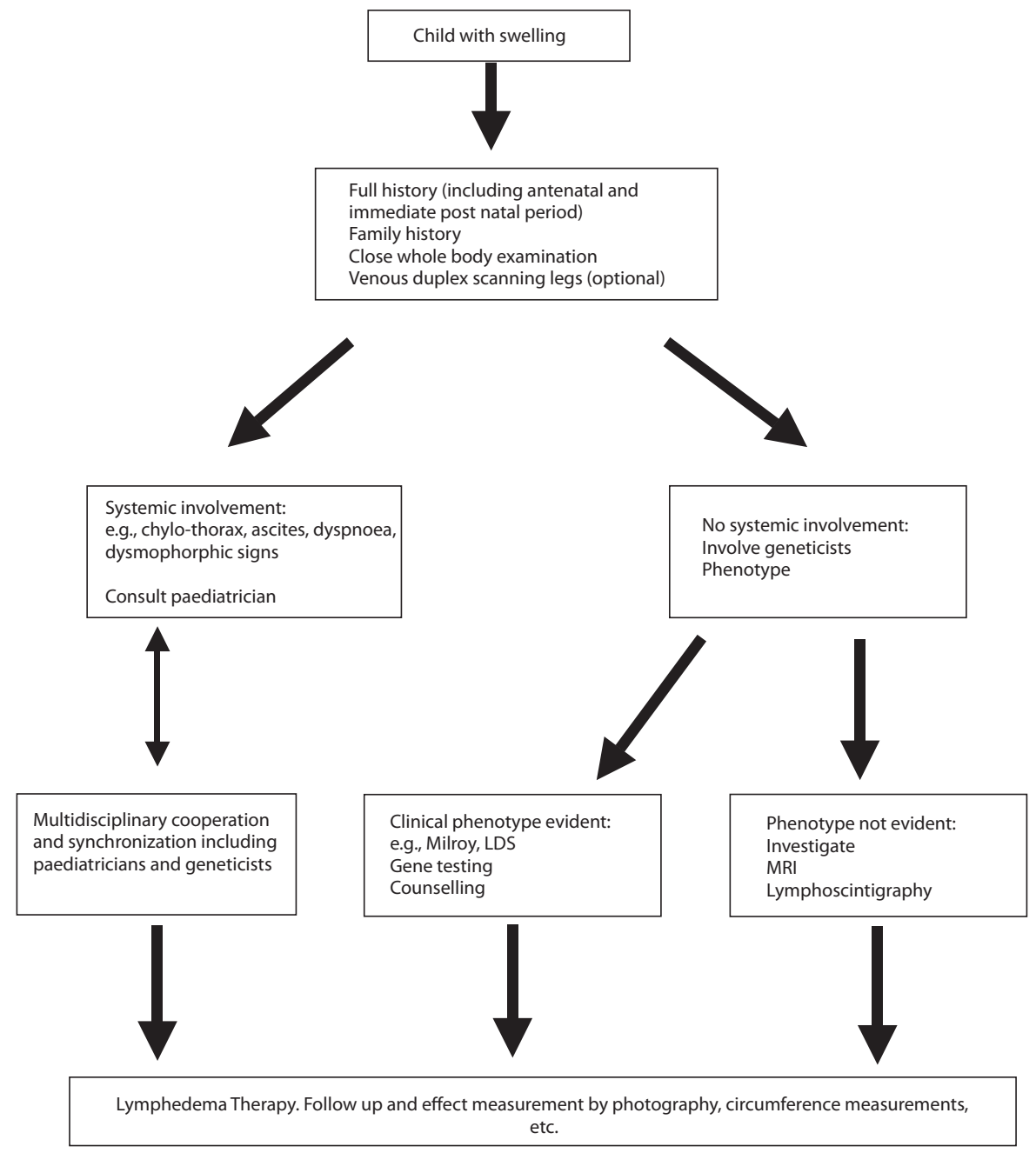

occurs as primary lymphedema. Close and meticulous clinical assessment can often lead to a final diagnosis. Additional paediatric expertise is necessary when there is systemic co-morbidity such as cardiac, neurological or intestinal defects. A detailed family history is essential to precisely determine the inheritance of lymphedema although more often lymphedema is sporadic. Nevertheless, an increasing number of cases due to de novo mutations are being reported, hence careful phenotyping is crucial.

Treatment will focus on non-operative options such as MLD, compression therapy and exercises with the close involvement of the parents. Training parents or relatives to 
perform several components of lymphedema therapy, such as putting on garments, can enhance independence from professional healthcare workers. In puberty, psychosocial guidance is essential for supporting the process of growing up with this disfiguring illness and teaching patients to cope with their disability. Because lymphedema is a chronic disease, life-long follow-up and control will be useful for preventing complications and monitoring the effects of treatment. 


\section{REFERENCES}

1 Mortimer PS, Levick JR. Chronic peripheral oedema: the critical role of the lymphatic system. Clinical Medicine (London, England) 2004:4(5):448-53

2 Gaffney RM, Casley-Smith JR. Excess plasma proteins as a cause of chronic inflammation and lymphedema: biochemical estimations. J Pathol. 1981;133:229-42

3 Warren AG, Brorson H, Borud LJ, Slavin SA. lymphedema: a comprehensive review. Annals of Plastic Surgery. 2007:59(4):464-72

4 Belov ST. Anatomopathological classification of congenital vascular defects. Semin Vasc Surg. 1993;6:219-24

5 Belov ST. Classification of vascular defects. Int Angiol. 1990;9:141-6

6 Alitalo K, Tammela T, Petrova V. Lymphangiogenesis in development and human disease. Nature. 2005; 438(7070): 946-53

7 Lee BB, Kim YW, Seo JM, Hwang JH, Do YS et al. Current concepts in lymphatic malformation. Vascular and Endovascular Surgery. 2005;39(1):67-81

8 Smeltzer DM, Gunnar B, Schirger A. Primary lymphedema in children and adolescents: a followup study and review. Pediatrics. 1985:76 (2):206-18

9 Greenlee R, Hoyme H, Witte M, Crowe P, Witte C. Developmental disorders of the lymphatic system. Lymphology. 1993;26(4):156-8

10 Dale RF. The inheritance of primary lymphedema. J Med Genet. 1985;22(4)274-8

11 Ramaiah KD, Das PK, Vanamail P, Pani SP. Impact of 10 years of diethylcarbamazine and ivermectin mass administration on infection and transmission of lymphatic filariasis. Trans $R$ Soc Trop Med Hyg. 2007;101(6):555-63

12 Wyatt L, Pribaz J. Lymphedema. In; Abeloff MD, Armitage JO, Lichter AS, Niederhuber JE, eds. Clinical Oncology $3^{\text {rd }}$ ed. New York: Churchill livingstone;2003, p.817-34

13 Schirger A, Harrison EG, Janes JM. Idiopathic Lymphedema. Review of 131 cases. JAMA. 1962;182:124-32

14 Szuba A, Rockson SG. Lymphedema: classification, diagnosis and therapy Vascular Medicine. 1998;2: 145-56

15 Online Mendelian Inheritance in Men (OMIN), John Hopkins University

16 Browse N, Burnand K, Mortimer PS. Diseases of the lymphatics. Arnold, London UK 2003 (ISBN: 034076203 9) Chap. 5:102-8

17 Stemmer R. Stemmer's sign: possibilities and limits of clinical diagnosis of lymphedema. Wien Med Wochenschr. 1999;149:(2-4):85-6

18 Brice G, Child AH, Evans A, Bell R, Mansour S, Burnand K, Sarfarazi M, Jeffery S, Mortimer P. Milroy disease and the VEGFR-3 mutation phenotype. J Med Genet. 2005;42 (2):98-102

19 Erickson RP, Dagenais SL, Caulder MS, Downs CA, Herman G, et al. Clinical heterogeneity in lymphedema-distichiasis with FOXC2 truncating mutations. J Med Genet. 2001;38 (11):761-6

20 Petrova TV, Karpanen T, Norrmén C, Mellor R, Tamakoshi T et al. Defective valves and abnormal mural cell recruitment underlie lymphatic vascular failure in lymphedema distichiasis. Nat Med. 2004;10(9):974-81

21 Mellor RH, Brice G, Stanton AWB, French J, Smith A et al. Mutations in FOXC2 are strongly 
associated with primary valve failure in veins of the lower limb. Circulation. 2007;115(14):191220

22 Leclerc S, Teixeira A, Mahé E, Descamps V, Crickx B, Chosidow O. Recurrent erysipelas: 47 cases. Dermatology. 2007;214(1):52-7

23 Jorup-Rönstrom C, Britton S, Gavlevik A et al. The course, cost and complication of oral versus intravenous therapy of erysipelas. Infection. 1984;12:390-4

24 Pavlotsky F, Amrani S, Trau H. Recurrent erysipelas: riskfactors. J Dtsch Dermatol Ges. 2004;2:895

25 Damstra RJ, van Steensel MAM, Boomsma JHB, Nelemans P, Veraart JCJM. Erysipelas as a sign of subclinical primary lymphedema: A prospective quantitative scintigraphic study of 40 patients with unilateral erysipelas of the leg. Br J dermatol. 2008;158(6):1210-5

26 Brice G, Child AH, Evans A, Bell R, Mansour S, Burnand K, et al. Milroy disease and the VEGFR-3 mutation phenotype. J Med Genet. 2005;42(2): 98-102

27 Scarsbrook AF, Ganeshan A, Bradley KM. Pearls and pitfalls of radionuclide imaging of the lymphatic system: part 2: evaluation of extremity lymphedema. BrJRadiology.2007;80(951):21926

28 Bollinger A, Amann-Vesti BR. Fluorescence microlymphography: diagnostic potential in lymphedema and basis for the measurement of lymphatic pressure and flow velocity. Lymphology. 2007;40(2):52-62

29 Berenji GR, lker E, Glass EC. Lymphoscintigraphic findings in chylous reflux in a lower extremity. Clinical Nuclear Medicine. 2007;32 (9):725-8

30 Aalami OO, Allen DB, Organ CH. Chylous ascites: a collective review. Surgery. 2000;128:761-78

31 Howarth D, Gloviczki P. Lymphoscintigrphy and lymphangiography of lymphangectasia. J Nucl Med. 1998;9:683-90

32 Chamouard P, Nehme-Schuster H, Simler J-M, Finck G, Baumann R, Pasquali J-L. Videocapsule endoscopy is useful for the diagnosis of intestinal lymphangiectasia. Digestive and liver disease: official journal of the Italian Society of Gastroenterology and the Italian Association for the Study of the Liver 2006;38 (9): 699-703

33 Campisi C, Bellini C, Errata C, Zilli A, Da Rin E, Davini D et al. Diagnosis and management of primary chylous ascites. J Vasc Surg. 2006;43(6):1244-8

34 Földi M, Földi E. Földi's textbook of lymphology. Munich, Germany 20062 nd editon. Mostby Elsevier (ISBN 13:978-0-7234-3446-7) 525-668

35 Van Geest AJ, Veraart JC, van Kroonenburgh MJ. Progressief lymfoedeem aan de benen van kinderen en adolencenten. NTvG. 2004;148(2):93-6

36 EWMA position document: understanding compression therapy. London: Medical Education Partnership (MEP) Itd, 2003

37 EWMA / lymphedema framework (UK) focus document: Lymphedema bandaging in practice. London: MEP Ltd, 2005

38 Lymphedema framework template for practice: Compression hosiery in lymphedema. London: MEP Ltd, 2006

39 Földi M. Treatment of lymphedema (editorial). Lymphology. 1994;27(1):1-5 
40 Mallon E, Powell S, Mortimer PS, Ryan TJ. Evidence for altered cell-mediated immunity in postmastectomy lymphedema. Br J Dermatol. 1997;137(6):928-33

41 Roseeuw D. Achilles foot screening project: preliminary results of patients screened by dermatologists. J Eur Acad Dermatol Venereol. 1999;12: Suppl 1 pp. S6-9; discussion S17

42 Shaw C, Mortimer PS, Judd P. A randomized controlled trial of weight reduction as a treatment for breast cancer-related lymphedema. Cancer. 2007;110(8):1868-74

43 Lam JC, Tobias JD. Initial experience with octreotide in the pediatric population. Am J Therapeutics. 2001;8(6);409-15

44 Browse NL, Wilson NN, Russo F, al-Hassan H, Allen DR. Aetiology and treatment of chylous ascites. Br J Surg. 1992;79:1145-50

45 Beghetti M, LaScala G, Belli D, Bugman P, Kalangos A, LeCoultre C. etiology and management of pediatric chylothorax. J of Peadiatrics. 2000;136:653-8

46 Browse N, Burnand KG, Mortimer PS. Diseases of the Lymphatics ISBN 0-340-76203-9: pp 1978

47 Damstra RJ, Voesten HGJ, van Schelven WD, van der Lei B. Lymphatic venous anastomosis (LVA) for treatment of secondary arm lymphedema. A prospective study of 11 LVA procedures in 10 patients with breast cancer related lymphedema and a critical review of the literature. Breast Cancer Res Treat. 2009;113(2):199-206

48 Campisi C, Da Rin E, Bellini C, Bonioli E, Boccardo F. Pediatric Lymphedema and correlated syndromes: role of microsurgery. Microsurgery. 2008;28(2):138-42

49 Pavlotsky F, Amrani S, Trau H. Recurrent erysipelas: riskfactors. J Dtsch Dermatol Ges. 2004;2(2):89-95

50 Mozes M, Papa MZ, Karasik A, Reshef A, Adar R. The role of infection in postmastectomy lymphedema. Ann Surg. 1982;14:73-83

51 Milroy WF. Chronic hereditary edema: Milroy's disease. JAMA. 1928;91:1172-4

52 Badger C, Preston N, Seers K, Mortimer P. Antibiotics / anti-inflammatories for reducing acute inflammatory episodes in lymphedema of the limbs. Cochrane Database Syst Rev. 2004;2:CD003143

53 Peyron N, Dandurand M, Guillot B. Malignant tumors as complication of lymphedema. J Mal Vasc. 1993;18(4):293-8

54 Brady MS, Garfein CF, Petrek JA, Brennan MF. Post treatment sarcoma in breast cancer patients. Ann Surg Oncol. 1994;1(1):66-72

55 Cerri A, Gianni C, Corbellino M, Pizzuto M, Moneghini L, Crosti C. Lymphangiosarcoma of the pubic region: a rare complication arising in congenital non-heriditary lymphedema. Eur J Dermatol. 1998;8(7):511-4

56 Hulme SA, Bialostocki A, Hardly SL, Tills MR. Stuwart-Treves syndrome in a congenitally lymphedematous upper limb. Plast Reconstr Surg. 2007;119(3):1140-1

57 Chung KC, Kim HJ, Jeffers LL. Lymphangiosarcoma (Stuwart-Treves syndrome) in postmastectomy patients. A review. J Hand Surg. 2000;25(6):1163-8 
Summary, Discussion and Recommendations for Further Research 


\section{SUMMARY}

The general introduction in Chapter 1 provides an overview of lymphology in general, focusing on lymphedema in particular as a relatively common yet underappreciated disease. Formerly, lymfhedema was considered to be a "static disease with non-pitting" edema, in which the presence of pitting or non-pitting distinguished edema and lymphedema. More appropriately, however, lymfhedema should be considered more as a continuum in time and severity based on various dynamic, genetic, and etiological aspects, which all impact the therapy program. From an etiological point of view, primary, congenital, heritable, connatal (present at birth) and secondary lymfhedema can all be defined. With the introduction genetic research, more forms of primary lymfhedema can be differentiated, leading to greater insight into basic, embryological development. From the pathophysiological perspective of the type of lymphatic impairment, lymfhedema can be divided into dynamic or static lymphatic insufficiency.

An extensive overview of diagnostic and measuring modalities is presented. Many methods are described for the characterization of lymfhedema. Relative measurements such as percentages of the normal arm and absolute definitions such as a $2 \mathrm{~cm}$ circumference difference or a 100 to $200 \mathrm{ml}$ volume difference are used. Absolute values seem less reliable because they do not take into account total limb volume and are therefore less suitable for defining a true cut-off point, above which a volume change is considered to be a significant indicator of lymfhedema. No consensus exists with respect to a commonly accepted and standardized method for measuring arm (and leg) volume in patients with lymphedema, although a 10\% volume change in the non-affected limb above preoperative values is considered to be pathological.

The therapeutic options for lymfhedema are multiple and must be adjusted for each patient considering age, physical ability, personal demands from the patient and his or her experience of quality of life, co-morbidities, and life expectancy. Most conservative treatment options are experience-based. The overwhelming majority of patients can be effectively treated by non-operative means such as complex decongestive therapy (CDT) including manual lymphatic drainage, compression therapy, physical exercise, skincare and 
self-management. Compression therapy forms the cornerstone of the treatment program and can be performed in many ways: during the initial treatment phase bandaging with short stretch (multi- or monolayer) bandages, with pneumatic pressotherapy, and with various types of garments and hosiery in the maintenance phase.

Manual lymph drainage is a generally accepted method to stimulate lymphatic transport by various grips and movements of the hands on the skin of the patient.

In end stage lymfhedema with many irreversible changes in the limb or midline region, reduction surgery can be performed. Many types of surgery in extreme forms of lymfhedema have unfortunately been mutilating and cosmetically and functionally ineffective, but new methods are being developed (this thesis). These treatments should be performed in a multidisciplinary setting, preferably in a specialized lymphedema clinic, with life-long follow-up treatment with garments and specialized protocols. Education of patients with chronic diseases to help in coping with the disorder and performing some self-treatment is essential to allow patients to be independent individuals, not enslaved to a professional healthcare worker, and to be in charge with their own disabilities.

In Chapter 2, the results from a validation study are presented for a new, self-designed and self-produced measuring method, which has been termed "inverse water volumetry" (IWV). In this validation study, 25 consecutive patients with one-sided breast cancerrelated lymphedema ( $B C R L)$ were included. Two observers ( $A$ and $B$ ) measured the volume independently at three consecutive times: A1-A2-B. Inter- and intra-observer agreement and the agreement between both methods on the various occasions were quantified using intra-class correlation coefficients (ICC). The ICCs were, respectively, 0.91 (A1-A2), 0.89 (A1-B) and 0.89 (A2-B).

IWV is the first validated method suitable for reliable measurement of the volume of the arm (including the hand) and is very efficient for use in general by healthcare workers for early diagnosis of lymfhedema and for effect measurement during treatment and followup.

In Chapter 3, the results of 288 consecutive patients presenting with primary lymphedema are presented. In studying one of the genes most frequently involved in inherited lymphedema, FOXC2, which encodes a forkhead transcription factor, we discovered six 
novel missense mutations. Using a luciferase assay to measure transcriptional activity, we sought to determine whether these new mutations were pathogenic. To our surprise, we found that some actually caused a gain of function, leading to increased transcriptional activity as measured by our assay. Our results contradict earlier assertions to the effect that FOXC2 mutations cause a clinical phenotype by haplo-insufficiency. Apparently, FOXC2 transcriptional activity is an important determinant in lymphangiogenesis, with an increase being just as deleterious as a decrease. This insight will eventually help us to understand how FOXC2 contributes to lymphatic vessel patterning.

Infections of the skin are often seen in daily practice by a dermatologist. Among these, erysipelas is a common skin infection usually caused by ß-hemolytic group A streptococci. After developing erysipelas in an extremity, a significant percentage of patients develop persistent swelling or suffer from recurrent erysipelas, with up to $46 \%$ recurrence during the first 2 years. From a clinical point of view, a dermatologist often uses compression treatment for 3 months after a period of erysipelas, but it is unclear what the scientific background and motivation of this treatment are other than just removing edema. We hypothesize that in cases of erysipelas without a clear precipitating agent, subclinical preexisting congenital or acquired disturbances in the function of the lymphatic system are present.

In Chapter 4, we examined 40 patients hospitalized with one-sided erysipelas who were hospitalized and enrolled in the study. However, retrospectively, a maximum history of 0-2 episodes of unilateral erysipelas in one leg was not rejected when any previous swelling was absent. Exclusion criteria were patients with known risk factors for erysipelas such as clinically evident lymphedema, chronic venous insufficiency, pressure ulcers, diabetes mellitus, obesity (BMI>30) or other skin diseases affecting the legs. Reflux in the venous system was excluded by duplex ultrasonography in all patients. During four months after release from the hospital, the patients wore elastic stockings. Elective quantitative and qualitative lymphoscintigraphy was then performed on both legs according to a standardized protocol. Routine qualitative assessment was performed regarding generally accepted parameters, but interpretation of qualitative lymphoscintigraphy is highly subjective and difficult to quantify. In the quantitative lymphoscintigraphy analysis, groin uptake of less than $15 \%$ was pathological; uptake between $15-20 \%$ was defined as 
borderline, and uptake of more than $20 \%$ was considered normal. The mean percentage of uptake in the groin nodes in the affected limbs was $9.6 \%$ ( \pm 8.5$)$ versus $12.1 \%( \pm 8.9)$ in the non-affected limbs, which indicated clear bilateral lymphatic impairment. The mean paired difference in uptake between the non-affected versus affected side was $2.5 \%$ (95\% confidence interval $1.1 \%$ to $3.9 \%)$.

This study showed a statistically significant correlation between erysipelas and preexisting bilateral lymphatic impairment. Consequently, treatment of erysipelas should address not only the infection itself but also the underlying lymphatic impairment. We recommend that any therapeutic regimen should include compression therapy and that patients be fitted with compression hosiery after completion of initial therapy, as is done in lymfhedema treatment.

In Chapter 5, three cases are presented with secondary lymfhedema due to diffuse cutaneous infiltration of lymphatics in ovarian carcinoma, squamous cell carcinoma and breast cancer. An intensive review of the literature showed many, often confusing, terms for this disease, and this type of lymfhedema is often erroneously called "malignant lymphedema," given that the lymfhedema itself is not malignant but is caused by malignant cell infiltration. When the diagnosis of lymfhedema is made in patients previously treated for malignancy, the physician must consider whether a recurrence of the cancer is causing the lymfhedema, or whether the lymfhedema is a complication of the initial cancer treatment. In $25 \%$ of the patients previously treated for breast cancer, lymfhedema is the first sign of local tumor recurrence.

Minor dermatological features can give clues for the diagnosis of early stage lymphangitis carcinomatosa. Early recognition of the origin of lymfhedema can sometimes influence patient therapy and prognosis. Close dermatological examination in patients with lymfhedema and a history of cancer is strongly advised.

In the second part of the thesis, several chapters on therapeutic approaches of lymfhedema are presented, consisting of both non-operative and operative methods. Initially, the majority of patients can effectively be treated by non-operative means such as complex decongestive therapy (CDT). In the long-term maintenance phase, therapeutic elastic stockings are mandatory. The goals of all non-operative treatment modalities are to reduce 
capillary filtration and improve lymph drainage of interstitial fluid and macromolecules, thereby reducing swelling, inflammation, and recurrence of erysipelas and improving quality of life.

Compression therapy is a powerful treatment modality in both phlebology and lymphology. Obviously, in order to compare results, it is clearly necessary to use standardized bandaging methods and measuring equipment. Recently, in 2006, the International Compression Club (ICC) published recommendations for the performance of measurements of interface pressure and stiffness for standardized measurement of pressure between the skin and medical compression devices. Regarding the effect of compression and the relationship between various bandaging methods and the effect on stiffness, volume and pressure, many phlebology studies are available. In comparative lymphology, however, studies in leg or arm lymfhedema have not been before performed. Nevertheless, some studies have focused on combination therapies such as MLD and compression therapy or the addition of exercise. Additionally, two studies were designed and conducted in the Lymphedema Clinic in Nij Smellinghe Hospital Drachten. In both studies, we used classic - and inverse water displacement. Pressure measurements were performed using an air-filled pressure transducer (Kikuhime ${ }^{\circledR}$, TT Medi Trade, Soleddet 15, DK 4180 Soro) with a large probe $(\varnothing 5$ centimeter), according the recommendations of the ICC.

Chapter 6 presents the relationship between interface pressure and volume in patients with stage II leg lymfhedema and a control group. Twenty patients ( 15 female and 5 males, age 20-78 years, mean age: 51.1years) were included. The control group consisted of nine volunteers. The pressure was measured at the B1 region in supine and standing positions after application of the bandage, after 30 minutes, with 2 hours of moving, and after 24 hours. In lymfhedema patients, the median value was $64 \mathrm{mmHg}$ immediately after bandage application. After 30 minutes, these values were reduced by about one-third, and after 2 hours, the median pressure was $32 \mathrm{mmHg}(20-64 \mathrm{mmHg})$. The initial bandage pressure in the healthy control group was similar to that of the lymfhedema patients. The pressure drop in the first two hours was less pronounced compared to the lymfhedema group but was still significant. In both the control group and the lymfhedema patients, the sub-bandage pressure was higher, and the pressure loss was less pronounced when standing compared to the supine position. The mean volume reduction after two hours 
was about $60 \mathrm{ml}$ in the healthy controls and in the lymfhedema group. After 24 hours, the volume reduction only progressed in the lymfhedema group, with mean value of $5.6 \%$ $(-290 \mathrm{ml})$. The interface pressure loss was associated with a considerable reduction in leg volume, taking place instantly in both groups and persisting in the lymfhedema group after 24 hours. This can be explained by a reduction in the fluid content of the compressed parts of the lower extremities and fatigue of the material alone. Redistribution to the upper part of the leg is plausible, although abnormal congestion of fluid around the knee was not observed.

Chapter 7 presents an experimental, randomized controlled and comparative study of two groups with initially high and low interface pressure among one-sided BCRL patients ("arm study"). In arm lymfhedema, the optimal compression pressure to obtain the highest volume reduction per unit time ("optimal effect") is unknown. There were 36 patients randomized into two groups: a low-pressure (LPB, 20-30 $\mathrm{mmHg}$ ) group and a high-pressure (HPB, 44-58 mmHg) group. Bandaging consisted of multiple short stretch bandages, with measurement of the interface pressure and volume at 0, 2 and 24 hours. No other therapeutic modalities were used. The median arm volume reduction after 2 hours in the LPB group was higher than in the HPD group: $217 \mathrm{ml}(\mathrm{p}<.01)$ and $56.5 \mathrm{ml}$, respectively. After 24 hours, edema decreased by a median percentage of $9.2 \%$ in the LPB group and $4.8 \%$ in the HPB group (n.s.). The sub-bandage pressure drop in the first 2 hours was between 41 and $48 \%$ in both treatment groups at both measuring sites. After 24 hours, the pressure drop was between 55\% and 63\%. No proximal swelling above the bandage was observed. According to the visual analog score (VAS), the group with high pressure had more complaints of pain and discomfort, especially in the beginning. The low-pressure bandage was better tolerated throughout the whole study.

Some theoretical explanations are discussed regarding veno- and lympho-dynamics. These remarkable results for the first study on sub-bandage pressure in BCRL lay the groundwork for further research and perhaps give an indirect explanation of why treatment of arm lymfhedema differs from that of leg lymfhedema.

Besides non-operative treatment of lymfhedema, operative modalities are available. Operative treatment is only indicated in a few cases as a last resort treatment and is 
divided into reconstructive and reductive treatment. Many reconstructive techniques have been described, such as lymphovenous anastomosis (LVA), lympho-venouslymphatic (LVL) transplant (especially in the presence of venous hypertension), forms of lymph vessel transplantation and recently lymph node transplantation. LVA has been the most frequently used type of operation.

In Chapter 8, we evaluate the effectiveness of LVA in the treatment of one-sided breast cancer-related lymphedema in a limited prospective study of ten patients with BCRL that was non-responsive to conservative treatment and we reviewed the literature. The patients were hospitalized in the lymphedema clinic to undergo LVA according to our protocol. All patients underwent objective measurements with validated methods for quality of life (SF-36 questionnaire), IWV, and qualitative and quantitative lymphoscintigraphy both preand postoperatively, with a follow-up of one year. For volumetric evaluation after one year, a small initial reduction (16\%) diminished to almost zero (2\%). Scintigraphic evaluation showed no significant difference between before and one year after the operation.

According to our results, no effect could be measured, despite the limited number of patients. The effects of LVA in the literature are unproven; there is a lack of standardization of the patient population, and the measurement methods are not validated. Therefore, we conclude that LVA is not effective for the treatment of unilateral BCRL. Although the LVA has been performed and studied for more than three decades, it still has not had a breakthrough and will likely never become a treatment of choice in daily practice.

Håkan Brorson has extensively published studies of reductive treatment for lymfhedema. Until now, no other study group has reproduced his data. In Chapter 9, we used a prospective, consecutive cohort study to study the one-year follow up of $37 \mathrm{BCRL}$ patients treated with circumferential suction assisted lipectomy (CSAL), according the specifications of Brorson, in a multidisciplinary setting with 2-4 days of CDT prior to the operation. All patients included had lymfhedema that was not responsive to conservative treatment and non-pitting edema with a volume difference of at least $600 \mathrm{ml}$ (or > 16\% difference according to the normal arm). Limb compression with short stretch bandages was resumed postoperatively, followed by flat knitted compression garments.

The results showed that the treatment was equally effective as seen in the previous study of Brorson. A total volume reduction of $100 \%$ was achieved at 1 month, with a further 
mean reduction reaching $118 \%$ (difference range to control arm: - 74 to - $234 \mathrm{ml}$ ). Adding CDT to the program pre-operatively for 2-4 days gave an extra mean preoperative volume reduction of $142 \mathrm{ml}$ (range, 81 to $888 \mathrm{ml}$ ) or $8.1 \%$ (range, 4.6 to $35 \%, p<0.0001$ ). No surgical complications were recorded. This new CSAL method is an excellent technique for therapyresistant $\mathrm{BCRL}$ to obtain $100 \%$ volume reduction compared to the contra-lateral side and is superior to any other technique. Although these patients had non-pitting edema, preoperative conservative treatment can optimize the condition of the arm. Therefore, this procedure should be performed in a multidisciplinary lymphedema clinic.

Lymfhedema is a complicated symptom due to lymphatic impairment, and it has a wide spectrum of etiological factors and is sometimes even a clue to a fatal disease. Knowledge, experience and an adequate work-up of patients with swelling are necessary to provide adequate patient care. Because swelling itself is a non-specific symptom, many medical specialists meet with these patients. The Dutch Institute for Healthcare Improvement (CBO) organized a task force on lymfhedema to evaluate the current literature and to propose evidence- and expert-based recommendations suitable for national implementation as guidelines for the treatment of lymfhedema. These guidelines were published in 2003. In Chapter 10, these recommendations in the field of diagnostics, early recognition, multidisciplinary treatment and follow-up of lymfhedema for physicians, paramedics, nurses, healthcare workers and patients regarding the management of lymfhedema are presented. To motivate the usage of this document in daily practice, an algorithm for the diagnostic and therapeutic work-up of patients suspected to have lymfhedema and a program for early diagnosis of lymfhedema in patients at risk (e.g. after (breast) cancer treatment) are provided.

General recommendations for lymfhedema do not address a child with unknown swelling or lymfhedema. The management of lymfhedema in children differs considerably from that in adults in terms of origin, co-morbidities and therapeutic approach. Based on the literature and expert opinions, Chapter 11 presents practical issues related to clinically relevant information for the diagnosis, etiology, work-up and treatment of lymfhedema in children. In contrast to adults, who usually experience secondary lymfhedema due to acquired lymphatic failure, most cases in children have a primary origin. The diagnostic 
and therapeutic work-up in children is distinguished from that in adults in terms of inheritance, genetic counseling, meeting technical and practical boundaries of treatment, the need to involve parents in the therapeutic process and specific psycho-social aspects in children and adolescents with lymfhedema. At the end of this publication, a flowchart for workup is described. Because lymfhedema in children is rare, it requires a specialized, multidisciplinary approach by experienced healthcare workers.

\section{DISCUSSION}

The field of clinical lymphedema has been underappreciated for a long time. In patients with secondary lymfhedema due to cancer treatment, the focus has mainly been on the cancer treatment itself, while lymfhedema was considered to be the "price of survival". For example, every year more than 12,000 new breast cancer patients are diagnosed, of whom 10-30 \% will develop lymphedema in the years ahead. Every year, about 9,500 prostate and penis cancer cases are diagnosed, of whom 30-50\% will develop lymfhedema after lymph node extirpation and/or radiotherapy (Nederlandse Kanker Registratie, NKR 2006). There are also many patients with primary lymfhedema who remain undiagnosed for a long time. Clearly, it is peculiar that a disease affecting more than 350,000 patients just in the Netherlands has had such little interest for such a long time. The Dutch Institute for Healthcare Improvement (CBO) provided lymphedema guidelines regarded as a starting point to better address lymfhedema and to relieve the enormous loss of quality of life and morbidity for so many people. When professionals are more familiar with lymphedema, advocate for more awareness, and start adequate therapy earlier, lymfhedema and its complications are better controlled, and cases of irreversible lymfhedema are reduced.

For dermatologists, it is obvious that patients suffering from erysipelas should be treated with antibiotics and compression therapy for a few days. When the initial swelling is diminished, adequate round knitted custom-made garments are provided. Other medical specialists have often discussed this treatment because swelling was thought to disappear on its own, and no scientific basis was provided for the approach. Our study unambiguously supported the idea that most patients with unexpected erysipelas are actually suffering from compensated primary lymfhedema. I consider this to be the scientific basic for 
lymphologic treatment with compression therapy in post-erysipelas patients.

There are a high number of recurrences of erysipelas, up to $46 \%$ in the first two years, when patients are not treated with compression. Therefore, the use of garments for two years without recurrence is mandatory. An adequate compression protocol probably makes maintenance treatment with antibiotics unnecessary in many patients with recurrent erysipelas.

The genetic etiology of lymfhedema disorders is a highly interesting and new field of research. There are currently three genes, VEGF-C, FOXC2, and SOX-16 that have been identified to cause lymphedema, but more are still to come. This gives treating doctors a greater opportunity to understand lymphangiogenesis and the basic pathophysiology of lymphatic impairment. By better understanding the genetics, we will perhaps be able to influence or improve the process of lymphangiogenesis in patients with lymphatic impairment in the future. Perhaps we will discover special markers suitable to predict whether a patient will develop lymphatic impairment or to forecast the severity of the disease. Within the identified genes themselves, more loci involved in lymfhedema are still to be discovered and will perhaps explain the variability of phenotypes in some types of lymfhedema. In the search for new mutations, the six novel missense mutations in FOXC2 presented in Chapter 3 showed a gain of function with increased transcriptional activity. Our results contradict earlier assertions to the effect that FOXC2 mutations cause a clinical phenotype due to haplo-insufficiency. Apparently, FOXC2 transcriptional activity is an important determinant in lymphangiogenesis, with an increase being just as deleterious as a decrease. FOXC2 also plays a role in the development of varicose veins. FOXC2deficient patients have obligatory superficial and deep venous incompetence; however, the relationship between the development of the lymphatic and venous systems is still not clear.

Although many different treatments have been used for lymfhedema, they often have no basis in scientific studies. In this thesis we focused on compression therapy for arm and leg lymfhedema in order to understand more about the relationship between volume change and pressure change. We realize that further studies are essential before final conclusions can be drawn. Nevertheless, more attempts at practicing evidence-based medicine should 
be made for other frequently used lymfhedema treatments, such as MLD, lymph taping, pressotherapy, garments and exercises, in order to develop lymphology and include the results in intended guidelines.

In the surgical field, we performed a study on a reconstructive treatment and reductive methods. In addition to the lack of effectiveness of lymphatic-venous anastomosis (LVA) in our hands, the literature was unconvincing. From a theoretical pathophysiological perspective, it is hard to imagine how a low pressure system such as lymphatics (5-15 $\mathrm{mmHg}$ ) could continue to drain to a venous system with higher pressures, especially when LVA is performed more distally on the limb. From a thrombo-embolic point of view, clotting is suspected at the anastomosis. Venous reconstructive surgery mostly lacks longlasting results due to thrombosis, and in arterial reconstruction, life-long anti-clotting therapy is obligatory to guarantee perfusion of the anastomosis. It is peculiar that in the LVA literature, anti-coagulants are not even mentioned.

This method is even more controversial as a "preventive procedure" for all patients after axillary dissection. Boccardo et al. ${ }^{1}$ studied 18 patients who received an LVA directly after axillary dissection for breast cancer and concluded that "LVA proved to be a safe procedure in order to prevent arm lymphedema". The follow-up was just 6-12 months without randomization, and there was no control group. Because the incidence of lymphedema after breast cancer treatment with axillary dissection is maximally $30 \%$ after 10 years, $70 \%$ of patients will be needlessly treated by this approach for a disease that they will never develop. This type of primary prevention with reconstructive surgery is undesirable from an ethical and cost-effective point of view.

Therefore, in terms of primary prevention, we must focus on developing protocols for risk-management, early detection of swelling, and programs for awareness and selfmanagement. Prospective guidelines will hopefully address more of these preventive issues.

Early stages of lymfhedema (stage 1 and 2), with a pitting component can be effectively treated by non-operative means. In general, operative treatment should be reserved for end stage non-pitting lymfhedema (stage 3 and 4) with objective functional limitations for patients in whom optimal conservative treatment is not beneficial. Obviously, more aggressive treatments are still necessary at this time. Reductive surgery in general and 
circumferential suction assisted lipectomy (CSAL) in particular are safe and very effective treatments in lymfhedema, guaranteeing $100 \%$ excess of volume reduction when performed according a strict protocol with long-lasting follow-up. CSAL is also effective in leg lymfhedema. In scrotal lymfhedema, reductive surgery can be performed by total excision of the tissue with re-implantation of the testis and the creation of a new scrotal pouch. All of these highly specialized procedures should be performed in a multidisciplinary lymphedema center and fully embedded in a non-operative treatment protocol.

In order to concentrate multidisciplinary experience, knowledge in (non)-operative treatment of lymfhedema, education and research, it is necessary for center of excellence to cooperate intensively with others active in the field to form a network of professional healthcare providers. In 2006, the foundation of the Dutch Lymphedema Network (NLNet) provided an explicit oral, visual and internet platform for both patients and professionals. The activities of the NLNet have already shown great advances in improving acquaintance with this neglected, disabling disease with great morbidity. Because lymfhedema is a common disease, programs for case management of lymphedema should be available in every hospital.

In the future, early diagnostics, self-management programs and the quality and quantity of effective treatments for lymfhedema will hopefully be enhanced and fully be funded as for all general accepted diseases. Awareness, primary and secondary prevention of lymfhedema, and early treatment will prevent more irreversible stages of lymfhedema. Thus, it will be possible to prevent severe loss of quality of life and morbidity for the patient and to cut down on high costs for insurance companies for more expensive treatment modalities of late stage disease. Society will benefit from the higher social and economical productivity of a patient who is treated at an earlier stage for his or her lymphedema.

Perhaps one question will remain: why should dermatologists focus on lymfhedema? lymfhedema has several interfaces with dermatology. Many dermatological features are seen in lymfhedema: $80 \%$ of the lymphatic system is situated in the subcutis - dermal layer, and dermatologists are familiar with one of the cornerstones in lymfhedema treatment, namely, compression therapy. Therefore, a dermatologist is perhaps the most likely to be active in the very interesting field of lymphology and to help patients with lymphologic problems. Knowledge and skills in diagnosis and treatment of lymphologic diseases are mandatory in the educational program (HOR) for trainees in dermatology defined by the 
Concilium Dermatologicum et Venerologicum.

\section{RECOMMENDATIONS FOR FURTHER RESEARCH}

Over the last decade, research in the field of lymfhedema has expanded, as evidenced by the increasing number of articles in the field and the introduction of new peer reviewed journals such as the Journal "Lymphatic Research and Biology" and the "Journal of Lymphoedema".

Further basic research is necessary for a better understanding of the genetics, (patho) physiological mechanisms and concomitant factors involved in the development and progression of lymfhedema. Gradually, the number of patients with primary lymfhedema (of unknown origin) will decline, and new diagnostics will arise based on the discovery of more new genes responsible for lymfhedema and perhaps some concomitant phenomena. This will likely lead to forms of gene therapy in the future that will influence lymphangiogenesis. Currently, lymphangiogenesis is a popular subject in oncology research concerning tumor biology and the prediction or inhibition of metastasis.

Immunology is a very important part of medicine and is extensively studied. It is surprising, then, that one of the major anatomical and functional systems involved in this field, the lymphatic system, is seldom studied. In the years to come, the lymphatic system will undoubtedly be of more interest in order to understand and perhaps influence the issue of immunological resistance and reactions. Especially in dermatology, this "lymphatic component" can easily be studied and is perhaps of great importance in understanding immune mediated diseases such as eczema, psoriasis and even skin cancer.

Many current treatments for lymfhedema are empirical, based on anecdotal reports or open clinical trials without adequate control groups. Well-designed, controlled and comparative studies are needed to demonstrate the effectiveness of many therapeutic options. For example, although MLD has been performed for many decades by ten thousands of therapists just in Europe, no indisputable data are available about its mechanism of action or the (additional) effect of MLD with or without compression, and there is no consensus about the method of performing of MLD. New methods for the treatment of lymfhedema such as lymph taping, endermology, new bandaging materials, heating by radiofrequency, 
soft laser therapy, self-management programs and new surgical procedures are primarily being published as case reports and need scientific validation provided by evidencebased research. The results of circumferential suction assisted lipectomy are excellent, and the surgical procedure is most effective when embedded in a multidisciplinary treatment program. In the future, perhaps new techniques will be developed to remove adipose tissue by either refining the surgical procedure with new suction techniques or by new methods that disintegrate and remove the supra-facial matrix and adipose.

Hopefully, the number of cases of secondary lymfhedema will decline, and more primary and secondary prevention methods will be used on patients at risk or patients with only minimal signs of lymphatic impairment. Methods must be developed to predict which patients will develop lymfhedema and which will not, in addition to indentifying who is at risk for developing lymfhedema. New methods to evaluate and calculate residual lymphatic capacity after cancer treatment can be helpful. Focusing on early diagnosis, awareness of the patient and self-management programs can enhance the prevention of late stages of lymphedema. In the end, all cases of lymphedema begin at some point, with only minor symptoms and/or volume differences.

In order to achieve these improvements in lymphologic research and care, for the sake of our patients, close multidisciplinary cooperation between many disciplines of medicine is essential. This will certainly be the challenge in the near future.

\section{REFERENCES}

1 Boccardo F, Casabona F, De Cian F, Friedman D, Villa G, Bogliolo S, Ferrero S, Murelli F, Campisi C. Lymphedema microsurgical preventive healing approach: a new technique for primary prevention of arm lymphedema after mastectomy. Ann Surg Oncol. 2009;16(3):703-8 


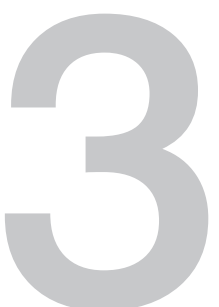

Samenvatting, discussie en aanbevelingen voor toekomstig research 


\section{SAMENVATTING}

Lymfologische aandoeningen in het algemeen en lymfoedeem in het bijzonder zijn lange tijd sterk onderbelicht geweest. Bij patiënten met secundair lymfoedeem als gevolg van de behandeling van kanker, was de aandacht primair gericht op de kanker en werd lymfoedeem vooral beschouwd als de "prijs van overleven". Jaarlijks worden in Nederland 12.000 nieuwe patiënten met borstkanker gediagnosticeerd. Bij 10-30\% van deze patiënten zal zich in de komende jaren lymfoedeem ontwikkelen, ondanks nieuwe behandelingstechnieken zoals de schildwachtklier operatie. Elk jaar wordt bij 9500 patiënten prostaat en penis kanker vastgesteld, bij 30-50\% van de patiënten die met een lymfklierverwijdering en/of radiotherapie te maken krijgen, zal zich lymfoedeem ontwikkelen (Nederlandse Kanker Registratie, NKR2006). Exacte cijfers voor gynaecologische kanker, met name vulva en cervix carcinoom, ontbreken maar ook hier lopen 30-50\% van de patiënten risico op het ontwikkelen van lymfoedeem. Daarnaast zijn er vele patiënten met primair lymfoedeem die lange tijd niet gediagnosticeerd zijn. Het is opmerkelijk dat een aandoening die meer dan 350.000 Nederlanders treft en vele anderen bedreigt, lange tijd zo weinig aandacht heeft gekregen. Met dit proefschrift wordt beoogd de diagnose en de behandeling van lymfoedeem de plaats te geven die deze aandoening verdiend.

In Hoofdstuk 1 wordt een state of art overzicht gegeven van de lymfologie in het algemeen en van lymfoedeem in het bijzonder. Tot voor kort werd lymfoedeem beschouwd als een "statische ziekte" met een kenmerkend niet pitting oedeem, waarbij het onderscheid tussen pitting en non-pitting oedeem ten onrechte het verschil vormde tussen oedeem of lymfoedeem. Echter, lymfoedeem dient als een continuüm te worden beschouwd in tijd en uitgebreidheid, met diverse dynamische, genetische en etiologische aspecten die van invloed zijn op de therapie. Op basis van etiologie wordt lymfoedeem onderscheiden in primair, erfelijk, connataal (aanwezig vanaf de geboorte) en secundair lymfoedeem. Met de opkomst van genetisch onderzoek worden meer vormen van primair lymfoedeem teruggevoerd naar een genetisch defect in de embryologische fase. Vanuit een patho-fysiologisch oogpunt wordt lymfoedeem onderverdeeld naar de aard van de lymfafvloedstoornis: dynamisch dan wel statische lymfatische insufficiëntie.

Voor de behandeling van lymfoedeem bestaan vele therapeutische mogelijkheden die individueel op de patiënt worden afgestemd, afhankelijk van leeftijd, fysieke conditie, 
hulpvraag, eventuele comorbiditeit en levensverwachting. De meeste conservatieve therapieën zijn experienced based. De grootste groep patiënten kan effectief conservatief worden behandeld met "complexe ontstuwingstherapie" (complex decongestive therapy, CDT) bestaande uit compressietherapie, manuele lymfdrainage, fysische oefeningen, huidverzorging en zelfmanagement. Zie de hoofdstukken 6 en 7. In de irreversibele stadia van lymfoedeem van een extremiteit of het midline gebied (genitaliën en hoofd-hals regio) valt reductie chirurgie te overwegen. Aangezien in het verleden vormen van reductie chirurgie zijn toegepast die uiterst mutilerend waren en een zeer slecht cosmetisch en functioneel effect gaven, zijn nieuwe methodes ontwikkeld. Zie hoofdstuk 8 en 9.

In Hoofdstuk 2 worden resultaten gepresenteerd van een validatie studie van een nieuw, zelf ontwikkeld apparaat (omgekeerde water volumetrie) waarmee veel nauwkeuriger en gemakkelijker het volume van de arm inclusief de hand gemeten kan worden, dan bij andere meetmethodes het geval is. De omgekeerde water volumetrie is geschikt voor grootschalige toepassing in de dagelijkse praktijk; zowel voor vroeg diagnostiek van zwelling bij patiënten met risico op lymfoedeem als voor effectmeting tijdens een behandelprogramma.

In Hoofdstuk 3 worden de resultaten gepresenteerd van onderzoek naar FOXC2 (een forkhead transcriptie factor die soms voorkomt bij erfelijk lymfoedeem) bij 288 opeenvolgende patiënten met primair lymfoedeem gezien tussen 2000-2007. Door gebruik te maken van een luciferase assay waarmee transcriptie activiteit van het gen is gemeten, zijn zes nieuwe missense mutaties ontdekt. Opvallend is dat een aantal mutaties een toegenomen transcriptie activiteit laten zien, hetgeen in tegenspraak is met eerdere bevinden in de literatuur waar een FOXC2 mutatie altijd een klinisch fenotype laat zien op basis van haplo-insufficientie. Blijkbaar is transcriptie activiteit van een mutatie een belangrijke determinant in lymfangiogenesis, die zowel schadelijk en pathologisch kan zijn. Deze ontdekking kan bijdragen aan de kennis welke invloed FOXC2 heeft bij het ontstaan van lymfvaten.

Erysipelas is een van de bekendste ernstige huidinfecties, meestal veroorzaakt door een ß-hemolytische streptococci groep A. Na een erysipelas blijft bij veel patiënten zwelling achter en is er een grote kans op recidief die kan oplopen tot $46 \%$ na twee jaar. Vanuit de klinische empirie wordt erysipelas vaak gedurende 3 maanden met compressietherapie nabehandeld. Is er een wetenschappelijke achtergrond voor deze 
therapie? Wij hypothetiseerden dat bij patiënten zonder duidelijke risicofactor voor erysipelas er misschien sprake zou kunnen zijn van een pre-klinische lymfatische stoornis. In Hoofdstuk 4 onderzochten we 40 patiënten met een eenzijdige erysipelas die klinisch zijn behandeld. Het voorkomen van eenzijdig erysipelas was essentieel; indien er geen klinische pre-exsistente zwelling bestond, werden ook patiënten met 0-2 periodes erysipelas geïncludeerd. Exclusie criteria bestonden uit bekende risico factoren voor het ontwikkelen van lymfoedeem zoals pre-existent lymfoedeem/zwelling, diabetes, chronisch veneuze insufficiëntie, overgewicht (BMI >30) of andere huidafwijkingen aan de benen. Reflux in het veneuze insufficiëntie werd bij alle patiënten middels duplex uitgesloten. De nabehandeling bestond gedurende 4 maanden uit op maat gemaakte vlakbrei therapeutische elastische kousen. Electieve kwantitatieve en kwalitatieve lymfscintigrafie werd aansluitend verricht van beide benen volgens een gestandaardiseerd protocol. Routinematige kwalitatieve beoordeling, waarbij naar parameters wordt gekeken als mate van dermale backfow, veel of weinig aankleuring van lymfklieren in de liezen en veel of weinig lymfbanen, heeft een hoge mate van subjectiviteit en is moeilijk te kwantificeren. Bij kwantitatieve scintigrafie worden uptake waarden berekend in een 'region of interest' en vergeleken met normaalwaarden. Uptake waarden in de lies van $<15 \%$ werden als pathologisch beschouwd; tussen 15-20\% als borderline en > 20\% als normaal. Bij de studiepopulatie bleek na 2 uur de uptake in de aangedane zijde 9.6 $\%( \pm 8.5)$ versus $12.1 \%$ ( \pm 8.9) in de niet-aangedane zijde, hetgeen betekent dat er een beiderzijdse ernstige afvloedstoornis bestond bij 79\% van de patiënten. De correlatie tussen gestoorde lymfafvloed capaciteit van beide benen bij een unilaterale erysipelas is niet eerder wetenschappelijk significant aangetoond. Wij concludeerden dat bij veel gevallen van erysipelas er sprake is van een pre-exsistent gestoorde lymfafvloed dan wel een subklinisch lymfoedeem precox, dat manifest wordt na een infectie en niet omgekeerd, zoals vroeger vaak werd vermoed. De consequentie van dit onderzoek is dat erysipelas in deze gevallen moet worden beschouwd als een symptoom van een onderliggende aandoening. De resultaten vormen ook de rationale waarom patiënten na erysipelas langdurig met compressietherapie behandeld moeten worden.

In Hoofdstuk 5 worden drie patiënten gepresenteerd met secundair lymfoedeem waarbij, pas na uitvoerig dermatologisch onderzoek, de oorzaak blijkt te liggen in lymfangitis carcinomatosa van een gemetastaseerd ovarium carcinoom, plaveiselcel carcinoom 
en een mamma carcinoom. In de literatuur wordt vaak de term "maligne lymfoedeem" gebruikt; een onjuiste benaming omdat het lymfoedeem zelf niet maligne is, maar veroorzaakt wordt door maligne infiltratie van lymfvaten. Indien de diagnose lymfoedeem wordt gesteld bij patiënten die voorheen voor kanker zijn behandeld, dient differentiaal diagnostisch altijd de mogelijkheid van metastasering als oorzaak overwogen te worden. Bij borstkanker blijkt lymfoedeem in $25 \%$ van de gevallen een eerste symptoom te zijn van recidive. Geringe dermatologische afwijkingen kunnen wijzen op beginnende lymfangitis carcinomatosa. Vroegtijdige onderkenning van de oorzaak van lymfoedeem kan bijdragen aan een vroegtijdige, nieuwe oncologische behandeling. Zorgvuldig dermatologisch onderzoek bij kanker patiënten met lymfoedeem en lymfoedeem patienten met kanker in de voorgeschiedenis is dan ook noodzakelijk.

De Hoofdstukken 6 tot en met 9 zijn gewijd aan conservatieve en operatieve behandelingen van lymfoedeem. De meeste patiënten, vooral in de vroege stadia van lymfoedeem, kunnen effectief worden behandeld met "complexe ontstuwingstherapie" (complex decongestive therapy, CDT) in de beginfase en met therapeutisch elastische kousen in de onderhoudsfase. Het doel van de niet operatieve behandeling is het verminderen van de capillaire filtratie en het verbeteren van de lymfdrainage door het vergroten van het interstitieel transport van vocht en macromoleculen. Hierdoor neemt de zwelling af, vermindert de kans op erysipelas, wordt de morbiditeit kleiner en neemt de kwaliteit van leven toe.

Compressie therapie is een zeer effectieve behandeling in de flebologie en lymfologie. Om verschillende vormen van compressie te kunnen vergelijken, zowel naar effectieve werkdruk, soort materiaal als verband techniek, is standaardisatie van bandage methodes en meettechnieken gewenst. Rationalisatie van technieken was voor de Internationale Compressie Club (ICC) de aanleiding om in 2006 aanbevelingen te publiceren over het gestandaardiseerd gebruik van verschillende meetmethodes voor het bepalen van druk tussen verbandmateriaal en de huid. Rekenkundig kan op deze wijze de stiffness van de verschillende materialen worden bepaald. In de flebologie zijn resultaten van dit onderzoek in toenemende mate voorhanden, maar in de lymfologie zijn zij nog niet eerder uitgevoerd. Naar aanleiding daarvan zijn in dit proefschrift zijn twee studies opgenomen die zijn opgezet en uitgevoerd in de Lymfoedeem Kliniek van Ziekenhuis Nij Smellinghe in Drachten. 
Aanvankelijk werd onderzoek bij lymfoedeem van het been opgezet. Hoofdstuk 6 beschrijft een prospectieve, gecontroleerde studie bij 20 patiënten met stadium II lymfoedeem van het been waarbij alleen compressietherapie werd toegepast. Doel van de studie was een verband aan te tonen tussen de hoogte van de initieel aangebrachte druk onder de bandage en de mate van volume afname. Deze gegevens werden gecontroleerd met een groep vrijwilligers. Bij lymfoedeem patiënten was de gemiddelde druk $64 \mathrm{mmHg}$, deze druk nam na 2 uur met de helft af. De druk in de controle groep was aanvankelijk hetzelfde, maar na 2 uur was de drukdaling minder uitgesproken, maar wel significant. $\mathrm{Na}$ 24 uur bedroeg de volume daling in de lymfoedeem groep 5,6\% (-290 ml). De drukdaling was gerelateerd aan de forse volume daling van het been in de eerste 2 uur, en zette door in de lymfoedeem groep na 24 uur. De drukdaling werd verklaard door de volume afname en door verlies van stijfheid van de gebruikte materialen. Theoretisch zou re-distributie van vocht naar het niet-gecomprimeerde bovenbeen kunnen optreden, maar zwelling rond de knie werd klinisch niet waargenomen.

Hoofdstuk 7 beschrijft een experimentele, gerandomiseerde, gecontroleerde en vergelijkende studie waarin 2 groepen zijn vergeleken waarbij patiënten met borstkanker gerelateerd lymfoedeem werden behandeld met hoge - en lage interface druk. De optimale druk om een maximale volume reductie per tijdseenheid te verkrijgen in arm lymfoedeem is onbekend. 36 patiënten werden gerandomiseerd in een lage druk groep (LDG, 20-30 mmHg) en een hoge druk groep (HDG, 44-58 mmHg). De patiënten werden gebandageerd met korte rek zwachtels en polstering waarbij 3 keer de drukken werden gemeten op 2 plaatsen op de arm (elleboog en pols) in 24 uur. Geen andere therapeutische interventies werden toegepast. The mediane volume reductie na 2 uur was in de LDG groter dan in HDG: $217 \mathrm{ml}$ respectievelijk 56,5 ml (p<0,01). Na 24 uur was er een afname van gemiddeld 9,2\% in de LDG en $4,8 \%$ in de HDG (n.s.). De compressiedruk daalde de eerste 2 uur 41\% (LDG) en 48\% (HDG) op beide meetplaatsen. Na 24 uur was de drukdaling $55 \%$ respectievelijk 63\%. Stuwing van de schoudertop werd niet waargenomen. Gemeten naar de visual analog score (VAS) toonde de HDG meer klachten en ongemak, met name in de eerste uren van behandeling. De LDG verdroeg de bandage gedurende de gehele studie beter. Sommige theoretische verklaringen worden besproken met betrekking tot veneuze - en lymfatische pathofysiologie. De opmerkelijke resultaten van deze eerste studie naar druk/volume relaties in borstkanker gerelateerd lymfoedeem geven 
misschien een indirecte verklaring waarom de behandeling van arm en been lymfoedeem zo verschillend zijn.

Naast de conservatieve behandelingen voor lymfoedeem zijn er ook operatieve modaliteiten. Operatieve behandeling is alleen op strikte indicatie wenselijk voor een geselecteerde groep lymfoedeem patiënten en kan worden onderverdeeld in reconstructieve- en reductie therapie. Veel reconstructieve methoden zijn de afgelopen decennia beschreven waaronder lymfo-veneuze anastomose (LVA), lymfo-veno-lymfvat transplantatie (LVL), andere vormen van transplantatie en recent lymfklier transplantatie. LVA is de meest toegepaste vorm van reconstructie therapie.

In Hoofdstuk 8 evalueren we de effectiviteit van LVA in een prospectieve studie bij 10 patiënten met eenzijdig borstkanker gerelateerd lymfoedeem die niet reageerden op conservatieve therapie. Uit een uitvoerige literatuurstudie blijkt de effectiviteit van LVA niet onomstoten; er is geen standaardisatie van patiënten populatie, er worden vaak niet gevalideerde meetmethodes gebruikt en de resultaten zijn beperkt. Onze conclusie is dat LVA niet effectief is voor de behandeling van eenzijdig borstkanker gerelateerd lymfoedeem. Ondanks dat LVA al meer dan drie decennia experimenteel wordt toegepast, is het onwaarschijnlijk dat de methode ooit een therapeutische optie voor de dagelijkse praktijk wordt.

Håkan Brorson heeft uitvoerig gepubliceerd over een nieuwe methode reductie therapie voor lymfoedeem. Tot nu toe waren deze resultaten nooit door een andere studie groep gereproduceerd. In Hoofdstuk 9 beschrijven we in een prospectieve cohort studie een 1 jaar follow-up van 37 patiënten met borstkanker gerelateerd lymfoedeem, die behandeld zijn met circumferential suction assisted lipectomy (CSAL) volgens de specificaties van Brorson in een multidisciplinaire setting met een conservatieve voorbehandeling met CDT van 2-4 dagen. Alle patiënten hadden therapie resistent non-pitting lymfoedeem niet reagerend op conservatieve therapie en een minimaal volume verschil van 600 $\mathrm{ml}$ (16\% volume verschil vergeleken met de niet aangedane arm). Postoperatief werd compressie therapie voortgezet met korte rek zwachtels gevolgd door een vlakbrei TEK. Dit bevestigde de resultaten van voorgaande studies van Brorson. Een totale volume reductie van $100 \%$ werd bereikt na 1 maand en een verdere reductie werd verkregen tot $118 \%$ ( $\Delta-74$ tot - $234 \mathrm{ml}$ ) na 1 jaar. Door het toevoegen van CDT preoperatief, werd een initiële volume reductie verkregen van $142 \mathrm{ml}(\Delta-81$ tot $-888 \mathrm{ml})$ of $8.1 \%$ ( $\Delta 4,6-35 \%$; 
$p<0.0001)$. er waren geen chirurgische complicaties. CSAL is een uitstekende behandeling voor onbehandelbare, therapie resistente vormen van lymfoedeem van de arm met een gegarandeerde volume reductie van 100\%. Daarmee is deze behandeling superieur aan andere behandelingsopties. Ondanks dat alle patiënten een non-pitting oedeem hadden, kon een conservatieve behandeling de preoperatieve conditie van de arm nog verbeteren. Daarom dient de behandeling uitgevoerd te worden in een multidisciplinaire lymfoedeem kliniek.

Het kwaliteitsinstituut voor de gezondheidszorg CBO heeft in 1999 een werkgroep de opdracht gegeven een richtlijn Lymfoedeem te ontwikkelen en evidence - en expert based aanbevelingen te doen die geschikt zijn voor nationale implementatie bij de diagnostiek en behandeling van lymfoedeem. De richtlijn is in 2003 gepubliceerd. In Hoofdstuk 10 zijn de aanbevelingen op het gebied van diagnostiek, vroegtijdige onderkenning en multidisciplinaire behandeling en follow-up van lymfoedeem beschreven. De richtlijn is bedoeld voor medici, paramedici, verpleegkundigen en andere gezondheidswerkers die met lymfoedeem te maken hebben en is weergegeven in een handzaam algoritme. Deze algemene aanbevelingen blijken in de praktijk niet geschikt voor de analyse van kinderen met zwelling waarbij aan lymfoedeem gedacht kan worden.

Gebaseerd op de literatuur en de ervaring van de auteurs staat in Hoofdstuk 11 een praktische richtlijn beschreven met relevante klinische informatie, etiologie, work-up en therapie van lymfoedeem bij kinderen. In tegenstelling tot volwassen, komt bij kinderen meestal primair lymfoedeem voor. De diagnostische en therapeutische work-up verschilt dan ook in termen van erfelijkheid, genetische advisering, andere technische en praktische beperkingen ten aanzien van de therapie en de noodzaak de ouders in de behandeling en begeleiding van dekinderen te betrekken. Daarnaast spelen er bijkinderen en adolescenten specifieke psycho-sociale aspecten mee die aandacht behoeven. Omdat lymfoedeem bij kinderen zeldzaam is, is een gespecialiseerde multidisciplinaire benadering gewenst door ervaren professionals.

\section{DISCUSSIE}

Zoals eerder betoogd is het opmerkelijk dat een aandoening die zoveel morbiditeit en verlies van kwaliteit van leven voor de patiënten met zich mee brengt, en die meer 
dan 350.000 Nederlanders treft en vele anderen bedreigt, lange tijd zo weinig aandacht heeft gekregen. Met het verschijnen van de CBO richtlijn lymfoedeem in 2003 werd een eerste en belangrijke stap gezet in de erkenning van en aandacht voor de problematiek van lymfoedeem. Als professionals meer bekend worden met primaire- en secondaire preventie van lymfoedeem, als er meer bewustwording bij de patiënten is en als er sprake is van vroegtijdige diagnostiek en behandeling van lymfoedeem en de bijbehorende complicaties, komen irreversibele vormen van eindstadium lymfoedeem minder voor.

Vanuit de empirie was het voor dermatologen duidelijk dat de behandeling van erysipelas bestond uit initieel antibiotica voor de infectieuze component en uit een nabehandeling met compressietherapie (bandageren en vlakbrei TEK) om oedeem te bestrijden en recidief te voorkomen. Bij andere medisch specialismen heerst vaak de overtuiging dat recidieven behandeld moeten worden met onderhoudstherapie antibiotica en dat de zwelling vanzelf verdwijnt. Voor compressie therapie zou geen wetenschappelijke basis bestaan. In dit proefschrift wordt onomstotelijk aangetoond dat patiënten met een onbegrepen erysipelas eigenlijk lijden aan een primaire lymfafvloedstoornis. De infectie is in feite de eerste complicatie van een tot dan toe subklinisch primaire lymfoedeem. Dit vormt de wetenschappelijke onderbouwing waarom na erysipelas eigenlijk een lymfologische behandeling geïndiceerd is. Er worden grote aantallen recidieven in de literatuur beschreven tot $46 \%$ in de eerste 2 jaar, als geen compressie wordt toegepast. Daarom beschouwen we onderhoudstherapie met compressie ten minste noodzakelijk gedurende de eerste 2 jaar. Mogelijk maakt dit compressie protocol een onderhoudstherapie met antibiotica ter voorkoming van recidieven overbodig.

Een interessant onderzoeksveld vormt de genetische achtergrond van lymfatische aandoeningen. Op dit moment zijn drie genen, VEGF-C, FOXC2, SOX-16, geïdentificeerd als oorzaak van lymfoedeem, maar mogelijk zullen er meer volgen. Deze bevindingen geven de clinicus practicus de gelegenheid om de lymfangiogenese beter te begrijpen als basis voor de lymfatische afvloedstoornis. Mogelijk worden er in de toekomst markers ontdekt die geschikt zijn om de ontwikkeling of de ernst van een lymfoedeem te voorspellen. Binnen genen worden meer mutaties gevonden die mogelijk de grote fenotypische variatie kunnen verklaren. In hoofdstuk 3 presenteren we 6 nieuwe missense mutaties die een toename van transcriptie activiteit vertonen daar waar tot voor kort werd gedacht dat het klinische fenotype werd bepaald door haplo-insufficiëntie. Blijkbaar kan de FOXC2 
transcriptie activiteit worden beschouwd als determinant bij de lymfangiogenesis. Een verhoogde activiteit is dan net zo pathologisch als een afname in transcriptie activiteit. FOXC2 speelt ook een rol bij de ontwikkeling van varicositas. FOXC2 deficiënte patiënten hebben een obligate oppervlakkige en diepe veneuze insufficiëntie. De correlatie tussen de ontwikkeling van het lymfatische en veneuze systeem heeft een onderlinge correlatie welke tot nog toe niet is ontrafeld.

Hoewel er vele behandelingen voor lymfoedeem worden toegepast, hebben ze niet allemaal een wetenschappelijke basis. In dit proefschrift richtte we ons op compressietherapie in armen en benen om zo meer te begrijpen van de relatie tussen volume- en drukverandering bij de behandeling van lymfoedeem. Wij realiseren ons dat meer studies met meerdere materialen en technieken nodig zijn voordat definitieve conclusies kunnen worden getrokken. Pogingen om ook voor andere behandelingsvormen van lymfoedeem zoals bijvoorbeeld MLD, lymftaping, pressotherapie en therapeutisch elastische kous, tot evidence based practice te komen, zijn gewenst.

Op het chirurgische terrein hebben we zowel reconstructie- als reductie behandeling van lymfoedeem onderzocht. Ondanks dat de effectiviteit van een lymfo-veneuze anastomose door ons uitgevoerd niet aantoonbaar was, bleek ook in de literatuur het effect niet overtuigend. Een tweetal theoretische beperkingen wil ik hier noemen. Vanuit pathofysiologisch perspectief is het nauwelijks voorstelbaar hoe een lage druk systeem zoals de lymfvaten (5-15 $\mathrm{mmHg}$ ) een continue drainage geeft naar een veneus systeem met hogere drukken. Dit geldt des te meer indien een lymfshunt meer distaal wordt aangelegd. Vanuit een trombo-embolisch perspectief zou thrombusvorming op de anastomose worden verwacht. Langdurige positieve resultaten in veneuze reconstructieve chirurgie wordt vaak belemmerd door trombose, en ook in arteriële reconstructieve chirurgie is levenslange antistollingstherapie geïndiceerd om goede perfusie van de anastomose te waarborgen. Het is merkwaardig dat dit aspect in the LVA literatuur nooit wordt genoemd.

De LVA methode is zelfs meer controversieel indien die als "preventieve procedure" na okselklierdissectie wordt toegepast. Boccardo et al. ${ }^{1}$ bestudeerde 18 patiënten die direct aansluitend aan een okselklier dissectie voor borstkanker een LVA kregen en concludeerde dat LVA een veilige procedure is om arm lymfoedeem te voorkomen. De follow-up van deze studie was slechts 6-12 maanden en er was geen randomisatie en geen controle groep. Omdat de incidentie van lymfoedeem na borstkanker behandeling met okselklier 
dissectie maximaal 30\% bedraagt na 10 jaar, zal bij deze benadering $70 \%$ van de patiënten onnodig worden behandeld voor een aandoening die ze nooit zullen krijgen. Dit type van primaire preventie met reconstructieve therapie is vanuit ethisch en kosteneffectiviteit oogpunt ongewenst. Daarom moeten we ons in termen van primaire preventie richten op het ontwikkelen van protocollen voor risicomanagement, vroegtijdige diagnostiek van zwelling, programma's voor bewustwording en zelfmanagement voor de patiënten. Toekomstige richtlijnen zullen hopelijk meer aandacht aan deze aspecten besteden.

Bij de vroege stadia van lymfoedeem met pitting component (stadium 1 en 2) is conservatieve therapie geïndiceerd. Een operatieve behandeling dient te worden voorbehouden voor eindstadium niet-pitting lymfoedeem (stadium 3 en 4) met objectieve functionele beperkingen bij patiënten waarbij optimale, niet-operatieve therapie niet succesvol is. Op dit moment blijven meer uitgebreide chirurgische interventies nodig. Reductiechirurgie in de vorm van circumferential suction assisted lipectomy (CSAL) is een veilige en zeer effectieve techniek waarbij 100\% reductie van het volumeverschil mogelijk is. Een strikt protocol met levenlange follow-up is hierbij essentieel. CSAL is eveneens effectief in lymfoedeem van de benen. Bij scrotaal lymfoedeem kan reductie chirurgie ook worden uitgevoerd door totale excisie van het overtollige weefsel met reimplantatie van de testis en de constructie van een nieuwe scrotum pouch. Al deze gespecialiseerde technieken dienen in een multidisciplinaire lymfoedeem centrum plaats te vinden waarbij volledige inbedding plaatsvindt in een niet-operatieve behandelingsprotocol. Om een specialistische expertise centrum te vormen is het gewenst dat kennis en vaardigheid van (niet)operatieve behandeling, onderwijs en research in een multidisciplinaire setting wordt gebundeld waarbij intensief met andere hulpverleners wordt samengewerkt.

In 2006 is het Nederlands Lymfoedeem Netwerk (NLNet) opgericht om een platform te vormen voor patiënten en hulpverleners actief op het gebied van lymfoedeem en lipoedeem. De activiteiten van NLNet hebben nu al bijgedragen aan meer bekendheid rond deze onderbelichte, invaliderende ziekte met grote morbiditeit voor de patiënt. Bewustwording, primaire en secundaire preventie van lymfoedeem en vroegtijdige behandeling kunnen het ontstaan van meer irreversibele van lymfoedeem voorkomen. Hierdoor wordt het mogelijk verlies van kwaliteit van leven en morbiditeit voor de patiënt te verminderen en kosten voor verzekeringsmaatschappijen te beperken. Dure behandeling van irreversibele vormen van lymfoedeem kunnen afnemen. De maatschappij tenslotte 
zal bevoordeeld worden door een hogere sociale en economische betrokkenheid indien een patiënt met lymfoedeem vroegtijdig wordt behandeld. Hopelijk zullen in de toekomst de kosten voor integraal ziekte management van lymfoedeem volledig vergoed blijven, zoals dat ook het geval is bij andere algemeen aanvaarde ziektebeelden.

Dan blijft er nog één vraag over: waarom zou een dermatoloog zich richten op lymfoedeem? Lymfoedeem heeft vele raakvlakken met het specialisme dermatologie. Er worden vaak huidafwijkingen aangetroffen bij lymfoedeem, welke ook vaak aan de lymfvaten zijn gerelateerd. Immers, $80 \%$ van het lymfatisch netwerk bevindt zich supra-faciaal; het gebied van subsutis, dermis en epidermis. Verder is de dermatoloog bij uitstek deskundig in een hoeksteen van de behandeling van lymfoedeem: de vele vormen van compressie therapie. Om deze redenen is een dermatoloog het meest aangewezen om patiënten met lymfologische aandoeningen te helpen. Kennis en vaardigheden in de diagnostiek en behandeling van lymfologische aandoeningen zijn dan ook verankerd in de opleiding tot dermatoloog en staan beschreven in het huishoudelijk opleidingsreglement (HOR) vastgesteld door het Concilium Dermatologicum et Venereologicum.

\section{AANBEVELINGEN VOOR TOEKOMSTIGE RESEARCH}

De laatste jaren is de research op het gebied van de lymfologie sterk uitgebreid zoals onder andere blijkt uit het ontstaan van nieuwe tijdschriften zoals "Lymphatic Research and Biology" en de "Journal of Lymphoedema". Toekomstig onderzoek is nodig voor een beter begrip van de genetica, patho-fysiologische mechanismen en bijkomende factoren die het ontstaan en de verergering van lymfoedeem kunnen verklaren. Mogelijk zal het aantal patiënten met primair lymfoedeem (met onbekende oorzaak) afnemen doordat er nieuwe diagnostiek komt en door de ontdekking van nieuwe genen die lymfoedeem veroorzaken. Mogelijk dat hieruit vormen van gentherapie ontstaan die lymfangiogenese kunnen beïnvloeden. Op dit moment is onderzoek naar lymfangiogenese in de oncologische research populair, met name in het kader van tumorbiologie en het voorspellen of remmen van metastasering.

Immunologie vormt een belangrijk onderzoeksgebied in de geneeskunde. Het is verrassend dat het anatomische en functionele systeem dat hierbij betrokken is, het lymfatisch systeem, hierin zo weinig aandacht krijgt. Mogelijk dat de komende jaren het 
lymfatisch systeem in dit verband belangrijker wordt om mechanismen die van invloed zijn op immunologische weerstand en reacties beter te begrijpen. Vooral in de dermatologie kan deze lymfatische component gemakkelijk worden onderzocht in immunologische gemedieerde aandoeningen zoals eczeem, psoriasis en zelfs huidkanker.

Veel huidige behandelingen voor lymfoedeem zijn gestoeld op empirie, expert-based of onderzochtin klinischetrialszondergoede controlegroep.Goed opgezette, gecontroleerde en vergelijkende studies zijn nodig om de effectiviteit van diverse behandelingen aan te tonen zoals bijvoorbeeld manuele lymfdrainage (MLD). Alleen al in Europa wordt MLD al decennia lang door tienduizenden oedeemtherapeuten uitgevoerd, zonder dat onweerlegbare gegevens bekend zijn over het werkingsmechanisme, de effectiviteit van MLD met en zonder compressie of welke methode van uitvoering of techniek het beste is. Dit geldt ook voor nieuwere behandelingstechnieken voor lymfoedeem zoals lymftaping, endermologie, nieuwe verband materialen, verwarming door radiofrequente golven, soft-laser en zelfmanagement programma's. De resultaten van circumferential suction assisted lipectomy zijn uitstekend indien de methode wordt ingebed in een multidisciplinair behandelprotocol. In de toekomst zullen mogelijk nieuwe technieken worden ontwikkeld om de overmaat aan vetweefsel te verwijderen door verfijning van de chirurgische techniek of door methodes om het vetweefsel in de suprafasciale matrix te desintegreren en dan te verwijderen.

Voor het ontwikkelen van risico management programma's moet er gezocht worden naar methodes om te voorspellen wie wel en wie geen lymfoedeem zal ontwikkelen. Mogelijk kan een functionele test om residu lymfcapaciteit te berekenen hierbij behulpzaam zijn. Patiënten die voor kanker zijn behandeld waarbij lymfvaten zijn beschadigd kunnen zo geselecteerd worden op een verhoogd risico op lymfoedeem. Om al deze doelen en verbeteringen in de lymfologie te bereiken, is het in het belang van onze patiënten dat multidisciplinair wordt samengewerkt tussen de vele medische en paramedische disciplines. Dit vormt de uitdaging voor de toekomst.

\section{REFERENTIE}

1 Boccardo F, Casabona F, De Cian F, Friedman D, Villa G, Bogliolo S, Ferrero S, Murelli F, Campisi C. Lymphedema microsurgical preventive healing approach: a new technique for primary prevention of arm lymphedema after mastectomy. Ann Surg Oncol. 2009;16(3):703-8 

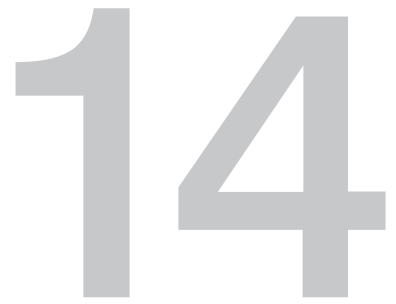

Dankwoord / Words of thanks / Curriculum vitae / Bibliography 
Mijn interesse in de lymfologie werd gewekt toen ik in 1992 toetrad tot de maatschap dermatologie van Ziekenhuis Nij Smellinghe. Ik zag een patiënt met een zwelling aan de arm en omdat ik met zijn aandoening eigenlijk niet goed raad wist, ben ik mij meer gaan verdiepen in behandeling van patiënten met dikke armen en benen.

Dit bleek een onontgonnen terrein te zijn in Nederland en het werd de voedingsbodem voor al het onderzoek dat ik in de jaren daarna heb opgezet, uitgevoerd en uiteindelijk in dit proefschrift heb neergelegd. Dit onderzoek heb ik echter niet alleen kunnen doen en daarom past hier een uitgebreid dankwoord.

Allereerst wil ik de mensen van het eerste uur hartelijk danken voor hun inzet en steun. Zij hebben samen met mij het terrein van de behandeling van lymfoedeem de afgelopen 15 jaar durven ontginnen en weten uit te bouwen tot het landelijk centrum voor lymfologie dat Drachten nu is.

Cees Meijer, directeur van Ziekenhuis Nij Smellinghe. Jij was bereid om het concept multidisciplinaire zorg te ontwikkelen tot een van de speerpunten van het ziekenhuis. Je gaf ons ruimte en geld om in nauwe samenwerking met chirurgen, urologen, gynaecologen, fysiotherapeuten, huidtherapeuten en gespecialiseerdeverpleegkundigen, een multidisciplinaire lymfoedeem werkgroep op te zetten. Zonder Rens de Groot, Harry Voesten, Gerk Hylkema (fysiotherapeut), Pirky Polter (Vodder therapeut), Trineke Hengst en Patrice van Schuppen (huidtherapeuten), Truus Severs (gespecialiseerd verpleegkundige) en Peter van de Wind (compressie specialist) was dit nooit gelukt.

Rens de Groot. Samen hebben we de praktijk de afgelopen 16,5 jaar kunnen uitbouwen. Jij hebt mijn plannen altijd volledig ondersteund, je gaf mij alle ruimte om me te ontplooien maar remde me ook af als het nodig was. Ik zal je inbreng in de praktijk missen nu je met pensioen bent. Gelukkig hebben we met Chantal Theunissen, een plezierige en waardige opvolger van je gevonden.

Christianne Bearda Bakker-Wensveen. In 2004 kwam jij onze maatschap versterken en je hebt al snel je eigen plek verworven en je de lymfologie eigen gemaakt. Door je plezierige omgang en je deskundigheid bij de patiëntenzorg ben je indirect behulpzaam geweest bij mijn onderzoek. Je bent een aanwinst voor de maatschap. 
Harry Voesten, chirurg, collega, vriend, sparringpartner en paranimf. Dankzij jou en je maten is een unieke samenwerking tussen chirurgen en dermatologen ontstaan. In 2002 hebben we de eerste stappen gezet naar een innovatieve chirurgische behandeling van lymfoedeem. Door de uitbreiding van onze werkgroep met Christianne Bearda BakkerWensveen, Piet Klinkert en Marald Wikkeling is de kennis, ervaring en vriendschap verder toegenomen. Dat je nu als paranimf aan mijn zijde staat, waardeer ik zeer.

Een woord van dank aan wijlen Peter van de Wind. Peter was zeer bevlogen en deskundig en heeft Harry en mij geïntroduceerd in de internationale lymfologie community. Meer dan 13 jaar hebben we met Peter uiterst plezierig samengewerkt. Toen zijn ziekte in 2006 terugkwam, bleef hij tot het einde toe zijn bijdrage aan de werkgroep leveren. In het harnas is hij gestorven. In gedachte blijft hij bij ons.

Eltjo Glazenburg, researcher in hart en nieren en een fantastisch mens. Jij hebt mij geholpen met het valideren van ons meetinstrument voor armvolume en je hebt mij, samen met Wim Hop, de eerste stappen van wetenschappelijk onderzoek bijgebracht.

Rene de Klerk van Varodem heeft in een vroege fase het belang van lymfoedeem ingezien en ons met raad en daad bijgestaan. Dankzij jou konden van het eerste Nederlandstalige boek over lymfoedeem "Lymfoedeem in de praktijk" meer dan 2500 stuks worden verspreid. Jij hebt mij het "kousenvak" tot in de kleinste details geleerd. Ik dank je hiervoor en hoop nog lang met je samen te werken.

De gedachte om op wetenschappelijk niveau verder te gaan met onderzoek naar lymfoedeem kreeg in 2000 een impuls door mijn voorzitterschap van de CBO werkgroep lymfoedeem. Carola Kaandorp van het CBO dank ik voor het feit dat zij mij veel geleerd heeft over het schrijven van wetenschappelijke artikelen.

De publicatie van de CBO richtlijn in 2003 en de introductie in de internationale lymfologie community gaven een impuls aan mijn onderzoek. Belangrijke contacten werden gelegd op de congressen van de International Society of Lymphology (ISL) in Genua (2001), in Freiburg (2003), op vele bijeenkomsten van de Deutsche Geselschaft für Phlebologie en tijdens de Bonner Venentage.

Prof. P.S. Mortimer. Dear Peter, our first acquaintance was at Oxford in 1999, during a course on wound healing, in which you taught us about a new, non-elastic bandaging 
technique for lymphedema. Later on, our paths crossed several times during conferences, and we had nice and inspiring conversations. In 2007, we discussed the possibility of writing an article about lymphedema in children, and you were so kind as to agree. Your drive in understanding the mechanisms of disease and to publish about them was stimulating and inspiring! I thank you for that.

Dr. H. Brorson. Dear Hakan, in regard to surgical ways to treat lymphedema, your merits are enormous. When we first met in Genova, we understood each other completely, since we were both Northern-Europeans. You accepted our request to visit you in Malmo and for you to teach our team your surgical techniques. After this initial step, we had annual meetings in Malmo and Drachten to discuss publications and new concepts, as well as to enjoy life. Your help and input was invaluable.

Prof. H. Partsch. Dear Hugo, "If I have seen further it is by standing on the shoulders of giants (Isaac Newton)". When we first met in Freiburg in 2003, I was impressed by your devotion to phlebology and lymphology and by your choice of an excellent restaurant in Colmar, France. Of course, I knew you from conferences and from publications, but working with and learning from you was a special experience. It was always instructive and a great pleasure to communicate with you, whether it was during our visits to Drachten, by e-mail, by Skype, or during our meetings and discussions at many places throughout Europe. You taught me a great deal in the field of research, particularly on bandaging and lymphedema, and we had a wonderful time visiting many people. I thank you for all of that. I hope this awesome collaboration will last many years to come!

In some studies, we cooperated with Martin Abel from Lohmann \& Rauscher, Germany. Martin, I thank you for the pleasant and constructive collaboration. Besides generating good results and publications, which was important for you as well, we had good times and joked around at many meetings. I thank you for that.

Uiteindelijk was het vanaf 2005 een samenloop van factoren die er voor zorgden dat de reeds gepubliceerde artikelen, de schat van ervaring en research gegevens die inmiddels in Drachten was opgebouwd, uitgebouwd zouden worden om tot een promotie te leiden. Allereerst was daar Peter Steijlen. Niet alleen wilde hij zijn medewerking verlenen om alle bouwstenen samen te voegen tot één bouwwerk maar ook kon hij, vanwege de speciale aandacht voor genetica in het Maastrichtse, het ontbrekende aspect van 
basaal wetenschappelijke research in mijn onderzoek faciliteren. Ten tweede was daar de overstap naar Apple ${ }^{\circledR}$. Immers, “Using Windows is like being stucked in a bad relationship. It works on some level so you don't want to take the effort switching to Mac. But once you do it, you realise you should've done it a long time ago".

Prof. dr. PS. Steijlen, promotor. Beste Peter, door jouw bijzondere wijze van aansturing, waarbij ongetwijfeld een zelfsturend team jouw voorkeur heeft, gaf je mij de ruimte dit boek te schijven. Ik hoop dat onze samenwerking zal blijven voortduren. De genetica bij primair lymfoedeem, en vooral bij kinderen, staat nog in de kinderenschoenen en er is nog veel te ontdekken.

Dr. M.A.M. van Steensel, co-promotor. Beste Maurice, het is moeilijk jouw snelheid in denken maar enigszins bij te houden. Je briljante ideeën en correcties van een manuscript leken wel mijn gehele first draft rood te kleuren. Ik heb er veel van geleerd en hoop nog lang met je samen te werken.

Dr. A.J. Veraart, co-promotor. Beste Joep, het was een voorrecht de samenwerking, die begon tijdens de CBO werkgroep in 2000, voort te kunnen zetten. Naast je drukke werkzaamheden voor het EPD zag jij ook tijd om mij te helpen en te begeleiden. Dank daarvoor.

Verder een woord van dank aan Martijn Heitink, Patty Nelemans en Michel van Geel en alle anderen uit het Maastrichtse die mij hebben geholpen: 320 kilometer lijkt ver, maar voor moderne communicatie middelen is geen afstand te groot.

De promotiecommissie bestaande uit de leden Prof.dr. F.C.S. Ramaekers, Prof. dr. A. Griffioen, Prof.dr. H.A.M. Neumann, Prof.dr. med. E. Rabe, en dr. G.W.H. Schurink ben ik zeer erkentelijk voor hun gewaardeerde beoordeling van het proefschrift en hun goedkeuring.

Tot slot de mensen dichter bij huis en haard, die op een voor ieder bijzondere wijze aan dit proefschrift hebben bijgedragen.

Uiteraard een woord van dank aan alle assistenten, medewerkers en verpleegkundigen van de polikliniek Dermatologie, het DV-team, de afdeling A3, het laboratorium en 
de automatiseringsafdeling. Zonder jullie bijdragen aan de zorg voor patiënten met lymfoedeem zou het voor mij een eenzame reis zijn geweest en had het onderzoek in de kliniek niet kunnen plaatsvinden. Expliciet wil ik Elske Wijbenga en Annet Bosma noemen. Jullie toewijding en deskundigheid met bandageren en het uitvoeren van druk- en volume metingen was fantastisch. Aan jullie heb ik veel te danken.

Els Brouwer, voor jou een speciaal woord van dank vanwege je onmiskenbare bijdrage aan het gehele proces de afgelopen 15 jaar. We zijn begonnen met het ontwikkelen en geven van cursussen en met de oprichting van de Stichting LCN. Later volgde de patiëntenorganisatie Het Nederlands Lymfoedeem Netwerk (NLNet). Toen je de overstap maakte naar Varitex, bleef je de lymfologie in Drachten volgen en is onze samenwerking en vriendschap een nieuwe fase ingegaan. Jouw aanstekelijke enthousiasme en mensenkennis staan garant voor toekomstige projecten.

Pieter Haans, paranimf. Onze vriendschap, samen met Judith en Jorine, is lang en bestendig. Ik wil je danken dat je ook dit moment weer met mij schouder aan schouder wilt staan.

Peter Ketelaar, ceremoniemeester, vriend en dorpsgenoot. Mijn verzoek om je organisatietalent aan te wenden voor mijn promotie, werd direct met ja beantwoord. Ik dank je hartelijk voor al het fantastische werk dat je verzet hebt om deze dagen voor mij onvergetelijk te maken.

Geert en Anneke, Jan en Annie. Dank voor jullie belangstelling in al mijn activiteiten en voor jullie hulp om drukke ouders af en toe te ontlasten. Ik vind het fijn dat jullie deze dag met ons kunnen meevieren en ik vind het heel bijzonder om mijn proefschrift te verdedigen met mijn vader in de corona.

Lieve Anne Marijn, Josephine en Hugo. Ik vind het fantastisch jullie vader te zijn en jullie te zien uitgroeien tot zelfstandige mensen. Jullie vormen voor mij een bron waaruit ik liefde en inspiratie kan putten en ik ben daar dagelijks dankbaar voor. Overigens heeft mijn apple-verslaving jullie geen windeieren gelegd en zijn jullie inmiddels ook volleerde appelaars.

Lieve Jorine, levensgezel en maatje, aan jou heb ik veel te danken. Samen hebben we ons leven zo opgebouwd en ingericht dat we ons allebei in harmonie kunnen ontplooien: onafhankelijk in gemeenschappelijkheid. De geestelijke ruimte en inspiratie die jij geeft, 
bieden een goede voedingsbodem voor creativiteit. Ik hoop nog heel lang samen met jou, onze kinderen, familie en vrienden van het leven te kunnen genieten! 


\section{CURRICULUM VITAE}

Robert Jacobus Damstra was born on July 15th, 1959, in Hengelo, Overijssel. He attended the Bataafse Kamp school in Hengelo and obtained a high school diploma (VWO-B) in 1979. In the same year, he commenced medical school at the faculty of medicine in Utrecht University (UU) and received his medical degree (MD) in 1986. From 1986 to 1988, he worked as a resident not in training in the Department of Surgery at the Academic University Hospital (head: Prof. Dr. P. Wittebol) and in 1986 he commenced his residency in Dermatology at the Academic University Hospital at Utrecht (currently known as The University Medical Centre at Utrecht, UMCU), with Prof. Dr. W.A. Van Vloten as head of the department.

He has worked as a dermatologist at the Nij Smellinghe Hospital in Drachten, the Netherlands, since 1992. Together with H.G.J.M. Voesten (surgeon), L.J. de Groot (dermatologist), and other medical professionals, he founded the "Drachten Working Group on Lymphedema" in 1995. Under his leadership, and in close cooperation with the managing director of the Nij Smellinghe Hospital, C. Meijer, the working group expanded into a specialized center for the diagnosis and treatment of lymphedema. Investigations into various diagnostic and therapeutic aspects of lymphedema were initiated in close cooperation with Prof. dr. H. Partsch (Vienna, Austria), Prof. dr. P.S. Mortimer (St. George's University, London, UK), Prof. dr. P.M. Steijlen, (Academic Hospital at Maastricht), and Dr. H. Brorson (Lund University /Malmö University Hospital, Sweden).

From 1999 to 2003, he was the chairman of the first multidisciplinary working group on "lymphedema" at the Dutch Institute for Health Improvement (CBO). Together with this group, he published the first national guideline on lymphedema, which gave an evidencebased, expert opinion on the starting point for the (early) diagnosis and treatment of lymphedema in the Netherlands. In 1999, he established the Stichting Lymfologie Centrum Nederland (SLCN), an independent organization in association with the Nij Smellinghe Hospital, which provides scientific research and education in the fields of lymphedema and lipedema. In cooperation with the SLCN and others, he founded the independent charitable organization Dutch Lymphedema Network (NLNet), an organization for patients and healthcare workers active in the field of lymphedema, in an effort to promote the effective management and awareness of lymphedema (and lipedema) in the Netherlands. NLNet works in close cooperation with other international patient organizations. Since 2007 , he has been the president of the advisory board of the NLNet. In 2008, he became a member of the advisory board of the Union Internationale Phlébologie (UIP) and 
participates in the UIP consensus group "Lymphedema and Lymphatic Malformations." In 2009 he became a member from the international advisory board of the international lymphoedema framework (ILF). He received the international lymphoedema framework award 2009; an award for recognition "For Excellence in Lymphoedema Practice".

He has been married to Jorine Janssen since 1987, and together they have three children: Anne Marijn (1991), Josephine (1993), and Hugo (1994). 


\section{CURRICULUM VITAE}

Robert Jacobus Damstra werd geboren op 15 juli 1959 te Hengelo (Ov). In 1979 deed hij eindexamen VWO-B aan de scholengemeenschap Bataafse Kamp te Hengelo (Ov) en begon hij met de studie geneeskunde aan de Universiteit Utrecht (UU). Het artsexamen werd behaald in 1986. Van 1986 tot 1988 was hij arts-assistent chirurgie (niet in opleiding) en in juli 1988 begon hij als arts-assistent dermatologie in het Academisch Ziekenhuis Utrecht (thans Universitair Medisch Centrum Utrecht, UMCU) onder begeleiding van Prof. Dr. W.A. van Vloten.

Sinds 1992 is Robert Damstra werkzaam als dermatoloog in het Nij Smellinghe ziekenhuis te Drachten. In 1995 richtte hij samen met H.G.J.M. Voesten (chirurg) en L.J. de Groot (dermatoloog) en met diverse paramedici de Lymfoedeem Werkgroep Drachten op. In nauwe samenwerking met C. Meijer, algemeen directeur van ziekenhuis Nij Smellinghe kon de Lymfoedeem Werkgroep uitgroeien tot een landelijk expertise centrum voor de diagnostiek en behandeling van lymfoedeem. Daarnaast zette hij diverse wetenschappelijke onderzoeken op met Prof. dr. H. Partsch (Wenen, Oosterijk), Prof. dr. P.S. Mortimer (St George's University, Londen, UK), Prof. dr. P.M. Steijlen, (Academisch Ziekenhuis Maastricht,) en Dr. H. Brorson (Lund University /Malmö University Hospital, Zweden).

Van 1999-2003 was hij voorzitter van de multidisciplinaire werkgroep Lymfoedeem van het kwaliteitsinstituut CBO. In 1999 richtte hij samen met anderen de Stichting Lymfologie Centrum Nederland (SLCN) op, die onderzoek verricht en onderwijs verzorgt op het gebied van lymfoedeem en lipoedeem. In 2006 was hij een van de oprichters van het Nederlands Lymfoedeem Netwerk (NLNet), een platform voor patienten en hulpverleners die aandacht vraagt voor de problematiek rond lymfoedeem en lipoedeem in Nederland. Sinds 2007 is hij voorzitter van de Raad van Advies van NLNet.

In 2008 werd hij lid van de adviesraad van de Union Internationale Phlébologie(UIP) en heeft hij zitting in de UIP consensus werkgroep "lymphedema and lymphatic malformations". In 2009 nam hij zitting in de internationale adviesraad van de the international lymphoedema framework (ILF). Hij ontving de international lymphoedema framework award 2009 als erkenning voor de "buitengewone verdiensten op het gebied van de lymfologische zorg voor de dagelijkse praktijk".

Sinds 1987 is hij getrouwd met Jorine Janssen en samen hebben zij drie kinderen: Anne Marijn (1991), Josephine (1993) en Hugo (1994). 


\section{BIBLIOGRAPHY}

Subdivided into the following categories and in chronological order:

\section{Wi-1: Scientific publication in international journal mentioned in the Social Science Citation Index, Science Citation Index or Arts \& Humanities Citation Index with Impact Factor.}

1. Damstra RJ, van Vloten WA. Cryotherapy in the treatment of condylomata acuminata: a controlled study of 64 patients. J Dermatol Surg Oncol. 1991;17:273-6

2. Damstra RJ, van Duren JA,Van ginkel CW. Incontinetia pigmenti (Bloch-Sulzberger). Br J Dermatol. 1991:125(3);280-1

3. Damstra RJ, van Vloten WA. Exacerbatie van psoriasis door malariaprofylaxe met chloroquine en proguanil. Ned Tijdschr Geneeskd. 1991;135 (15):671-4

4. Damstra RJ, van Ginkel CJW, van Vloten WA. Allergic contact dermatitis to 1,2-benzisothiazolin3-one: a study of 32 patients at risk and a controlled study to cross reactions with Kathon-CG. Contact Dermatitis. 1992;27:105-9

5. Damstra RJ, Toonstra J. A rare skin ulcus: cutaneous B-cell lymphoma mimicking an ulcus cruris venosum: Phlebology. 1992;7:82-4

6. Dammer MH, Damstra RJ, Hol C. Een ongewone vorm van tenia capitis in Friesland. Ned Tijdschr Geneeskd. 1994;138(49): 2470

7. van de Kerkhof PCM, Cambazard F, Hutchinson PE, Haneke E, Wong E, Souteyrand P, Damstra RJ, Combemale P, Neumann HAM, Chalmers RJG, Olsen L. The effect of addition of calcipotriol ointment $(150 \mathrm{ug} / \mathrm{g})$ to acitretin therapy in psoriasis. Br J Dermatol. 1998;138(1):84-9

8. van de Kerkhof PCM, Cambazard F, Hutchinson PE, Haneke E, Wong E, Souteyrand P, Damstra RJ, Combemale P, Neumann HAM, Chalmers RJG, Olsen L. Der Effect einer Zugabe von calcipotriol Zalbe (150ug/g) zu einer acitretin Behandlung der Psoriasis. Hautarzt.1998;73(1)47-52

9. Damstra RJ, de Groot LJ, van de Mijle HCJ, Voesten HJGM. Minitattoo marking as an aid in the effective use of duplex scanning in the treatment of varicose veins. Phlebology 1999(14):39

10. Partsch H, Damstra RJ, Tazelaar DJ, Schuller-Petrovic S, Velders AJ, de Rooy MJ, sang RR, quinlan D. Multicentre, randomised controlled trial of four-layer bandaging versus short-stretch bandaging in the treatment of venous leg ulcers. VASA. 2001;30(2):108-13.

11. Berth-Jones J, Damstra RJ, Golsch S, Livden JK, Van Hooteghem O, Allegra F, Parker CA. Multinational Study Group. Twice weekly fluticasone propionate added to emollient maintenance treatment to reduce risk of relapse in atopic dermatitis: randomised, double blind, parallel group study. BMJ. 2003;21;326(7403):1367.

12. Damstra RJ, Kaandorp CJ; Dutch Institute for Health Care Improvement (CBO) Richtlijn lymfoedeem. Ned Tijdschr Geneeskd. 2003;147(14):648-52. 
13. Knol A, Damstra RJ, van den Akker ThW, de haan J. Teledermatologische consultatie. Ned Tijdschr Geneeskd. 2004;148(7):314-8

14. Knol A, Damstra RJ, van den Akker ThW, de Haan J. Teledermatology saves referrals of the patient to the dermatologist. Journal of Telemedicine and Telecare. 2006;12(2):75-8

15. Damstra RJ, Glazenburg E, Hol W. The validation of the inverse water volumetry: New gold standard for arm volume measurement. Breast Cancer Res Treat. 2006;99(3):267-73

16. de Korte J, van der Valk PGM, Sprangers MAG, Brakman M, Damstra RJ, van Neer PAFA, Oranje AP, de Rie MA, Hol CW, van de Kerkhof PCM. Improvement of health-related quality of life in patients with mild-to-moderate psoriasis: a randomized controlled trial comparing intensified calcipotriol and dithranol treatment. Br J Dermatol. 2006;155(4):800-7

17. de Korte J, van der Valk PGM, Sprangers MAG, Brakman M, Damstra RJ, van Neer PAFA, Oranje AP, de Rie MA, Hol CW, van de Kerkhof PCM. A comparison of twice-daily calcipotriol ointment with once- daily short-contact dithranol cream therapy: quality-of-life outcomes of a randomized controlled trial of supervised treatment of psoriasis in a day-care setting. $\mathrm{Br} J$ Derm. 2008;158(2):375-81

18. Damstra RJ, Brouwer ER, Partsch H. Controlled, comparative study of relation between volume changes and interface pressure under short stretch bandages in leg lymphedema patients. Dermatol Surg. 2008;34(6):773-8

19. Damstra RJ, van Steensel MAM, Boomsma H, Nelemans P, Veraart JCJM. Erysipelas as a sign of subclinical primary lymphedema: A prospective quantitative scintigraphic study of 40 patients with unilateral erysipelas of the leg. Br J dermatol. 2008;158(6):1210-5

20. Damstra RJ, Voesten HGJ, van Schelven D, van der Lei B. Lymphatic Venous Anastomosis (LVA) for Treatment of Secondary Arm Lymphedema. A Prospective study of 11 LVA procedures in 10 patients with breast cancer related lymphedema and a critical review of the literature. Breast Cancer Res Treat. 2009;113(2):199-206

21. Voesten HGJ, Damstra RJ, Klinkert P. Nieuwe chirurgische mogelijkheden voor patiënten met uitbehandeld secundair lymfoedeem van de arm. Ned Tijdschr Geneesk. 2008;152(18):1061-5

22. Damstra RJ, Mortimer PS. Diagnosis and therapy in children with lymphedema. Phlebology. 2008;23(6):276-86

23. Vreeburg M, Heitink MV, Damstra RJ, Moog U, van Geel M, van Steensel MAM. Lymphedema - distichiasis syndrome: a distinct type of primary lymphedema caused by mutations in the FOXC2-gene.

Int J Dermatol. 2008;47 Suppl 1:52-5

24. Damstra RJ, Partsch H. Compression therapy in breast cancer related lymphedema. A randomized controlled, comparative study of relation between volume and interface pressure changes. J Vasc Surg. 2009;49:1256-63

25. Damstra RJ, Voesten HGJ, Klinkert P, Brorson H. Reduction surgery by Circumferential SuctionAssisted Lipectomy (Brorson method) in end stage breast cancer-related lymphedema: a prospective study. Br J Surg. In press

26. Damstra RJ, Jagtman EA, Steijlen PM. Cancer related secondary lymphedema due to cutaneous lymphangitis carcinomatosa: Clinical presentations and review of literature. Eur J Cancer Care. In pres 
Wi-2: Scientific publication in international journal with referee system and without Impact Factor

1. Damstra RJ, van Vloten WA. Use of Fine-Needle Cryotherapy found to curb Condyloma. Skin Allergy News. 1991;22(11):16-7

2. Damstra RJ, Knol A, van den Akker Th, de Haan J. Teledermatological consultation: from pilot project to regular care. Health information developments in the Netherlands. 2005(7);4:80-3

3. Brouwer ER, Damstra RJ, Partsch H, Warum kommt es zu einem Druckabfall unter Kurzzugverbänden? VasoMed. 2005(4);17:139

4. Damstra RJ. Lymphödem: erfahrungen aus den Niederlanden; Multidisciplinäre richtllinie, volumen-Anpressdruckmessungen, Patienten-Bewusstsein und neue Perspectiven. VasoMed. 2006(18);1:28-9

5. Damstra RJ, Kaandorp C. Multidisciplinary guidelines for early diagnosis and treatment of lymphoedema. J of Lymphoedema. 2007;2(1):57-65

6. Damstra RJ. A history of the Dutch lymphedema network. J of Lymphoedema. 2007;2(1):78-9

7. Damstra RJ.Verbindung zwischen lymphödem und chronischer venöser Insuffizienz. VasoMed. 2006:18(4);155

8. Damstra RJ. Volumenreduktion bei Armlymphödem durch Mammakarzinom: Ergebnisse mit onverschillig straff angelegten Kurzzugverbänden. Vasomed. 2008;20(1):28-9

\section{LE: Letters to the Editor}

1. Damstra RJ. ReDeSys. Ned Tijdschr Derm Venereol. 2000; 10:141

2. Damstra RJ. Comment on: Wilting J, Schweigerer. Engeneering of lymphatic endothelial cells. Phlebology digest. 2004(3);17:18-20

\section{WN: Scientific publication in national journal with referee system.}

1. Damstra RJ, van Ginkel CJW, Young E, van Vloten WA. Contact allergie bij een behanger voor 1,2- benzisothiasolin-3-one (Proxel(R)): conserveringsmiddel in behangerslijm. Bulletin. Contactdermatosen. 1990:4;162-4

2. Damstra RJ. Lasers in de Dermatologie: behandeling van tatouages Ned Tijds Dermatol Venereol. 1991(1):230-1

3. Damstra RJ. Hoe behandelt men de huidafwijking couperose? Vademecum nascholing huisartsen. 1993;11(14):14

4. Damstra RJ. Wat is de therapie van een clavus aan de zijkant van de teen? Vademecum nascholing huisartsen. 1994;12(22):31

5. Damstra RJ, de Groot LJ, van de Mijle HCJ, Voesten HGJM. Communicerende vaten: een multidisciplinaire flebologische benadering in de praktijk. Scripta Phlebologica.1995(3):3; 56-8 
6. Damstra RJ, de Groot LJ. Dermatologisch verpleegkundig team (DVT); een unieke combinatie van intramurale dermatologische specialistische zorg en decubitusconsulentschap. Ned Tijdschr Dermat Venereol. 1996;(6)5:161-3

7. Damstra RJ. Wondbehandeling en klinische dermatologische zorg door het Dermatologisch Verpleegkundig Team: een uitstekende combinatie. Ned. Tijdschr Derm Venereol. 1997;7(1):24-5

8. Damstra RJ, Voesten HGJM, de Groot LJ, van der Mijle HCJ. Een nieuwe multidisciplinaire benadering van lymfoedeem: Opzet en resultaten van een gecombinneerd spreekuur. Med Contact. 1998(53);16:546-8

9. Damstra RJ. Is bij wratten immuuntherapie een optie? Vademecum nascholing huisartsen. 1998(16)24a

10. Damstra RJ, Nutma J, de Groot LJ. Digitale fotografie en dermatologische praktijkautomatisering binnen het ziekenhuisautomatiseringssysteem: verslag van 3 jaar ervaring. Ned Tijdschr Dermatol Venereol. 2002;12(10):226-31

11. Damstra RJ, Akker van der ThW. Werkboek teledermatologische consultatie. Digitale communicatie tussen huisarts en dermatoloog in Nederland. Ned Tijdschr Dermatol Venereol. 2002;12(10):379-87

12. Damstra RJ, Akker van der ThW. Teledermatolgische consultatie in Nederland; tweede lijns expertise in de eerste lijn: een praktische handleiding. Ned Tijdschr Dermatol Venerol. 2002;12(10):373-7

13. Severs-Holman G, Visser W, Damstra RJ. Lymfoedeem, een complex probleem. Multidisciplinaire benadering voor de behandeling van lymfoedeem. Oncologica. 2003;20(4):211-3

14. Damstra RJ. Lymfologie in de praktijk. Ned Tijdschr Dermatol Venereol. 2004;14(3):110-3

15. Damstra RJ, Knol A, Akker van den ThW, de Haan J. ICT-zorgmodule teledermatologische consultatie: van proefproject naar reguliere zorg. Tijdschrift voor Zorgadministratie en Informatie. 2004;116(30):24-6

16. TH.W van den Akker, Knol A, Damstra RJ, de Haan J. Teldermatologische consultatie. Modern Medicine. 2004;(6):343-8

17. Damstra RJ, Knol A, van den Akker Th, de Haan J. Teledermatologische consultatie (TDC) in de praktijk: ervaring met meer dan 2500 reguliere consulten. Ned Tijdschr Dermatol Venereol. 2005(15);4:145-8.

18. Kucharekova M, van Geel M, Stoutenbeek B, Damstra RJ, Steijlen PM, van Steensel MAM. Palmoplantaire keratodermie areata et striata. Ned.Tijdschr Dermatol Venereol. 2006(16);5:2057

19. Zwart N, Damstra RJ, Knol A, van den Akker ThW, de Haan J. Teledermatologie: ervaringen van huisartsen. Modern Medicine. 2006(7);351-3

20. Van Tuyll van Serooskerken AM, Verstraeten VLRM, Damstra RJ, van Marion AMW, van Steensel MAM. Een man met scrotaal oedeem sinds 3 jaar. Ned. Tijdschr Dermatol Venereol. 2006:16(7):304-6

21. Damstra RJ, Witkamp L Teledermatologie in Nederland: veilige, effectieve en vergoede zorg. Dermatologen Vademecum. 2007;1(6):1-3

22. Damstra RJ. Hebben diuretica een plaats bij de behandeling van lymfoedeem? Dermatologen 
Vademecum 2008;2(4):1-2

\section{WB/WBC: Scientific publication as a book or as a contribution to a book including proceedings.}

1. Antimalariamiddelen in de Dermatologie. Damstra RJ, Baart de la Faille H. Uitgeverij: Reed Press 1992. ISBN 90-5029-032-9

2. Damstra RJ, redacteur boek: Lymfoedeem in de praktijk. Diagnostiek, behandeling en een nieuwe multidisciplinaire benadering. Uitgever SLCNN 2000 ISBN: 90-805399-1-0

3. Damstra RJ, Kaandorp C, (red). CBO Richtlijn lymfoedeem. Van Zuiden communications Alphen a/d Rijn 2002 ISBN 90-76906-52-1

4. Van Muilekom HAM, van Spil JA, Damstra RJ. Hoofdstuk 13: Lymfoedeem. In: Handboek prostaatcarcinoom. Van Muilekom HAM, van Spil JA. Elsevier 2006 (ISBN90-352 2831 6)

5. Balans bij lymfoedeem van het been. Zee T, Damstra RJ. Redactie Damstra RJ, Warns R . NPI Amersfoort 2008. ISBN: 978-90-7686-45-6

\section{posters}

Damstra RJ, Voesten HGJM. Multidisciplinair spreekuur voor patiënten met lymfoedeem na oncologische therapie: vroegtijdige diagnostiek, begeleiding en behandeling (Jan Olthoff Congres1997)

Damstra RJ. Calcipotriol cream and concurrent steroids in psoriasis; placebo, multicentre dubble blind controlled study of 726 patients (MC 9302) ERDS Congress Copenhagen 28-30 april 1995

Charles H, Damstra RJ, Fürst $D$, Jünger $M$, Partsch H. In vivo measurement of pressure and stiffness with a new multi-layer compression kit. Poster congres European Wound Management Association, Stuttgart 2005

Berth-Jones J, Damstra RJ, Golsch S, Livden J, van Hooteghem O, Allegra F. Fluticasone propiate (FP) reduces risk of relapse in patients with atopic dermatitis (AD) EADV Geneve 2000

Damstra RJ, Partsch H. Which pressure do we need to reduce breast cancer related lymphedema by short stretch compression bandages? 21 ${ }^{\text {st }}$ meeting American Venous forum (AVF) 2009 Phoenix, Arizona.

\section{Other publications}

1. Damstra RJ. De Friesland kiest voor flebologie dicht bij huis. Dialoog. 1996;2:7

2. Damstra RJ. Opzet en organisatie van een multidiscipinaire werkgroep voor patienten met lymfoedeem: Een nieuwe patientgerichte aanpak. Medi Business Club Magazine. 1998;2(7):22-3

3. Damstra RJ, Jagersma M. Persoonlijke aandacht werkt positief. HUID. 2000:2(4):28-9

4. Damstra RJ, Huidafwijkingen en lymfoedeem . Oedeminus2001;4(4):27-9 
5. Damstra RJ. Dermatologisch Verpleegkundig Team: Vliegende keep bij huid- en wond problemen HealthCare magazine. 2001;5:6-9

6. Damstra RJ. Lymphedema Care at height in Holland. National Lymphedema Network Lymphlink. 2001;13(3):9

7. Damstra RJ. Aanmeten van kousen is het sluitstuk van de behandeling. Zorgkundig nieuws. 2001;3:8-9

8. Damstra RJ. Samenwerking met dermatologie. Oedeminus. 2001;2:10-2

9. Damstra RJ. Dermatologisch Verpleegkundig Team: Vliegende keep bij huid- en wond problemen HealthCare magazine. 2001:5:6-9

10. Damstra RJ. Multidisciplinaire werkgroep voor lymfoedeem: opzet en resultaten van een geïntegreerde werkwijze. WCS nieuws. 2001;17:23-8

11. Damstra RJ, Goedhart M. Digitale fotografie HealthCare magazine. 2002;5:6-9

12. Damstra RJ. Een nieuwe multidisciplinaire benadering van lymfoedeem. OLIJF. 2002:17(3):1-3 











